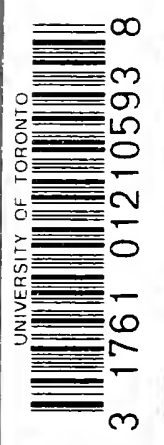





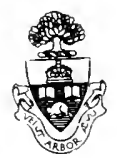

$$
\text { Presented to the }
$$

UNIVERSITY OF TORONTO

$$
\text { by }
$$

$$
\text { Mr. J. R. McLeod }
$$


Digitized by the Internet Archive in 2007 with funding from Microsoft Corporation 


$$
\begin{aligned}
& \text { AP.Mefeod } \\
& \text { mar.12.1915. }
\end{aligned}
$$

X RAYs 


\section{TABLES OF PHYSICAL}

AND CHEMICAL CONSTANTS AND SOME MATHEMATICAL FUNCTIONS

BY

G. IV. C. KA Y E,

B.A. (Cantab.), D.Śc. (Lond.), A.R.C.Sc. (Jond.) ANi

T. H. L A B Y. B.A. (C'antab.)

Royal 8vo, 4s. 6d. net

LONGMANS, GREEN AND CO.

LONDON, NEW FORK, BOMEAY, CALCTTTA, AND MADFAS 



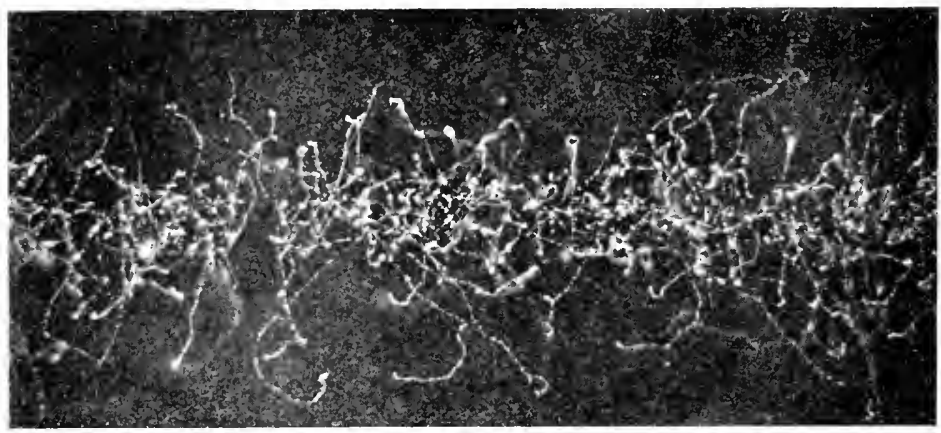

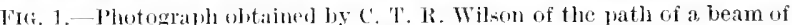
I rays in supersaturated air. The bean of rays some :2 $\mathrm{mm}$. in dianeter, was sent throngh the moist air (from left to riglit in the iigure) immediately after the expansion which yodnced the supersaturation (see p. 149). The

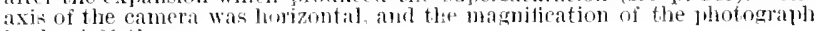
is a Jumt 2 ?

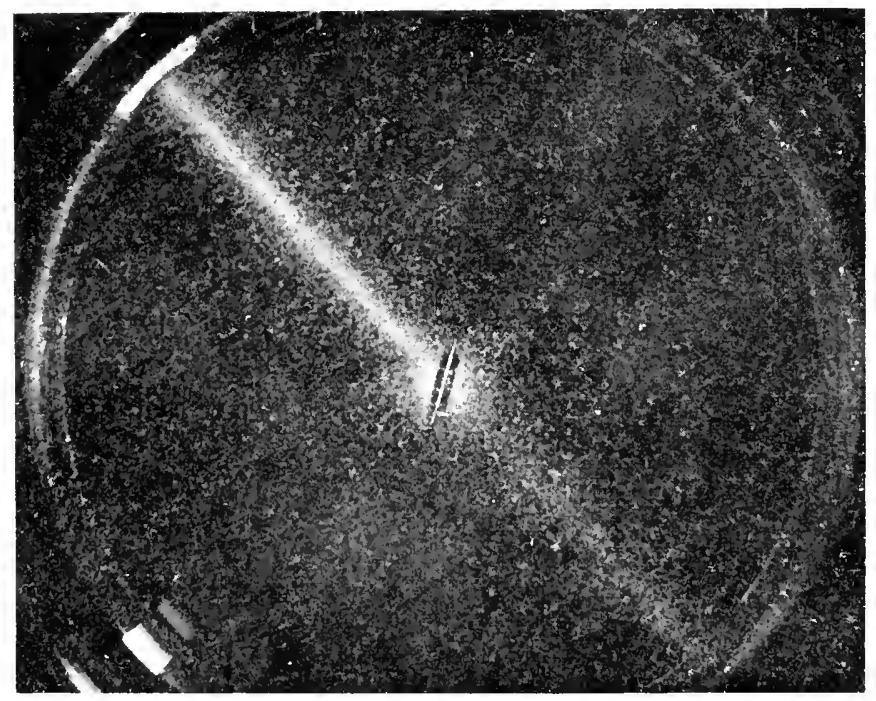

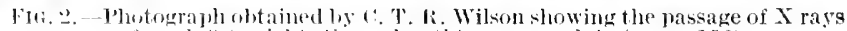
(from lert to right) throngh a thin coppler plate (see p. 152). 


\section{RAYS}

\section{AN INTRODUCTION TO THE STUDY OF RÖNTGEN RAYS}

BY

G. W. C. KAYE, B.A., D.Sc.

HEAD OF TIE RADIUM IDPARTMEST AT THF NATTONAL. PHYAICAL, LABORATORY FXAMIER IN MEDH'AL PHYSI'S FOR THE CNIVERSITIES OF LONION AND GIASOOW IFMPER OF COENCL OF THF, ROETTES SOCIE'Y

LONGMANS, GREEN A ND CO. 39 PATERNOSTER ROW, LONDON

FOURTH IVENUE \& zOTH STREET, NEW YORK bOMbaY, CalCUTTA, AND MADRAS

I 9 I 4 


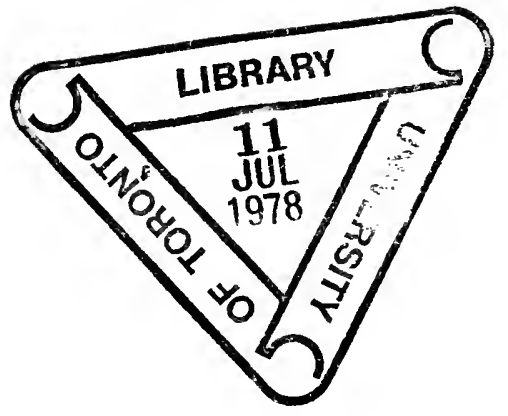




\section{PREFACE.}

T'HIs little book does not profess to be a treatise or handbook on $\mathrm{X}$ rays. It aims merely at giving an account of such of the present-day methods and apparatus as appear valuable or novel, and which, in many cases, can only be found seattered throughout many journals; it treats critically, and here and there somewhat comprehensively, some of the features which have laid claim to the interests of the writer from time to time; it is concerned to some extent with the development of theory as well as of experiment; and it attempts to convey a notion, however disconnected and ill-proportioned, of the historical trend of events from Prof. Röntgen's world-famous discovery in 1895 down to the end of the year 1913.

The author trusts that the form of the book will be aceeptable, not only to the student of physics, but to the man of general scientific interests, and particularly to the members of the medical profession, most of whom are keenly alive to the possibilities of the rays which Röntgen has placed at their service. He is aware from experience as teacher and examiner of medical students, at Cambridge and London, of their need of a book on the subject which is neither recondite nor mathematical.

To two of his colleagues at the National Physical Laboratory, the writer wishes especially to record his grateful thanks. Mr. E. A. Owen has revised both manuseript and proof, and has co-operated extensively in the treatment of Chapter XII., on the Interference and Reflection of X Rays by Crystals, a section which the writer believes to be the first collected account of this new and fascinating branch 
of physies. Mr. W. F. Higgins has given frecly and generonsly of his time and energies, and rendered invaluable aid in all the different stages of the work. He has executed with great care a large proportion of the diagrams, and is responsible for the preparation of the index and some of the more lengthy tables.

Sir J. J. Thomson, Prof. Bragg, and Mr. C. T. R. Wilson have kindly given permission to include original photographs. 'The writer's obligations are also due to the Councils of the Royal Society, the Cambridge Philosophical Society, and the Röntgen Society, the Editor of the Archives of the Röntgen Ray, Messrs. J. and A. Churchill, and Messrs. Taylor and Francis, for the loan of original blocks; and to Messis. F. R. Butt \& Co., A. C. Cossor, H. W. Cox \& Co., C. H. F. Muller, Newton \& Wright, The Sanitas Electrical Co., Schall \& Son, and Siemens Bros. \& Co. for various trade blocks.

Finally, the author would wish to thank his wife and Mr. J. R. Willis for general criticism, and Mr. A. A. Robb of St. Joln's College, Cambridge, for permission to include his verses on Maxwell's famous equations and the birth of an X ray. Mr. Robb's skill in parody is not so well known outside Cambridge as his mathematical researches; and the author ventures to hope that the "Revolution of the Corpusele," which first saw light in the Post-Prandial Proceedings of the Cavendish Laboratory, will serve to "temper the wind" of those critics who can see only the numerous shortcomings in the book.

The writer will be content if his work can be regarded as one of the many tokeus of esteem with which old students of the Cavendish School of Research have delighted to honour their distinguished professor, Sir J. J. 'Thomson.

$$
\text { G. W. C. K. }
$$

February 1914. 


\section{CONTENTS'.}

PAGE

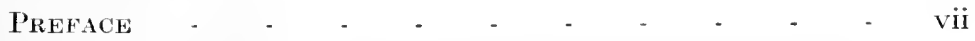

'Table of Nature and Propertes of Various Kinds of "RAYs" -

"The Revolution of the Corpuscle" - - - - XV INTRODUCTION

Table of Abbreviations of References to Journals - $\mathrm{xx}$

\section{CHAP'TER I.}

THE PHENOMENA OF A DISCHARGE TUBE.

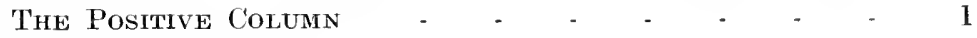

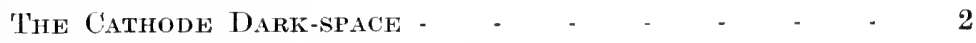

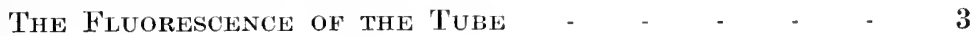

\section{CHAPTER II. \\ CATHODE RAYS.}

HISTORICAL - $\quad$ - $\quad$ - $\quad$ - $\quad$ - $\quad$ - $\quad$ - $\quad$ - 4

The Nature of the Cathode Ras' - - - - . 5

J. J. 'Тномson's Experiments - $\quad$ - $\quad$ - $\quad$ - $\quad$ - 7

Corpuscles ANd Electrons - - - - - - - 8

WEHNELT CATHOdes -

Properties of Cathode Rays - - - $\quad$ - $\quad$ - $\quad 10$

Electron 'Theory of MatTer - $\quad$ - $\quad$ - $\quad$ - $\quad$ - $\quad$ - 18

POSITIVE RAYS.

Nature of the Positive Ras's - $\quad$ - $\quad$ - 19

J. J. Thomson's Experiments - - - - - - $\quad$ - 20 


\section{CHAPTER 111.}

X RAIS.

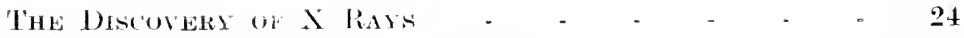

Methol, of Pronuction of I Risis - - $\quad$ - $\quad$ - $\quad 25$

\section{CHAP'TER IV.}

AN X-RAY BULB.

EARLY X-RAY 'JUBES - $\quad$ - $\quad$ - $\quad$ - $\quad$ - $\quad$ - 99

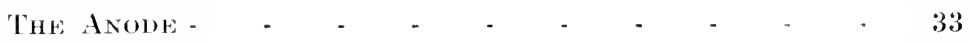

THE ('ATHODE - $\quad$ - $\quad$ - $\quad$ - $\quad$ - $\quad$ - 34

'The AnTtCATHODE

SUTtable Metals for The Antrathode - - - - 38

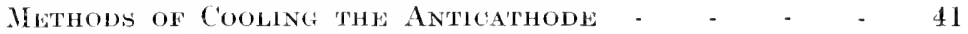

\section{('HAP'TER V.}

H.GH-PO'TEN'TIAL GENERATORS.

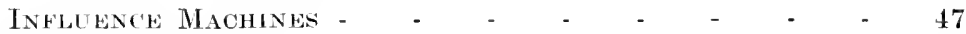

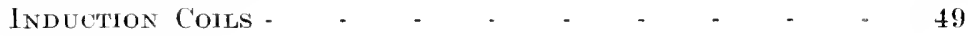

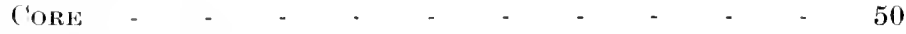

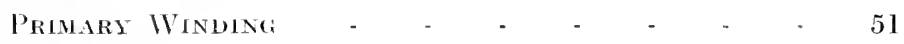

CONDENSER - $\quad$ - $\quad$ - $\quad$ - $\quad$ - $\quad$ - 51

SECONDARY WINDING - $\quad$ - $\quad$ - $\quad$ - $\quad$ - 53

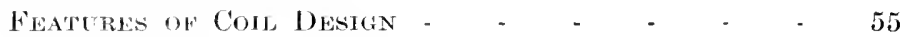

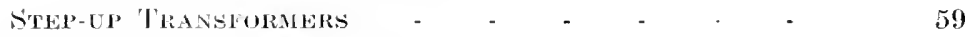

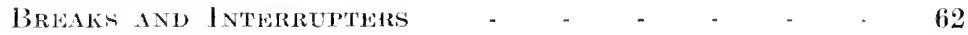

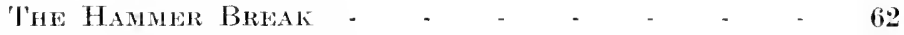

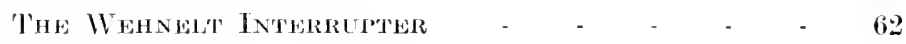

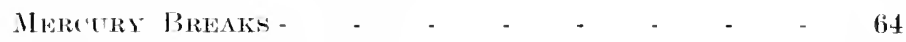

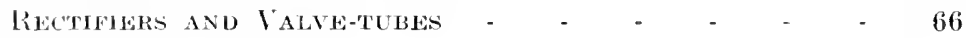

CHAP'TER VI.

'THE "HARDNESS" OF AN X-RAY BULB.

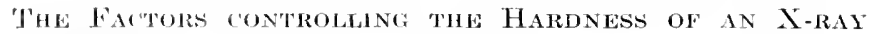

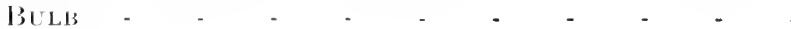


The P'rotressive Hardening of an X-ray Bulb with Use

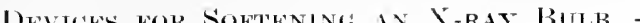

\section{('HAP'IER VII.}

'THE BLACKENING OF AN X-RAY BULB.

Cathodil Disintegration or "Sputtering" - - - 76

Thermal Volatilisation of the Anticathode - - S

Violet Coloration of the Bulb - $\quad$ - $\quad$ - $\quad$ - 83

\section{CHAP'TER VIII.}

THE MEASUREMENT OF $\mathrm{X}$ RAYS.

'T'he International and British Radium Standards - 84

Methods of Measuring Tntensity - - . - - 85

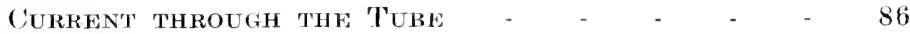

Thermal Methods of Measuring Intensity - - 87

IONISATION METhoDs -

Рhotographic Methods

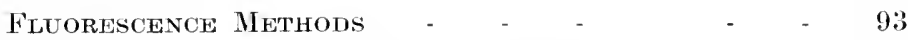

Methods used in Medicine: the Pastille, etc. - 93

Methods of Measuring Hardness - - $\quad$ - $\quad$ - 94

IVAVE-LENGTH

Potential applied to X-ray Tube - - - - 96

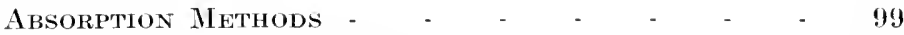

Benoist's Penetronhteir, hTC. - - - - - 104

\section{CHAP'IER IX. \\ SECONDARY RAIS.}

SCATTERED X RAYS - - - - - - . - . 108

Distribution - $\quad-\quad-\quad-\quad-\quad-\quad-\quad-110$

POLARISATION

Characteristic or "Honochromatic" X Rays - - 112

$K$ and $L$ Series of Radiations - - - - - 113

Characteristic Radiations from Radioactive Elements 118 
('ILARACIERISTIC LAGHT RiYS - - - - . . 119

DIRECT GENERATION OF CHARACTEREST: RAYS - - 121

CONNECLION WITH GATHOde RAY VElOCITY - - 124

Sienective Absorpton of Characteristic liass - 129

Corpuscular Rays

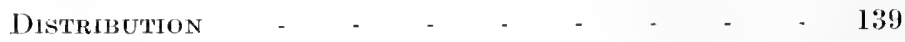

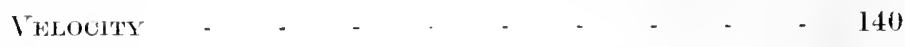

IBSORPTION - $\quad$ - $\quad$ - $\quad$ - $\quad$ - $\quad$ - $\quad$ - $\quad$ - 141

('HAP'TER X.

FUR'THER PROPERTIES OF THE I RAYS.

IONISATION PROUUCED BY X RAYS - - - - - $\quad$ - 145

C. 'T. R. Wilson's Fog ('ONDensation Experianents - 149

VELOCITY OF X RAYS - $\quad$ - $\quad$ - $\quad \ldots \quad \ldots$

\section{CHAPTER XI.}

PRACTICAL APPLICATIONS OF X RATS.

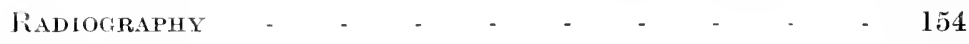

INSTANTANEOUS RADHOGRAPHY - $\quad$ - $\quad$ - $\quad$ - $\quad$ - $\quad 159$

Physhoggical and Curative Actions of $X$ Rays - -161

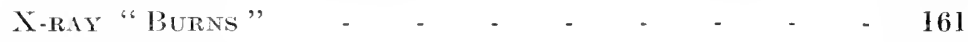

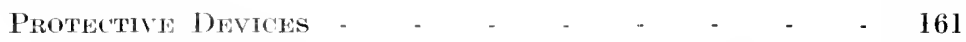

Glasses esplelably Transparent to X Rass - - - 165

Therapeutic Use of Homogeneous X Rays - - 166

\section{CHAPTER XII.}

INTELFERENCE AND REFLECTION OF $~ X$ RAYS.

LAUE's 'THeORY OF DIFFraction bY CRYstals - - $\quad 169$

Thl: Explarmanes of Friedrich and KNIPping - - 171

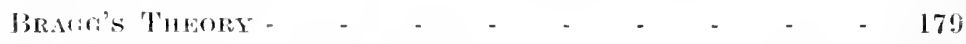

Experiment's on Rabium $\gamma$ RaYs - - - - -

BRAGG'S EXPERIMEN'S ON C'RYS'TAL-REFLEC'TION * . 186 


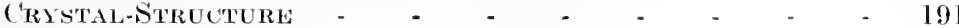

Wave-Lengths of $\mathrm{A}$ Rals and Atome Distanegs in Cristals

\section{CHAPTER XIII.}

THE NATURE OF THE $\mathrm{X}$ RAYS.

P'Lanck's Quantum 'Theors - - - - . . 205

BragG's Neutral-Pair Theory - - - - - 205

Identity of X Rays and Ultara-violet light Rays - 206

Stokes' SPherical Pulse Theory - . - - . 208

The localised Pulse Theor of J. J. Thomson - - 213

The Outstanding Problem of Radiation - - . 215

\section{APPENDIX 1.}

An Interview with Prof. Röntien-by sir James Mackenzie Davidson

\section{APPENDIX II.}

Coolidge's X-RaY Bulb with Hot Cathode -

\section{APPENDIX III.}

The Production of High Vacua - - - - - 222

\section{APPENDIX IV.}

Electrical Insulators

\section{APPENDIX $V$.}

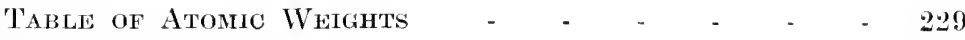

Table of Densities - $\quad$ - $\quad$ - $\quad$ - $\quad$ - $\quad$ - $\quad$ - 231

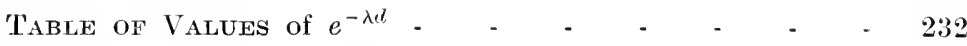

Table of Cathode-ray Velocity and Potential - - 233

Table of Characteristic $\gamma$ Rays - - $\quad$ - $\quad-\quad 2 \quad 234$

'Table of Wave Lengths of Lines in X-Ray Sípectra - 235

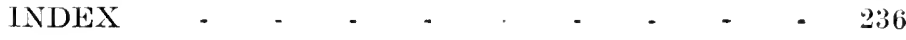




\section{NATURE AND PROPERTIES OF VARIOUS KINDS OF "RAYS."}

$c:=$ unit of electricity $\left\{\begin{array}{l}=\text { charge carried by hydrogen ion in electrolysis, } \\ =4.7 \times 10^{-10} \text { electrostatic units (E.S.U.), } \\ =1.57 \times 10^{-20} \text { electromagnetic units (E.M.U.) }\end{array}\right.$

\begin{tabular}{|c|c|c|c|c|c|}
\hline \multirow[t]{2}{*}{ NATURE. } & \multirow[t]{2}{*}{ lisys. } & \multicolumn{2}{|c|}{$\begin{array}{c}\text { RATIO OF CHARGE TO } \\
\text { MASS, }(e / m) .\end{array}$} & \multirow{2}{*}{$\begin{array}{l}\text { VELOCITY. } \\
\text { cims./sec. }\end{array}$} & \multirow[t]{2}{*}{ RANGE, ETL. } \\
\hline & & E.M.U.grnI. -1 & E.s.U.grm. ${ }^{-1}$ & & \\
\hline \multirow{4}{*}{$\begin{array}{l}\text { ELECTRI- } \\
\text { CALLY } \\
\text { NEUTRAL. }\end{array}$} & $\begin{array}{l}\text { Hertyian waves. } \\
\text { Infra-red rays. } \\
\text { Visiblelight rays. } \\
\text { Ultra-violet light. } \\
\text { Entladung- } \\
\text { strahlen. }\end{array}$ & \multicolumn{2}{|c|}{$\left.\mid \begin{array}{l}10^{6} \text { to } 0.1 \text { ems } \\
0.013 \text { to } 7.7 \times 10^{-5} \\
17 \cdot 7 \times 10^{-5} \text { to } \\
133.6 \times 10^{-5} \\
3 \cdot 6 \times 10^{-5} \text { to } 10^{-5} \\
\text { About } 10^{-6} ?\end{array}\right\}$ Wave } & $3 \times 10^{10}$ & $\begin{array}{l}\text { From a rew } \\
\text { mm. of air to } \\
\text { infinity. }\end{array}$ \\
\hline & $\mathrm{X}$ rays. & \multicolumn{2}{|c|}{ Wave length; about $10^{-8}$} & $3 \times 10^{\prime \prime}$ & $\begin{array}{l}\text { From a few } \\
\text { cms. to over } \\
100 \text { metres in } \\
\text { air at N.T.P. }\end{array}$ \\
\hline & $\begin{array}{l}\gamma \text { rays of kit, U, } \\
\text { Ac.'Th, etc. }\end{array}$ & \multicolumn{2}{|c|}{ Wave lengtl ; about $10^{-1, ?}$} & $3 \times 10^{14}$ & $\begin{array}{l}\text { Reduced to } 1 \\
\text { per cent. by } 3 \\
\text { mile of air at } \\
\text { N.T.Y. }\end{array}$ \\
\hline & $\begin{array}{c}\text { Grdinary atoms } \\
\text { and molecules. }\end{array}$ & $\begin{array}{r}\mathbf{H}_{2} \text { at } \\
m=1 \cdot 64 \\
\text { Diam. }=2.2 \times\end{array}$ & $\begin{array}{l}\text { tom } \\
\times 10^{-2}+g_{12 m} \\
10^{-8} \mathrm{cni} . \\
\end{array}$ & 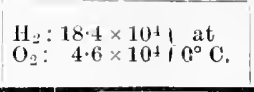 & $\begin{array}{l}\text { Mean free patls } \\
\text { of } \mathrm{H}_{2} \text { at } 0^{\circ} \mathrm{C} \text {,, } \\
1.8 \times 10^{-5} \mathrm{~cm} .\end{array}$ \\
\hline \multirow{7}{*}{$\begin{array}{l}\text { CARRIERS } \\
\text { OF } \\
\text { NEGATIVE } \\
\text { ELECTRI- } \\
\text { CITY. }\end{array}$} & \multirow{4}{*}{$\begin{array}{l}\text { Electrons. } \\
\text { Corpuscles. } \\
\text { Cathode rays. } \\
\text { Lenard rays. } \\
\text { Negative iol at } \\
\text { low pressures, } \\
\text { B rays of lia, U, } \\
\text { Th, Ac, K, etc. }\end{array}$} & \multirow{3}{*}{\multicolumn{2}{|c|}{\begin{tabular}{|c|} 
(For small velocities.) \\
$1 \cdot 77 \times 10^{7} \mid 5 \cdot 31 \times 10^{t 5}$
\end{tabular} \mid}} & $\begin{array}{l}\text { Photoelectrons } \\
10^{7} \text { to } 10^{8} \text {. }\end{array}$ & Very small. \\
\hline & & & & $\begin{array}{c}\text { Welunelt cathode rays } \\
10^{8} \text { to } 10^{9} \text {. }\end{array}$ & Very small. \\
\hline & & & & $\begin{array}{l}\text { Cathode rays } \\
10^{\prime \prime} \text { to } 10^{10} \text {. }\end{array}$ & $\begin{array}{l}\text { Range in air a } \\
\text { few mus. }\end{array}$ \\
\hline & & \multirow{2}{*}{\multicolumn{2}{|c|}{$\left[\begin{array}{l}m_{11}=1 / 1830 \mathrm{H}_{\mathrm{n}} \text { atomi. } \\
\text { Diam. }=4 \times 10^{-1: 3} \mathrm{~cm} .\end{array}\right]$}} & $\begin{array}{l}\beta \text { rays of Ra } \\
10^{1 i} \text { to } 2.99 \times 10^{10}\end{array}$ & $\begin{array}{l}\text { stopped by } \\
\text { about } 1 \text { cn. of } \\
\text { lead }\end{array}$ \\
\hline & $\begin{array}{l}\delta \text { rays } \\
\text { (slow } \beta \text { rays). }\end{array}$ & & & As low as $3.2 \times 10^{8}$. & $\begin{array}{c}\text { Too slow to } \\
\text { ionise. }\end{array}$ \\
\hline & Negative ion. & \multicolumn{2}{|c|}{$\begin{array}{l}\text { May have several charges } \\
\text { (though usually one) and } \\
\text { up to } 30 \text { molecules. }\end{array}$} & $\begin{array}{l}\text { fu air } ; 1.8 \text { for unit } \\
\text { electric field. }\end{array}$ & - \\
\hline & $\begin{array}{l}\text { Negatively } \\
\text { charged atoms } \\
\text { and molecules in } \\
\text { discharge tubes. }\end{array}$ & ${ }^{104}\left(\right.$ for $\left.\mathrm{H}_{2}\right)$ & $\begin{array}{l}3 \times 1017 \\
\quad\left(\text { for } \mathbf{H}_{0}\right)\end{array}$ & Up to $10^{8}$. & - \\
\hline \multirow{4}{*}{$\begin{array}{l}\text { CARRIERS } \\
\text { OF } \\
\text { POSITIVE } \\
\text { ELECTRI- } \\
\text { CITY. }\end{array}$} & $\begin{array}{l}\text { a rays of Ra, U, } \\
\text { Th, Ac, etc. } \\
\text { (hetium atoms } \\
\text { with charge } 2 e \text { ). }\end{array}$ & $\left\{\begin{array}{r}4 \cdot 8 \times 10^{:} \\
{\left[\begin{array}{r}{[m=6 \cdot 56} \\
\left.\times 10^{-: 4}\right]\end{array}\right.}\end{array}\right.$ & $1.4 \times 1014$ & $\begin{array}{l}\text { Iuitial value } 1 \cdot 6 \times 10^{\prime} \\
\text { to } 2 \cdot 2 \times 10^{9} \text { (depend- } \\
\text { ing on souree). }\end{array}$ & $\begin{array}{l}3 \text { to } 8 \text { cms. in } \\
\text { iir at N.T.P. }\end{array}$ \\
\hline & Recoil atoms. & $47(\mathrm{RaB})$ & $1.4 \times 10^{12}$ & $5 \times 10^{-4}(\operatorname{RaC})$. & \multirow[t]{3}{*}{$\begin{array}{l}110 \mathrm{~mm}_{\text {. in air }} \\
\text { at X.T.P. }\end{array}$} \\
\hline & $\begin{array}{l}\text { Positively } \\
\text { charged atoms } \\
\text { and molecules } \\
\text { (Kantstrahlen) } \\
\text { in discharge } \\
\text { tubes. }\end{array}$ & $\left.{ }_{(\text {for }}^{10} \mathrm{H}_{2}\right)$ & $\begin{array}{l}3 \times 10^{14} \\
\left(\text { for } \mathrm{H}_{2}\right)\end{array}$ & U, to $10^{\mathrm{N}}$. & \\
\hline & Positive iol. & \multicolumn{2}{|c|}{$\begin{array}{l}\text { May liave several cliarges } \\
\text { (thougl usually one) and } \\
\text { up to } 30 \text { molecules. }\end{array}$} & $\begin{array}{l}\text { In air : } 155 \text { for unit } \\
\text { electric field. }\end{array}$ & \\
\hline
\end{tabular}




\section{THE REVOLUTION OF THE CORPUSCLE. 1}

A corpuscte onco chich oscillate so quickly to and fro.

He always raised disturbances wherever he did go.

He struggled hard for freedom against a powerful foe-

An atom-who would not let him go.

The aether trembled at his agitations

In a manner so familiar that I only need to say,

In accordance with Clerk Maxwell's six equations

It tickled people's optics far away.

You can feel the way it's done,

You may trace them as they run-

$d \gamma$ by $d y$ less $d \beta$ by $d z$ is equal $K . d X / d t$.

While the curl of $(X, Y, Z)$ is the minus $d / d t$ of the vector $(a, b, c)$.

Some professional agitators only holler till they're hoarse, But this plucky little corpuscle pursued another course, And finally resorted to electromotive force,

Resorted to electromotive force.

The medium quaked in dread anticipation,

It feared that its equations might be somewhat too abstruse,

And not admit of finite integration

In case the little corpuscle got loose.

For there was a lot of gas

Through which he had to pass.

And in case he was too rash.

There was sure to be a smash,

Resulting in a flash.

Then $d \gamma$ by $d y$ less $d \beta$ by $d z$ would equal $K . d X / d t$

While the curl of $(X, Y, Z)$ would be minus $d / d t$ of the vector $(a, b, c)$.

The corpuscle radiated until he had concoivecl

A plan by which his freedom might be easily achieved,

"Air: "The Interfering Parrot" (Geisha). 


\section{xri REVOLUTION OF THE CORPUSCLE}

I'll not go into details, for I might not bo believed,

Indoerl I'm sure I should not be helieved.

How rver, thoro was one decisive action,

'The aton and tho corpuscle each made a single charge,

But the atom could not hold him in subjection

Though something like a thousand timos as liurge.

The corpuscle won the day

And in freedom went away

And became a cathode ray.

But his life was rather gay,

And he went at such a rato,

That he ran against a plate:

When tho aether saw his fato

Jts pulse did palpitate.

And $d \gamma$ by dy less $d \beta$ by dz was equal $K$. dS/dt.

While the curl of $(X, Y, Z)$ was the minus $d$ dt of the vector $(a, b, c)$.

A. A. R. 


\section{IN'TRODUCTION.}

In the early nineties, it was not infrequently maintained that the science of physics had put its house in complete order, and that any future advances could only be along the lines of precision measurement. Such pessimism has been utterly confounded by a sequence of discoveries since 1895, mparalleled in their fundamental nature and promise.

Even many not specially concerned have had their attention directed to the recent attempts at solving the riddle which has excited interest and taxed ingenuity since the beginning of civilisation-the problem of the ultimate strueture of matter. The chemist and physicist have long built upon a theory of atoms and molecules; though information as to the existence and behaviour of individual atoms was only based on speculation, however justifiable.

But within the last decade we have not only isolated the atom, but we have learnt a great deal about its internal structure. Radioactivity has, for examplc, introduced us to an electrically charged atom of helium (the a ray) with characteristics such that it can, in spite of its extreme smallness, ${ }^{1}$ make individual appeal to our senses. The speed of a rays is so abnormally high, ${ }^{2}$ that if, for instance, they are allowed to strike a fluorescent screen, as in the Spinthariscope of Sir Wm. Crookes, each atom possesses enough energy to record its arrival by a visible flash of light. This provided what was probably the first instance of the registering of a single individual atom. Rutherford and Geiger similarly turned to account the electric charge, and have

${ }^{1}$ Mass about $7 \times 10^{-24}$ gramme; diameter about $2 \times 10^{-4} \mathrm{~cm}$.

${ }^{2}$ About 12,000 miles or $2 \times 10^{9} \mathrm{~cm}$. per sec. 
actually recorded the arrival of single atoms by means of a delieate electrometer.

More recently, C. T. R. Wilson, by the aid of his most beautiful and ingenious experiments on fog condensation, has succeeded in rendering visible and photographing the paths, not only of single charged atoms, but of electrons and $\mathrm{X}$ rays as well.

The emission of such charged atoms from the radioactive elements proceeds entirely regardless of let or hindrance on our part: we have, however, the ability and means to create similar abnormal carriers for ourselves-they are, for instance, to be found in abundance in a rarefied gas through which an eleetric discharge is passed. Under these conditions, the gas molecules, which are ordinarily electrically inert, assume, in many cases, electrical charges and, in addition, may have their usual velocities ${ }^{1}$ increased a thousand-fold, so that they acquire properties which single them out from their fellows.

These facts are sufficiently attractive in themselves, but even those few among us who, severely practical, still look askance at 'ionics,' cannot but agree that the close study which has been given to the phenomena of a discharge tube has already been more than repaid by the further discovery of electrons by .J. J. Thomson and of the $\mathrm{X}$ rays by Röntgen.

The diseovery of electrons provided us with the present accepted theory of the constitution of matter; it paved the way for a ready recognition of the properties of the radioactive elements, then on the point of discovery; and it led to a new school of physics which aceepted as a ereed the transmutation of the elements, an idea entirely repugnant to the orthodox chemist who had been taught to regard the elements as fundamental and immutable-the foundation stones of a science which had been well and truly laid.

The amazing properties of the $\mathrm{X}$ rays exeited universal astonishment at the time of their discovery. An X-ray outfit is now indispensable to the surgeon and physieian;

1 Abrut 20 miles per minute in the case of air molecules. 
and the debt which the world of humanity owes to the $\mathrm{X}$ rays is a heavy and increasing one.

Through the efforts of a devoted band of workers, with an outlook on life not immediately utilitarian, the Röntgen rays have thrown a searchlight on many phases of atomic physics not susceptible to other methods of attack.

And, last of all, and quite recently, $\mathrm{X}$ rays have come to the aid of the crystallographer and triumphantly displayed in the hands of Laue, Friedrich and Knipping, Bragg and others, the regular grouping of the atoms in a crystal. The experiments, which have opened up an immense field of enquiry, have at the same time given the long-deferred answer to the problem of the nature of the unknown or $\because \mathrm{X}$ " rays.

The Geissler discharge tube ${ }^{1}$ - the former beautiful plaything of the scientist-has proved the pioneer of some of the most wonderful discoveries and speculations that physical science of this or any generation has known. Truly, as Maxwell predicted in the early seventies, the vacuum tube has shed light upon the whole domain of electrical science, and even upon the constitution of matter itself.

Our present intent, that of the study of the $\mathrm{X}$ rays, is approached most naturally by way of a scrutiny of the general phenomena of a discharge tube and of electrons in particular. To these branches of the subject we accordingly first direct ourselves.

${ }^{1}$ Known at different times and in different countries as the Pliicker. Hittorf, or Crookes tube. 


\section{ABBREVIATIONS OF REFERENCES TO JOURNALS.}

A.d.P. Annalen der Physik.

A.Rt.R. Archives of the Röntgen Ray.

C.R. Comptes Rendus.

D.P.G.F. Terhandlungen der Deutschen Physilsalischen Gesellschaft.

J.d.P. Journal de Physique.

J.Rt.S. Journal of the Röntgen Society.

N. Nature.

P.C.P.S. Proceedings of the Cambridge Philosophical Society.

P.M. Philosophical Magazine.

P.P.S. Proceodings of the Physical Society.

P.R. Physical Review.

P.R.S. Proccedings of the Royal Society (Series A).

P.R.S.E. Proceedings of the Royal Society of Edinburgh.

P.T. Philosophical Transactions.

P.Z. Physikalische Zeitschrift. 


\section{CHAPTER I.}

THE PHENOMENA OF A DISCHARGE TUBE.

When a current of electricity from an induction coil or influence machine is sent between two metal electrodes fused into the ends of a glass tube (say 12 inches long) from which the air is gradually withdrawn by a pump, the tube presents a continuous succession of striking appearances.

At high pressures, air is a very bad conductor of electricity ; and a large force is necessary to produce a visible discharge while the pressure remains in the region of atmospheric. But a reduction of pressure facilitates the passage of the spark, which after a time loses its noisy character and is replaced by a collection of sinuous and irregular pink streamers which later broaden and fill almost the whole of the tube with a pink diffuse glow known as the positive column. Simultaneously the alternative spark-gap of the coil diminishes to a small fraction of an inch--evidence that the rarefied air is now conducting well.

Meanwhile the eathode-the electrode by which the current leaves the tube ${ }^{1}$-assumes at its tip a luminous tuft - the negative glow-violet in colour, which later grows until it completely envelops the cathode. Between these two luminous glows comes a darker ill-defined region called the Faraday dark-space. These general appearances correspond to a pressure of some 8 to 10 millimetres of mercury.

As the pressure is further reduced, the alternative sparkgap begins to lengthen, the anode becomes tipped with a

1 The electrode by which the current enters the tube is the anode. 
vivid speek of glow, and the positive column proceeds, if the current density is suitable, to break up into thin fluctuating pink dises or striae, which subsequently thicken and diminish in number, intensity and extent. 'The Faraday dark-space enlarges, and in the meantime (at about $1 \mathrm{~mm}$. pressure), the violet negative glow increases in brightness and volume, ${ }^{1}$ and the glass walls of the tube are seen to fluoresce with an olive-green light which, as J. J. Thomson (P.C.P.S. 1910) has shown, is due to the action of extremely active ultra-violet light from the negative glow. ${ }^{2}$

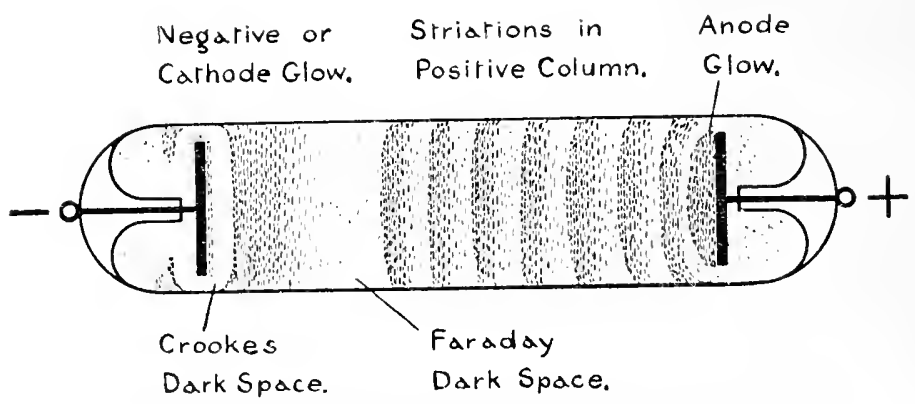

Fic. 3.-Discharge tulbe at low pressure, fhowing cathode dark-space and positive striations.

As the exhaustion proceeds, this fluoreseence disappears, the negative glow detaches itself like a shell from the cathode, while a new violet film forms and spreads over the surface of the cathode. Thus the negative glow now consists of two parts : they are separated from each other by a narrow dark region called the Crookes or cathode dark-space, which has a sharply defined ontline rumning parallel to that of the cathode. (Sce Fig. 3.)

With a rerluetion of pressure, the dark space increases in willh. and pushes the outer negative glow before it. The dark space is often used as a rough indieation of the pressure, though its width depends also on both the current

'The longth of the ghow on the eathode depends also on the current: the two ame induret romghly poportional (Hehl, 1903).

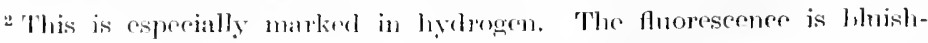
green will lead glass. 
density and the metal of the cathode, and is not really a reliable guide to the degree of exhaustion. ${ }^{1}$

With higher rarefactions (say $\frac{1}{5} \overline{0} \mathrm{~mm}$.) both positive and negative glows become less bright and definite in outline, and finally lose almost all traces of luminosity. Meanwhile the cathode dark space has grown at the expense of all else, until finally it becomes so large that its boundaries tonch the glass walls of the tube. It is at this stage that the tube begins to shine, first in the region of the cathode, and then (as the dark space extends) over its whole surface, with the brilliant apple-green fluorescence ${ }^{2}$ well known to those who are accustomed to X-ray tubes.

All this time the length of the alternative spark-gap has been stcadily increasing. If the exhaustion is pressed still further, the fluorescence diminishes, and the resistance of the tube increases, until finally it becomes impossible for the discharge to pass at all. The pressure at which this comes about depends partly on the induction-coil and partly on the size of the discharge tube. A large tube always runs more easily than a small one at the same pressure. ${ }^{3}$

The above are the more salient features to be observed in a discharge tube. At atmospheric pressure the discharge consists mainly of positive column; at low pressures it is the phenomena of the cathode dark-space which are most conspicuous and have attracted widespread attention.

1 See Aston, P.R.S. 1912.

2 This is quite different in appearance from, and mueh more brilliant than, the olive-green fluoreseenee at higher pressures (see above). The yellow-green colour holds only for soda-glass tubes. Learl and lithium glasses yield a bhish fluoreseence.

${ }^{3}$ It should be remarked that induction coils do not give pure midirectional currents, but, in some eases, show marked "reverse" eurrents as well, more especially with easy discharge paths. So that as the pressure is lowered both eleetrodes may appear to act as eathode until the fluorescenee stage is reached. In some eases it is quite diffieult at the higher pressures to say which electrode will ultimately prove to be the eathode. 


\section{CHAPTER II.}

\section{CATHODE RAYS.}

\section{Historical.}

The study of the green fluorescence on the glass was commenced by Pliicker as long ago as 1859, and carried on vigorously by Hittorf (1869) and Goldstein (1876) in Germany, by Crookes (1879) in England, and by Puluj in Austria. It was soon ascertained that the fluorescence was produced by something coming from the region of the cathorte; for a suitably interposed obstacle cast a sharp shartow on the walls of the tube. "This "something" was given the name cathode rays (Kathodenstrahlen) by Goldstein. who believed that the fluorescence was produced by waves in the ether for whose propagation the gas in the tube was not necessary. The expression has been retained, and rightly, for although the word "ray" has come to be associated with a wave-motion in the ether, the connection is quite fortuitous; indeed Newton used the term in his corpuscular theory of light.

The general properties of the cathode rays soon revealed themselves. Plïcker had found that their path was bent by a magnet. Goldstein, by suitably contrived shadow 'xperiments, confirmed Hittorf's observation that the ravs travel in straight lines, and showed further that they start at right angles to the surface of the cathode. Crookes, by the use of cathodes shaped like a concave mirror. demonstrated that the rays concentrate near the centre of ('mrvature. and there display in a marked degree heating propertics and an ability to exeite phosphorescence in 
many substanees. They tend also to push away any object against which they strike, and eause, for example, paddlewheels of mica to rotate, although we now know that such experiments depend for their success, not on the momentum of the rays, but on heating effects such as prevail in a radiometer. ${ }^{1}$ Most important of all, eathode rays, when they strike matter, generate $\mathrm{X}$ rays, as Röntgen showed in 1895.

\section{The Nature of the Cathode Rays.}

For nearly thirty years the English and German schools of physies disagreed as to the nature of the cathode rays. German physicists, following Goldstein's lead, held that the rays were similar to light-a wave motion in the ether with which matter had nothing to do. This view received much support from the experiments of Hertz (1892), and

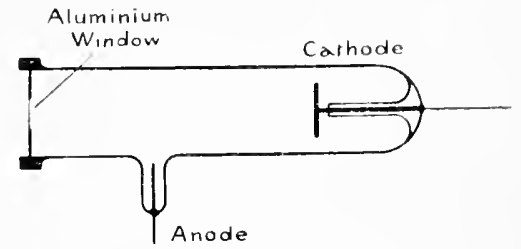

FIG. 4.-A Lenard tube for showing the passage of cathode rays through a thin aluminium vindow.

his friend and colleague Lenard (A.d.P. 1894), who showed that solid bodies were not absolutely opaque to the rays which could pass, for example, through gold and aluminium foil. Lenard's historic vaeuum-tube was provided with a small "window" of aluminium foil, $0.000265 \mathrm{~cm}$. thick. (See Fig. 4.) When the eathode rays were shot against this window, he found that they passed through without puncturing it, and were able to exeite phosphorescence, etc., a few millimetres away in air. ${ }^{2}$ There was no difficulty in aceounting for the transparency of thin solids on the ether-wave theory, though it was apparent that the relation to ordinary optical transpareney was slight; for instance, gold leaf is more transparent than clear mica to

1 A paddle-wheel made of a good thermal conductor such as aluminium does not show the effect. In a radiometer the vanes are propelled by the recoil of the gas molecules from the warmer face of each vane.

2 The Lenard rays travel farther in attenuated air. We know now that part, at any rate, of the phosphorescence which these "Lenard rays" produced was due to $\mathrm{X}$ rays generated by the aluminium. $\mathrm{X}$ rays were not discovered until the following year. 
cathode lays. On the other hand, the normal emission of the rays from the cathode could scarcely have been anticipated on any wave theory: one would have inferred a gencral enission in all directions.

But the magnetic deflectibility of the cathode rays, and its unsatisfactory explanation on a wave theory, were regareled as crucial by English physicists, who were manimous in the view that the rays consisted of particles of matter charged with negative electrieity and projected with immense speeds from the cathode. Varley in 1870 seems to have been the first to suggest, though somewhat vaguely, the presence of such particles in the electric discharge ; and Sir Wm. Crookes, in a series of papers in the Philosophical Trunsactions (1879-1885), definitely adopted this standpoint to explain and coordinate the many striking results of his experiments.

In a flight of intuition, Crookes suggested that the matter constituting the cathode rays was neither gas nor liquid nor solid as ordinarily known, but in a fourth state transcending the gascous condition-an extremely happy surmise, as events proved. It is interesting to recall that Faraday as long ago as 1816 speculated on the possibility of the existence of such a fourth state of matter.

Crookes supposed the eathode particles to have the dimensions of molecules, but this view became hard to reconcile with their penetrating power for metals found (as mentioned above) by Hertz and Lenard some years later. To meet the difficulty, the suggestion was put forward that the metal, under the bombardment of the cathode rays, acted as a pseudo-cathode, and itself emitted eathode rays. It was further pointed out that instances of the penetration of metals by molecules were not unknown; to wit, the pasisage of hydrogen through hot palladium and platinum, the squerzing of water under hydraulic pressure through gold and other metals, and the gradual penetration of lead by gold when dises of the two are in close contact. ${ }^{1}$ However, these axplanations were not very satisfying, nor did

\footnotetext{
1 'here experinents of Roberts-Austen on the interdiffusion of metals were being conducted about this time (see P.T. 1896).
} 
they prove to be necessary, for abont this time new evidence began to aceunulate in favour of the charged particle theory.

Sir J. J. Thomson eame to the conchusion that the veloeity of the cathode lays was appreciably less than that of light; and the French physicist Perrin in 1895, by eatching the rays in a Faraday eylinder, demonstrated that they earried a charge of negative electricity with them. But though Perrin's experiment carried conviction to the majority, it was not regarded as conchusive by the extreme ether-wave supporters, who looked on the electrification as merely

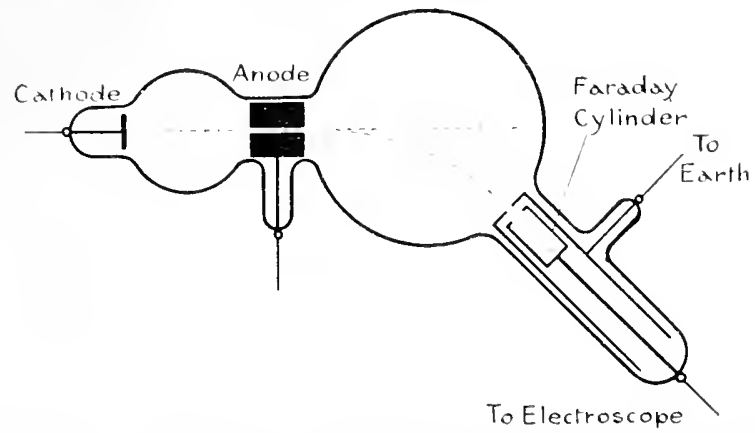

FLi. כ.-J. J. Thomson's morlitication of Perrin's apparatus for proving that catlode rays are negatively charged.

revealing the presence of clectrified particles which were an accidental accompaniment of, and were not essentially commected with, the cathode waves.

But J. J. Thomson in 1897, by suitably modifying Perrin's apparatus, showed that when a magnet was used to deflect the cathode rays the negative electrification followed exactly the same course as the rays which produced the fluorescence on the glass (Fig. 5). He further succeeded in deflecting the cathode rays by an electric field: Hertz had tried this experiment fourteen years previonsly, and had failed because the pressure of his gas was too high, the gas conducting sufficiently well to mask the effect of the clectric field.

After these results it coulel harlly be doubted that the cathode rays were negatively charged particles, and the objections to this view, on the score of their penetrating 
ability for solids, were finally set at rest by J. J. Thomson in 1897-1898. In a series of experiments, which for ingenuity and insight have rarely been equalled, Professor Thomson, by deflecting the cathode rays in magnetic and electric fields of known strength, was able to infer the size of the charged particles; and later, to deduce their mass, velocity and electric eharge. (See p. 14.) He showed that the cathode rays were neither atoms nor molecules, but something far smaller: the mass of each of the particles proved to be about $\frac{1}{1 \times 00}$ th part of the smallest mass hitherto recognised by chemists-that of the atom of hydrogen. Their nature depends neither on the nature of the cathode nor on that of the residual gas in the discharge tube. The charge is invariable, and agrees with that carried by the hydrogen ion in liquid electrolysis: the velocity depends upon the electric force which is applied to the tube; the speeds are found to be an appreciable fraction of the speed of light, ${ }^{1}$ in some cases as much as one-third.

Thus the cathode rays proved to be neither ethereal waves nor ordinary material particles, but bodies of sub-atomic size moving with prodigious velocities, a state of things so nearly realising Newton's long-abandoned conception in his corpuscular theory of light that J. J. Thomson called the small particles which constitute the eathode rays, corpuscles. Johnstone Storey had previously suggested the name electron for the electrolytic unit, or atom of electricity, and the suitability of the expression for the cathode rays was at once recognised: both terms have since come into common use.

It is perhaps difficult to realise the disproportion ${ }^{2}$ between the size of an atom and the size of an electron: the two have been aptly compared to a fly in a cathedral, or a speck of dust in a room!

\section{Wehnelt Cathode.}

If the cathode is constructed of a strip of platinum which caun be raised to a bright red heat, ${ }^{3}$ and on which is mounted

\footnotetext{
1 The velocity of light is 186,300 miles or $3 \times 10^{10} \mathrm{cms}$. per sec.

${ }^{2} 1$ : 100,000 in linear dimensions; $1: 10^{15}$ by volume.

${ }^{3}$ by means of an independent current.
} 
a speck of lime ${ }^{1}$ (see Fig. 6), all the ordinary phenomena of a discharge tube can be reproduced by means of quite small potentials-100 volts or less between the cathode and anode. The hot lime emits torrents of corpuscles and the pencil of cathode rays, owing to their low speed (see p. 12), produces vivid luminosity in the rarefied gas. The velocity of the rays is proportional to the square root of the potential applied: the velocities are of the order of $\frac{1}{10}$ th of those in

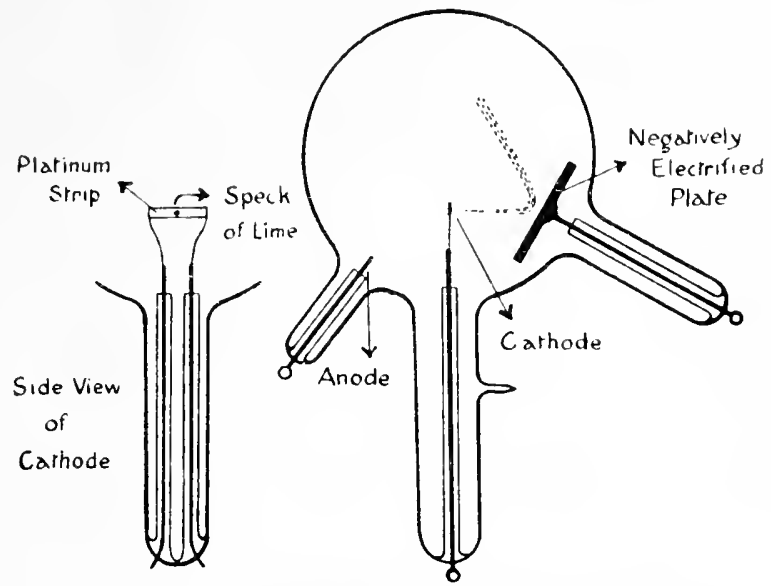

Fit. 6.- I discharge tube with a Wehnelt cathode, displaying the repulsion of the cathode rays by a negatively charged plate.

an ordinary discharge tube; e.g. with 50 volts, the velocity $=4 \cdot 2 \times 10^{8} \mathrm{cms}$. per sec. The magnetic and electrostatic deflection of these rays can bo strikingly demonstrated owing to their relatively small velocity.

It is possible with the hot-lime cathodes to send very large currents through the discharge tube-currents of 7 ampere and more are readily attained. With high cathode temperatures and voltages of 200 or 300 on the tube it requires precautions to prevent the discharge growing into an arc ${ }^{2}$ with the consequent destruction of the cathode.

I Or any of the alkaline earths (a speck of sealing-wax, ignited in situ, is very convenient). See Wehnelt (P.M. July 1905).

${ }^{2} \mathrm{~A}$ water resistance in the poteutial circuit serves to prevent this. 


\section{Transmission and Absorption of Cathode Rays.}

lenard (llied. Ann. 1895) showed that for fast-moving cathode rays, the extent of the absorption iu different substances is roughly proportional to the density. The penetrating power of a eathode ray varies very greatly with its speed. The highest speed rays, which move at the rate of about $10^{10}$ ems. per sec., can only penetrate 2 or $3 \mathrm{mms}$. of air at ordinary temperature and pressure. The fastest $\beta$ rays from radium are cathode rays which have no more than about three times this speed, and yet their range in ail is nearly 100 times as great. The range is, of course, increased by lowering the pressure of the gas, as the molecules are not so closely packed, and the cathode rays suffer fewer concounters with the atoms.

During its journey, the cathode ray loses velocity both by ionising and by deflection. So long as its speed remains high, it pursues a fairly even course; as it slows down, it becomes more and more liable to deflection by the encountered atoms, until finally it loses so much energy that it becomes undistinguishable as a cathode ray. Thus a fine pencil of cathode rays gradually becomes fuzzy and scattered.

Some of the cathode rays are actually swung completely round by the surface atoms, and so may be "reflected" with velocities up to the original velocity. The more obliquely incident the rays, the greater the number "reHected." In regard to the transmitted rays, Whiddington (P.R.S. 1912) has recently shown experimentally the truth of a relation deduced theoretically by Sir J. J. Thomson some years ago. He finds that the maximum velocity $\left(V_{d}\right)$ with which a eathode ray may leave a material of thickness $d$ is given by

$$
V_{0}^{4}-V_{d}^{4}=a d,
$$

where $V_{0}$ is the initial velocity of the cathode ray and $u$ is a constant $\left(2 \times 10^{40}\right.$ for air ; $732 \times 10^{10}$ for $\mathrm{Al} ; 2540 \times 10^{40}$ for gold ; all in cm. sec. units). This fourth-power scattering law holds also for Ra $\beta$ rays, except the very fastest. Whiddington was unable to trace any simple eomnection between the value of $a$ and the atomic weight or density of the material. 
Cathode rays lose their speed very quickly in passing through solids, and thin metal leaf has to be used in experimental work. ${ }^{1}$ The maximum thickness of aluminium or glass which transmits high-speed cathode rays to any appreciable extent is about $0.0015 \mathrm{~cm}$. (Cf. p. 45.)

\section{Heating Effects produced by Cathode Rays.}

The bulk of the energy of the cathode rays is dissipated as heat when the rays strike an obstacle. A simple calculation shows that if in a tube of moderate vacuum the current earricel by the cathode rays is a milliampere $\left(10^{-3}\right.$ amp.), the energy given up by the rays per minute is of the order of 100 calories.2 Now a milliampere is only a moderate current; as will be seen later, eurrents up to 50 or 60 milliamperes and even more (with momentary discharges) obtain in practice. No target can withstand such currents for any. length of time if the rays are concentrated by using a concave cathode. Platinum may be fused, diamonds converted into coke; even tantalum and tungsten ${ }^{3}$ with melting points in the neighbourhood of $3000^{\circ} \mathrm{C}$. can be rendered molten. Owing also to the low pressure, most metals ean be vaporised with ease.

The heating effects reach a maximum at a certain pressure, which is not very low, and are not so marked in very high vacua.

\section{Ionisation produced by Cathode Rays.}

A cathode ray has the property of ionising a gas, i.e. of rendering it electrically conducting. The ionising power is

${ }^{1} \mathrm{Al}, \mathrm{Cu}, \mathrm{Ag}, \mathrm{Sn}, \mathrm{Pt}$, and An can be got in the form of thin leaf. (Stee Kaye and Laby's Physical Constants, p. 35.)

2 The energy $E=\frac{1}{2} i \cdot \frac{m}{e} \cdot v^{2}$, where $i$ is the current, $v$ is the velocity of the rays, $m$ is the mass of and $e$ the charge on each ray. If $E$ is cxpressed in calories per min., $i$ in milliamperes, and $v$ in cms. per sec, then $E=4.10^{-18} i v^{2}$. This assumes that all the cathode ray cnergy is turned into heat.

${ }^{3}$ Von Wartenberg (1907) detemined the melting point of tumgsten by means of a cathode-ray vacum furnace. He used a concave Wehnelt cathode (p. 8) for the purpose. See also Tiede (1913) for an account of a cathode-ray furnace with a water-cooled cathode. 
especially conspicuous with the slower rays-the ionisation per centimetre of path was in fact found by Glasson (P.M.

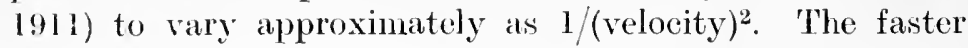
rays have the greater energy, it is true, but they do not begin to ionise to any great extent until their velocity has dropped. ${ }^{1}$ A cathode ray (like the a ray) ionises most towards the end of its path, until finally it loses so much energy that it ean no longer ionise, and ceases to be distinguishable as a cathode ray.

The strong ionisation is responsible for the luminosity which eathode rays produce in the residual gas of a discharge tube-a luminosity which at higher pressures is displayed as the outer negative glow bounding the cathode dark-space (see p. 2), and at lower pressures lights up' the path of the rays themselves (see p. 34). The luminosity of the track reaches a maximum at a certain pressure; as the pressure is further reduced, the rays gradually become fister and less luminous, but simultaneously their power of exciting fluoreseence in the glass walls of the tube increases, until finally the rays become quite invisible and are manifested solely by the fluorescence on the glass.

\section{Fluorescence produced by Cathode Rays.}

An ordinary X-ray tube affords abundant evidence of the fluoreseing properties of glass subjected to cathode rays. Crookes found in 1879 that glass which had suffered prolonged bombardment by the rays fatigued and lost a good deal of its fluoreseing ability. Most of the fatigue is only temporary, but a portion is very permanent. Crookes found, for instance, that complete recovery was not brought about even by fusion of the glass; and Campbell-Swinton (P.R.S. 1908) refers to a tube in which the fatigue persisted for more than ten years. Swinton showed that the fatigue is purely a surface effect, and is removed by grinding away the surface of the glass. He found that the thickness which had to be removed for this purpose was always about $.015 \mathrm{~mm}$.

${ }^{1}$ The total iomsation of the fuster ray is, of course, greater than that of the slower. 
There are many substances which afford striking and beautiful examples of the fluorescing ability of cathode rays. Among those which are useful in practice are barium platino-cyanide (a material of which fluorescent screens are usually made), the mineral willemite (a silicate of zinc), zinc blende (sulphide of zinc), and kunzite (a lithium felspar).

The fluorescing power of a cathode ray increases with its velocity, and does not seem to be possessed by the very slowest rays. Rays as slow as those from a Wehnelt cathode are, however, capable of eausing fluorescence.

\section{Magnetic Deflection of Cathode Rays.}

When a charged particle (mass $m$, charge $e$ ) is projected along a line of magnetic force, it continues to move along it; but if it is projected (with velocity $v$ ) at an angle $\theta$ to the magnetic field (of strength $H$ ), the deflecting force acting upon it is $H e v \sin \theta$. Hence, if $\rho$ is the radius of curvature of the resulting path,

or

$$
H e v \sin \theta=m v^{2} / \rho
$$

(1)

$$
\rho=\frac{m v}{H e-\sin \theta},
$$

which represents a helix. So that, in general, the effect of

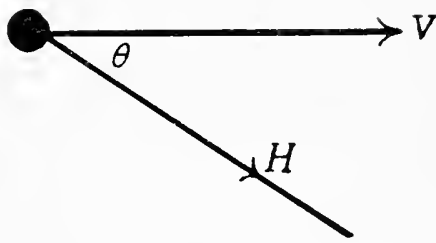

FIG. 7. a magnetic field on the path of a moving corpuscle is to twist it into a helix wound on a eylinder with the lines of force as axis. With the slow cathode rays given out by a Wehnelt cathode (p. 8), the helix can be beautifully demonstrated: with strong fields, the helix becomes so long and attenuated that the rays appear to follow the lines of force.

In the particular case when the eathode ray is projected at right angles to the magnetic lines of force, $\sin \theta=1$, and

$$
\rho=m v / H e \text {. }
$$

Thus in a uniform magnetic field, the path of the particle is a circle in a plane at right angles to the magnetic force, i.e. the particle is bent away in a direction at right angles 
both to the field and to its former direction. ${ }^{1}$ The extent to which cathode rays are bent by a magnetie field thus depends on the strength of the field, on the speed of the particles, and on the quantity denoted by $e / m$. As to the speed, that is related directly to the potential which is applied to the tube; the reloeity is, indeed, roughly proportional to the square root of the potential or alternative spark-length (see p. 96).

\section{Electric Deflection of Cathode Rays.}

If an electric field $X$ is acting at right angles to the direction of projection of the cathode ray, the force on it is $\mathrm{X} e \mathrm{in}$ the direetion of the field. Thus, as above, the radius of curvatare is

$$
\rho=\frac{m v^{2}}{X e} \text {. }
$$

The eorresponding expression for the magnetic deflection was

$$
\rho=\frac{m v}{H e} \text {. }
$$

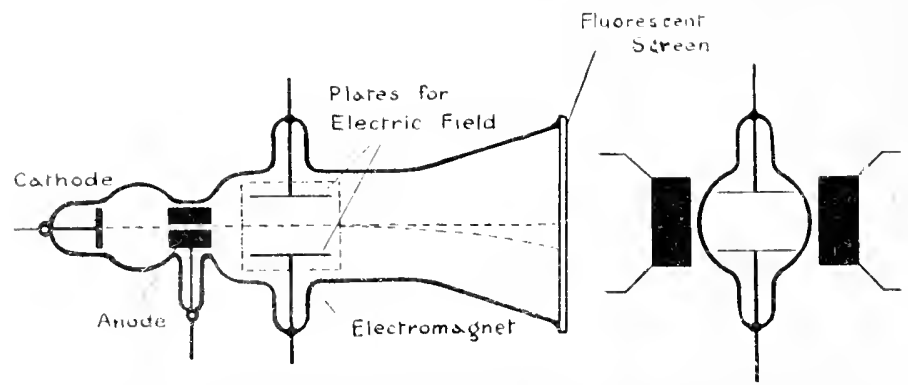

PIG. 8.-T. .T. Thomson's apparatus for measuring $e / m$ of eathorle rass. An dectrif and a magnet ir tield are contrived so that their effects on a beam of cathode rays balanee rach other exactly, in which rass the fluoreseent spot

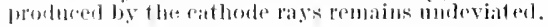

If we contrive things so that the magnetie and electrie dellections are expal and opposite, we can, at onee, from a knowledge of the fields, derive both the veloeity and $\mathrm{e} / \mathrm{m}$

The following momonical rule is eonvenient for remembering in which

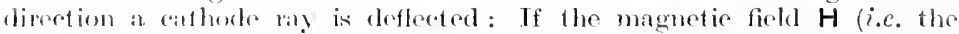
direction in which a $\dot{N}$-seeking pole would move) is mpwards towands the Hatel, and the eathode Ray is moving horizontally towats the Right hand, the medanieal Fore on the ray is horizontally towards the Front. 
for the cathode ray; for $v=X / H$, and $e / m=X /\left(\rho H^{2}\right)$. It was in this way that J. J. Thomson first arrived at the nature of the cathode rays (p. S). (See Fig. s.)

\section{Braun Tube.}

A practical application, due to Braun, of the bending of eathode rays under magnetic or electric force has come into use in electrical engineering for the purpose of studying the wave-form of rapidly changing alternating currents. In the Braun tube, a narrow pencil of eathode rays is received on a fluorescent screen, and is subjected en route to both a magnetic and an electric field. The two fields are at right angles, and are both actuated by the alternating current. The eathode rays, having practically no inertia, are able to follow the most rapid vagaries of the fields, and so trace out on the screen a pattern, from which the wave-form can be deduced.

\section{Magnetic Spectrum of Cathode Rays.}

Each interruption of the primary current in an induetion coil produces a small train of strongly-damped oscillations in the discharge (p. 59). Thus the potential on the tube is intermittent, and the result is a stream of eathode rays with a variety of speeds, each peaklet on the oseillatory potential eurve produeing a group of iniformly fast cathode rays, of which the speed diminishes with successive oscillations.

Accordingly, if the cathode rays are subjected to a magnetic field, the different groups are differently deviated-the greater the speed, the less the magnetic deviation. Thus a slit of eathode rays, when allowed to fall on a fluorescent plate, produces in a magnetic field a number of bright lines or bands which go to make up a "magnetie spectrum "an appearance first notieed by Birkeland (C.R.) in 1896. The brightness of each band is a measure of the number of rays moving with the same speed : the displacement of the band from the undeflected position is inversely proportional to the velocity, and directly proportional to $\mathrm{e} / \mathrm{m}$ and the strength of the field. 
If the gas pressure in the discharge tube is not very low, the bands may be numerous ( 30 or more), but if the pressure is lowered, the oscillations are more strongly damped, and so the lines become fewer, group themselves more elosely, are less deviated as a. whole (the eathode rays being faster), while the least deviated linc becomes the brightest; thus
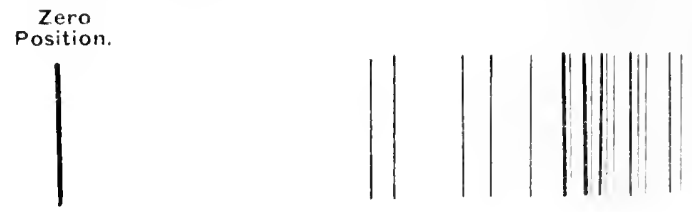

Pressure $0.008 \mathrm{~mm}$.
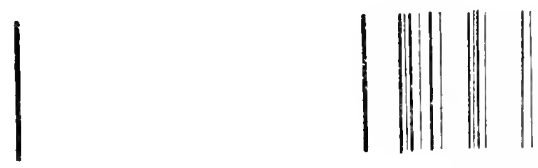

\section{Pressure $0.004 \mathrm{~mm}$.}

Fis. 9.- Txamples of magnetic spectra of cathode rays.

most of the cathode rays now possess the maximum veloeity. Fig. 9 shows two magnetie speetra obtained by Birkeland at rlifferent pressures.

Beatty (P.R.S. 1913) found that with a potential of about 60,000 volts on the tube, the main stream of eathode rays had a veloeity corresponding to about two-thirds of the potential as given by a spark-gap.

A speetrum of rays can also be produeed by an electric field, in which ease the deviations are inversely proportional to the square of the veloeity.

A tube driven by a Wimshurst machine or a battery of cells does not yield a magnetic spectrum, but only a single bright line, whieh is evidenee of the fact that all the cathode particles have the same velocity.

Constants of Cathode Rays.

Mrasurements of the spect of eathode rays have been marle by various experimenters; the rays in an ordinary 
discharge tube have velocities ranging from about $10^{9}$ to rather more than $10^{10} \mathrm{cms}$. per sec., i.e. from one-thirtieth to one-third of the speed of light.

The latest determinations of $e / m$ (see $p$. 14) for the slowest rays give a value of $1.77 \times 10^{7}$ expressed in electromagnetic units. Measurements of the jonic charge make $e=1.57 \times 10^{-20}$ E.M.U., so that, for small velocities, $m$ is $8.8 \times 10^{-28}$ gramme. Theory indicates that electrons owe all their mass to their velocity, and that for cathode rays moving, for example, with one-third the speed of light $m$ would have a value about $6 \%$ greater than the above.

Now, according to the best authorities, the mass of the hydrogen atom is $1 \cdot 6 \times 10^{-24}$ gramme, so that the number of electrons equal in mass to the hydrogen atom is about 1830 .

Further constants will be found on p. xii.

\section{The Ubiquity of Electrons.}

Since their discovery in so artificial a source as a vacuum tube, electrons have been found literally to pervade the universe. Relatively low-speed clectrons are emitted in many chemical reactions and by metals when exposed to light, especially ultra-violet. High-speed electrons with velocities almost up to that of light constitute the $\beta$ rays of radium and the radioactive substances: the alkaline metals (at any rate $\mathrm{K}$ and probably $\mathrm{Rb}$ ) also emit corpuscles. They are ejected in abundance from hot bodies, markedly so from the alkaline earths (lime, baryta, etc.) with velocities and in amounts depending on the temperature. Withont doubt they play a part in cosmical physics: the most recent explanations of the aurora or northern lights regard them as dne to enormously fast electrons ejected by the sun, which are collected and guided in long spirals (sce p. 13) to the polar latitudes by the earth's magnetic lines of force. ${ }^{1}$ They there ionise and cause luminosity in the

1 Aurora occur most abundantly not at the poles, but at about latitude $68^{\circ}$. This requires for the electrons a velocity closely approaching that of light-a velocity even greater than that possessed by the fastest known $\beta$ particles from radium. 
upper attenuated regions of the earth's atmosphere, just as they do in a vacum tube.

But whatever their origin, electrons have always been found to maintain their invariable and indivisible character: they earry the unit of electricity, and can indeed be regarded as the ultimate fundamental earrier of negative electrifieation.

\section{The Electron Theory of Matter.}

Rutherford's theory of the constitution of matter, which satisfies a number of the main facts, regards an atom as built up of a minute nucleus of positive electricity ${ }^{1}$ (no bigger than $10^{-12} \mathrm{~cm}$. in diameter) surrounded by an inner cluster of negatively eharged electrons which rotate round the nucleus, and an outer group of electrons which also rotate and are less rigidly attached. The total negative charge of the electrons is equal to the positive charge of the nuelens. The onter electrons, by their number and arrangement, are responsible for the chemical and physical properties of the atom: the inner electrons have influence only on the phenomena of radioactivity. This explains why physical and chemical behaviour do not go hand in hand with $\mathrm{X}$ and $\gamma$-ray phenomena. Present theory indicates that the number of corpuseles in an atom is equal to either the atomic weight of the material or not more than a small multiple or submultiple of it. As positive electricity has never been found to be associated with bodies less than atoms, it would appear that the atom owes most of its mass to its positive nuelens, which is capable of deflecting both a and $\beta$ particles out of their paths.

The electron theory of matter has been elaborated by Lorentz and others, and extended to many departments of physies. For instanee, the phenomena of magneto-opties show that aleetrons are intimately concerned with the speetrum lines. An electronie theory of magnetism has been devoloped by Larmor (1s!7) and Langevin (190.5).

${ }^{1}$ Rutherford (P.M. 1911). Ser also Bohe (P.M. Tuly, Sept. and Nov. 1!13), and J. J. 'Thomson, Enginecring, Mareh 21. 1913. 
In the case of solids, there are supposed to exist unattached and wandering electrons interspersed between the molecules. These can be ejected by ultra-violet light or heat: they are the important agents in thermo-electricity. and in the conduction of electrieity and heat; a good conductor, for example, is one which contains many of these free electrons. The electron theory has, among other things, led to important deductions eoncerning the specific heats of metals at low temperatures-a subject to which Nernst. and others have lately given attention.

For an account of the electron theory see Lorentz, Theory of Electrons, 1909, and N. R. Campbell, Modern Electrical Theory, .nd ed., 1913.

\section{Positive Rays.}

Though the ordinary eathode rays are the most eonspicuous of the rays existing in a discharge tube, there are others also present. As long ago as 1886 , Goldstein, by perforating the cathode of a discharge tube, observed that a stream of rays travelled through the tube in the reverse direetion to the cathode rays. To these rays he gave the general name of ('anal-rays (Kanalstiahlem). Wien showed that the Canal rays were deflected in the opposite direction to eathode rays when subjected to a magnetic force, and he came to the eonelusion that they must consist of positively eharged particles. The deflection detected in this case, however, was small eompared with that obtained with eathode rays. ${ }^{1}$ but the deflection in the electric ficld was of the same order of magnitude for both positive and negative particles. This pointed to the fact that the positive particle had greater mass than the eathode or negative particle; Wien, in fact. found that the mass of the positive particle was of the same order of magnitude as that of a hydrogen molecule.

The existence of the two kinds of rays in a discharge tube can very easily be shown by the different colours the produce in lithium ehloride. This substance fluoresees blue

\footnotetext{
'Posit ive rays require, roughly speaking, magnetic ficlds of 1000 gauss or more, i.e. at least forty times as strong as are needed to deflect cathode rays.
} 
under the action of cathode rays, and red under the action of positive rays, so that a small glass bead coated with lithium chloride and placed in a suitable position between the electrodes in the tube will appear red on the side towards the anode, and blue on the side facing the cathode. This bead can be utilised to explore the region between the electrodes in order to determine in what part of the tube the positive rays have their origin. Starting with the bead at the anode, we should find that it does not appear red on the side facing the anode until we arrive at the boundary between the negative glow and the Crookes dark-space (p. 2); it continues to fluoresce red throughout the Crookes dark-space. The amount of fluorescence in various parts of the dark-space, however, shows that most of the rays start from the boundary of the dark-space.

The positive rays have strong ionising, fluorescing, and photographic actions. They cause soda glass to fluoresce a dull green; willemite, a bright green: in both cases, the effects are much inferior to those produced by cathode rays. The positive rays show strong pulverising properties, and roughen or disintegrate any surface against which they strike.

During the last few years the whole question of the electric discharge from the point of view of positive electricity has been taken up by Sir J. J. Thomson. He has shown that there exist in the tube high-speed atoms and molecules of the gases present, some positively charged, some negatively. and some moheharged. In no ease has a positive ray been detected whose mass is smaller than that of the hydrogen atom; a positive alectron, if such exisis, has hitherto eluded search. The velocities of these positive particles are in the neighbourhood of $10^{8} \mathrm{cms}$. per seeond (the fastest have a speed of about $2 \times 10^{8} \mathrm{cms}$. per second) : this is of the order of 100 n times the ordinary velocity of molecules as ealeulated from the kinetic theory of gases (p. 73).

It is found that there are many more of these high-speced charged particles (or ions) moving towards the cathode than from it. ${ }^{1}$ If a hole is made in the cathode, the positive

"These latter "potrograde rays" travel with and among the cathode rays, but can be dotected when the rathode rays are removed hy a magnet. 
ray's stream through it and form the Canal rays of Goldstein; and in this region, where they are separated from the cathode rays, they can be independently investigated.

Professor Thomson received a very fine peneil of these rays on a photographic plate, and en route subjeeted them simultaneonsly to the action of magnetic and electric fields, the magnetic field deflecting the rays at right angles to

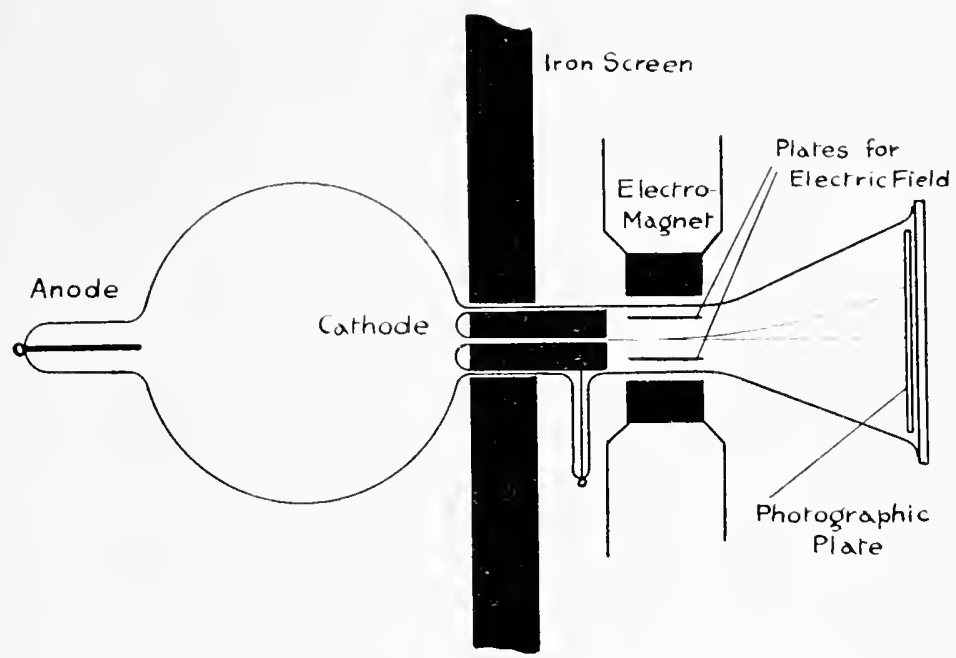

Fit. 10.-J. J. Thomson's apparatus for measuring $\mathrm{e} / \mathrm{m}$ of positive rays (Kanalstrahlen).

the deflection caused by the electric field (see Fig. 10). ${ }^{1}$ It is found that only a small portion of the beam is deflected, - the main part goes on unaffected by the deflecting forces. If $x$ and $y$ are the deflections of a particle due to the action of the electric and magnetic fields respectively, and $e, m$, and $v$ the charge, mass, and velocity of the particle, then we have

$$
\begin{aligned}
& x=A \cdot \frac{e}{m v^{2}}, \\
& y=B \cdot \frac{e}{m v^{2}}
\end{aligned}
$$

where $A$ and $B$ are constants depending upon the strengths

${ }^{1}$ In the corresponding cathode-ray experiment (p. 14) the magnetic force and electric force were parallel. 
of the electric and magnetic forces, and the distances the ray's have to travel from the time they enter the field of foree until they reach the photographic plate.

The equation to the trace on the photographic plate becomes

$$
\frac{y^{2}}{x}=\frac{B^{2}}{A} \cdot \frac{e}{m} .
$$

'This is the equation of a parabola, so that we have on the plate a series of parabolas representing the loci of particles

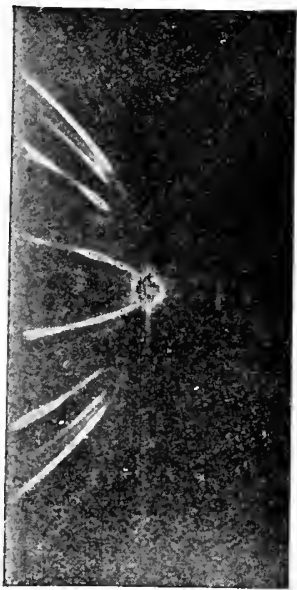

Fit. 11.-Photograph obtained by .J. J. Thomson of parabolic loei of positive particles subjected to magnetic and electric fields at right angles to each other. The different traces represent ditherent substances. In the figure, the magnetic deflections are vertical. The nuagnetic ficld was reversed half-way through the exposure, so that both halves of each parabola are recorcled. which have a constant value of $e / \mathrm{m}$. (See Fig. 11.) Different particles register different loci on the plate, and for each locus $m$ has a definite value, so that the method affords a means of determining accurately the atomic weights of substanees which are present in the tube. The system of eurves obtained on the sereen depends, of course, upon the nature of the gas in the tube. Most positive rays carry only one ionic charge (equal to that carried by the cathode rays), though with some elements 2, 3, and up to 8 charges have been found.

By this method, Professor Thomson has been able to determine the atomie weights of numerous elements, ${ }^{1}$ and has, indeed, discovered substances as yet unknown to the chemist. IIhen, for example, nitrogen is put into the tube there are seen on the photographie plate parabolas corresponding to $\mathrm{N}^{+}$(an atom of nitrogen with one charge), $\mathrm{N}^{++}, \mathrm{N}_{2}{ }^{+}$, $N_{3}^{+}$. A rery interesting case is afforded by marsh gas $\left(\mathrm{CH}_{4}\right)$, which yields lines corresponding to the combinations $\mathrm{CH}, \mathrm{CH}_{2}, \mathrm{CH}_{3}$, and $\mathrm{CH}_{4}$. The great advantage

\footnotetext{
${ }^{1} \mathrm{c} / \mathrm{m}$ for the hychrogen molecule carying a single charge is $10^{4}$ electromagnetic units.
} 
of the method lies in the fact that only a very smatl quantity of the gas investigated is required in the tube; and, in addition, a combination of atoms in an unstable state has only to exist for a minute fraction of a second in the tube in order to allow it to be recorded on the photographic screen.

For a fuller account of this ingenious method, see J. J. Thomson, Posilive Rays (Longmans, 1913).

The positive rays are important from the point of view of the X-ray worker, in that by their bombardment of the cathode, they liberate the cathode rays. Furthermore, the positive rays are responsible for the positive electrification which the inner surface of the glass walls of an X-ray bulb ahways assumes (p. 32), and which serves to heighten the Huorescence of the glass by attracting the secondary cathode rays from the anticathode.

The positive rays doubtless also play a prominent part in the action of valve-tubes (p. 66). 


\section{CHAPTER TII.}

\section{RAYS.}

\section{The Discovery of X Rays. ${ }^{1}$}

We have dealt above in some detail with many of the features which cathode rays possess; we have, however, made no more than mention of their most striking property of all-that of generating $\mathrm{X}$ rays. In the autumn of 1895 Professor Wilhelm Konrad Röntgen of Würzburg, Bavaria, discovered, it may be said almost accidentally, the rays which now bear his name. During the course of a seareh for invisible light rays, he turned on a low-pressure discharge tube, which for the purpose was completely enclosed in stont black paper, and to his surprise noticed that a fluorescent screen lying on a table some 3 metres or so distant shone ont brightly. The light-tight eover precluded any possibility of the effeet being due to ordinary ultra-violet light: there was evidently some curious radiation coming from the tube. If obstacles were interposed, Röntgen found that they cast shadows on the sereen; and in this way he traced back the unknown or " $\mathrm{X}$ " rays to their souree, which proved to be the region of impact of the cathode rays on the glass walls of the tube.

Further investigation revealed the fundamental fact that Röntgen or $\mathrm{X}$ rays are produced whenever and wherever cathode rays encounter matter. It was inagined by many that I rays were present in the original eathode ray beam, and were obtained by nere subtraction. But this was disproved by the discovery that when the eathode ray's were magnetically deflected, the source of the $\mathrm{X}$ rays also moved. The experiment also put out of eourt the notion that $\mathrm{X}$ rays were due to the impact of particles of metal from the eathode.

$$
1 \text { Soe also p. } 217 .
$$


But the faseinating feature of the new rays was their extraordinary ability to penetrate many substances quite opaque to light. The degree of penetration was found to depend on the density ; for example, bone is more absorbent than flesh, and if the hand is plaeed in the path of the rays, the bones stand out dark against the Hesh in the shadow cast on a fluorescent sereen. Röntgen at once appreciated the immense significance of his discovery to the surgieal profession, and eommunicated his results to the PhysicoMedieal Soeiety of Würzburg in November 1895. ${ }^{1}$

It was soon aseertained that $\mathrm{X}$ rays affected a photographic plate, ${ }^{2}$ eould not apparently be refraeted or reflected (see p. 168), and, unlike cathode rays, were not bent by a magnetic or electrie field, ${ }^{3}$ a result which shows that the $\mathrm{X}$ rays do not carry a free electric eharge. In $1896, \mathrm{~J} . \mathrm{J}$. Thomson, Hurmuzeseu, Benoist, Dufour, and others found that Röntgen rays shared with eathode rays (and ultraviolet light) the property of ionising or imparting temporary eleetrieal conductivity to a gas, which ordinarily is a nearly perfect insulator.

Before considering in any detail the advanees that have been made in the various branches of the subject, it will probably be useful first to recount briefly the essential partieulars of the working of a simple X-ray equipment.

\section{A Brief Account of tife Production of X Rays.}

\section{An X-ray Bulb.}

When a current of electricity from a Ruhmkorff induction eoil is sent through an $\mathrm{X}$-ray tube, a peneil of eathode rays from the concave eathocle is foeussed on the target or anti-

1 Sce also L'Éclair Élect. 6. 241. 1896. For an account of Röntgen's later work, see Berl. Ber. 1847, and Ann. Phy. Chem. 189s. Röntgen's three memoirs are translated in the Electrician (Jan. 24, 1896 and April 24, 1897) and A.Rt.R. (Feb. 1899).

2 'The inexplicable fogging of unopened packets of photographic plates in the neighbourhood of a Crookes tube was engaging the attention of more than one English physicist at the time of the diseovery of the $\mathrm{X}$ rays.

${ }^{3}$ WaIter (A.d.P. 1904) used magnetic fields up to 19,000 gauss. Pasehen (P.Z. 1904) similarly exposed lia $\gamma$ rays to fields of 30,000 gauss. 
cathorle, the surface of which is inclined at $45^{\circ}$ to the rays, and is ustally made of a metal of high atomic weight, such as platinum (Fig. 12). An additional anode is mistally provided, but is not indispensable. The anode and eathode are generally of aluminimm. From the point of impact of the cathode rays on the anticathode, $\mathrm{X}$ rays are given ont in all directions. The anticathode tends with continued use to becone very hot, and is often either made massive

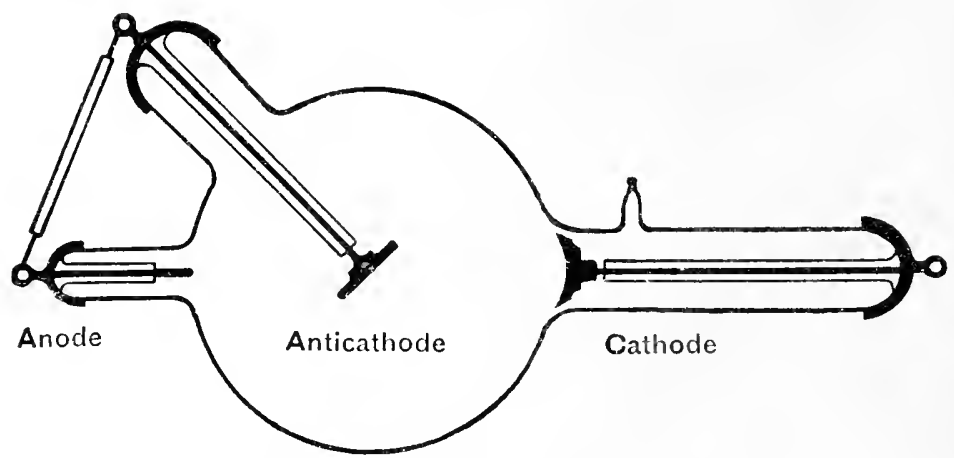

Ift. 12. - I simple type of focus bulb showing the various electrodes.

or cooled in some fashion. The pressure of the gals in an X-ray tube beeomes lower" with use, and a device for "softening " the tube (i.e. raising the pressure) is thereforo usually provided.

The higher the pressure, the less the potential required to drive the tube and the less penetrating the $\mathrm{X}$ rays; both the $X$ lay's and the tube are often termed "soft" if the pressure is high. The lower the pressure, the "harder" we the rays. In the $X$ rays from any particular tube there are many qualities present; this is shown by the fact that rays which have traversed one thickness of material wre more penetrating to a second.

X rays are invisible and do not make glass fiuoresce; the pale green hemisphere of fluorescence on the bulb is due to "reflected" cathode rays from the anticathode striking the glass walls. That this is so is shown by the distorting action of a magnet on the boundary of the fluorescence. 


\section{An Induction Coil.}

An induction coil is merely a device for transforming a low-potential current, such is is yiclded by a battery of a few cells, into a high-potential current of the kind suitable for driving an X-ray bulb. An induction coil consists essentially of a cylindrical iron core round which is wound a coil of stout insulaterl wire; this eoil, which is known as the primary, consists of relatively few turns. Outside this is the secondary coil consisting of many thousands of turns of finer wire carefully insulated. Fig. 13 shows diagram-

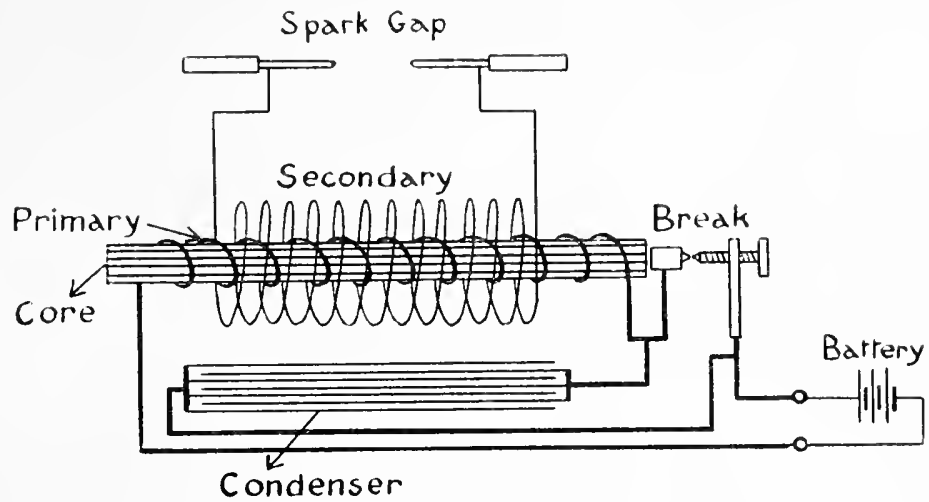

lif. 13.-Diagrammatic representation of an induction coil.

matically the various parts of a small coil. A hanmerbreak interrupter is shown in the primary circuit, and a condenser, usually mounted in the base of the coil, offers an alternative path to the break. The primary circuit is joined to a suitable battery; and the object of the interrupter is to make and break the eurrent in rapid succession. The consequence of this is at every "make" to induce in the secondary coil a momentary current, and at every "break" an equal momentary current in the opposite direction.

But in X-ray work it is important that the current through the X-ray tube should be all in one direction, and herein lies the chief function of the condenser. When the circuit is made, the eondenser takes and stores the first rush of current, which therefore grows relatively slowly and magnetises the 
core ; at break, however, the condenser discharges its electrieity through the primary circuit with great rapidity and demagnctises the core. The induced potentials in the secondary are accordingly much feebler at make than at break; the currents resulting from the former are known "ts "reverse" or "inverse" currents, and in a good coil are nearly suppressed. Thus the sparks which pass between the terminals of the seeondary circuit are due chiefly to the break and only pass one way. The power of a coil is often designated by the length of its longest spark, e.g. a 6-inch coil.

The iron core serves to increase the number of lines of force through the coils. The condenser is made of alternate layers of tinfoil and paraffined pajer. The hammer-break consists essentially of a stecl strip on which is mounted a piece of soft iron; this is attracted by the core when the current passes, and so breaks eireuit between two platinum studs in the primary circuit. The spring is thus caused to vibrate backwards and forwards like the hammer of an eleetric bell, and so altermately makes and breaks the primary current.

An extended account of the induction coil is given on p. 49 et seq. 


\section{CHAPTER IV.}

\section{AN X-RAY BULB.}

\section{Early X-ray Tubes.}

The vaeuum tube with which Röntgen made his famous diseovery in 1895 was pear-shaped, with a flat dise for rathole mounted in the body of the bulb at its narrow

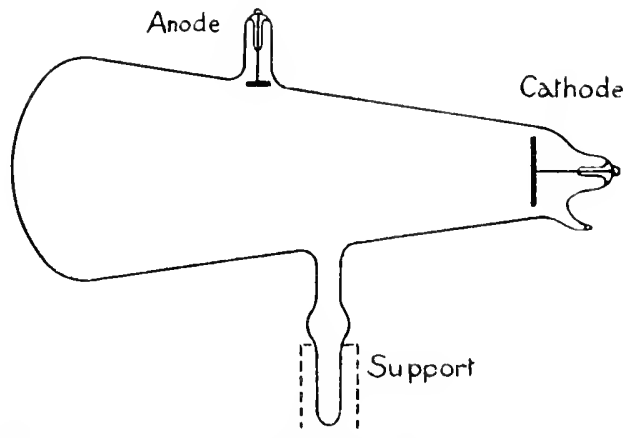

Fir. 14. - Type of tube with which kïntgen discovered $\mathrm{X}$ rays. The cathode rays impinged on the broal end of the tube.

end ; the anode was in a small side tube (Fig. 14). ${ }^{1}$ 'The eathode rays impinged on the large end of the bulb, produeing vivid fluorescence. This pattem of tube was widely eopied, bnt it was soon found that it did not survive many of the prolonged exposures which were necessary to seemre radiographs of any value. Moreover, owing to the large area of emission of the rays, the photographs were always blured and somewhat indistinet. Experimenters set about

${ }^{1}$ In another early form of X-ray bulb used by Röntgen, the anode consisted of a large ring in the borly of the bulb. 
to find ways and means of prolonging the life of the tube, of shortening the exposure, and of improving the definition. Under the impression, then prevailing, that active fluorescence was essential for the genesis of the $\mathrm{X}$ rays, ${ }^{1}$ various workers, about 1897, constructed tubes of fluorescent glass (e.g. uranium and didymium glasses) with the idea of enhancing the output of the tube; it was, however, found later that the fluorescenee was quite immaterial.

Campbell-Swinton in 1896 modified Röntgen's design of tube by inserting a shect of platinum obliquely in the path of the eathode rays. The improvement was considerable, though the radiographs were still lacking in sharpness, and the rxposures unduly protracted.

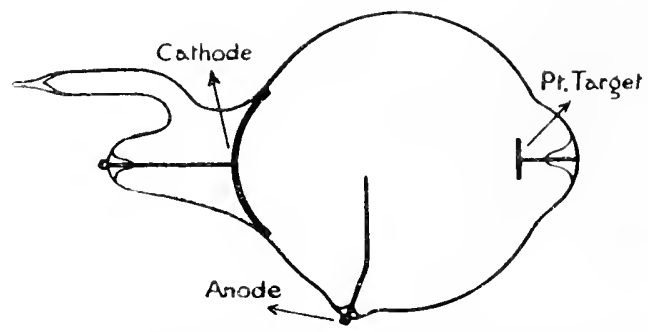

Fia. 15.-Tube ased by chookes to display the heating effects of focussed cathorle ritys.

The same year Professor H. Tackson of King's C'ollege, London, turned to account a former diseovery of Sir Wm. crookes, and replaced the flat cathode by a concave one. crookes had shown in 1874 that a hollowed-out eathode brought the cathode rays to a focus, and five years later actually constructed a tube with a plate of platinum at the focus to display the heating effects of the rays (Fig. 15). The tube must have given out $X$ rays in abundance, but they remained mmoticed. Professor Jackson mounted the platinum target at $45^{\circ}$ to the rays (Fig. 16); in essential resperets his tube agreed with that of crookes. The new

It may be recilled that the late Henri Beequerel, at the suggestion of 11. Poincare, was led to investigate whether X mys were an invariable areompaniment of phosplobescence in general. Among the substances

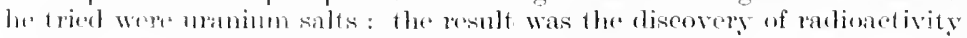
in 1s96, two menthe after the diseorery of $\mathrm{X}$ rays. 
focus tube was a vast improvement on its predecessors; the exposures were shortened enormously, and, owing to the small area of emission, the resulting photographs showed wonderful sharpness and detail.

It is remarkable how slight the subsequent changes have been; many thousands of $\mathrm{X}$-ray tubes have been made, but the design of the present-day model agrees essentially with that of fifteen years ago. ${ }^{1}$ Indeed, it may fairly be said that the $\mathrm{X}$-ray bulb has not kept pace with the very extensive improvements that have been made in the rest of the X-ray equipment. There is no gainsaying the fact

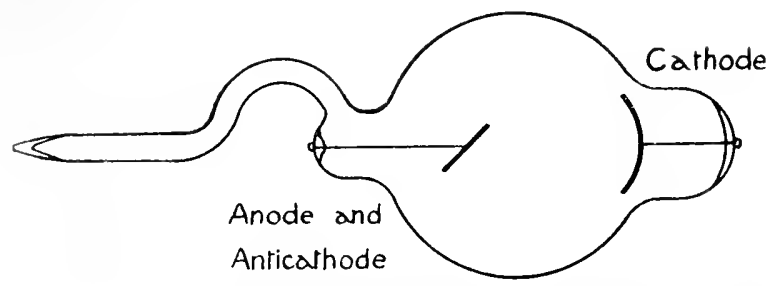

Fis. 16. Tackson's first focus tube, employing focusserl cathode rays.

that even now X-ray tubes are prone to be fickle, and it is scarcely possible to guarantee their bchaviour. A bulb will be perfectly satisfactory one day, and yet refuse to work reliably the next; and of two bulbs apparently precisely similar, one may work well for months, the other may break down within a few days. Many X-ray workers take the precantion of resting a favourite bulb occasionally; a bulb is often improved by being allowed to lie idle for a few weeks.

In general, a large bulb is better than a small for passing a heavy current (see p. 68). Some makers have accordingly constructed monster bulbs, which have, however, little to commend them on account of their mowicldiness and the greater thickness of the glass.

In all the earliest tubes, the cathode was mounted in the body of the bulb, but by the end of 1896 it was withdrawn just within the neck of a side tube-a design typical of all later makes, and one which conduees to greater steadiness

1 see, however, p. 21 !!. 
and hardness ${ }^{1}$ (see p. 69). In Jackson's bulb and its predecessors the target served also as anode; we find an auxiliary anode introduced in a tube by Gundelach in 1896. Both forms persisted for some years, but nowadays the anxiliary anode always finds a place.

Abont 1902, makers vainly songht to improve the effieiency of their tubes by coating some or all of the electrodes with radioactive material. Sinee then they have devoted most of their attention to the design and material of the anticathode.

\section{The Electrodes of an X-ray Bulb.}

The electrodes are fixed to stont wires or rods which, for ease of manufacture and repair, are invariably mounted in side tubes projeeting from the main bulb. It was found as early as 1896, that the discharge is materially steadied by eompletely sheathing the supporting wires with glass tubes. This largely serves to eheck the tendency for the discharge to pass along the walls of the tube, more especially at low pressures, and eheeks the "sputtering" 2 which is pronounced "with wires and points. The glass walls beeome highly eharged, negatively in the region of the cathode (p. 70) and positively in the main body of the tube (p. 23): these charges, particularly with a blackened tube, may cause the foeal-point to wander and lead to sparking along the glass.

The passage of the discharge along the glass walls is not moreover eonfined to the inside of the tube. Alippi found in 1906 that if a large jet of steam were allowed to play on the bulb, the X-ray output and general fluoreseenee greatly increasert. The effect is probably due to the removal of dust and the surface alkali in the glass with a eonsequent diminution of conduetivity. Loeal surface electrification is probably responsible for the green wisp-like discharges which ean often be seen plaving over the imner surface of a bull) when in use.

${ }^{3}$.T. T. Thomson ( $\left.P . M .1912\right)$ finds that this position of the cathode is also the mosi farmulable for the production of the positive "camal "rays. spe p. 7t. 
The part that surface electrification plays, and the control it possesses over the hardness and steadiness of a discharge is not, I think, generally appreciated.

\section{'The ANODE.}

As remarked above, the modern $\mathrm{X}$-ray bulb is always provided with an additional anode of aluminium which is joined externally to the anticathode (Fig. 12). The precisc benefit of the anode is a little doubtful, though in some cases the result of disconnecting it from the anticathode is to soften the tube. C. E. S. Phillips (A.Rt.R. 1902) conclucled that the auxiliary anode was helpful, probably by electrostatic action, in steadying the discharge. He remarks that the most advantageous position for the anode is behind the anticathode. The auxiliary anode is also probably beneficial during the passage of the inverse current which exists with all coil discharges: in these circumstances, the aluminium anode, rather than the platinum anticathode, tends to act as a temporary cathode, and as aluminium exhibits much less cathodic sputtering (p. 78) than platinum, the walls of the tube are not blackened to the same extent.

It is usually stated that the discharge is independent of the position of the anode. This is only true if the anode is outside the cathode dark-space: if the anode is within the dark-space, the discharge only passes with difficulty. Now, in an X-ray tube, working under ordinary conditions, the cathode dark-space is big enough to enclose the anticathode within its boundaries, and the presence of the anode, which is invariably inserted within a confined side tube, is thcrefore advantageous.

There is this, too, to be remembered : the easiest direction for a discharge to cross an unsymmetrical tube is that which makes the less restricted electrode the cathode-in other words, that direction which offers the cathode dark-space least obstruction; the tube runs harder if the dark-space touches the walls. If the design of an X-ray bulb is borne in mind, it will be realised that this property (which is made use of in the various valve-tubes, p. 66) would, in the 
absence of the confined anode, result in facilitating rather than in retarting the passage of the inverse current. Most workers have experieneed this tendency of X-ray bulbs to act as rectifiers, and their refusal, on occasion, to let through the "break" eurrent at all.

\section{The Cathode.}

For the reasons given elsewhere (p. 78), the eathode is made of aluminium, and is mounted just within the neck of a side tube to the bulb. In a focus tube, the cathode is concave. Now, while the normal ejection of cathode rays holds for plane surfaces, it is not the case for concave cathodes except when the pressure is not very low. As the exhaustion proceeds, the focus of the rays recedes farther and farther from the cathode, and may reach a distance of something like four or five times the radius of curvature of the cathode: ordinarily the distance between the cathode and anticathode is some two or three times the radius of curvature. The focus may vary somewhat capriciousiy in practice, without any apparent alteration in the current or gas pressure.

The correct disposition of anticathode and cathode is a matter of some nicety for the maker, who has to be guided mainly by his experience and the hardness at which the tube is to be rum. The anticathode is usually mounted a shade out of focns to avoid its premature destruction by fusion, though for radiographic purposes this entails some loss in definition. Some of the earlier X-ray tubes were provided with devices for moving the anticathode to suit the conditions of use.

Campbell-Swinton (P.R.S. 1897) found that, at moderate pressures, the eathode rays do not form a solid cone of rays, but are condensed into a hollow conical shell. At low pressures, however, the rays are chiefly coneentrated along the axis of the cathode. Owing to the ionising effect on the residual gas this bundle of rays is displayed as a luminous pencil which stretehes from eathode to anticathode. The origin of the pencil of rays, which usually is readily dis- 
cernible in a soft $\mathrm{X}$-ray bulb, is due to the repulsive effect. of the electricity on the walls of the tube adjacent to the cathorte. The same effect obtains also with plane cathodes (sce p. 70). With a cathode made of a metal tube, a concentrated peneil of rays emerges from each end along the axis: such cathodes are sometimes convenient in experimental bulbs.

It would appear from the work of some experimenters that to keep the cathode cool is of service in diminishing the tendency of the bulb to harden with use. In the GaiffeBarret tube, for instance, the cathode is cooled by directing an air blast on its back surface.

One may mention here that cathodes made of the electropositive metals conduce to smooth running of the discharge ; for example, an ahminium cathode faced with calcium metal permits a tube to be run with safety much harder than one with the plain aluminium cathorle. This is probably due to the comparative ease with which such metals emit electrons. See also the Coolidge tube (p. 219).

\section{The Axticathode.}

The desiderata in an anticathode intended for modern radiography are :

(1) A high atomic weight-to secure a large quantity of rays.

(2) A high melting point-to permit sharp focussing of the cathode rays without fusing the target.

(3) A high thermal conductivity-to diminish local heating.

(4) A low vapour pressure at high temperatures-to aroid thermal "sputtering" on the walls (see p. sl).

\section{The Atomic Weight of the Anticathode.}

It was known almost from the first that the heavier metals, or rather those of high atomic weight, make the most efficient anticathodes. Röntgen himself found in 1896 that the rays from platinum are more intense than those from aluminium. Campbell-Swinton, Kaufmann, Roiti, Sir Oliver Lodge, S. P. Thompson, and Langer, all about 1897, did work comnecting atomic weight and intensity of radiation. 
These earlier workers used photographic or fluorescence methods of measuring intensities, and consequently most of their observations are of qualitative rather than quantitative interest.

In some experiments made by Kaye in $1908^{1}$ the metals used as anticathodes, some twenty in number, were mounted on a trolley inside the discharge tube (see Fig. 17). By

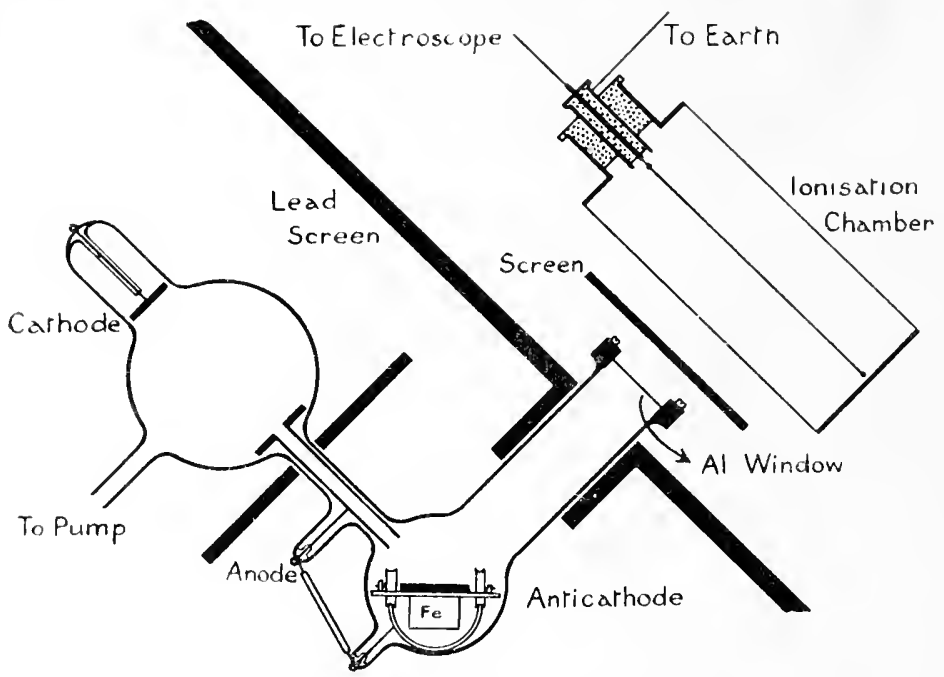

Fift. 17.-Apparatus for generating and measuring the $\mathrm{X}$ rays from different anticathorle metals.

means of a magnetic control, the trolley could be moved and any metal desired brought under the beam of cathode rays. The tube was provided with an aluminium window $0.0065 \mathrm{~cm}$. thick, and the emergent rays, which thus suffered hut slight absorption, were measured by an ionisation method. The discharge was maintained by an induction coil.

The experiments showed that there are, in general, at least two classes of $\mathrm{X}$ rays given out by an anticathode ${ }^{2-}$

J'hil. Thans. Roy. Soc. A, 209, p. 123.

2The $\mathbb{X}$ rays from an anticathode will ordinarily be supplemented by at least two types of soft $\mathrm{X}$ rays-one produeed by the $\mathrm{X}$ rays in passing throngh the glass walls; the other from the impact of "reflected " cathode lays against the glass and the residual gas molecules. 
heterogeneous "primary" or "independent" X ray's, and homogeneous $\mathrm{X}$ rays charaeteristic of the metal.

The quality and amount of the latter rays are controlled by the nature of the anticathode and the potential on the tube; if the tube is soft, with mainy metalis the $X$ rays are

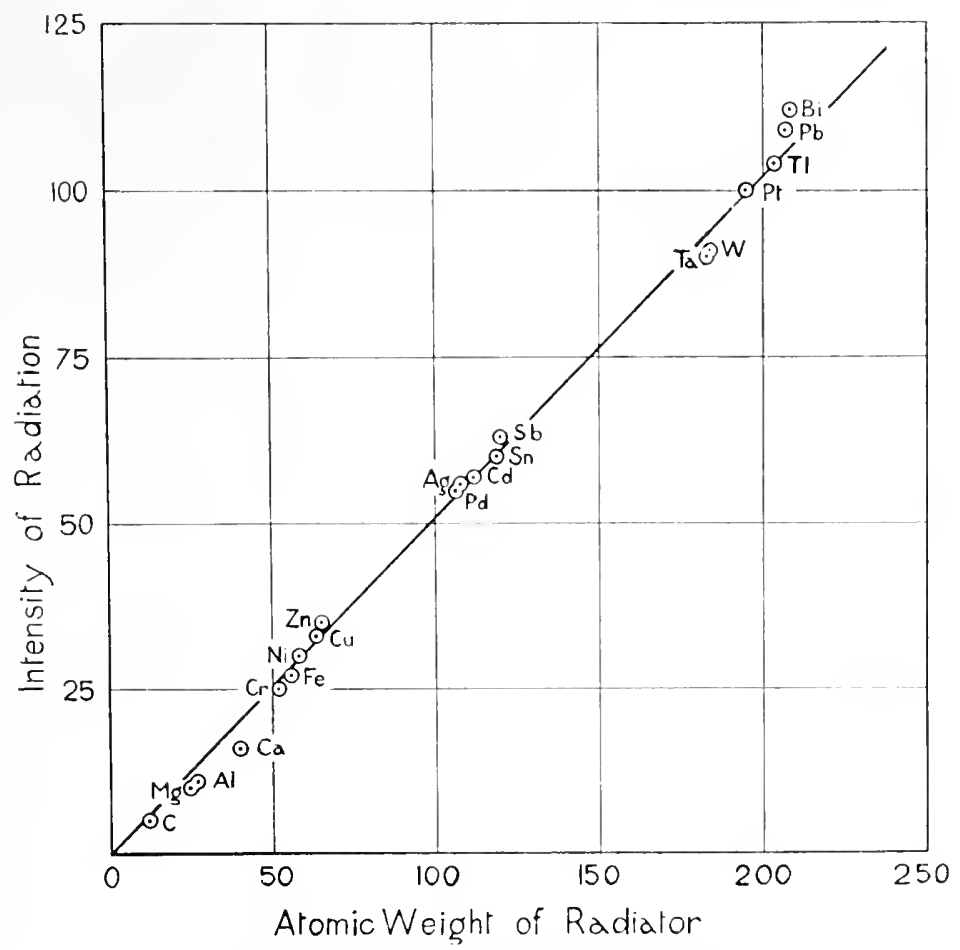

f'16. 18.- Graph conneeting atomic weight of anticathode with intensity of "independent" $\mathrm{X}$ rays. $(1 \mathrm{t}=100$.

ahmost wholly eharacteristic (see p. 121). Tu some cases, such rays are too soft to penetrate the glass walls of an ordinary tube. However, the aluminim window enabled their presence to be readily detected. Their intensities did not follow any simple atomic weight order-for example, the metals of the chromium-zinc group ${ }^{1}$ emit radiations very rich in soft and ionising rays.

$$
{ }^{1} \mathrm{Cr}, \mathrm{Mn}, \mathrm{Fe}, \mathrm{Ni}, \mathrm{Co}, \mathrm{Cu}, \mathrm{Zn} \text {. }
$$


'To remove the characteristic rays, an aluminimm screen 2 or more mms. thick was used, and it was then found that the intensity of the remaining harder "independent" rays increased with the atomic weight of the anticathode; the two are indeed roughly proportional. ${ }^{1}$ Fig. 18 shows the relation for a potential of about 25,000 volts on the tube. Very little change was produced in the relative intensities by increasing the thickness of the aluminium sereen-the rays from all the metals were, under these conditions, very fairly homogeneous and of the same quality. Thick sereens of other metals yielded much the same sort of curve, modified a little here and there. When the potential on the tube was raised the heavy-atomed anticathodes became slightly more efficient; with a diminished potential the lighter elements somewhat increased their relative intensity values.

\section{Suitable Anticathode Metals.}

The list in 'Table 1 . gives the atomic weights, the radiation values, the melting points, and thermal conduetivities (where known) of those elements which by reason of their refractoriness may be regarded as suitable for the anticathode of a focus bulb. The radiation values are for hard rays and are taken from Kaye's experiments (p. 36); in some cases the numbers have been obtained by interpolation. The thermal conductivities quoted are at room temperatures; most metals diminish in condnctivity as the temperature rises. The remaining constants are from Kaye and Laby's Physicul Constants. The properties of some of the metals are not convenient, and to others the scarcity and price are at present an insurmountable objection.

Anong the metals which have been commonly employed as anticathodes in radiography are osmium, iridium, tungsten, tantalum, and, of course, platinmm. Platinum, which is aimost miversally used, has a melting-point none too high for the purpose, sputters badly, and its price, steadily becoming exorbitant, is being instrumental in directing attention to the properties of tantalum and tungsten, metals

1 Gray (I'R.s. 1911) obtained the same result for the $\gamma$ rays produced by the impact of radium $\beta$ rays on different elements. 
whose chemistry has beeome familiar through their extensive employment in electric lamps. Neither metal sputters so badly as platinum, ${ }^{1}$ both have a very much higher meltiug point, and but a slightly inferior radiation value, while tungsten has a superior thermal conduetivity, thus permitting sharper focussing of the eathode rays. Tantalum was introcluced into anticathode work some years ago, but it is only reeently that it has been possible to obtain forged pieces of pure, dense and malleable tungsten suitable for the purpose. It remains to be seen whether these metals prove as good as their promise.

TABLE 1.

\begin{tabular}{|c|c|c|c|c|c|c|c|}
\hline \multicolumn{3}{|c|}{ Metal. } & $\begin{array}{l}\text { Atomic } \\
\text { Weight. }\end{array}$ & bensity. & $\begin{array}{l}\text { Intensity of } \\
\text { Radiation. }\end{array}$ & $\begin{array}{l}\text { Melting } \\
\text { Point. }\end{array}$ & $\begin{array}{c}\text { Thermal } \\
\text { Conductivity. }\end{array}$ \\
\hline & & & $(O=16)$ & grums.ce.e. & $\left(I^{\prime} t=100\right)$ & ${ }^{\circ}($. & c.g.s. \\
\hline Uranimulı & - & - & $238 \cdot 5$ & c. 18.7 & c. 125 & - & -- \\
\hline 'Ilhorium & - & - & $232 \cdot 0$ & $11 \cdot 3$ & c. 120 & $\ldots$ & $\cdots$ \\
\hline Gold & - & - & $197 \cdot 2$ & $19 \cdot 3$ & 101 & 1064 & 0.70 \\
\hline P'attinum & - & - & $195 \cdot 2$ & $21 \cdot 5$ & 100 & 1750 & $0 \cdot 17$ \\
\hline lridiun11 & . & - & $193 \cdot 1$ & $22+4$ & 98 & 2290 & 0.17 \\
\hline Ostnium & - & - & $190 \cdot 9$ & $22 \cdot 5$ & 97 & 2700 & 0.17 \\
\hline 'Tungsten & - & - & $184 \cdot 0$ & $19 \cdot 3$ & 91 & 3200 & 0.35 \\
\hline Tantalıu & & - & 181.0 & $16 \cdot 6$ & 90 & 2900 & 0.12 \\
\hline Palladium & & - & $106 \cdot 7$ & 11.4 & 55 & 1550 & 0.17 \\
\hline lihodium & & - & $102 \cdot 9$ & $12 \cdot 4$ & 54 & c. 1900 & - \\
\hline Rutheniun & & - & $101 \cdot 7$ & $12 \cdot 3$ & 53 & $1950 \%$ & - \\
\hline Molybdenu & u111 & - & $96 \cdot 0$ & $8 \cdot 6$ & 50 & 2500 & $\ldots$ \\
\hline Niobium & - & - & $93 \cdot 5$ & $12 \cdot 7$ & 49 & $2200 ?$ & $\ldots$ \\
\hline Zireonium & & - & $90 \cdot 6$ & $4 \cdot 1$ & 47 & c. 1300 & $\ldots$ \\
\hline Yttrium & - & - & $89 \cdot 0$ & $3 \cdot 8 \%$ & 46 & - & - \\
\hline Copper & - & - & $63 \cdot 6$ & $s \cdot 9$ & 33 & 1084 & 0.92 \\
\hline Cobalt & - & - & $59 \cdot 0$ & $8 \cdot 6$ & 30 & 1480 & - \\
\hline Nickel & - & - & $58 \cdot 7$ & $8 \cdot 9$ & 30 & 1450 & 0.14 \\
\hline Iron - & - & - & $55 \cdot 9$ & $7 \cdot 9$ & 27 & 1530 & 0.15 \\
\hline Manganese & & - & $54 \cdot 9$ & $7 \cdot 4$ & 26 & 1260 & - \\
\hline C'bromium & & - & $52 \cdot 0$ & $6 \cdot 5$ & 25 & 1520 & $\ldots$ \\
\hline Vanadium & & - & $51 \cdot 1$ & $5 \cdot 5$ & 24 & 1720 & - \\
\hline Titanium & - & - & $48 \cdot 1$ & $3 \cdot 5$ & 22 & 1800 & $\ldots$ \\
\hline
\end{tabular}

Iridium is even more expensive than platinum, but appears to behave satisfactorily if there is no oxygen in the X-ray

${ }^{1}$ It is important in the case of tumgsten to get rid of water vapour or oxygen in the tube, if excessive sputtering is to be aroided. 
tube. Usmiun, which was introduced in the very early days of $\mathrm{X}$ rays by Sir James Mackenzie Davidson, while excellent as an anticathode, is very scarce and expensive. Rhodium would seem to have much to recommend it as a material for anticathodes; it has a high atomic weight and low volatility. Bragg has moreover shown that the rhodium radiation from a soft tube is remarkably homogeneous (sec also pp. 121 and 198).

\section{Platinised Nickel Anticathodes.}

It should be remarked that almost all the cheaper $\mathrm{X}$-ray tubes are fitted with nickel anticathodes faced with very

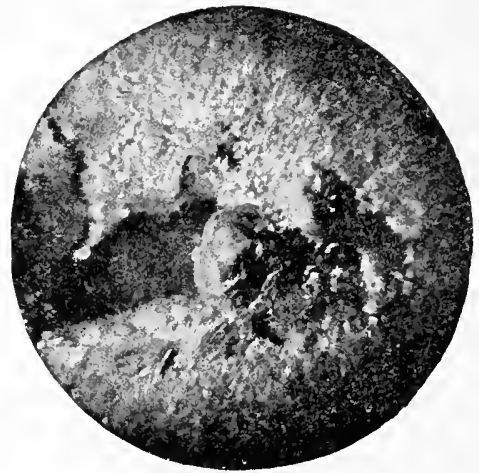

FIti, 19.-Photomicrograph of a platinised nickel anticathode fused by at discharge.

thin platinum sheet (about $\frac{1}{100} \mathrm{~mm}$. thick). The high price of platinum was responsible for the introduction (in 1897) of these composite anticathodes of which nowadays large numbers are turned out. There is no objection to the plan if the tube is intended only for moderate output; but care shonld be taken that the platimum facing is not fused, as nickel is a greatly inferior radiator. Fig. 19 is a photomicrograph (due to Mr. J. H. Gardiner) of a fused platinised nickel target.

Design of the Anticathode.

Some makers envelop the anticathode in a glass slecve, others fit it within a porcelain ring. Both devices tend to 
reduce the evil effects of the inverse eurrent. In some cases, the anticathode is made trough-shaped or is surrounded by a hollow aluminium cylinder to do away with the $\mathrm{X}$ rays produced by the reflected cathode rays striking the glass

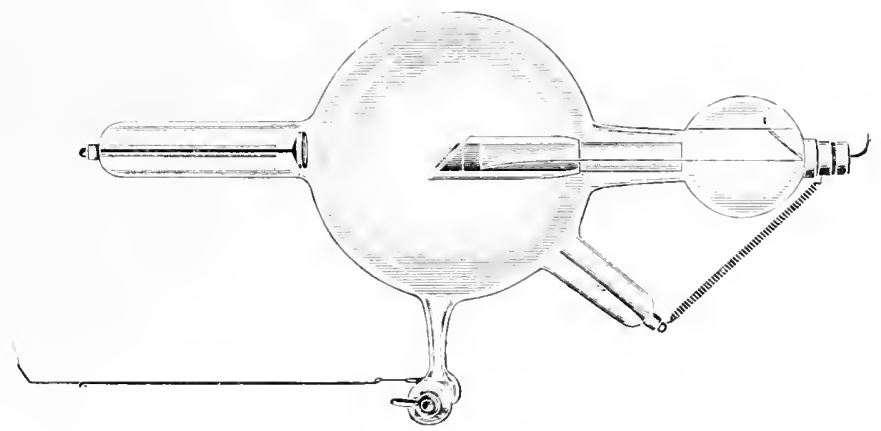

lis. 20.- I Muller bulb, showing water-cooled anticatlode and autunatic softening device.

walls: the definition is deseribed as being improved. Kurlbaum in 1900 eonstructed an anticathode coated with platinum-black with the object of increasing the heat-loss by radiation.

Nowadays, the very pronounced heating of the anticathode is overeome in many tubes by cooling the back

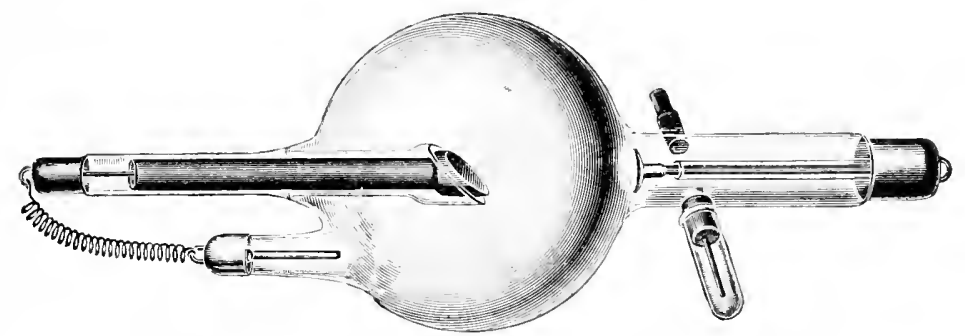

11G. 21.-A siemens bub, showng massive anticathode and osmosis softening device.

surface by water or a stream of air (Fig. 20). In some makes of tube, no attempt at cooling is made, the anticathode being designed for continuous use at a red heat. With other designs of target, the temperature is kept down by increasing the massiveness of the anticathode (Fig. 21); 
this is done by backing up the platinum plate with copper, nickel, or iron. In some cases, the support extends to the

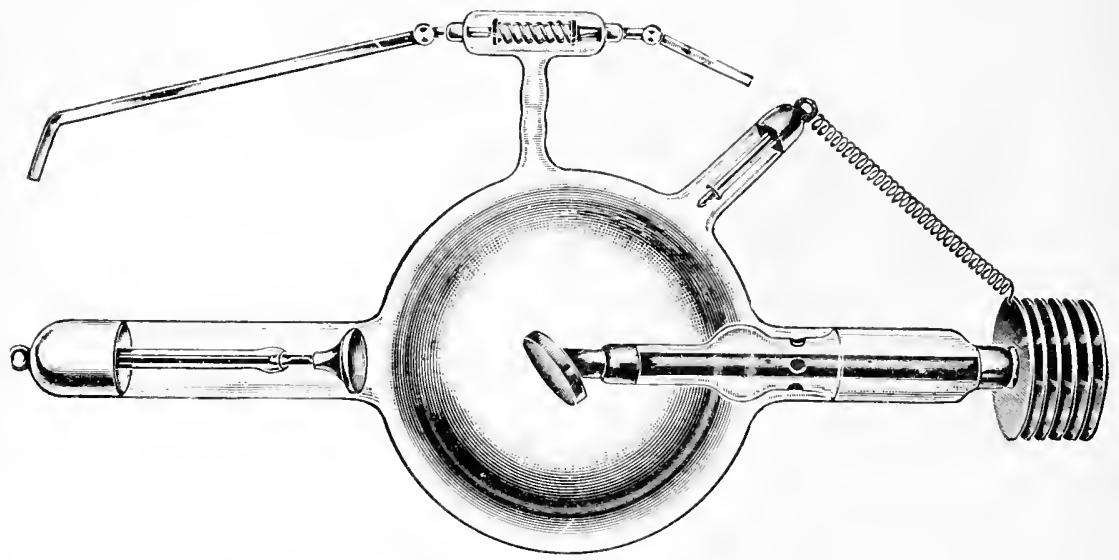

lig. 22.- I cossor bull, with antonatic softening device and lin radiator for cooling anticathorle.

outside of the tube, and is there provided with fin radiators (Fig. 22). Muller has recently introduced a method of

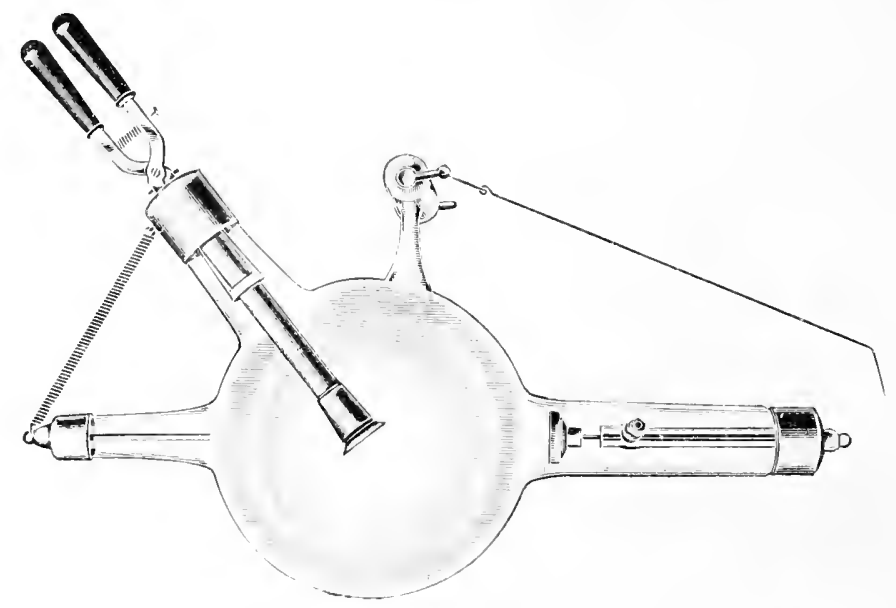

H14. 23.-1 Muller bulb with tong nethod of cooling anticathode.

cooling the anticathode by means of cooling-tongs (Fig. 23). A thin copper tube is closed at one end, to which is 
fastened the platinum target: the other end of the tube is fused to the glass through the intermediary of a platinum belt, and thus the inside of the copper tube is open to the air. Into the aperture can be introduced a pair of metal tongs, by means of which both the massiveness of the anticathode can be greatly increased and its temperature lowered. ${ }^{1}$

The point of impact of the cathode rays is generally not more than 1 or 2 mms. across, and with a heavy discharge the heating is so intensely restricted and rapid that the anticathode

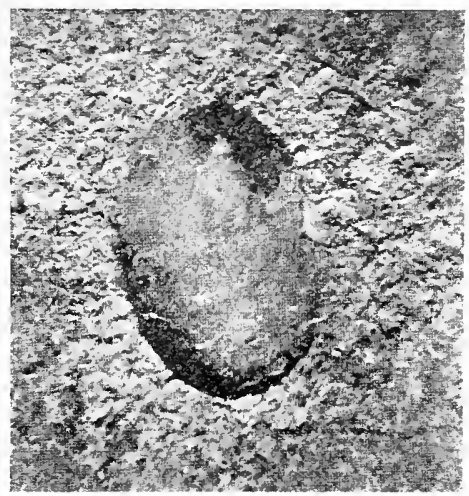

Fu. 24.-Photomierograph of fused focus-spot in a tantalun anticathode.

may be melted locally without damage to the rest of the plate. Fig. 24 is a photomierograph (kindly lent me by Mr. J. H. Gardiner) of the focus spot of a tantalum anticathode subjected to a momentary heavy discharge. The metal was liquefied, and the pool of molten metal was blown away from the cathode into a mound, where it solidified on the cessation of the current.

Gardiner (J.Rt.S. 1909), by the use of a small magnet to deflect the cathode rays to a new portion of the anticathode, showed that, without in any way impairing photographic definition, it is possible to prolong very greatly the life of an anticathode.

1 Reference may be made to Muller's 1914 catalogue of X-ray bulbs which, besides being unusually well illustrated, deals comprehensively witl many points of practical interest. 
Obliquity of the Anticathode.

The derign of tube introduced by L'rof. Jackson, in which the cathode lays are foeussed on an anticathode inelined at $45^{\circ}$ to the beam of cathode ray's, has become the universal pattern. It has two disadvantages:

(1) The obliquity of the antieathode to the cathode rays increases the area of emission of the $X$ rays. This is to the detriment of definition in photographic work, though it must be conceded that in any case a point source of $\mathrm{X}$ rays is not feasible in practice.

$(2)$ It is impossible, with a coil discharge, to suppress entirely the reverse current at " make," during which time the eathode rays proeeeding from the anticathode impinge on the glass walls, with the consequent risk of piercing the tube.

Both objections could be met by mounting the antieathode parallel to the cathode and using normally incident eathode rays.

The writer showed (P.R.S. 1909), in some preliminary experiments, that the ontput of a tube was almost inclependent of the obliquity of the anticathode. The fluorescence of the bulb, which is due to the "reflected" cathode rays from the anticathode, increased very markedly as the angle of incidenee (to the normal) of the cathode rays increased, but the $X$ rays did not show any corresponding variation either in quality or quantity. Thus the $45^{\circ}$ position enjoys no advantage over any other ; and probably a tube employing normal incidence would be found to possess usefu] features.

\section{Depth of Origin of $\mathrm{X}$ Rays in an Anticathode.}

Various observers have foumel that the mean depth at which Röntgen rays originate in an anticathode is directly proportional to the potential employed. Ham (P.R. 1910) found that with a potential of 21,500 volts the mean depth was $5 \cdot 9 \times 10^{-5} \mathrm{~cm}$. in the ease of a lead anticathode. The writer showed (P.C.P.S. 1909) that with spark-gaps of from $1 \mathrm{~mm}$. to $1 \mathrm{em}$., a thickness of from $1 \times 10^{-5}$ to $4 \times 10^{-5} \mathrm{~cm}$. 
of gold, copper, or aluminium, was more than sufficient to generate $\mathrm{X}$ rays.

These distances may be compared with the minimum thicknesses which have been found essential for complete "reflection" of cathorle rays of various velocities. These are as follows :

Table II.

\begin{tabular}{|c|c|c|}
\hline Potential. & Thickness of Metal. & Authority. \\
\hline 11,000 volts & $5 \cdot 3 \times 10^{-5} \mathrm{~cm} . \mathrm{Al}$ & Warbure 1905 \\
\hline $16,500 \quad$, & $19.0 \quad$. $\quad$ Al &, \\
\hline $21,800 \quad \ldots$ & $24 \cdot 4$ & ., \\
\hline $27,800 \quad$.. & $<6 \cdot 6$ & , \\
\hline $90,000 \quad$.. & $0.2 \pi$ & Ham 19]"1 \\
\hline
\end{tabular}

\section{Distribution of the $\mathrm{X}$ Rays.}

The distribution of the $X$ rays from a bulb of the ordinary type is not quite uniform. Ham (P.R. 1908), Bordier (1908), and Gardines (J.Rt.S. 1910) agree that in alane retermined

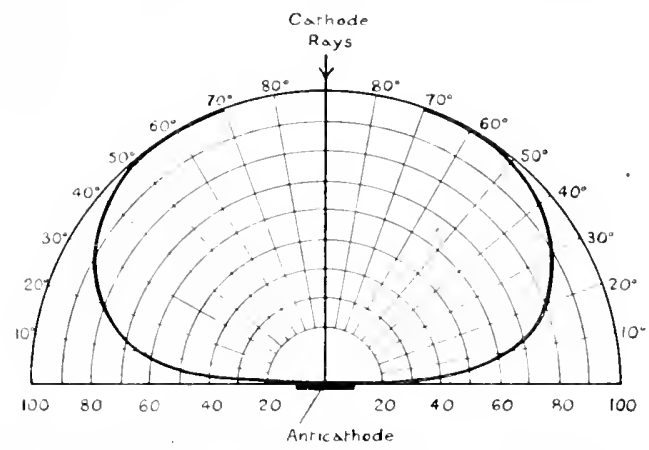

FIG. 25.-- Eraph showing distribution of $\mathrm{x}$ rays, the eathode rays being incident normally on anticathode.

by the beam of cathorle rays and the normal to the anticathode, the intensity reaches a maximum in a direction at abont $60^{\circ}$ from the normal. (Cf. p. 112.) A distribution curve obtained by the writer (P.R.S. 1909) for normally incident cathode rays is given in Fig. 25. in which the length of the radius rector in any clirection is proportional to the 
intensity. It would be interesting to obtain similar curves for very thin anticathodes in which the scattering of the cathode rays would not be eomplete.

\section{Thin Anticathodes.}

Some information on this point is afforded by the writer's experiments (P.C.P.S. 1909) on the emission of $\mathrm{X}$ rays in both backward and forward directions from anticathodes eonsisting of aluminium, eopper, gold, or platinum leaf'. The apparatus is shown in Fig. 26. The results indicate that'

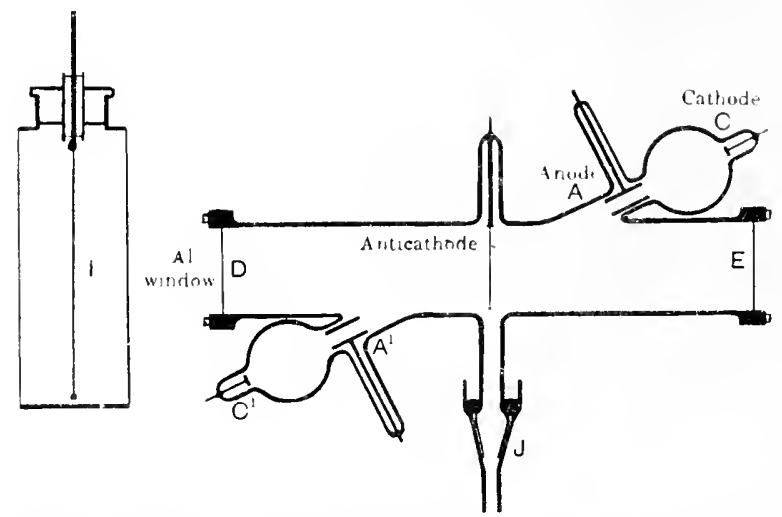

Fif. 26.-Apparatus for measuring $\mathrm{X}$ rays emitted from each side of a very thin anticathode.

the forward or "emergence" $X$ rays exceed the backward or "incidence" rays both in intensity and hardness. In other words, the $\mathrm{X}$ rays tend to proceed in the same direction as the eathode rays which produce them. This is most pronouneed in the ease of aluminimm, where with leaf about $0.0000 \mathrm{i} \mathrm{cm}$. thick, and a spark-gap of 1 to $2 \mathrm{cms}$., the emorgenee rays were two or three times as intense as the incidence. Stark (P.Z. Ig0(I), using a photographic method, has obtained similar results for a carbon antieathode.

It would be of interest to test the homogeneity of the $\mathrm{X}$ rays from thin anticatholes. In many eases the proportion of characteristic radiation might be expected to be musually large. 


\section{CHAP'TER V.}

HIGH-POTENTIAL GENERATORS.

The various means of exciting $X$-ray bulbs may be conveniently gromped into :
(1) Influence machines.
(2) Induction coils.
(3) Step-up transformers.

\section{Influence Magmines.}

Influence machines, which are nowadays almost always of the Wimshurst type, have been largely used in France, Germany, and the States for the production of $\mathrm{X}$ rays, but, probably owing to climatic reasons, have found little favour in this country. Very few influence machines, sold as such, are really suitable for the purpose; nearly all of them need redesigning both from a mechanical and an electrical point of view. If glass is chosen for the material of the revolving plates, it should be free from excess of alkali, which in damp weather makes the surface conducting: ordinary window glass is quite unsuitable. Alkalifrce glass is now procurable; it is, for example, used in the Moscicki condenser. Such glass should not be coated with shellac varnish according to the usual custom; shellac is slightly hygroscopic, and. although it is a better insulator than bad glass. it is not so good as the best glass. Care should be taken to avoid undue fingering of the plates.

Ebonite plates have advantages over glass (see p. 226), certainly on the score of safety for high-speed machines. 
With continued exposure, however, to the stray brushdischarges, the ebonite tends to deteriorate, ${ }^{1}$ probably owing to the ozone, which is always generated in abundance, and which many workers find objectionable.

For leads, massive or india-rubber sheathed wires free from points and sharp bends, and as short as possible, should be used, otherwise the leakage by brush-discharge, always considerable, will prove exeessive. When an X-ray bulb is run by a machine, either two short spark-gaps or two Leyden jars should be put in series with the bulb, one on each side of it : this will prevent undue frittering away of the electricity.

With a multiple-plate machine in good working order, a beautifully steady X-ray discharge can be obtained. The current is, moreover, unidirectional, and is found to be not so destructive to the anticathode as pulsating or alternating current.

The voltage from a Wimshurst machine is proportional to the speed of the plates: there is no theoretical limit to the potential obtainable, except such as is imposed by leakage or disruptive discharge. A Wimshurst machine is peculiar in that the current obtained is almost entirely independent of the voltage. The current output can be raised by increasing the number of plates. The voltage is readily controlled by altering the tilt of the rod supporting the brushes: a needle-point spark-gap is useful in regulating minor variations of the potential.

But, as has already been remarked, the idiosynerasies and unreliability of influence machines have caused most workers to fight shy of them, at any rate for X-ray work. For instance, some machines refuse to work at all inside the glass cases provided for them; yet, in their absence. the machines attract all the dust within reach and require continual cleaning. It is a habit with nearly all machines to reverse their electrification if stopped and restarted : in at least one type, a device is provided to comnteract this.

${ }^{1}$ A mixture of French chalk and methylated spirit is deseribed as useful in restoring perished ebonite surfaces. The new insulator "bakelite" is suid not to deteriorate with exposure to an electric discharge. 
As an example of the successful large design of machine, one may mention that of Hulst in America. The plates, fifty in number and small in diameter, are constructed of compressed mica, and are motor-driven at a very high speed about a vertical axis. Such a machine will send a current of some 15 to 20 milliamperes ${ }^{1}$ through an $\mathrm{X}$-ray tube, and yield rays of an intensity such as would require double the current from a coil. The machine is, however, excessively noisy, and there is, of course, the danger attendant on the high speed of the whirling plates.

Villard and Abraham (C.R. 1911) describe a somewhat smaller 20-plate Wimshurst machine, whose construction allowed speeds of from 1200 to 1400 revolutions per minute. The plates were of ebonite $70 \mathrm{cms}$. across. The maximum current obtained was 3 milliamperes, the highest voltage about 320,000 volts, and the longest spark-gap $55 \mathrm{cms}$.

Some worker have been sucecssful with Wimshursts, which work in air-tight cases into which air or carbonic acid is pumped under pressure. The idea is to kill the losses due to brush discharge; but the working difficulties are so great that the latest designs of Wimshursts have reverted to the simple unenclosed pattern.

\section{INDUCTION COILS.}

It is only within the last few years that makers of induction coils have stirred themselves to meet the special requirements of the X-ray worker. The improvements in design and performance are doubtless not wholly unconnected with the competition offered by the various step-up transformers. The present-day coil offers improvements even on its predecessors of only five years ago ; standardising of proportions proceeds, and any differences of design among the different coil makers depend more on individual predilections than on theoretical grounds.

It is not generally realised that the same eoil cannot be equally efficient for all purposes; it cannot, for example.

${ }^{1}$ A milliampere $=\frac{1}{1000}$ ampere. 
prove equally satisfactory for hard and soft bulbs, or for all speeds of interrupters.

While all the ambitious efforts of the early coil maker were directed towards phenomenally long sparks, nowadays, for X-ray work, he is content with a 10 to 12 inch spark, provided it is a "fat" one and as unidirectional as possible. $A$ fat spark means heavy current and intense $X$ rays, and that satisfies the radiographer, who requires short exposures for much of his work, and finds that very long sparks mean rays too penetrating for his purpose. ${ }^{1}$ Some of the later coils will pass through an X-ray tube sustained secondary currents up to 60 milliamperes with relatively small primary currents and but little inverse current. It will not be unprofitable to consider in some retail the various partis of a mollern coil, a brief account of which was given on p. 27 .

\section{Core.}

The aim of the coil-maker is to magnetise the eore slowly (at make) and demagnetise it rapidly (at break). The spark-length depends on how quickly the core can be demagnetised. On the other hand, the output or power of the coil depends largely on the degree of magnetisation. With morlem high-frequency intermpters the core is never either fully magnetised or demagnetised.

The ideal size of core depends on the size of the primary and the eurrent in it, on the frequency and eharacter of the break, and on the output required: the heavy discharge coil of to-day has a conspicnonsly large and stout iron core whose length is some five or six times the diameter.

The chief objects kept in mind in core design are (1) to diminish the inverse current. and (2) to reduce the losses due to eddy-currents and hysteresis in the iron. The inverse current is lessened by packing as much iron as possible into the space available for the core. The hystresesis loss is diminished by using iron as soft as ean bo obtained. The eddy-currents are reduced by using, instead of a solid iron core. closely packed wires or plates varnished to

\footnotetext{
1 i propos of tone-spark eoils, Carpentier showed in 1910 at Paris a monster coil capable of a 50 -incls spark.
} 
diminish the electrical contact between them. Laminated plates have a better "space factor" than wire in a cylindrical core-in other words, there is less space unoccupied by iron-and accordingly plates are used for nearly all large coils. Iron with very high resistivity is now available, and so fairly thick plates can be employed.

\section{Primary.}

The primary is usually wound in three layers, either as a simple winding, or in some form of adjustable winding to secure adaptability to prevailing conditions. There are in common use three different methods of winding primary coils which permit adjustment. In one, the connections are arranged so that each of the three layers can be put in series or parallel with its fellows; in a second, a number of "tapping-off" wires permit connection to different parts of the primary circuit; in a third, the primary is wound with several wires "abreast," so that these multiple windings ean be put either in parallel or series at will.

A heary-discharge coil has a primary stout enough to permit direct coupling to the electric light supply of 100 or 200 volts. Great care has to be paid to the insulation of the primary, owing to the induced E.M.F. from the secondary. of which all observers are well aware by reason of the shock which ean be obtained from the primary of even a small coil in action. Nowadays, if a fault develops in a coil, it is usually in the primary rather than in the secondary; the defect is probably due to nitric acid formed by brush-discharges indueed by the secondary.

\section{Condenser.}

It was Fizeau, nearly a century ago, who, by the addition of a condenser, revolutionised the induction coil and obtained sparks of lengths hitherto unheard of. But Lord Rayleigh demonstrated some vears ago that if the primary current is interrupted with sufficient rapidity-e.g. by severing a wire with a rifle bullet-it is possible to dispense altogether with the condenser without impairing the length of the spark from the coil. Owing to the increasing 
use of Wehnelt and high-frequency mercury breaks, the condenser, once paramount in importance, has become in such cases unessential. With the older patterns of breaks the condenser is, of course, still important. Its functions are three in number: it performs each of them with incomplete success. ${ }^{1}$

(1) To increase the suddenness of the "break" and the slowness of the "make," and so to reduce the inverse current.

(2) To suppress undue sparking and arcing at the intermupter.

(3) To retard the formation of induced currents in the primary.

It is important that the eapaeity of the condenser should be as nearly as possible adapted for the particular value of the inductance of the primary as well as for the magnitude and frequeney of the primary current. If the capacity is too large or too small, the secondary wave of potential will be neither so large nor so sudden. ${ }^{2}$ The eapacity required depends also very considerably on the type of break-for instance, less capacity is required with a gas break than with an oil break-and accordingly an adjustable condenser should be used in the primary if a coil is recpuired for a variety of purposes. But for coils restricted to X-ray work alone the invariable condenser is being increasingly fitted, on account of its simplicity.

Condensers have improved ont of all recognition during the last few years. With condensers of tin-foil and waxedpaper, this is chiefly due to a better knowledge of the hygroseopic properties of paraffin wax and of the impoltance of manipulating it by machinery rather than by hand.

\section{Primary Tube.}

Between the primary and secondary coils comes the primary tube; this is male of ehonite, mieanite, or, less

'Sioe W. H. Wilson, P.K.S. Mareh 1912.

2 Ser Jones and Roberts ( $P^{\prime} . M$. Now. 1911). Tn one instance, by redueing the cupacity to one-fourth its value, the maximum potential was increased two and a half times. 
commonly, poleclain. Ebonite has the advantage of being readily machined and worked, but micanite, on account of its greater electric strength, is gencrally used in large coils, though it is ineonvenient mechanically.

\section{Secondary.}

It is in the methods of winding the secondary that the greatest improvements have been effected in the modern eoil.

Simple winding is never used, partly because of the dangerous strain on the insulation owing to contiguous

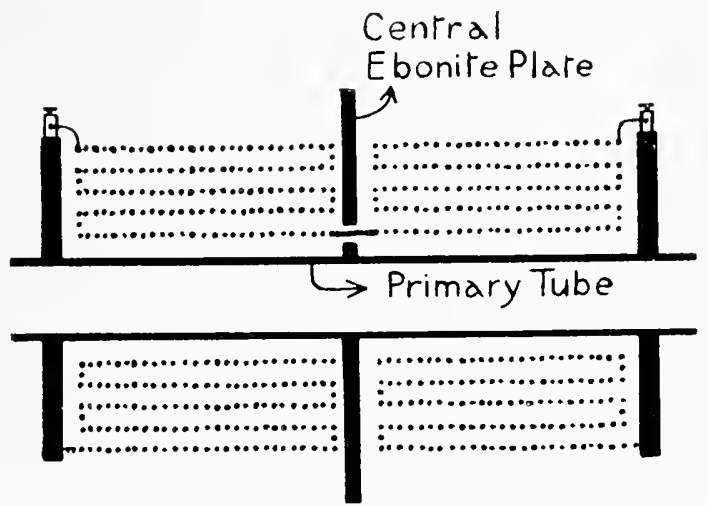

17G. 27.-Diagrammatic representation of a bisectional winding of the secondary of an induction coil.

layers being at very different potentials, and partly because one end of the wire finishes up at the innermost layer. An obvious way to avoid this, is to divide the secondary into two sections, wind each of them simply, mount them side by side, and connect the two innermost ends of the wires together at the adjacent faces (Fig. 27). This plan has several advantages. The electric strain on the primary tube is slight; the tube may accordingly be very thin, so that the primary and secondary windings are close together; with a consequent gain in the efficieney and a diminution in the size and weight of the coil. The method is aceordingly of special value for smaller and portable coils. Owing to the electric stress between the outermost points of the 
adjacent faces of the two sections, the intermediate ebonite plate has to be made thick and protruding from the body of the coil (Fig. 28).

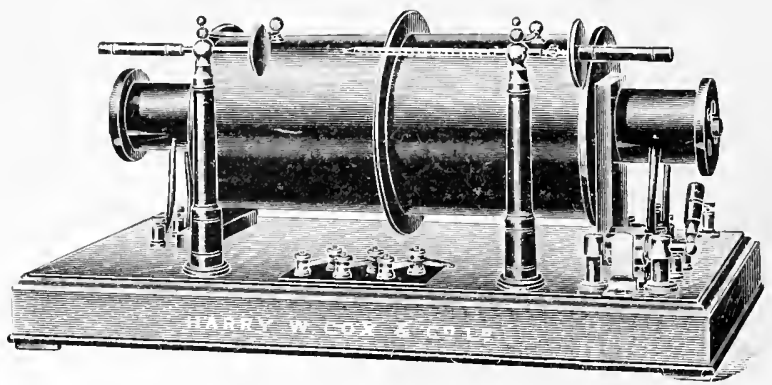

FIG. 2S.-A ('ox coil wound on the bisectional principle.

For large coils (snch as is shown in Fig. 29), some form of sectional winding is used, in which a large number of

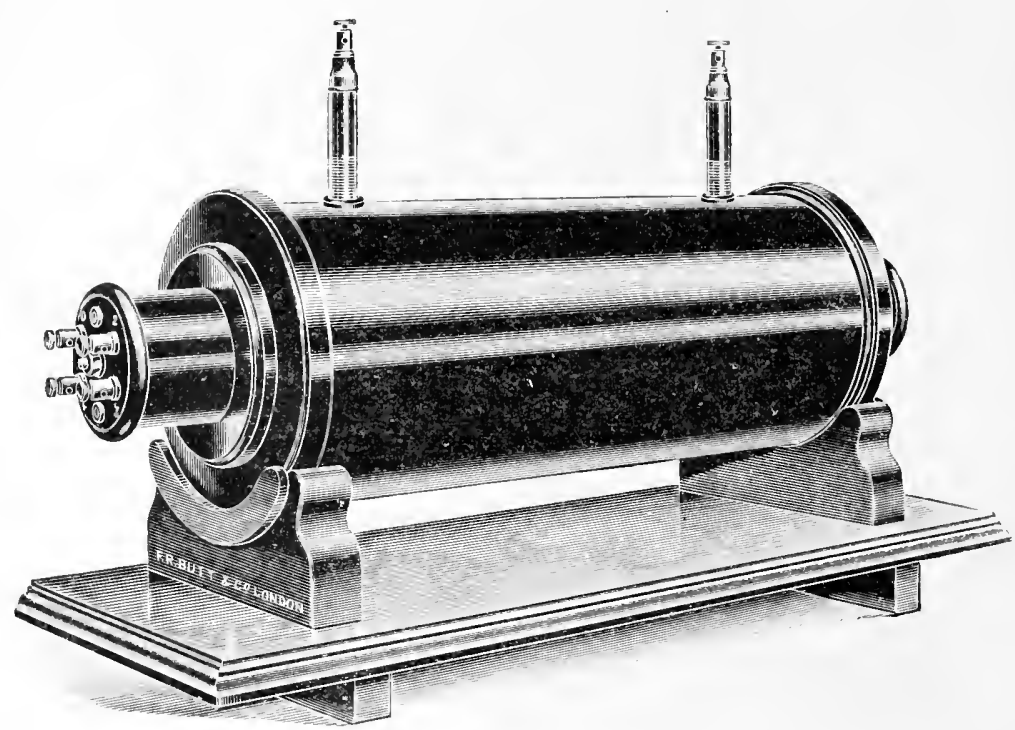

Fiti, 29. - I Butt coil wound on a multisectional principle

circular flat sections, a few wires thick, are threaled side by side on the primary tube and separated by partitions 
of waxed or valnished paper. In some cases, these seetions are connected up in series by joining the innermost wire of the first section to the innermost of the second, the ontermost wire of the second section to the outermost of the third, and so on (Fig. 30), as in the bisectional method; in other's, by joining the innermost wire of one section to the outermost of the next, and so on. Much ingenuity has been exereised in devising methods of winding. ${ }^{1}$ It may be noted that the method of sectional winding requires a thick primary tube.
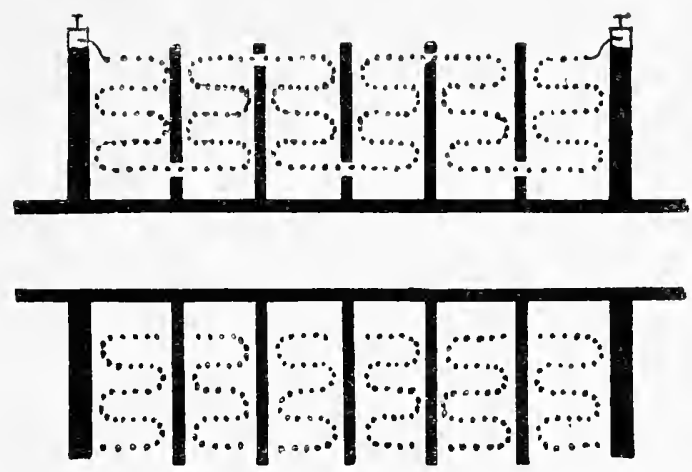

Fit. 30.- l)iagrammatic representation of a method of multisectional windint of the secondary of an induction coil.

Whatever the method of winding, the secondary coil, when eomplete, is immersed in hot paraffin wax in vacuo. It is highly important to exclude air bubbles from the wax and the method of vacuum-exhaustion is absolutely essential, if a break-down in the seeondary is to be avoided.

\section{Some Points in Coil Design.}

The ehief objeetion to induction coils for X-ray work is the inverse eurrent which all coils generate, chicfly at "make," but also to some extent at "break." The inverse current may be lessened

(1) by making the number of turns in the primary as large as possible,

${ }^{1}$ See a paper by R. S. Wright (J.Rt.S. 1913)-to which the writer is much indebted 
(2) by reducing the magnetic leakage between the prinary and secondary: this means paying attention to the core.

The inverse current is angmented by irregular interruption, and care should therefore be taken to keep the break in good order. The inverse current also tends to increase if the X-ray bulb is softened.

Sparking at the interrupter, with its attendant waste of energy, may be reduced

(a) by increasing the self-induction of the primary,

(b) by lowering the frequency of the interruptions.

(1) and (a) are consonant, but they both imply a large secondary if the coil is to give long sparks. This is objectionable from the coil maker's point of view who, to obtain a heavy discharge, is very desirous of keeping down both the resistance and the number of turns in the secondary. It is, however, possible to obtain long sparks with a secondary of reasonable size, by increasing the rate of interruption. (b), however, requires a low-frequency break; and, moreover, eddy-current losses become considerable with very high frequencies.

If a heavy output is required from a coil, and the voltage available for the primary is only low, the self-induction of the primary should be kept down. This is inconsistent with but more important than (a). In such cases the output can often be materially improved by taking eare that the leads from the battery to the coil are kept as short and straight as possible, the object being to diminish the selfinduction in the circuit.

The effieiency of even the best induction coils, considered as transformers, is not high--in the region of 50 to 70 per cent. It could, of course, be increased by using a eompletely closed (ring) core instead of a straight one, and no diminishing the magnetic leakage. But the difficulty hitherto has been that, with a closed core, demagnetisatioli does not occur with the intermittent current which obtains in a coil discharge. The objection does not apply to true altemating current, in which there is a complete reversal, 
and for which, of course, elosed-core transformers are always used.

Enough has been said to indicate some of the problems which confront the coil designer. It is in reconciling necessarily antagonistic factors to suit the main purpose of the coil that his skill finds chief scope.

\section{The Wave-form of the Primary and Secondary Currents.}

The oscillograph ${ }^{1}$ has been employed by a number of workers to investigate the shape of the waves of current

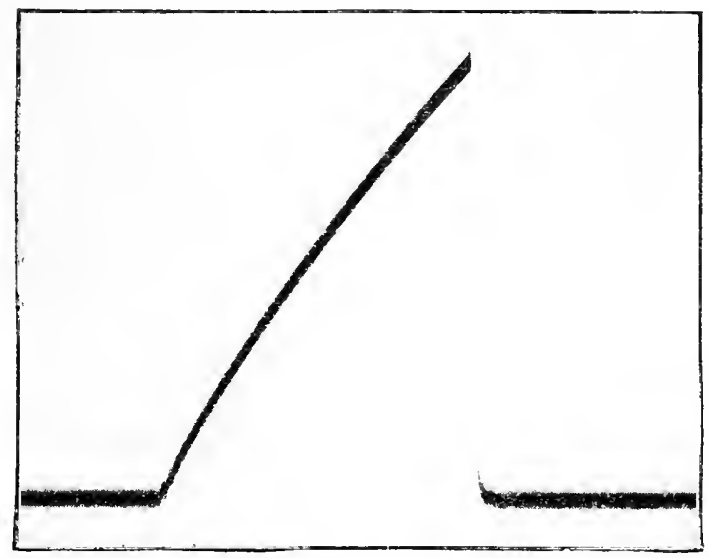

Fid. 31.-Oscilograph record of a make and hreak of the primary current of an induction coil.

and potential generated by a coil at each make and break of the interrupter. Fig. 31 shows a typical record (due to Salomonson, J.Rt.S. 1911) of a single make and break of the primary current in the ease of a 13-inch coil giving a 10-inch spark: a mercury-oil break was used. As soon as the circuit is completed, the enrent starts from zero and rapidly grows in strength until the moment at which the cirenit is broken. The current then falls to zero in about $1 / 1000$ sec. In some cases, the curvature of the rising part of the curve is more marked than in Fig. 31. A close

1 An oscillograph is essentially a low-resistance, moving-coil galvanometer of few turns and with a very short time of swing. 
inspection will show that superposed on the main eurrent are extremely rapid oseillations: these are produced by the condenser. W. H. Wilson (P.R.S. 1912) noted that much longer sparks could be obtained from a coil when these high-frequeney oscillations were pronounced in the primary current. Fig. 32 illustrates them

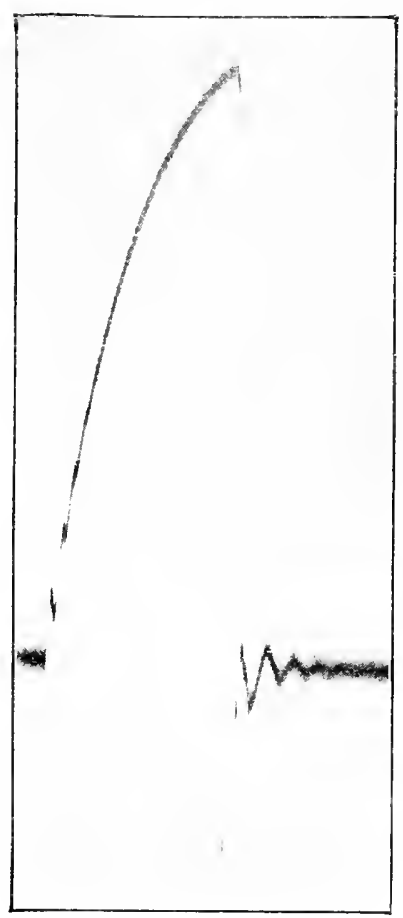

FiG. 32.--Oscillograph record of a primary current showing superposed high-frequeney oscillations. very well. The frequeney of these rapid oseillations may reach many thousands a seeond.

In regard to the secondary circuit, Duddell (J.Rt.S. 190S) found that the discharge consisted of isolated groups of strongly-damped impulses very abrupt and short-lived. The interval between successive groups of waves was relatively long compared with the actual duration of each group, which latter was of the order of $1 / 1000$ sec. Fig. 33 gives a general notion of the state of things that obtains with a medium vacuum in the X-ray bulb. ${ }^{1}$ The upper graph shows the eurrent, the lower the potential. In the latter curve: the upjer peak is the potential tending to send the current in the right clirection througin the tube: the smaller and broader inverted peak is due to the inverse potential, which in this casc is conspicuous. The maximum direet potential is about 60,000 volts, the maximum inverse potential about $3: 3,000$ volts. The current curve is very similar to the potential curve: a small inverse current is deteetable.

In Fig. 34 a reetifying spark-gap is inserted in the circuit : its ability to suppress the obnoxious inverse pulses is well

${ }^{1} A$ graph showing greater detail is a good deal more complicaicd. 
displated. The maximum direct potential now supplied to the bulb is 39,000 volts. Thus some 21,000 volts have been

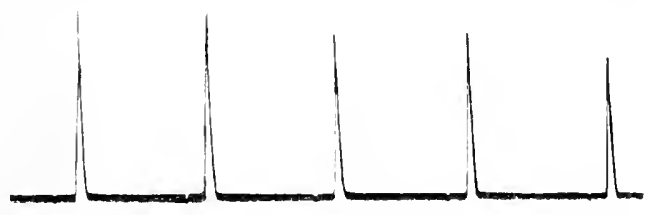

Current.

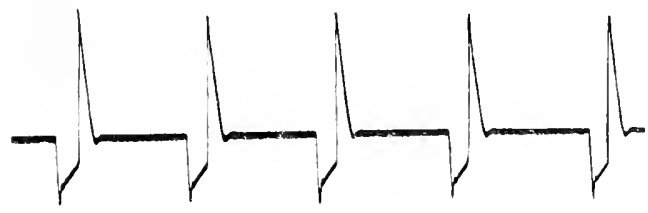

Potential.

FIG. 33.--Oscullograph record of groups of impulses in the secondary circuit of an induction coil.

used up in the spark-gap; and the illustration serves to point out the loss of energy that occurs in a sparti-gap, and

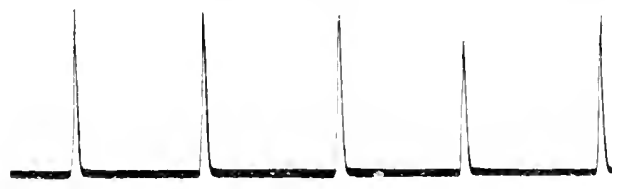

Current.

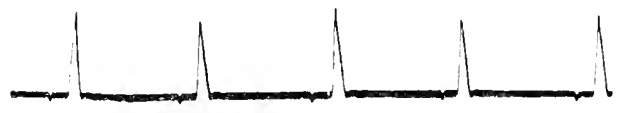

Potential.

Irt: 34,- Conditions as in lig. 33, but with rectifying spark-[nil] inserted.

the desirability of aroiding its use by not generating the inverse current at all, if that were possible.

High-texsion Step-up Transformers.

About 1908 the first high-tension transformer for X-ray work was introdnced by Snook (Fig. 35), and since then transformers have been largely used in X-ray work, more 
especially in instantancous radiography. The machine is essentially nothing more than an oil-immersed step-up transformer, which is supplied with alternating current from an alternator. A rotating pole-changing switch rectifies the high potential alternating current from the secondary of the

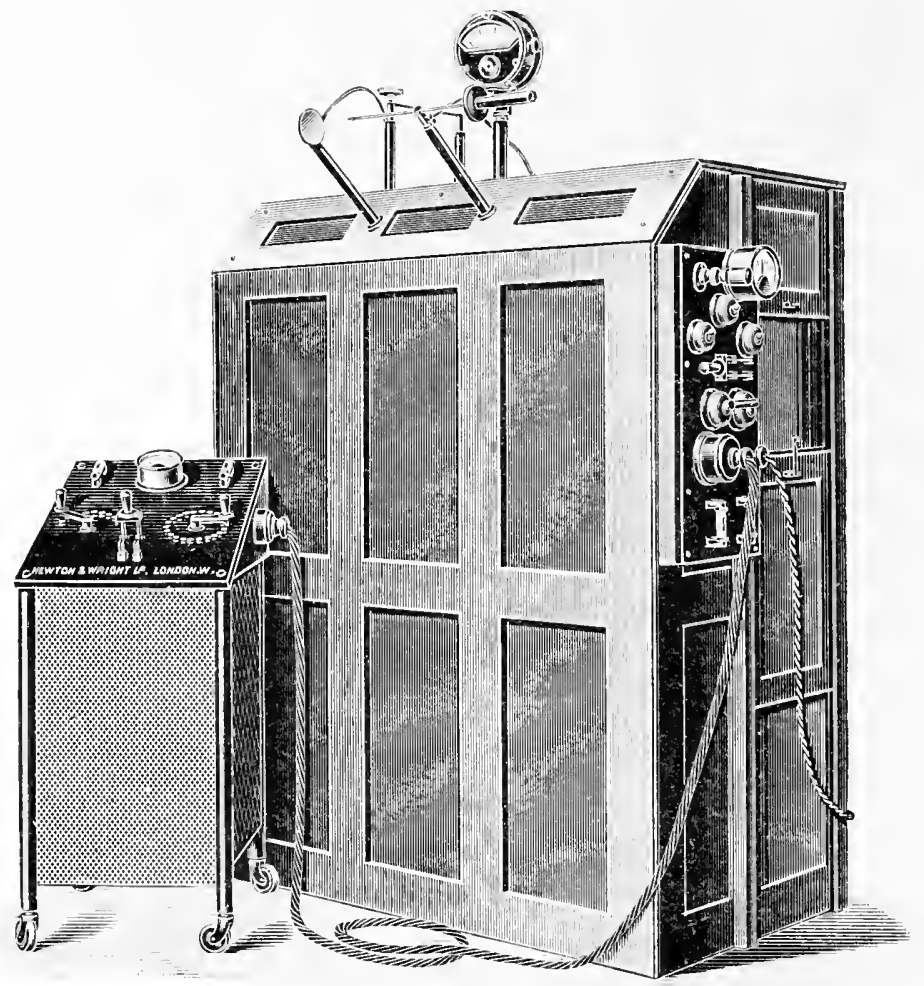

FIG. 35.-Present design of Snook high-tension transformer.

transformer. To secure the perfect synchionism which is essential for rectification, the commutator is mounted on the same shaft as the alternator. The resulting current is, of comse, not uniform, but pulsating as in $B$ (Fig. 36); its amount can be varied at will from $\frac{1}{2}$ to 100 milliamperes.

The efficiency of the transformer, which is of the ring type, is considerably greater than that of an induction coil. The 
chief objections to such transformers are the high eost and large size, the excessive noise, and the attention which moving machinery requires. On the other hand, they are eapable of enormous ontput and easy eontrol, there is littl.

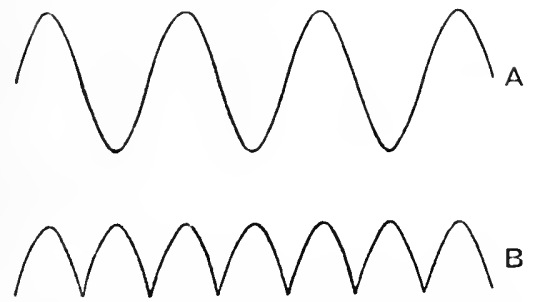

FiG. 36.-A. Alternating purent of sine form. R. l'ulsating current produced by rectification of $A$.

or no inverse eurrent, and no interrupter is needed. Recently, very considerable improvements in design and performance have been effected.

It has been suggested that the sinusoidal eurrent curve of the high-tension transformer is not quite as efficient, from an X-ray stand-point, as the long steep peaks of an induction coil (see p. 59), and that they are relatively more destruetive to X-ray tubes; and doubtless there is something to be said for this point of view.

In one direction it would appear that simplification is possible in the use of step-up transformers for X-ray work. Instead of sending into the primary of the transformer a sinusoidal eurrent, use an alternator specially designed to give a very unsymmetrical wave form consisting of an abrupt high peak on one side and an almost suppressed loop ${ }^{1}$ on the other. The necessity for the commutator thus disappears. Boas deseribed such an arrangement in 1911, and found it to work well in practice.

Cabot has recently designed a high-potential rotary eonverter, in which by the commutation of a symmetrical 9-phase system, the voltage fluetuates no more than 1 to 2 per eent. The maximmm voltage attainable with the machine is 100,000 volts, and the output up to 15 kilowatts.

${ }^{1}$ Merely sufficient, in fact, to demagnetise the core after pach rerersal (see p. 56). 
BREAKS AND INTERRUPTERS.

\section{The Hammer Break.}

The hammer break (sec p. 28), the accompaniment of most of the earlier eoils, has been greatly improved recently. Attention has been paid to its period and its mechanieal stoutness. Some of the later types compare favourably in steadiness with any kind of intermpter, when only a light ontput is required, as with a soft $\mathrm{X}$-ray tube. ${ }^{1}$ But, on a heavy load, the hammer break is useless: it cannot earry the eurrent without exeessive sparking and disintegration of the platinum. This does not contribute to steadiness and ceonomy of working.

The frequency of a liammer break never reaches more than about 200 (per see.), and is usually much less: with a large coil it may be as low as 25 to 30 . Aceordingly a variety of other breaks have been introduced from time to time. These include the electrolytic intermpters. and the various kinds of motor-driven breaks which employ mercury.

\section{The Wehnelt Electrolytic Interrupter.}

Wehuclt in 1899. turning to account an earlier observa-

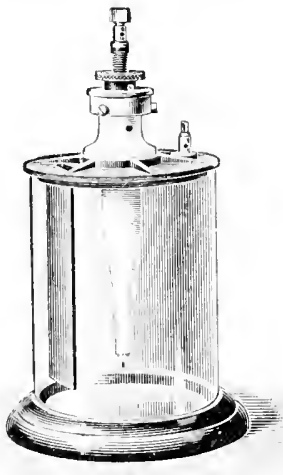

Fix. 37.- Wehnelt interrupter with single platimm anode (siemens). tion of Violle in 1892, levised his interrupter, which now enjoys extensive popularity. It consists of two electrodes immersed in dilute sulphurie acid. ${ }^{2}$ The cathode is a large lead plate. the anode consists of one or more platinum points. The amount of the anode exposed to the liquid can be adjusted by means of a porcelain sleeve round each of the platinum points (Fig. 37).

For effieient interruption, the eurrent must lie between certain

1 The parallelism and flatness of the contact-pices shonld be seen to: a thin piere of flat wood fared on both sides with a fine grade of emery paper is useful for passing between the platimm sturts.

2 A rensity of 1.2 is suitable. Some workers add a litte cuso, 
limits; if it is too small (below about 10 amperes) mere ordinary electrolysis oceurs, if too great (say 40 amperes or more) the polarisation increases to such an extent that the current almost ceases and the anode becomes whitehot, and hisses and disintegrates in the liquid. With a suitable current the anode is normally surrounded by a violet light, and the interruptions are of an explosive and almost deafening character-a very umpleasant feature of the break. ${ }^{1}$ Eleetrolytic breaks will not work with voltages exceeding 80 to 120 volts; they are eapable of a larger output than any type of break, but the reverse current is considerable and the X-ray tubes suffer in consequence.

Opinions are still very much divided as to the mode of action of the break : the usual explanation is that the interruptions are brought about by the periodic sealing and unsealing of the anode by liberated bubbles of gas; but this does not meet all the circumstanees. There are many factors to take into account - the size of the anode point. the eurrent, the concentration and temperature of the acid, the inductance and capacity in the circuit: all these affeet the interruptions. Compton (P.R. 1910) showed that just as with the ordinary hammer break, the "break" is more sudden than the "make."

The Wehnelt break usually requires a little humouring. and works rather better when the acid is warm, a state of things which soon results in practiee; indeed, for prolonged use, it is necessary for regular interruption to eool the acid, e.g. by means of a water-cooled worm of lead tubing. The interruptions are extremely rapid - as high as 1500 to 2000 per see. when a very small anode point is used : even with very large currents the frequency may reach 200. The frequency is inereased (1) by diminishing the size of the anode point, (2) by raising the temperature of the acid, (3) by diminishing the self-incluetion in eircuit. Some selfinduction is, however, essential or there will be no interruptions. A condenser across an electrolytic break is not beneficial, and is, in faet, generally detrimental to the working of the break, which itself functions as a condenser.

1 Nany makers now fit sileneers to the break. 
The energy required is diminished by raising the temperature and (slightly) by using stronger acid. It is found that

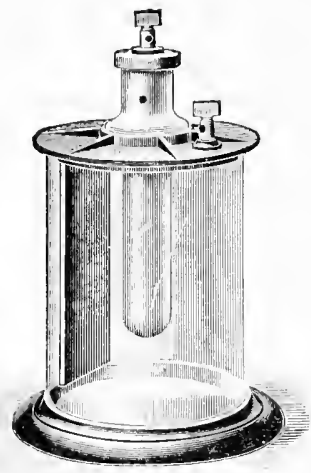

F's $38--$ Wehnelt interjunter with perforated tube romnd lead anode (Śchall).

to get the same spark-length, a more powerful coil is required with the Wehnelt than with any other break. An electrolytic break does not, in fact, conduce to the highest efficiency in the working of a coil.

In another form of electrolytic break, both electrodes are of lead (Fig. 38), but one is surrounded by a porcelain cylinder pierced with a number of small holes, at which the bubbles of gas are formed. This type permits no control over the current, ${ }^{1}$ but the reverse current is said to be smaller. This latter break is also suitable for alternating current, in which case it may be noted that the frequency is always equal to the frequency of the supply current, and is not affected by any of the controllable features of the break.

\section{Mercury Breaks.}

There are many ingenious forms of these breaks on the market, some of which are extensively used.

'They are invariably motordriven. The early forms depended on the rapid dipping of a plunger inte a trongh of merenry ; in some of the later types a jet of merenry is pumped against a series of rapidly revolving metal vanes. To these anct other types of breaks, the

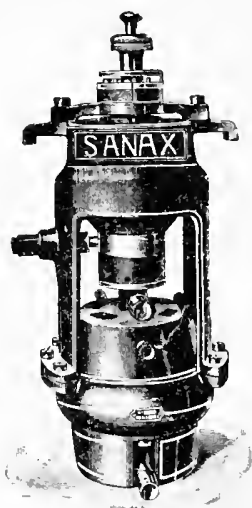
various makers' catalogues do full justice. Two varieties of mercury break are illustrated in Figs. 39 and 40.

1 In the calchell-swinton pattern, the cylinder is piereed with only one lode, the size of which can be regulated and the current thus varied. 
In the earlier forms the revolving system was immersed in paraffin oil or methylated spirit. With either liquid, but especially with the oil, the mercury emulsifies in most breaks, and the cleaning is a frequent and a disagreeable operation, besides being rather wasteful of mercury. A notable exception is the Sanax break, which. by reason of its ingenious design and mode of action. avoids all these difficulties.

Coal gas or hydrogen at 1 or 2 atmospheres is generally used nowadays in mercury breaks: the break needs less cleaning, and is usually more reliable and economical than with a liquid dielectric. Salomonson has shown (J.Rt.S. I!ll), by means of the oscillograph, that stronger and more abrupt quench. ing of the spark is obtained with a gaseous dielectric than with a liquid in which a conducting charred track

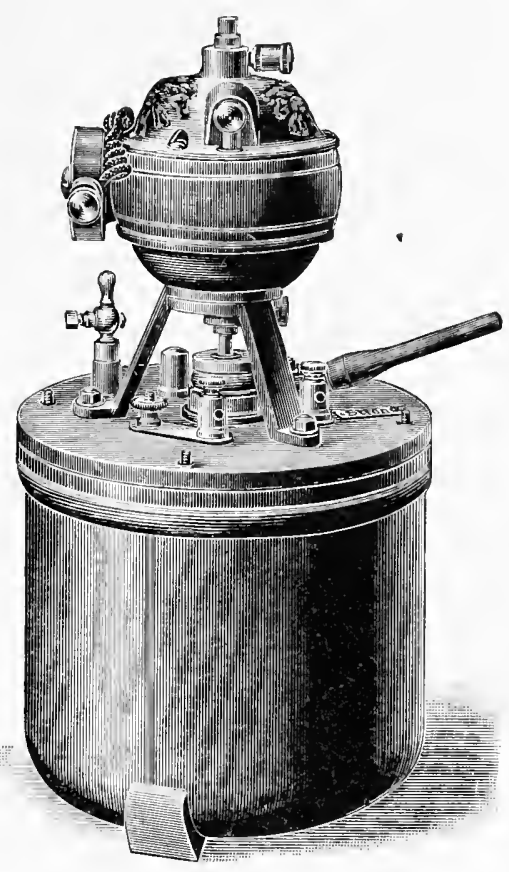

FIa. 40.-Cox mercury-gas break. persists after each spark. Less condenser capacity is required for a gas break than for an oil or spirit break.

With most coils, these motor-driven breaks produce a heavier discharge current at the higher speeds. The mercury break is designed so that the current is "off" rather longer than "on"; in this respect it is superior to the Wehnelt, in which the "on" period is equal to the "off," to the detriment of the demagnetisation of the core.

Doubtless most workers would prefer a mercury break to any other kind for general use; though for heavy instantaneous work an electrolytic break is probably unequalled. 
A mercury break permits greater control, however, and the good types are not subject to current and roltage limits of working, such as ohtain with an electrolytic break.

\section{Rectifiers AND VALVE-TUBES.}

The chief defect of the induction coil from the point of view of the X-ray worker is that it does not give unidirectional currents: the reverse current at "make" has a disastrous effect on the $\mathrm{X}$-ray tube, and requires to be suppressed.

For this purpose we may introduce into the circuit the simple point and plane spark-gap, which depends on the fact that the spark passes more readily when the point is positively charged than when it is negatively charged. The device is an old one, and is not always particularly efficient. more especially if the current is considerable. The greater

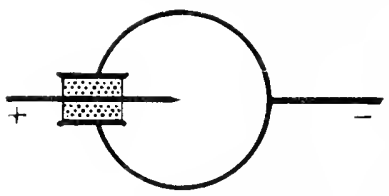

FId. 41.-The Duddell spark-gap. the current which passes, the longer is the spark-gap required for rectification. For a current of about a milliampere, a sparklength of $1 \mathrm{~cm}$. or more is suitable.

Duddell (J.R.t.S. 1908) showed that with a point anode and a given spark-length, a cup-shaped cathode will rectify a larger current than a plane, and a plane a larger current than a sphere. Duddell has accordingly designed a rectifying spark-gap, in which the point electrode is surrounded by a hollow sphere, through which the point enters by means of a glass tube in a cork (Fig. 41). Correctly disposed, one rectifier in series with the $X$-ray tube and a second (reversed) in parallel with the tubc. the arrangement is described as extremely efficient.

For most purposes, especially when electrolytic breaks are used, the various valve-tubes are more efficient than sparkgaps. These consist of a large aluminimm eathode, often spiral in form, mounted in an exhausted bulb: the anode is small, and is contained in a restricted side tube (see p. 33). 'The design is due to Villard: in Sir Oliver Lodge's modi- 
fication (Fig. 42), the anode (of iron wire) is surrounded with a eopper sheath, partly to prevent sputtering on the glass walls and partly to increase the resistance of the tube

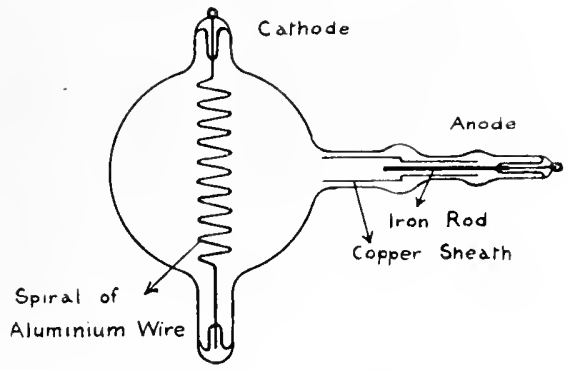

FIG. 42.-Section of a Lodge valve-tube.

for the reverse current (see p. 69). Owing to the use of a phosphorus method of completing the exhaustion, the Lodge valve is red in eolour (see p. 225). The Lodge tube is said not to harden with use, but other types of valves should be fitted with some softening device, as they harden considerably with use and do not reetify well if the pressure becomes very low. A valvetube is only effieient over a limited range of pressures.

The Wehnelt valve-tube employs a hot-lime cathode such as is described on p. 8 . Sueh a tube, in series with an

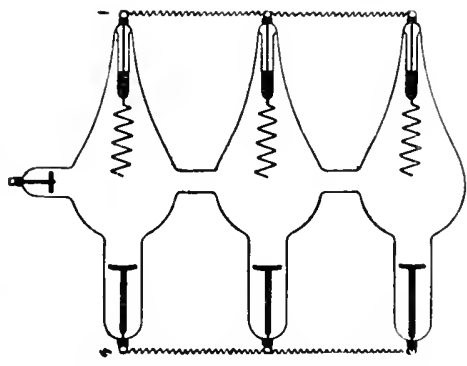

Tig. 43. $\rightarrow$ A multiple valve-tube. X-ray bulb, will transmit, from the eathode to the anode, only the negative phase of the diseharge from the coil. Miller's neat mica-dise valve should also be noticed.

For heavy instantaneous work, a number of multiple valve-tubes (Fig. 43) are advisable, both in series and parallel with the X-ray bulb. 


\section{C'HAPTER VI.}

\section{THE HARDNESS OF AN X-RAT BULB.}

\section{Factors controlling the Hardness of an X-ray Bulb.}

The hardness of the $X$ rays produced by a bulb is mainly dependent on the maximum potential difference between the electrodes. There are a number of ways of controlling this potential difference:

(1) The most generally recognised method is by varying the degree of exhaustion of the bulb. The lower the pressure, the higher the voltage required and the harder the $X$ rays. The range of effective pressures for producing $\mathrm{X}$ rays is very wide. It is. however, possible to make use of other methods which do not involve any change in the gas pressure.

(2) By inserting a spark-gap or valve-tube (p. (66) in series with the bulb, the tube is hardened. With very soft bulbs, Winkelmann (A.d.P. 1900) states that the spark-gap) should be placed between the cathode and the coil. At lower pressures, the position of the spark-gap is immaterial.

(3) By employing Tesla or other currents of extremely high potential, the tube runs harder. Tesla currents are obtained by transforming up the secondary current from a coil by means of a special transformer immersed in oil.

(4) By bringing the electrodes nearer together. the tube may be hardened (see p. 33).

(5) By altering the nature of the gas in the tube. For the same pressure, a tube puns harder in hydrogen and still harder in earbon dioxide than in air. In other words, in order to generate $\mathrm{X}$ rays of equal hardness, a tube filled with air must run at a lower pressure than one eontaining hychogen or cartom dioxirle. 
(6) By increasing the enrent density through the tube. 'This can be done:

(a) By increasing the current in the printary of the coil.

(b) By diminishing the size of the eathode. A tube with a fine wire cathode runs harder than one with a cathode of moderate size.

(c) By diminishing the size of the tube. Winkelmann in 1900 experimented with various sizes of tubes, and found that with a tube $5 \mathrm{mms}$. in liancter, he could get $X$ rays at as high a

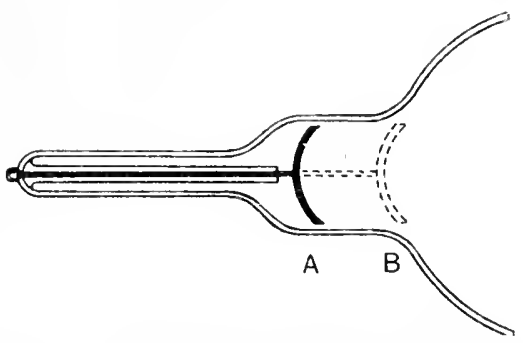

Hets, 44,--The discharge is hadened by withelrawing the cathode lom $B$ to i. pressure as 10 mms. of mereury with air as the residual gas. In the case of hydrogen and a tube $10 \mathrm{mms}$. in diameter, he obtained $\mathrm{X}$ rays at the remarkably high pressure of 30 mms. of mereury. If the tube is made too narrow, the hardening effect is spoilt.

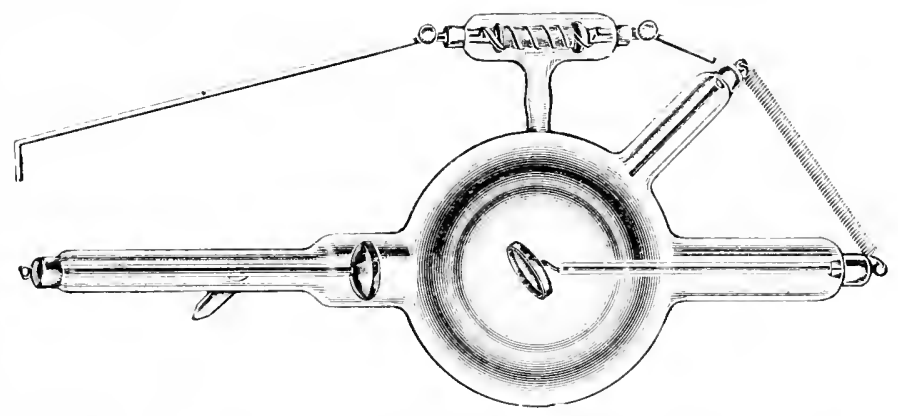

Fu. 15. -A ('ussor bulb of lithium-olitss with recessed cathode. (bee l'ig. 14.)

(d) By diminishing the elearince between the cathode and the surrounding tube. It was pointed out on p. 31 that if the spaee round the cathode is restricted, the clischarge passes with difficulty, so that if the eathode is withdrawn from the bulb into a side tube, the discharge hardens aceordingly (Figs. 44 and 45). Preeisely the same effect is obtained with a plane as with a coneave cathode, and, indeed, with 
a tube in which the cathode is so inclosed the curvature of the eathode need only be very slight. A tube with a movable cathode employing this principle was described by Campbell-Swinton in 1897 (Electrician); the tube is in the Röntgen Society's collection of X-ray tubes in the South Kensington Museum. Swinton also employed an alternative device consisting of a glass sleeve, a part of which was narrowed to slide along the glass rod which supported the

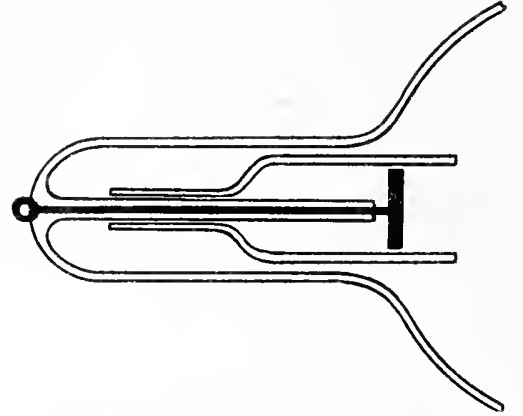

114. 40.- Adjustable glass sleeve over the cathode for varying the hardness of the discluage. eathode (Fig. 46). The remaining portion was widened so as to form a sheath round the cathode and project a varying distance beyond it. Wehnelt (D.P.G.V. 1903) found that the arrangement allowed the altemative gap to be varied as much as eight times. Whiddington (P.C.P.S. 1913) observed that, within limits, the distance the sheath projected beyond the cathode was proportional to the potential required to run the bulb.

The hardening effect, as Goldstein remarked (I).P.G.V. 1901 ), is due to the glass round the eathode becoming negatively charged owing to leakage from the cathode. The cathode rays accordingly retreat to the centre of the eathode, where they form a concentrated pencil. In this way, the current-density and effective resistance of the tube are increased, and the more markedly if the adjacent glass is conted with sputtered metal.

This charging up of the glass is responsible for a wellknown effect produced by touching the tube near the cathode while the diseharge is passing. The glass under the finger becomes vividly fluorescent, and a bundle of cathode rays is deviated towards the hand. Maltézos (C.R. 1897) showed that if the finger is replaced by the knob of a Leyden jar, the jar becomes positively charged, a clear indication of the negative electrification within that part of the tube (see 
p. 32). It is possible to vary the hardness of a tube by putting patches of tin-foil on the outside in suitable places.

In the case of the hardening sleeve referred to above, Whiddington has shown that the tendeney of the sleeve is to slide back into the side tube owing to electrostatie repulsion by the eathode; and, further, that if part of the sleeve is cut away, the eathode rays are bent away from the portion which remains. It can readily be demonstrated that a metal tube, if slid over the eathode inside the glass, will harden the diseharge just like a glass tube. In fact, the cathode may be removed altogether and the eylinder alone used in its place; a sharply defined pencil of rays will still proceed out along the axis of the eylinder (see p. 35).

\section{The Progressive Hardening of an X-ray Bulb wITH UsE.}

With a new discharge tube, the first effect of ruming the discharge is to cause an outburst of gas. The effect, which may persist for some time, is due largely to gas ejected from the cathode. Aluminium almost always contains large quantities of gas, chiefly carbon compounds. Such gas is more readily reabsorbed than air let into the tube. In an X-ray tube, the anticathode also gives out considerable amounts of gas: indeed, the method of bombardment by eathode rays is a most effective one for liberating the gas held by a metal.

But, after some time, the gas-pressure becomes progressively lower with continued running of the discharge. The eause of this has been a problem ever since the days of Plücker (1858), and one to which a good deal of enquiry has been direeted. The effeet is undoubtedly not a simple one, and there appear to be several contributory causes. Formerly, the responsibility for the absorption was thrown. largely on the metal electrodes, more particularly on the anode $^{1}$; and doubtless some such occlusion does take place, if only to a slight extent.

${ }^{1}$ See, for instance, Hodgson (P.Z. 1912). 
But Hill (P.P.S. 1912) has recently shown that a marked absorption of gas oceurs even with electrodeless discharges, and it would seem that it is to the glass walls of the tube we must look for the explanation. Campbell-Swinton (P.R.S. 1907 and 1908) concluded from his experiments that the gas is aetually driven into the glass by the discharge. He found that when the glass was subsequently fused, such gas (which proved to be ehiefly hydrogen) segregated into small bubbles ${ }^{1}$ whose depth below the surface did not exceed about $0.015 \mathrm{~mm}$. This thickness of glass is, as Swinton points out, the greatest that will transmit cathode rays to any appreciable extent. A propos of this, it may be remarked that the effeet appeared to be intimately associated with the fluorescence-fatigue which glass displays when subjeeted to prolonged bombardment by cathode rays (see p. 12). If the gas-permeated region of the glass is removed by grinding, the glass reeovers its usual fluoreseing ability. Hill (loc. cit.) found a similar absorption-fatigue; and it would be interesting to test whether such removal of the fatigued surface promoted vigorous gas-absorption on further rumning of the discharge.

Hill agrees with Willows ( $P . M .1901)$ in attributing the hardening of discharge tubes to chemieal aetion between the gas and the glass. His experiments show that Jena glass gives the least absorption, lead glass coming next, while soda glass gives most of all. The greater stability of Jena glass is well known from its behaviour in other directions. Possibly fused silica or alkali-free glass would prove to be superior even to Jena glass. It would be interesting to subject an ordinary soda glass bulb to steam or boiling-water treatment before exhaustion, to see if the removal of the alkali affected the rate of hardening.

Ramsay and ('ollie ( $N$. I!)2) discovered helium (and a trace of neon) along with hydrogen in the deeply stained glass of an old X-ray tube." 'This is suggestive, for hydrogen

1 The formation of hubbles in such circumstances was also noticed by Comy (C.R. 1896) and Villard.

2 Sir J. J. Thomson (I.R.S. 1913) finds, however, that nearly all substances when subjected to prolonged bombardment by cathode rays emit hydrogen and helinm. 
and helium molecules have the highest speeds of all molecules. Under the electric discharge, these speeds may be increased a thousandfold, e.g. the average velocity of positive rays of hydrogen is $2 \times 10^{8} \mathrm{cms}$./see. (see p. 20). Goldsmith (P.R. July 1913) found that such high-speed molecules of hydrogen and helium can penetrate, for example, mica sheet from 0.001 to $0.006 \mathrm{~mm}$. thick, though the slower air, argon, or $\mathrm{CO}_{2}$ molecules camnot. But molecules which eould penetrate so great a distance as $0.015 \mathrm{~mm}$. of glass would have to be considerably faster. How fast, we may infer from the fact that a particles (helium atoms) from RaC have a range of $0.04 \mathrm{~mm}$. in glass. Such particles have an initial speed of about $2 \times 10^{9} \mathrm{cms}$. $/ \mathrm{sec}$, i.e. ten times the above velocity. It has, of eourse, never been shown that sufficiently high instantaneous velocities are not possessed by individual hydrogen molecules in a discharge tube-one can only measure average velocities. But, in any case, it is obvious that any explanation such as this conld only be a partial one ; it does not, for instance, explain the marked difference in the behaviour of different kinds of glass.

The absorption may be due in part to chemical activity excited in the gas by the discharge, such as has recently been found by Strutt to be the ease with nitrogen. It may be, too, that the action is stimulated by a species of electrolysis of the glass produced by the high-tension discharge playing over its surface. It is well known that glass may be readily electrolysed by quite moderate potentials, if the temperature of the glass is raised, and it is a matter of experience that the discharge seems to have an ageing effect on the glass, to the detriment of subsequent working in the blowpipe. Such electrolysis might have a marked effect on the gas film which glass and other solids can condense on their surfaces. Possibly in such circumstances the gas film is capable of taking up abnormal amounts of the residual gas in the bulb.

The hardening of an $\mathrm{X}$-ray tube is well known to be pronounced with tubes whose walls have become blackened by metal sputtered from the electrodes (see p. 76). The finely divided metal behaves like spongy platinum in its 
absorptive properties for gases. ${ }^{1}$ In most cases this is probably the right explanation of the hardening.

\section{To soften an X-ray Tube.}

It was early discovered that the resistance of a tube could be lowered by warming the bulb with a spirit lamp or gas burner, but the resulting benefit was only temporary, and various "softening" methods have been devised from time to time. Many of these methods involve the heating of some substance which has been inserted in the tube, e.g. sealing-wax, earbon, and red phosphorus have each been employed by various experimenters in the past : Sir William Crookes used caustic potash for this purpose as long ago as 1879.

In many X-ray bulbs, this occlusion method is arranged to work automatically. A small alternative discharge tube communicates with the

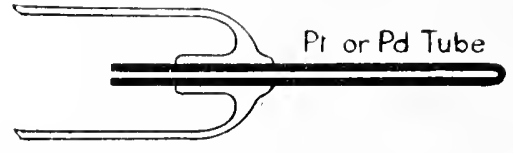

Ha. 47.-Osmosis tube for admitting hydrogen into an X-ray bulb. main bulb (Fig. 22). When the resistance increases beyond a certain degree, the discharge chooses the alternative path, and in so doing heats up some absorbent material sueh as asbestos, sheets of mica, or glass-wool enclosed in the small tube (see Fig. 22). The consequent liberation of gas (largely $\mathrm{CO}_{2}$ and water vapour) lowers the resistance of the bulb, and the discharge resumes its proper path. But, in time, such substances "fatigue," having yielded all their available gas; and the only course is to open up the tube and renew the material.

The plan often employed nowadays for softening bulbs is the "Osmosis" method, originated by Prof. Villard of Paris in 1898, and discovered independently by Profs. Winkelmann and Straubel of Jena in 1899. A small platinum or palladium tube closed at one end is sealed into the bulb, the unclosed end being open to the bulb (Figs. 47 and 21).

${ }^{1}$ Soddy and Mackenzie (P.R.S. 1907) showed that helium was absorbed by aluminiun scattered from the cathode of a discharge tube. In such a case the gas may be mechanically trapped by a compact filn of motal. 
By applying a Hame to the tube a small quantity of hydrogen diffuses through the hot metal, and the pressure of the bull, can be restored to the right amount. Palladium slows the effect so very markedly that care should be taken in the heating; otherwise the result will be a bulb too soft for use. Indeed, this method should never be employed except when the discharge is ruming.

The Bauer valve (J.Rt.S. Jan. 1907) is a more recent contrivance for letting minute quantities of air into Röntgen bulbs. The valve (see Fig. 48) consists of a smąll unglazed porcelain disc, through the pores of which air can pass. Ordinarily the clise is sealed by mercury, but by means of a pnemmatic piston the disc can be laid bare for a moment by pushing the mereury away (page $80)$.

\section{To harden an X-ray Bulb.}

If by any mischance a bulb becomes too soft for use, the only thing

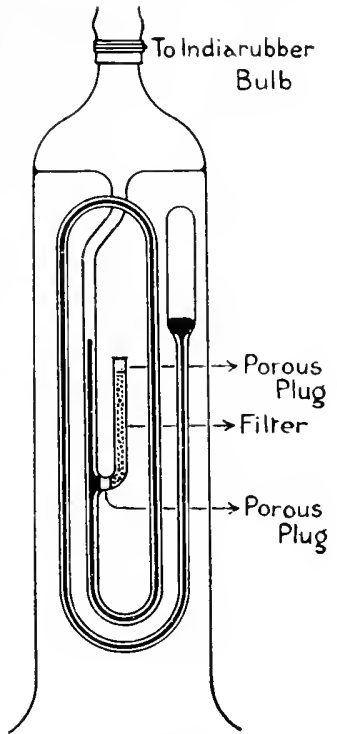

Interior of Bulb

FIG. 48.-The Bauer vilve lor admitting air into an X-ray bulb. The filter is of gold leaf to absorb nereury vapour. possible, apart from drastic re-exhausting, is to try and harden it by prolonged rumning with as large a coil as can be got. Often it is beneficial to send this hardening discharge in the reverse direction, i.e. from cathode to anode, temporarily discomecting the anticathode for the purpose. 


\section{C'HAP'TER V'HI.}

'THE BLACKENING OF IN X-RAY BULB.

WiTn continued use, an $X$-ray bulb becomes blackened on its inner surface. The blackening is mischievous from several points of view. Firstly, the deposit not only tends greatly to increase the resistance of the tube to the diseharge, but accelerates the absorption of the residual gas; secondly, the discharge is wont to spark irregularly along the walls of the tube instead of through the gas ; and thirdly, the film of metal arrests the softest $X$ rays.

Two main eanses are answerable for the blackening :

(1) The disintegration or "sputtering " of the anticathode while acting as eathode during the inverse carrent; and also of the eathode during the direct phase.

$(2)$ The volatilisation of the anticathode due to its high temperature undex reduced pressure.

\section{CATHODIC SPITTERING.}

Workers with discharge tubes have long been aware that. when a high-potential eurent is passed through a vacum tube provided with platinum elcetrodes, the glass adjacent to the cathode generally becomes coated with a mirror of platinum (Fig. 49). The anode, on the contrary, shows little or no such effect. This property of eathodic sputtering is common in greater or less degrec to all metals. The effect was noticed in the very early days of 
vacuum tubes: both Geissler and Plüeker (1858) remarked on it.

Thus, quite apart from the cathode rays and positive rays, there is a cathodie emission which eonsists of particles of disintegrated metal from the eathode. These particles appear to be projected normally (at any rate, very approximately) from the surface of the eathode, and to travel in straight lines. The streams of metal are negatively charged,

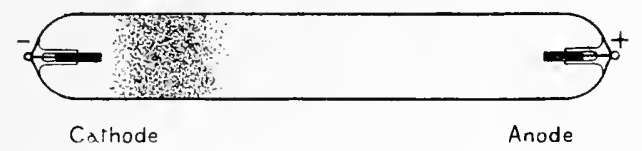

FIc. 49.-Illustrating cathodic sputtering. (From the Chemirnl World.)

and it is found that they deposit more readily on surfaces which are positive with respect to the cathode. The positive electrification which the inmer surface of an X-ray bulb usmally possesses, is thus favourable to eathodic deposition.

It does not appear that. in ordinary cireumstanees, the disintegration of the cathode plays any appreciable part in the passage of the current. Unlike the eathode rays, the sputtered particles require strong magnetic fields (2000 gauss and upwards) before any deviation of their path can be detected. The inference would be, either that the particles are very fast moving or that they are relatively large aggregates of molecules; the latter view is supported by other evidence. The lower the pressure in the tube and the higher the potential applied, the farther are the particles hurled. There is no deposition within the eathode darkspace. The sputtered metal does not appear to excite fluoreseence when it strikes the glass walls of the tube.

cathodic disintegration is not a simple phenomenon, and the exact mechanism of the production of the sputtered particles is doubtful. It appears, however, to be conneeted with the bombardment of the eathode by the positive rays, the pulverising properties of which we have already notieed (1) 20). 
Experiment shows that the amount of metal shot from a cathode depends on

(1) The nature of the metal of the cathode.

(2) The temperature of the cathode.

(3) The nature of the gas in the tube.

(4) The current through the tube.

(5) The fall of potential at the cathode.

\section{(1) The Metal of the Cathode.}

Sir William Crookes (P.R.S. 1891) was the first to investigate systematically the relative sputtering of a number of metals under like conditions of discharge. The residual gas was air; the pressure, that corresponding to a dark-space $6 \mathrm{mms}$. thick (say $05 \mathrm{~mm}$. $\mathrm{Hg}$ ). A coil discharge was used, and in these circumstances the relative losses of weight at ordinary temperatures resulted as follows:

Table III. Cathodic SPUTtering.

(Palladium $=100$.)

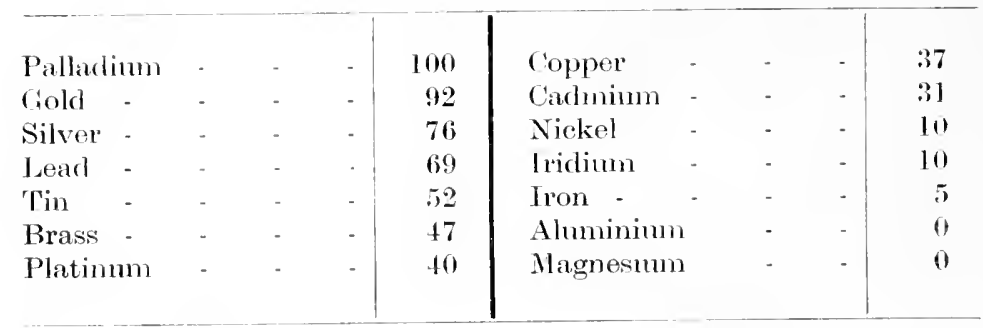

The order of these metals must not be regarderl as inviolable. It is affeeted to some extent by a change in the pressure of the gas (which may, for instance, put platinum above gold), the nature of the gas, or the temperature of the cathode. Nevertheless, the sequenee is of value to users of diseharge tubes in general and of X-ray tubes in particular. The reason for the invariable choice of aluminium ${ }^{3}$ for the cathode is as readily apparent as the need for suppressing the inverse current through a tube and so preventing the platinum anticathode from officiating as cathode. It

1 Geissler noticed that aluminium did not sputter appreciably: 
is not right, however, to assume that it is impossible to make aluminium sputter appreciably, as will be evident from a scrutiny of the cathode of an old X-ray bulb: a brown deposit may usually be found on the central area of the cathode as well as on the glass in the vicinity. ${ }^{1}$

Tantalum has also proved to be an excellent material for cathodes from the point of view of sputtering. I brlicre tungsten displays equally good properties.

\section{(2) The Temperature of the Cathode.}

Crookes showed that if the temperature of the cathode is raised appreciably, for instance by the passage of the discharge, the sputtering of many metals is markedly increased. The electrodes tend to get very hot if the tube is at all soft, as more current is then passed by the gas. The rise of temperature of the cathode is roughly proportional to the current.

\section{(3) The Nature of the Gas.}

The nature of the residual gas has a very marked effect both on the degree of sputtering that a metal exhibits and on the appearance of the deposit. Hydrogen, nitrogen, and carbon dioxide are in most cases unfavourable to the effect, while oxygen and especially the monatomic gases, mercury vapour, $\mathrm{He}, \mathrm{A}, \mathrm{Ne}, \mathrm{Kr}$, and $\mathrm{Xe}$ bring about pronounced disintegration of most metals. Helium shows the effect least of all these gases, but argon is particularly potent, and metals so varied as $\mathrm{Al}, \mathrm{Ag}, \mathrm{Cd}, \mathrm{Pt}$, and $\mathrm{Au}$ are all excited to a maximum activity in this gas. Aluminium shows only feeble sputtering in hydrogen or nitrogen, and but little more in oxygen. Iron sputters a little in hydrogen; silver and lead sputter markedly in this gas.

Systematic work is needed to find the most suitable gas for an X-ray tube. Unless precautions to the contrary have been taken, the gas will probably consist largely of hydrogen and carbon dioxide liberated from the electrodes. Pt and especially Al (and $\mathrm{Mg}$ ) emit large quantities of gas when used as cathodes. The point is also of importance in

1 See Kaye, P.P.S. Ap. 1913. 
connection with the various methods of controlling the hardness of bulbs (p. 74). The automatic devices introduce chiefly carbon dioxide, and, in some eases, a little water vapour; the osmosis valves, hydrogen; the Bauer valve, air. So far as sputtering goes, hydrogen and earbon dioxide would appear to have advantages, though there is some diversity of opinion on the point. On the other hand, it may be remarked that a tube rendered unsteady by the hardening effect of hydrogen may often be eaused to run smoothly by letting in a little air.

(4) The Current through the Tube.

The disintegration of a cathode increases with the eurrent through the tube, apparently either as the first power or the square of the current.

(5) The Fall of Potential at the Cathode.

The volatilisation of the cathode is angmented by increasing the potential on the tube, and such control is

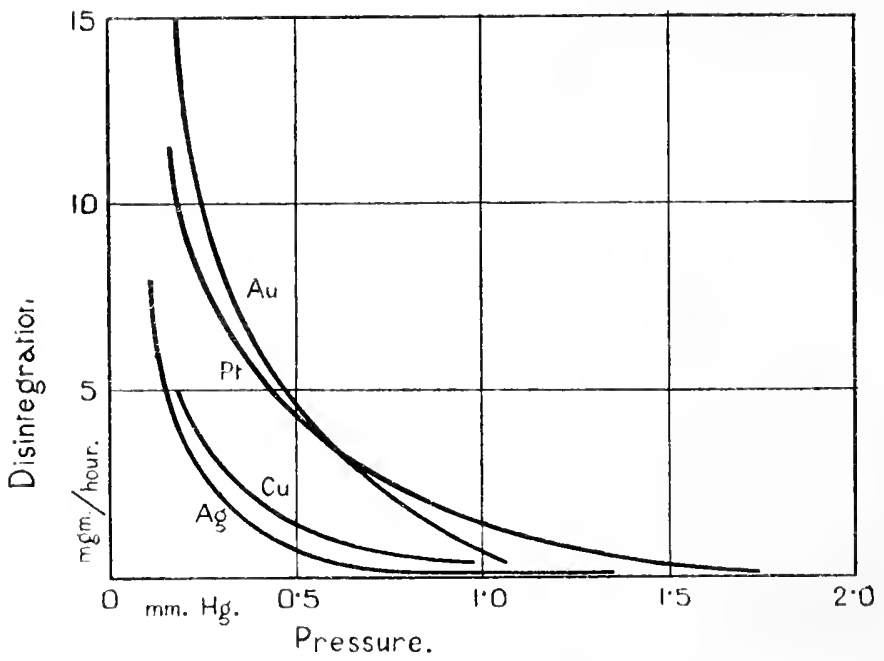

Fra. 50.- Redalion between rathodic sputtering and pressure. (From the Chemieal IVorld.)

readily obtained by lowering the pressure of the gas. Sputtering is much more pronounced at low pressures than at 
high, though at the very low pressures of an X-ray tube the disintegration is not quite so marked as at rather higher pressures, when the tube runs more easily. Fig. 50 displays the relation between the pressure and eathodic disintegration of a number of metals. It is due to Granquist (1898).

The potential that is applied to an $\mathrm{X}$-ray tube is not distributed evenly between the electrodes. The greater part is used up elose to the eathode; there is a gentle potential gradient in the space between the electrodes, and the remaining fall of potential occurs close to the anode. The amount of sputtering depends on the cathode-fall of potential, and this increases as the pressure of the gas is lowered. It appears to be essential that the potential fall at the cathode shall exeeed a certain minimum value before the metal becomes ionised and disintegrated to any appreciable extent. Holborn and Austin (1904) found that this eritieal potential was about 500 volts for a number of metals.

\section{Volatilisation of the Anticatione.}

The high temperatures which anticathorles may attain in a foeus tube are familiar enough, but the extent of the sublimation which most metals exhibit at temperatures well below their melting points may not have been brought home to many observers. A homely example of sublimation at low pressure is provided by the blackening which is a not uncommon feature of earbon and tungsten glow lamps. The subject has received attention at the hands of a number of workers, ${ }^{1}$ and it appears that the degree of volatilisation is affected by :

(1) The nature of the metal.

(2) The temperature of the metal.

(:) The nature of the surrounding gas.

(4) The pressure of the gas.

The disintegration of metals increases rapidly as the temperature rises. Of the platinum metals, platinum, rhodium, and iridium all disintegrate less as the pressure is redneed.

${ }^{1}$ See Kaye, Chemical IVorld, June 1913. 
and there is evidence to show ${ }^{1}$ that in these cases the volatilisation is not a simple process, but is brought about by the formation of endothermic oxides more volatile than the metals themselves. It would seem that in order to reduce the sublimation of these metals to a minimum, the important thing is to ensure the absence of oxygen in the surrounding gas ${ }^{2}$ - a wise precantion, indeed, with most metals, as almost all observers agree. Hydrogen and nitrogen do not in general favour disintegration.

With palladium and most other metals, a reduction of pressure is favourable to volatilisation - as would be anticipated in cases of true sublimation.

Table IV. ${ }^{3}$ gives, for a number of metals, data concerning the effect of pressure on the boiling point, as well as the temperatures at which appreciable vaporisation has been detected (mostly at low pressures). The corresponding melting points are added for the sake of comparison.

'TABLE IV.

\begin{tabular}{|c|c|c|c|c|c|c|c|}
\hline & \multirow{2}{*}{\multicolumn{3}{|c|}{ Metal. }} & \multicolumn{2}{|c|}{ Briling Point. } & \multirow{2}{*}{$\begin{array}{l}\text { Volatilisation } \\
\text { detectable at }\end{array}$} & \multirow{2}{*}{$\begin{array}{l}\text { Yelting Point } \\
\text { at } 1 \text { Atmos. }\end{array}$} \\
\hline & & & & At 1 Atmos. & In Vacuo. & & \\
\hline \multicolumn{2}{|l|}{ Cadmium } & - & - & $778^{\circ} \mathrm{C}$ & $450^{\circ}(!$ & $160^{\circ} \mathrm{C}$ & $321^{\circ} \mathrm{C}$ \\
\hline Zinc. & - & - & - & 918 & 5.50 & 180 & +19 \\
\hline Lead & - & - & . & 1525 & 1150 & 360 & 327 \\
\hline silver & - & - & - & 1955 & $1400 ?$ & 680 & 961 \\
\hline ropper & - & - & - & $2: 310$ & $1600 ?$ & 400 & 1084 \\
\hline Tin & - & - & - & $2 \cdot 2711$ & $1700 ?$ & $36 \div 1$ & 232 \\
\hline f:old] & - & - & - & $2530 ?$ & $1800 ?$ & 1370 & 1064 \\
\hline Trom & - & - & - & 2450 & - & 950 & 1530 \\
\hline Plationm & & - & - & $2.5110 ?$ & - & 1200 & 1750 \\
\hline Osminm & & - & - & - & - & 2300 & 2200 \\
\hline Tridium & & - & - & $2600 ?$ & - & 1400 & 2290 \\
\hline 'Tumesten & & - & - & $3700 ?$ & - & 1800 & 3000 \\
\hline
\end{tabular}

The table gives a notion of the extent to which volatilisation oeeurs with metals, while still at temperatures well

1 See Pioberts, P.M. 1913.

2 'This is especially important in the case of iridium.

3 Sre Kinge and Fwen, P.R.S. 1913. 
below their melting points. There is scope for a good deal of systematic work on the volatility of platinum, tungsten, iridium, etc., when heated at low pressures in different gases. The results would be of great practical value to the user of X-ray bulbs. It is known that tungsten, for example, when heated, readily disintegrates and becomes brittle in the presence of oxygen or moisture. Irving Langmuir ${ }^{1}$ has recently traced this to the formation of oxides.

\section{Coloration of the Glass of an X-ray Bulb with Use.}

The eathode rays "reflected" from the anticathode are responsible either directly or indirectly for the violet colour which the glass assumes in well used X-ray tubes. This coloration is most prononnced on the front side of the anticathode, and can be prevented by sereening the glass with metal foil. Radium rays affect glass and quartz in the same way, though to a greater depth; and cathode rays produce a similar colour in crystals of rocksalt or fluorspar. Possibly, therefore, the action is of the same nature in all these eases; and may be the phenomenon is related to the violet permanganate coloration produced by ultra-violet light and sunlight in window glass. The violet colour is in all cases destroyed by heating.

X-ray bulbs of lead glass become brown in colour rather than vjolet. Flster and Geitel (1898) have smggested that the various colorations are due to ultra-microscopic particles of reducerl metal in the salt.

1 Proc. Amer. Inst. Elect. Eng. Oet. 1913. 


\section{CHAPTER VIII.}

THE MEASURENENT OE X RAYS.

\section{The International Radium Standard.}

The general desire to have a standard by which the out put of an X-ray tube could be measured in a manner free from the defects of the usual methods. led the Röntgen Socicty in 1909 to appoint a Committee (with Dr. W. Deane Butcher as secretary) to eonsider the question. This Committee decided to initiate standards of radioactivity. These depended on the $\gamma$-ray activity of radium bromide and were prepared by Mr. C. E. S. Phillips. Largely owing to the efforts of Prof. Rutherford, the question was taken up by the Congress of Radiology at Brussels in September 1910. An International Committee was formed with Prof. Rutherford as President; in March 1912 the Committee met at Paris and adopted as an International Radium Standard a specimen consisting of 21.99 milligrammes of pure radium chloride which had been prepared by Mme. C'urie. The radium is eontained in a thin-walled glass tube, and nse is made of the $\gamma$-ray ionisation. The International Standard is preserved at the Burean International at Sivres near Paris. Secondary standards are obtainable by the various nations who require them.

\section{The British Radium Standard.}

The British Radium Standard, consisting of $21 \cdot 10$ milligrammes of pure radium ehloride, has been certified in terms of the International Standard. and is now deposited at the National Physical Laboratory at Teddington. The radium salt is eontained in a small glass tube. through which a platinum wire is inserted to dissipate acemmulated 
electric eharges (Fig. 51). The standard serves ats a meants of standardising radioaetive preparations as well as the energy output of X-ray bulbs.

In this eonnection it may be recalled that the average $\gamma$ rays of radium are something like thirty to forty times as penetrating to air as the $X$ rays from a very hard bulb, while the $\beta$ rays are a trifle more absorbable than very soft $\mathrm{X}$ rays.

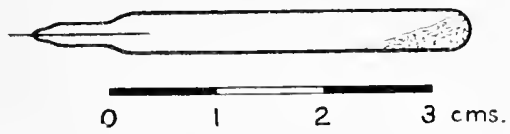

Fla. 51. -The british Ratium standard at the Xational l'hysical Laboratory.

\section{Standardisation of X-ray Bulbs. ${ }^{1}$}

The difficulty of standardising the output of X-ray bulbs by means of such an ionisation standard is chiefly one of speeifying and reprodueing the working conditions of the bulbs. Possibly the various maker's could be induced to work to standard dimensions, but few would assert that the design of an X-ray bulb has reached or even approached finality. Moreover, even if agreement in design were secured, the performanee of a bulb is peeuliarly susceptible to slight valiations in the prevailing conditions (see p. 6s), over sone of which control is scarcely possible. It is a matter for urgent enquiry to find neans of holding a bulb to conditions which have been specified; until then, the standardisation of an X-ray bulb ean only be regarded as an assessment of the output which prevailed at the moment of test.

From a practieal point of view, the output from an $\mathrm{X}$-ray bulb has to be specified with respect to both intensity and hardness, i.e. quantity per mit area and quality.

\section{Methods of Measuring Intensity.}

The intensity of the $\mathrm{X}$ rays at a particular point is defined as the energy falling on one square centimetre of a

${ }^{1}$ For a full account of the various methods of measuring $\mathrm{X}$ rays (more especially for medical purposes), see Christen, Messung und Dosierung der Röntgenstrahlen. 
receiving surface passing through the point and placed at right angles to the rays. Röntgen was able to show, and the fact has been amply confirmed by later workers, that the intensity of a beam of $X$ rays from a focus-bull, falls off as the inverse square of the distance from the anticathode.

\section{General Remarks on Intensity Measurements.}

1t. nlay be noted that ahmost all the methods of intensitymeasurement, as ordinarily practised, are unduly favourable to the soft rays when regarded from an energy standpoint. The ideal method of test would afford an exact comparison of the energy of a hard $X$ ray with that of a soft ray; but what almost always happens is that the hard rays are not wholly arrested by the testing instrument, and hence show up relatively badly. For instance, very hard $\mathrm{X}$ rays do not affect a photographic plate to the same extent as the softer rays; and, again, soft rays have greater ionising power per centimetre than hard rays. In order to make a fair comparison between two bulbs, all the rays given out by both should be taken into account. The hard rays as well as the soft ones should be completely absorbed, in which ease the measurements would give a fair estimate of the relative amounts of energy emitted from the bulbs.

\section{(I) Current through the X-ray Tube.}

A rough notion of the intensity of the $X$ rays from a bull, may be obtained by measuring (with a milliammeter) the current passing through the tube, provided the potential differenee is kept eonstant. This method, which is often employed, would be a more reliable guide if all the current were carried solely by the eathode rays, and if all the athocte rays gave birth to $X$ rays. But this is undoubtedly not the case, ${ }^{1}$ and, as Blythswood and Seoblo (.J.RI.S. 1907) showed, a knowledge of the current in the

1 Sir Oliver Lodge (P.M. 1911) maintains, indeed, that the current is mostly conveyed ly positive rays, though Sir J. J. Thomson (P.M. 1912) inclines to the opposing vicw that the greater part of the current is carried by the cathode particles. 
secondary dircuit does not afford an aecurate measure of the intensity of the $X$ rays. It is important, howerer, in a set of comparative observations to keep the current in the primary constant, for an increase in the eurrent through the primary not only augments the intensity of the rays, but hardens the tube and lengthens the alternative spark-gatp.

But, however constant the enrent in the primary is, it is difficult to estimate how any particular eurrent-measurer will average up the peculiar pulsating current of a coil clischarge (see p. 59). The interpretation to be put on the readings of the milliammeters ordinarily used for the purpose is dubious to a degree. Salomonson (J.Rt.S. 1912) has recently shown experimentally that both the form of the current and the frequency of the interruptions must be controlled in exact comparative measurements. To this end some form of electrostatic oscillograph would be useful.

In usual practice, the methods for measuring intensity depend on one or other of the properties of the rays : heating, ionising, fluorescing, photographic, or chemical.

\section{(2) Thermal Methods of Measuring Intensity.}

The heat produced when X rays are completely absorbed by a metal was first measured by Dorn in 1897. Angerer (A.d.P. 1907) and Bumstead (P.M. 1908) have shown that the same amount of heat is generated by a stream of $\mathrm{X}$ ray's, no matter what the absorbing metal - a result unfavourable to the view formerly held that it was possible to unlock the internal stores of atomic energy by such means. The experiments are difficult, for the heating effects are minute, and can only be detected by instruments as sensitive as the radiomicrometer, bolometer, or radiometer. It will be seen that at present the method is only fitted for the research laboratory, and does not enter into the sphere of ordinary practice.

\section{(3) Ionisation Methods of Measuring Intensity.}

The exact mechanism of ionisation is even now not fully comprehended, but the outcome is the formation of positively 
and negatively electrified particles-ions-the presence of which imparts to the gas a conductivity that persists for some little time. The extent of the ionisation depends on the number of ions produced, and this is reflected in the degree of excellence with which the gas conducts. The generally accepted view of the formation of ions is that a negative muclens (the electron) is broken off from the atom, leaving a positive nuelens; each of these charged nuclei gathers round itself a cluster of gas molecules-sometimes in considerable numbers-and the resulting molecular aggregates constitute the gaseous ions, both positive and negative. At low pressures, the negative ion exists as the electron mencumbered by any attached molecules.

An ionisation method of evaluating $\mathrm{X}$ rays thus resolves itself into the measurement of an electric current-an operation which can be carried out with such delicacy and convenience that practically all recent workers have utilised this property of the rays. The ionised gas is subjected to an electric field which drives the two classes of ionspositive and negative-in opposite directions with velocities which depend on the strength of the field. The magnitude of the eurrent generated by the motion of these charged particles dependis to some extent on the potential difference of the surfaces between which the field is applied; with small potentials, the two are roughly proportional, just as in cases of metallic conduction; but with higher potentials the eurent responds less and lesis to the potential, and finally reaches a constant value called the saturation current (see Fig. 52). This is the eurent which should always be measured in practice, and care should accordingly be exercised that the potential differenee applied to the surfaces is sufficient to give the saturation current The electric field necessary incleases with the degree of ionisation, but for most cases likely to arise in X-ray work, 100 volts per ( $\mathrm{m}$. is adequate.

The shape of the first part of the eurrent-potential curve is explained by the liability of a eharged particle to encomter and coalesce with another of opposite sign before reaching one of the bounding surfaces. But this tentency, which 
militates, of course, against the growth of the eurent, will be lessened if the speed of the particles is increased by putting up the voltage between the surfaces. For the higher the speed, the shorter the time of passage, and the less likely are the chances of recombination. Finally, with the saturation voltage, all the ions peach the boundaries, and the number arriving exactly equals the number produced in the same time by the I rays passing through the gas. This

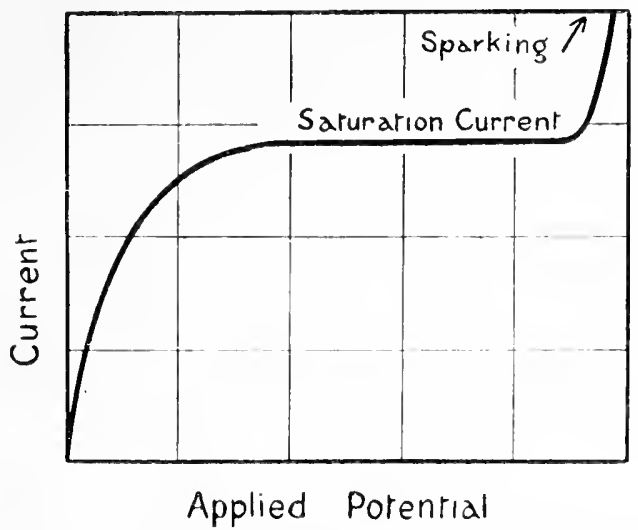

Fid. 52.-1)iagrammatic representation of the relation between current and potential for an ionised gas.

is not the case with the lower voltages, and thus only from a knowledge of the saturation current can we infer the true degree of ionisation that the rays have produced.

With still higher potentials, the current rapidly increases until the sparking point is reached. On this steep part of the eurve, both positive and negative ions acquire sufficient speed to produce fresh ions by colliding with the atoms of the gas. Thus, by working with potentials just insufficient to cause the passage of a spark, the original ionisation may be greatly increased-a hundredfold or so. The plan hats been adopted for the measurement of very feeble ionisations.

Before adopting one or other of the various forms of ionisation chamber for any particular purpose, it is necessary to decide what we wish to measure. If it is the total ionisation that is desired, then we must arrange for the rays to 
be completely abrorbed in the gas of the chamber, if necessary by contriving a suitably long path, or by increasing the pressure of the gas, or, again, by choosing a sufficiently dense gis 1: the total ionisation, we have reason to believe, is the one measure of the energy in the rays and eannot be increased by reflection or any other device. If, on the other hand, we wish merely to aseertain the ionising power of a beam of rays at some particular point, then almost any form of ionisation chamber will suffice.

One convenient design is shown in Fig. 5:. A circular thin aluminium sheet is mounted midway between two similar sheets which are raised to

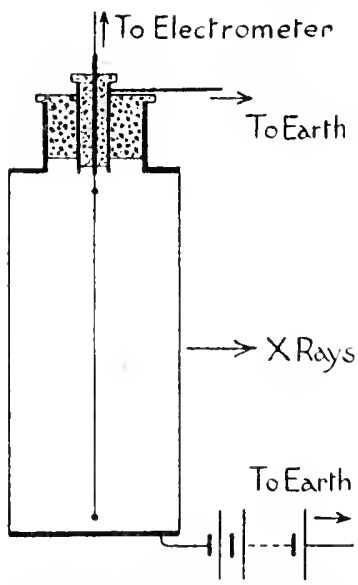

Fit. 53.- In ionisation chamber, showing earthed guard-tube in the insulation. a potential of a few hundred volts by a battery of cells. The central sheet is carefully insulated and joined to an electrometer. It is easy to calculate the electric field with this shape of vessel, a statement that does not apply to the very common design made up of a cylinder provided with an insulated wire electrode along the axis. ${ }^{2}$ In this latter form, the field, which is very strong near the wire, falls off a great deal towards the surface of the cylinder; the applied potential must be very considerable to ensure a saturating field throughout the ehamber.

Ionisation currents produced by $\mathrm{X}$ rays are usually of the order of $10^{-10}$ to $10^{-15}$ ampere; the exact amount varies it great deal according to the cireumstances. For the larger currents, it is sometimes possible to use a sensitive galvanometer $^{3}$; but in general it is much more convenient to

${ }^{1}$ E.g. sulphur dioxide or methyl iodide are very useful for the purpose.

2 See, for instance, the comparison ionisation chamber in Fig. 71.

${ }^{3}$ The most sensitive galvanometers yet introduced are the Paschen and the Einthoven. 'The former, with a low resistance and a short period, will readily indicate $10^{-10}$ ampere. See Camb. Sci. Inst. Co.'s list. 
derluee the eurrent from the ehange of potential as measurert by means of a Dolezalek quadrant electrometer or some form of gold-leaf electroscope. With an electrometer and at suitable condenser, eurents from $10^{-8}$ to $10^{-11}$ ampere can be measured. For smaller eurrents-down to $10^{-17}$ ampere-an electroseope is better.

Of the eleetroseopes, the (. T. R. Wilson tilted variety ${ }^{1}$ in convenient and sensitive, and possesses a small capacity. Some observers use eleetroseopes provided with aluminium windows, the $\mathrm{I}$ rays being sent directly into the electroseope instead of into a separate chamber. The leaf in this (ase is charged to a high potential, and its rate of leak to the outer case is measured. There are on the market several "direct reading" X-ray quantimeter's of this type, which are eonvenient for eomparative measurements but are not eapable of aceurate absolute work. All the various instruments require to be calibrated, and their eapacity (as well as that of the ionisation vessel) determined, before tho currents can be dedued from the potential measurements.

'The French workers largely employ the late Prof. Curie's piézo-électrique, in which the eleetricity generated by gradually relieving the tension on a stretched quartz lamina is balaneed against the ionisation eurrent to be neasured. The method requires eonsiderable manipulative skill. ${ }^{2}$

\section{(4) Photographic and Fluorescence Methods of Measuring Intensity.}

Practieally all the earlier workers used photographie or tluoreseenee methods of measuring the intensity of their $\mathrm{X}$ rays, but nowadays these methods, at any rate for most purposes, have been displaced by ionisation methods. An ordinary photographie plate is ineapable of arresting and recording the hardest kinds of $\mathrm{X}$ rays, and therefore, from an energy standpoint, the softer rays are given undue weight when a heterogeneous beam is used. We need, therefore, to exereise eare in drawing conclusions from the density of the photographie image as to the intensity of the rays. Moreover, Barkla and Martyn (P.M. 1913) have shown that

I See, for example, the Camb. Sci. Inst. Co.'s list of electrometers.

- See Rutherford's Radioactive Substances, 1913. 
if the $\mathrm{X}$ lays are just sufficiently hard to exeite the radiations characteristic of silver or of bromine (the heaviest constituents of a photographic film), they are selectively absorbed and the photographic effect is greatly enhanced. $\mathrm{X}$ rays a little softer than this do not excite the characteristic rays, and are, therefore, recorded disadvantageously. Thus the photographic action is not proportional to the direct absorption of the $\mathrm{X}$ rays by the sensitive film.

As far as practical difficulties are concerned, it should be remarked that the emulsion on an ordinary plate may vary in thickness by as mueh as 10 per eent., through want of flatness of the glass baeking. This ean be reduced to the order of 5 per cent. by the use of patent plate glass and the exercise of special care in the coating. The slower fine grained plates are to be preferred for more precise work, and, of course, one should adhere to some standard developer and method of development. In regard to the sensitiveness of different plates to $\mathrm{X}$ rays, Blythswood and Scoble (J.Rt.S. 1906) showed that but little guidance can be obtained from the speeds for light. In some eases the divergence amounted to as much as four times.

'To the worlier with limited resonrces the photographic method of measuring intensity offers advantages because of its simplieity. Some form of opacity-meter for obtaining a measure of the density of the image is the chief requirement. The opacity meter measures the extent to which a standard beam of light is cut down by the photographic film whose density is required. If $I_{0}$ is the intensity of the testing light which is ineident on the developed film, and $I_{t}$ that of the transmitted light, then, if $\lambda x$ is the fraction of the energy which is absorbed by a very small thickness, $x$, of the film,

$$
I_{t}=I_{0} e^{-\lambda d},
$$

where $d$ is the thickness of the film ${ }^{1}$ (see p. 100). The film is assumed equally dense throughout its thickness.

For filns of uniform thickness, $d$ is constant, so that $\lambda$ is proportional to $\log \left(I_{0} / I_{t}\right) . \quad \lambda$ is called the absorp-

${ }^{1}$ More precisely, this assumes monochromatic light. $\lambda$ is different for different wave-lengths. 
tion coefficient; $\left(I_{0} / I_{t}\right)$ is known as the opacity, ${ }^{1}$ and equals the number of times the incident light is cut down. $\log \left(I_{0} / I_{t}\right)$ is termed the opacity-logarithm. Now, by definition. $\lambda$ is proportional to the density of the image, i.e. to the amount of silver per unit area of film. Thus the ratio of two opacity-logarithms gives the ratio of the film densities. and therefore the ratio of the photographic energies in the two cases. The opacity meter is graduated to read directly in opacity-logarithms.

In fluorescence methods the luminosity is matched against some standard fluorescence excited by a steady source of radiation such as radium. The drawback to such methods is that the fluorescing salt becomes "tired " mnder the action of the rays. The sensitivity of a screen may also vary considerably from point to point, so that it is difficult to make a fair comparison. Barium platinocyanide is the material commonly used to sensitise a fluorescent sereen : recently. considerable improvements have been effected in the fluorescing ability of the salt.

\section{(5) Methods of Measuring Intensity used in Medicine.}

In the therapeutic use of $\mathrm{X}$ rays, various chemical reactions brought about by the rays have been suggested and employed from time to time as aids to " closage" ; for example, the discolouring of various alkaline salts (Holzknecht, 1902); the liberation of iodine from a 2 per cent. solution of iodoform in chloroform ${ }^{2}$ (Freund, 1904 ; Bordier and Galimard, 1906); the darkening of a photographic plate (Kienböck), see p. 92 ; the precipitation of calomel from a mixture of mercuric chloride and ammonium oxalate solutions ${ }^{2}$ (Schwarz, 1907); and the change of colour of pastilles of compressed barium platinocyanide (SabourandNoiré and Bordier). X rays resemble light in their property of lowering the electrical resistance of selenium; this property, if the pronounced fatiguing of the seleninm could be overcome, would doubtless fumish the basis of a very convenient method of measurement. It must bo admitted

1 The transparency is the reciprocal of the opacity.

${ }^{2} \mathrm{X}$ rays share this property with Ra rays and ultra-violet light. 
that most of these methods, if not all, provide nothing more than the roughest notion of the intensity of a beam of ordinary heterogeneous $X$ rays.

Of all the various intensity-measurers, the pastille finds most favour with medical men. The barium-platinocyanide dises are some $5 \mathrm{mms}$. in diameter, and their colour, initially a bright green, changes, when exposed to the rays, to a pale yellow, and finally to a deep orange. The pastille is placed at a specified distance from the anticathode of the bulb, and the colour is matched against one of a number of standard tints. The method is extremely easy in practice, and is fairly reliable as a guide for short exposures, but it is not very trustworthy for times exceeding ten minutes or so. Possibly for long exposures, some of the other platinocyanides, all of which show similar colour changes when exposed to $\mathrm{X}$ rays, would be more reliable. The change of colour appears to be due to dehydration. If the pastille is put aside, rehydration subsequently takes plaee, especially in the presence of light, so that the pastille should not be exposed to full daylight during the X-ray treatment. Ultra-violet light and radimm rays cause similar browning in such pastilles.

The following table gives an idea of the relation between the different scales:
5H units 1
(Holzknecht; alkaline salt)
$=$ Tint $\mathrm{B}$
(Sabouraud-Noiré : pastille)
$=$ Tint 1
(Bordier ; varnished pastille)
$=: 3$ to $4 \mathrm{I}$
(Bordier and Galimard ; iodine solution)
$=10 \mathrm{X}$ units
(Kicnböck; photographic plate)
$=3.5$ Kaloms (Schwarz: mereury solution)
= Villard dose.

\section{Methods of Measuring QuattTy or Hardness.}

The range of qualities of $\mathrm{X}$ rays is very wide, as would be inferred from the fact that, while some rays are mable to penctrate more than a centimetre or two of air

1 Thit $1 H=$ one-third of the radiation necessary to set up the first signs of reaction in the healthy skin of the face. 
at atmospheric pressure, others have been detected at distances of 100 motres or more.

The hardness of a bulb is mainly dependent on the maximum potential difference between the electrodes: an account of the various methods of controlling this potential is given on p. 6s. It is sufficient to repeat here that the $X$ rays from a bulb may be divided into two main classes:

(1) the heterogeneous "general" or "independent" radiation which depends in quality solely on the speed of the parent cathode rays;

(2) the homogeneous "characteristic" or "monochromatic " radiations which are characteristic of the metal of the anticathode (p. 112).

The proportion of these two classes depends on the conditions of discharge, and on the metal of the anticathode. The general radiation is always present, and has a range of hardnesses which depends on the range of specds of the cathode rays. The characteristic radiations only appear when the cathode rays are sufficiently fast; their hardness depends only on the material of the anticathode.

\section{(1) Wave-length.}

We have good reason now for believing that $X$ rays and light are identical, and that the hardness or penetrating power of an $\mathrm{X}$ ray is precisely defined by its ware-length : the shorter the wave-length, the harder the ray. The subject is dealt with elsewhere (p. 186), but it has been shown by many observers that $\mathrm{X}$ rays are reflected by the invisible parallel planes of atoms in the interior of a crystal. From a knowledge of the distances separating the atoms, we can arrive at the wave-lengths of the $X$ rays. If one compares corresponding radiations (i.e. in the same series) of different elements, it is seen that the heavier atom gives the shorter wave: Prof. Bragg has, in fact, shown that the wave-length is inversely proportional to the square of the atomic weight of the radiating element (see p. 200). W. L. Bragg (P.R.S'. 1913) has calculated the atomic distances in thr case of rock-salt (p. 197), and the following wave-lengths for the 
several characteristie radiations depend on his estimate. A more complete table will be found on p. 201.

Table $r$. Wave-tenctiths of some Characteristic Radiations.

\begin{tabular}{|c|c|c|c|c|c|}
\hline \multicolumn{3}{|c|}{ Platinum. } & Tungsten. & Rhodium. & Nickel. \\
\hline $\begin{array}{l}1 \cdot 303> \\
I \cdot 109 \\
1 \cdot(1) 91 \\
0 \cdot 948 \\
0 \cdot 918\end{array}$ & $\begin{array}{l}101^{8} \mathrm{~cm} . \\
\therefore \\
., \\
., \\
,\end{array}$ & $\begin{array}{l}\text { strong } \\
L \text { radin. }\end{array}$ & $\begin{array}{l}1.25 \times 10^{-8} \mathrm{~cm} \\
L \text { rardiation, } \\
\text { (very soft) }\end{array}$ & $\begin{array}{l}0.607 \times 10^{-8} \mathrm{~cm} . \\
\quad \text { (strong). } \\
0.533 \times 10^{-8} \mathrm{~cm} . \\
\quad \text { (weak) }\end{array}$ & $\begin{array}{c}1.66 \times 10^{-8} \mathrm{~cm} . \\
K \text { radiation. } \\
\text { (very soft) }\end{array}$ \\
\hline
\end{tabular}

Thus, it appears, we may regard the rays from an X-ray bulb as consisting of a mixture of homogeneous radiations characteristic of the metal of the anticathode, together with a "baekground" of "white" rays (in other words, the analogue of white light). It is not yet settled whether these latter rays, which constitute the independent radiation referred to above, consist of a mixture of a number of eharaeteristic rays of different hardnesses, or whether they represent a perfeetly continuous speetrum of rays.

\section{(2) Potential Difference between Electrodes.}

A measure of the hardness of a beam of $\mathrm{X}$ rays is afforded by the potential difference between the terminals of the generating tube. On this potential difference depends the velocity of the eathole rays; and since both the quality and energy of an $X$ ray are related to the speed of the exciting cathode ray, it is important to be able to measure the potential with some precision.

If $E$ is the potential difference to which a cathorle ray owes its velocity $(v)$, then the two are connected by the energy equation

$$
\stackrel{!}{2} m \cdot i^{2}=E \cdot e \text {, }
$$

where $e$ and $m$ are respeetively the charge and the mass of the cathode ray.

Thaking $e / m=1.77 \times 10^{7}, E$ in volts and $v$ in cms./sec.,

$$
\begin{gathered}
E=2 \cdot 82 v^{2} \cdot 10^{-16} \\
v=5 \cdot 95 \sqrt{E} \cdot 10^{7} .
\end{gathered}
$$


A series of values of cathode-ray velocities and potentials up to 200,000 volts is tabulated on p. 233 .

The potential difference on a tube may be measured by a high-potential electrostatic voltmeter, of which there are now one or two excellent examples on the market. $\mathrm{Or}$, failing this, the length of the alternative spark-gap may be noted. The hardness of the $\mathrm{X}$ rays is roughly proportional to the square-root of the spark-gap, at any rate for the same bulb. It does not, however, by any means follow that two bulbs having the same equivalent spark-gap will give ont rays of the same quality : nsmally they will not.

Table VI. Sparkine: Potentials.

\begin{tabular}{|c|c|c|c|c|c|c|}
\hline \multirow{2}{*}{\multicolumn{2}{|c|}{ Spark-gap. }} & \multicolumn{5}{|c|}{ Diameter of Balls. } \\
\hline & & Neerlle-pts. & $0.5 \mathrm{~cm}$ & $1 \mathrm{~cm}$. & $2 \mathrm{~cm}$ & ; rm. \\
\hline $\mathrm{cm}$ & inch. & $\begin{array}{l}\text { A. volts. } \\
\text { (Max.) }\end{array}$ & D.c. volts. & 1.c. volts. & 1r.c. volts. & B.C. volts. \\
\hline 0.1 & .114 & 1,0000 & 5,0001 & 5,0000 & $5,00(0)$ & 5,000 \\
\hline $01 \cdot 2$ & .118 & $2,00(1)$ & 8,000 & 8.0000 & $8,0(0)()$ & $9.0(10)$ \\
\hline $0 \cdot 3$ & $\cdot 12$ & 4.0000 & 11.0000 & 11,0000 & 11,0000 & $12,0(1) 1)$ \\
\hline 0.4 & $\cdot 16$ & 5,000 & 14,000 & 14,000 & $14,(10100$ & 15.0110 \\
\hline 0.5 & $\cdot 211$ & 6,000 & 16,0000 & 17.1700 & 17,1100 & 18,0001 \\
\hline $0 \cdot 6$ & .24 & 7,000 & 17,11001 & $2(1,1)(1)$ & $20.11011)$ & 21,000 \\
\hline 0.7 & $\cdot 28$ & 8,1100 & $18,01111)$ & $22,(1)(1)$ & 23,00101 & $24,(10) 10$ \\
\hline 0.8 & 31 & 10,1000 & 19,00110 & $24,0(1)(1)$ & 26,0010 & 27.00010 \\
\hline $11 \cdot 9$ & $\cdot 35$ & 11,0000 & 20,000 & $26,000)$ & 29,000 & 30,6000 \\
\hline 1 & .39 & 12,0000 & 21,000 & 27,000 & 31,000 & 33.1100 \\
\hline 2 & $\cdot 7 !$ & 24,000 & 24.0000 & 36,000 & 48,01110 & 57,01010 \\
\hline 3 & $\mathrm{~J} \cdot 18$ & 34,0001 & $26.0100)$ & 42,000 & 58,000 & 77.91010 \\
\hline 4 & $1 \cdot 58$ & 42,000 & 27,00010 & 45,0000 & 05.0000 & $983,0(10)$ \\
\hline 5) & $1 \cdot 97$ & 49,000 & Brush & 47.000 & 71.0001 & 10.5 .0010 \\
\hline 6 & $2 \cdot 36$ & 55,000 & discharget, & Brosh & 77,0000 & $116,(1)(1)$ \\
\hline 7 & $2 \cdot 76$ & 61.01101 & usually & discharge & $82.00(1)$ & 125,0000 \\
\hline 8 & $3 \cdot 15$ & $66,(10)(1)$ & ocenust. & usually & 87,000 & 1333.0000 \\
\hline 9 & $3 \cdot 54$ & $71,0000)$ & & ocentrs. & 91,000 & 1411,1100 \\
\hline 10 & $3 \cdot 94$ & 76,1000 & & & 95,10000 & $1+5,10000$ \\
\hline 15 & $5 \cdot 91$ & 102,000 & & & Brush & 170,11000 \\
\hline 20 & $7 \cdot 9$ & 122,000 & & & discharge & 190,0010 \\
\hline 30 & $11 \cdot 8$ & 170,000 & & & usually & \\
\hline 411 & $15 \cdot 8$ & 220,000 & & & occurs. & - \\
\hline
\end{tabular}


Table VI. gives the approximate sparking voltages in air at atmospherie pressure and room temperature. Too much relianee must not be placed on the figures, as the results of different experimenters do not agree well, probably owing to the difficulty of measuring the potential. The values for the needle-point electrodes are for alternating current of sine form, and are due to Steinmetz (Proc. Amer. Inst. Elec. Eng. 1898). For alternating currents, the striking distance is most probably governed by the maximum voltage, which is accordingly given in the table rather than the effective (root-mean-square) value $[=(\max .) / 1 \cdot 42]$.

For ball electrodes, the most recent and reliable measurements of the maximum spark-potentials for alternating eurrent ${ }^{1}$ come out about 5 per cent. smaller than those for direct current, the values for which are given in the remaining columns of the table. ${ }^{2}$ These latter results refer to smooth polished metal balls of the same size.

An inspection of the table shows that, in general, the spark passes more readily, the smaller the ball; and that short spark-gaps require proportionately more potential than long. The measurements are taken in the absence of any visible brush-diseharge, a condition essential for refinite sparking. It is better in practiee to use moderately large balls than small. as with the latter, brushdiseharge tends to occur, more especially at the negative pole: such glow is, of course, a prominent feature with needlepoint electrodes. The needle-point spark-gap often supplied with induction coils, while it enhances the apparent eapabilities of the eoil, is not suitable for measuring purposes. If unequal-sized balls are used, the smaller electrode controls the spark-gap for moderate lengths of spark: the larger ball whould be made the negative electrode.

Trowbridge ( $P . M .1898)$ found a spark-length of $200 \mathrm{cms}$. with a potential of $3,000,000$ volts. With very long sparks, the shape of the electrodes (if of moderate size) is im-

1 See Kowalski and Rappel (P.M. 1909), who employed balls up to 30 ems. diameter.

2 Based largely on the results of Algemissen (A.d.P. 1906) and Tripler (A.1.P. $1907 \overline{7})$. 
material. For instance, with a potential of 240,000 volts, Jona obtained the same sparking distance $(47$ cms.), whether a point and plate or two balls ( 2 ems. diam.) were used.

In the case of an X-ray tube, as the break-down voltage is ligher than the rumning voltage, it is doubtful what precisely either voltmeter or spark-gap affords. With a pulsating current, we need to know the shape and abruptness of the potential curve, as well as the proportion of time between the impulses, before we can estimate the effective potential (sce p. 59). It is probable, however, that, at any rate in the case of a hard tube, either instrument indicates a value not very far from the maximum potential (sce p. 98), and that the bulk of the $\mathrm{X}$ rays are generated by cathode rays with a velocity which they owe to this maximum potential rather than to a mean potential (see p. 16).

In the case of the characteristic radiations, the quality can be defined rigorously in terms of the speed of the parent cathode rays. It is found that a certain minimum voltage on the tube is required to excite a particular radiation. There is thus a critical cathode-ray velocity for each characteristic $\mathrm{X}$ ray : slower cathode rays can only cxcite independent "rays"; faster eathode rays are, within limits, increasingly effective generators of the characteristic rays, but with very high-speed rays the "independent" rarliation is once again generated.

The subject is dealt with later (p. 126), but it may here be mentioned that the critical cathode-ray speed is proportional to the atomic weight of the anticathode. Not only that, but the velocity of the secondary corpuscular rays, which such a radiation excites when it strikes matter. is equal to the velocity of the cathode rays which generated the radiation.

\section{(3) Absorption Coefficients.}

The customary way of spccifying the character of $\mathrm{X}$ rays is to measure their absorption in a sheet of ahminimm of definite thickness. Aluminium is not an ideal standard of reference, but it is chosen because it is readily procurable 
in convenient form, and, so far as we know, does not, in the majority of cases, complicate matters unduly by superposing a eharacteristic radiation.

Now it is found that if all the rays both entering and leaving a plate of material are homogeneous (that is, wholly of the same quality), then the rays are absorbed exponentially by the plate, i.e. successive similar sheets of the material absorb equal fractions of what they receive. In other words, if there is no "scattering" or transformation of the $\mathrm{X}$ rays, and if $\lambda x$ is the fraction of the intensity which is absorbed when the rays pass normally through a very thin sereen of thickness $x$ (cm.), then for a plate of thickness $d$ (cms.).

$$
I=I_{0} \cdot e^{-\lambda d},
$$

in which $I_{0}$ is the intensity of the beam when it enters, and $I$ that of the beam when it leares the sereen. $e(=2 \cdot 72)$ is the base of the hyperbolic system of logarithms. $\lambda$ is termed the linear absorption coefficient. ${ }^{1}$

Tt follows that $\lambda=\frac{2 \cdot 3}{d}\left(\log I_{0}-\log I\right)$; the logarithms are to base 10. If in a set of observations with homogeneous rays, $\log I$ is plotted as ordinate against $d$, the graph is a straight line and $\lambda$ is $2 \cdot 3$ times the slope of the line.

The logarithmic curve of absorption for heterogeneous rays. such as are given out by an ordinary $\mathrm{X}$-ray bulb, is not a straight line, but a eurve which is steeper for thin screens than for thick. The general shape is like the heavy curve in Fig. 63.

A large value of $\lambda$ corresponds to easily absorbed rays. and a small one to very penetrating rays. $\lambda$ also varies with the nature of the absorbing sereen, so that it is necessary to specify the material used. For medical purposes, it has recently been suggested that water should be chosen as the standard absorbing medium, since the absorptive power of water agrees closcly with that of animal tissue.

It may be notieed that $I / \lambda$ is the distance to which the

1 'The precise physieal interpretation of an exponential law of absorption is not so simple is its compact and convenient mathematical expression womlel head one to stypose. 
lays penetrate before their intensity is reduced to $1 / e$ of the original amount. Some workers prefer to think in terms of the thickness, $D$, which rednees the intensity to half value. $D$ is connected with $\lambda$ by the expression $J=0.69 \lambda$. It follows that, if after traversing 1 cint of a substance, the intensity is refueed by one-half, $\lambda=0.696 \mathrm{~cm}^{-1}$. A notion of the order of values of $\lambda$ may be got from the fact that an X-ray beam of average hardness has a $\lambda$ in $\mathrm{Al}$ of about 10 . $\lambda$ for fatty tissue varies from about 0.4 for hard rays to 0.7 for medium rays. A table comnecting $I_{0} / L$ and $\lambda d$ is given on p. 23:2.

A more fundamentally important constant is obtained by dividing the absorption coefficient $(\lambda)$ by the density $(\rho)$ of the absorbing screen. 'This quantity, $\lambda / \rho$-usually called the mass-absorption coefficient-gives a measure of the absorption per unit mass of the sereen for a normally incictent pencil of rays of mit cross section. Since it is mass alone that affects absorption, at any rate as determined by the usual nethods of measurement, it is more profitable to use masscoefficients than linear-coefficients.

If, as was at one time supposed, the absorbing power's of different materials were truly proportional to their densities, then for the same rays $\lambda / \rho$ would be a constant, no matter what the substance used as sereen. In point of fact, dense substances are a good deal more absorptive, mass for mass, than light, and $\lambda / \rho$ inereases rapidly with the atomic weight of the screen. ${ }^{2}$ The increase is more noticeable with hard rays than with soft (see also p. 132).

Benoist (J.d.P. 1901$)$ was the first to examine systematically the absolption of a beam of ordinary heterogencous $X$ rays in various absorbing elements. For our purposes it is convenient to translate his results into quantities proportional to absorption cocfficients; and, when this is clone,

1 For the standard material, aluminium, $\rho=2 \cdot 7$.

2 A similar relation holds for the soft $\gamma$ rays from raclium. For hard $\gamma$ rays, a density law holds, and $\lambda / p$ is constant, except for the heaviest metals. which are a little more absorbent; In other words, these very penetrating rays ahmost entirely ignore atomie structure. For hard $\gamma$ rays, $\lambda \rho=004$ for all absorbing substances with an atomie weight less than 100 . 
lig. 54 is the result. It will be noticed that $\lambda / \rho$ increases steadily with atomic weight both for hard and soft $\mathrm{X}$ rays. For example, with hard rays, lead is twenty-five, silver

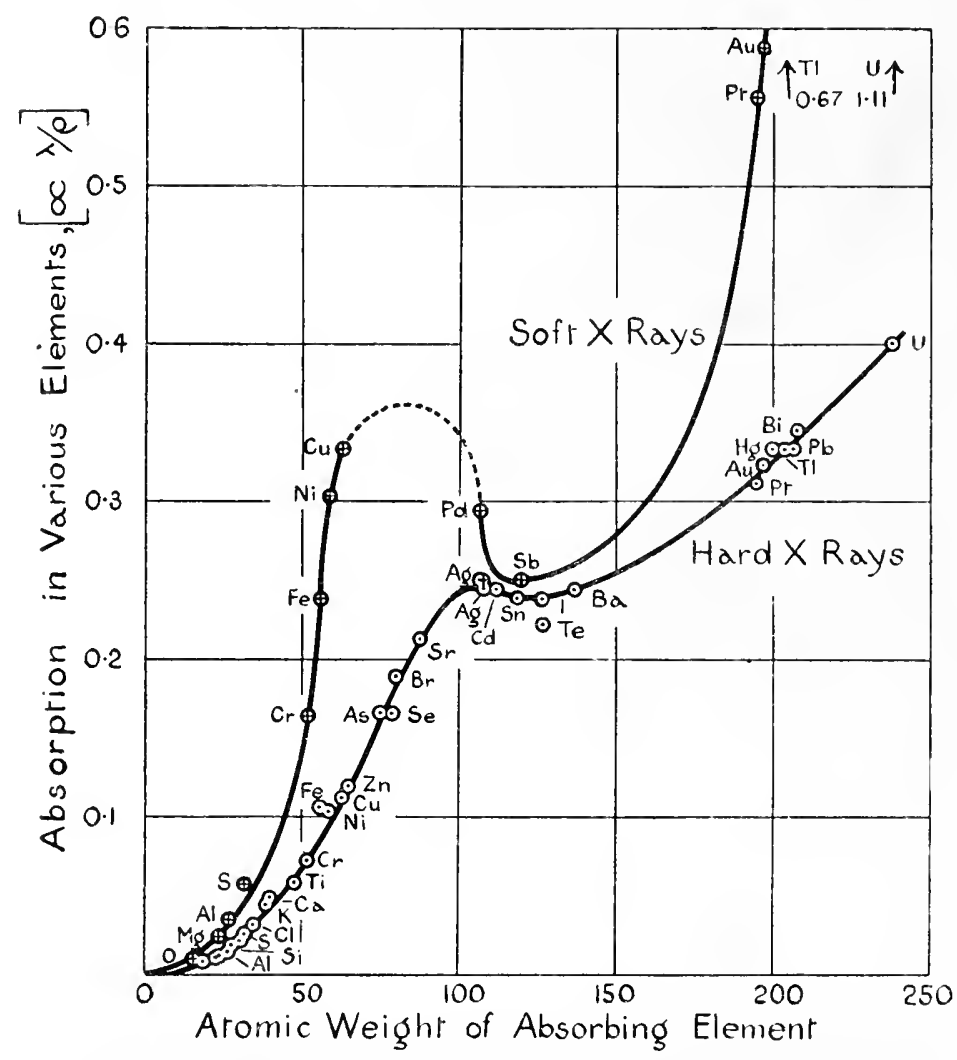

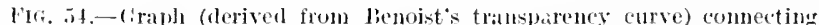
absorption with atomio: wejght and displaying a region of selective absorption.

eighteen, and copper eight times as absorbent as an equal mass of aluminium.

There is a region of selective absorption round and about silver: the two beams of $\mathrm{X}$ rays: one hard, the other soft: are, moreover, absorbed almost equally by the silver group of elements. The explanation of this, as will be seen later (1). 135), is bound up with the amount of seendary radiation that silver enits under ordinary conditions. 


\section{Absorption Coefficients of Heterogeneous Rays.}

But it may be urged that although characteristic rays have a perfectly definite $\lambda$, the $\mathbf{X}$ rays from a coil-driven bulb are so very far from being homogeneous that the absorption coefficients as above defined are not particularly useful in X-ray practice. However, it should be pointed out that considerable guidance can be obtained from a knowledge of even an average value of $\lambda$, calculated thongh it may be, on loose assumptions. And, moreover, while it is true that the $\mathrm{X}$ rays from a bulb are in general very heterogeneous, they become less so as the spark-gap is increased. ${ }^{1}$ The rays from a bulb with a spark-gip of some centimetres, which are transmitted by an aluminium screen 2 mms. or more thick, are rery fairly homogeneous.

Eve and Day (P.M. 1912) have measured at various ranges (up to 100 metres) the absorption coefficients in air of the rays from X-ray bilbs of different degrees of hardness. Table VII. contains some of their results.

Table Vil. Absorption Coefficients in Air.

\begin{tabular}{|c|c|c|c|c|c|c|}
\hline \multirow{3}{*}{$\begin{array}{l}\text { Alternative } \\
\text { Spark-galp. }\end{array}$} & \multicolumn{6}{|c|}{ l)istances from X-ray Bulb. } \\
\hline & \multicolumn{2}{|c|}{ t to 10 metres. } & \multicolumn{2}{|c|}{20 to 40 metres. } & \multicolumn{2}{|c|}{40 to 60 metres. } \\
\hline & $x$ & $\lambda / \rho$ & $\lambda$ & $\lambda / \rho$ & $\lambda$ & $\lambda / \rho$ \\
\hline $\begin{array}{l}1 \cdot 5 \text { to } 5 \text { cm. } \\
\text { (soft bulb) }\end{array}$ & $\left\{\begin{array}{c}0 \cdot 0010 \\
\text { to } \\
0 \cdot 0018\end{array}\right.$ & $\left\{\begin{array}{l}0 \cdot 8 \\
\text { to } \\
1 \cdot 4\end{array}\right.$ & - & - & - & - \\
\hline $\begin{array}{l}11 \text { cm. (med- } \\
\text { ium buth) - } \\
30 \text { cm. (hard }\end{array}$ & $0 .(1) 0(0) 40$ & 0.32 & 0.000040 & $11 \cdot 32$ & $1) \cdot(1)(1)-2 ! 1$ & 11.23 \\
\hline bulb) - & 0.010029 & 0.23 & 0.000027 & $0 \cdot 21$ & $0.0(0014(?)$ & () $11(?)$ \\
\hline
\end{tabular}

Eve and Day note that $\lambda=0.0004$ is a good value for radiographic work; but rays whose $\lambda$ is 0.0003 are too penetrating for such a purpose. The above ralues may be compared with those of Chadwick (P.P.S. 1912) for the

1 'The explanation of this is probably bound up with the simpler eharacter' of the magnetic spectrum of the cathode rays at low pressures (see p. 16). 
Ra $\gamma$ rays when absorbed hy air. His values of $\lambda$ for air are 0.000062 and $0.000059 \mathrm{~cm}^{-1}$ in the case of rays which have previously traversed $3 \mathrm{mms}$. and $10 \mathrm{mms}$. of lead respectively.

The absorption coefficients for the various characteristic radiations are given on pp. 115 and 132.

\section{(4) The Benoist Penetrometer.}

Among medical men Benoist's radiochromometer or penetrometer enjoys extensive use as a measurer of hardness. It consists of a thin silver dise $0.11 \mathrm{~mm}$. thick, surrounded by twelve numbered aluminium sectors from 1 to $12 \mathrm{mms}$. thick (Fig. 55). The $\mathrm{X}$ rays are sent through the instru-

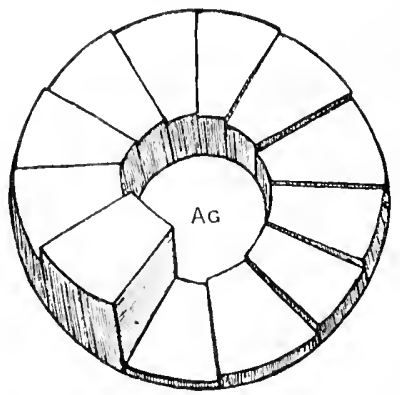

Fli. 55,-- lienoist's penetrometer. ment, and the observations consist merely in matching on a fluorescent screen or photographie plate the image cast by the silver disc against the images of the aluminium plates: the thickness of the matching sector increases with the hardness of the rays.' Thus "Benoist 4 to $5 "$ is a good average hardness for curative work, while for general racliography No. 6 on Benoist's scale is useful. A notion of the discharge potential across a tube may be got from the very rough relation that the voltage is from 6,000 to 10,000 times the Benoist reading of the X rays.

Salomonson, following the principle of the "light-wedges" employed in photometry, uses two aluminium wedges, the one sliding orer the other. A plate of aluminium of variable thickness down to $\frac{1}{0} \pi \mathrm{mm}$. is thus obtainable. a match being made against a silver plate $0.11 \mathrm{~mm}$. thick. Other hardness measurers by Wehnelt (who also uses an aluminium

${ }^{1}$ Benoist (C.R. 1902) based the theory of his instrument on the curves displayed in Fig. 54. which go to show that while the transparency of aluminium alters a good deal with the quality of the $\mathrm{X}$ rays, silver is ahmost equally dransparent to hoth hard and soft rays. As Table XI. shows. the assumption of a constant transparency for silver is by no means correct. 
wedge), Walter (a sequence of Pt dises), and Batrer (an electrostatic voltmeter) are in common wse. The corresponding hardness-numbers are all much the same as Benoist is, except those of Wehnelt, which are 50 per cent. bigger for the same quality of rays. Christen has recently introduced a "half-value " meter, with water as the ultimate standard of absorption.

\section{The "ENergetirs" OF an X-RaY Bulb.}

When a stream of eathode rays strikes an anticathode, the different rays suffer a variety of fates. By far the greater number merely fritter away their energy mutil it becomes too small to render them distinguishable: the heat generated at the anticathode is ample proof that the energy of the eathode rays is mostly dissipated into heat.

The remaining cathode rays either suffer conversion into X rays or are "reflected " by the anticathode in all directions against the glass walls of the tube with velocities which may be anything up to the original speed of the cathode rays. There is good evidence for believing that a cathode ray can pass through many atoms without being in any way deflected or transformed. The fate of the cathode ray is to some extent dependent on the material of the anticathode. Tho heavier the atom the more capable it is of swinging round a cathode ray which endearours to pass it. Not only that, but the chances of the generation of $\mathrm{X}$ rays are also greater with the heavy atom. The density of the anticathode is of no consequence from this point of view; it is only atomic weight which matters, for the cathode ray is never under the influence of more than one atom at a time.

It seems certain from Whiddington's experiments (1). 1:25) that $X$ rays are not formed from cathode rays unless the speed of the latter exceeds a certain critical value-a value which increases with the atomic weight of the anticathode. It does not necessarily follow that even if it has the requisite speed, a cathocke ray will ultimately come into suitable conflict with some atom and so generate an $\mathrm{X}$ ray. In 
faet, the chances would appear to be against it, for the efficiency of the present methods of generation of $\mathrm{X}$ rays is very low: the $\mathbf{X}$ ray is merely a small bye-product in the energy transformations of a Röntgen tube.

Wien, Angerer, and Carter (A.d.P. 1905 and 1906) have worked independently at the subject. They agree that the ratio of the energy of the $X$ rays to that of the exeiting (heterogeneous) cathode rays is of the order of $\frac{7}{100}$; Carter found that the efficiency increases with the hardness (is, in fact, proportional to the voltage on the tube), is independent of the current, but increases with the atomic weight of the anticathode. This value of the efficiency is not inconsistent with the estimate of Eve and Day (P.M. 1912), who remark that, of the energy supplied to an ordinary X-ray bulb, not more than about 1 in 20,000 is contained in the $X$ rays as measured by their ionising ability.

The efficiency of a soft $\mathrm{b}_{\mathrm{s}}$ bulb is probably even less than this, for more energy is converted into heat with fow-speed cathode rays.

\section{Beatty's Experiments.}

Beatty (P.R.S. Nov. 1913) has recently evaluated the energy of $\mathbf{X}$ rays in terms of the velocity of the parent cathode rays and of the atomic weight of the anticathode. Homogeneous rays of known velocity were sifted from a cathode stream by a magnetic-spectrum method, and feil upon one of a number of antieathodes affixed to a sliding tray. The $\mathrm{X}$ rays so produced passed through a sheet of Al foil $0.0002 \mathrm{~cm}$. thick, and were completely absorbed in an ionisation chamber consisting of a eylincler over a metre long filled with the vapour of methyl iodide. The resulting (total) ionisation was taken as measuring the energy of the $\mathrm{X}$ rays. The ionisation eurrent was balaneed against a fraction taken from the primary eathode-ray current by a variable shunt, so that a null defleetion was obtained in the electroseope (see p. 128). Thus reliable readings could be obtained even when the eathode-ray current was very irregular.

The ionisation which the cathode rays would have pro- 
dueed in methyl iodide vapour was deduced from the work of Glasson (p.12) and Whiddington (p. 10) on the passage of cathode rays in air.

The result finally established by Beatty was

$$
\begin{aligned}
& E_{X} \\
& E_{C}
\end{aligned}=2 \cdot 54 \times 10^{-4} A \beta^{2},
$$

where $\quad E_{X}=$ energy of the $\mathrm{X}$ rays,

$E_{C}=$ energy of the parent cathode rays,

$A=$ atomic weight of anticathode,

$\beta=$ velocity of the cathode rays expressed as a fraction of the velocity of light (i.e. $3 \times 10^{10}$ cms./sec.).

Thus, for an anticathode of platinum (with an atomic weight of 195) and a bulb of medium hardness, with cathode rays of speed, say $7.5 \times 10^{9} \mathrm{cms}$. $/ \mathrm{sec}, 3 \frac{1}{2} 0$ of the cathoderay energy reappears as $\mathrm{X}$ rays. With slower cathode rays, or an anticathode of lower atomic weight, the fraction would be smaller.

These results refer only to the "independent" or primary $X$ rays (p. 127). When characteristic rays are excited, their effects have to be added to those given by the above formula. A formula comprising both classes of radiation has not yet been obtained. 


\section{C'HAP'TER TX.}

SECONDARY RAIS'.

Wuen X rays strike at substanee, three classes of radiation are given off in general: scattered X rays, characteristic I rays, and corpuscular rays. Of these, the first two are I rays, the third negatively charged electrons.

The proportions of the three classes depend both on the substance and on the quality of the primary rays. With materials of low atomic weight, by far the greater proportion of the $\mathrm{X}$ rays, if of a penetrating type, is merely scattered. With the elements of the chromium-zinc group, most of the emitted radiation is charaeteristie. The heavy elements give off both scattered and characteristic rays. As to the corpuscular radiation, there is in general a more copious emission, mass for mass, from the elements of high atomic weight.

We may consider in some detail cach of these secondary radiations.

\section{SUATERED X RaYs.}

All substances, when exposed to a beam of X rays, themselves give out $X$ rays, some of which are identical with the primary rays in quality, and can, in fact, be tonvenicntly regarded as so many unchanged primary rays which have been merely "seattered" or deviated in direction by the substance. Such scattered radiation may be readily perceived experimentally by exposing a body of low density to $\mathrm{X}$ rays and viewing it with a fluorescent sereen which is itself shielded from the dircet action of the rays from the bulb. 


\section{Scattering produced by Different Elements.}

Scattering occurs at all depths, and increases in amount with the thickness traversed by the rays.

The elements of low atomic weight (up to sulphur) scatter very much the same, mass for mass; but the heavice clements seatter proportionally more than the light elements, though. owing to the greater absorbing power of the denser elements. it may happen that less of the scattered radiation actually escapes. With elements of quite low atomic weight, such as carbon, by far the greater proportion of the emerging rays is merely scattered radiation, more especially if the primary rays are of a penetrating type. The seattered radiation from aluminium is a good deal less in amount than that from vegetable or animal matter, in which eases it may amount to 90 per cent. or more.

With the copper group of elements, the scattered radiation is so small in amount (sometimes less than wo of the total radiation) that it is, for most purposes, negligible.

Barkla has introduced a coefficient of scattering. $s$, which is clefined similarly to the absorption eofficient $\lambda$ (p. 100). For an absorbing sereen of low atomic weight, $s$ is proportional to the density $\rho$, of the scattering substance: and the mass-seattering coeffieient, $s / \rho$, has a constant value of $0 \cdot 2$, according to Barkla. no matter what the quality of the X rays. Crowther (P.R.S. 1912) has found, however, that the scattering coefficient increases considerably with the atomic weight ${ }^{i}$; anct that while, for example, s/p (as determined by him ) is $0 \cdot 27$ for filter paper and $0 \cdot 28$ for aluminimm. it increases to 0.9 for copper and nickel, and 1.5 for tin.

$s / \lambda$, the fraction of the absorption coefficient due to scattering, becomes important when hard rays are sent through light elements. In those instances where scattering accompanies absorption, it is necessary to subtract the scattering term from the total absorption to obtain the true absorption. For example, in the ease of the absorption of a homogeneous rarliation, the apparent $\lambda / \rho$ has to be amended to $(\lambda-s) / \rho$ to give the true mass-absorption coefficient. 


\section{Distribution of Scattered X Rays.}

The scattered $X$ rays are distributed in all directions, though not uniformly; more are to be found in the backward and forward rlirections of the original beam than at right angles.

Barkla and Ayres (P.M. 1911) and Owen (P.C.P.S. 1911) have experimentally verified, over a considerable angular

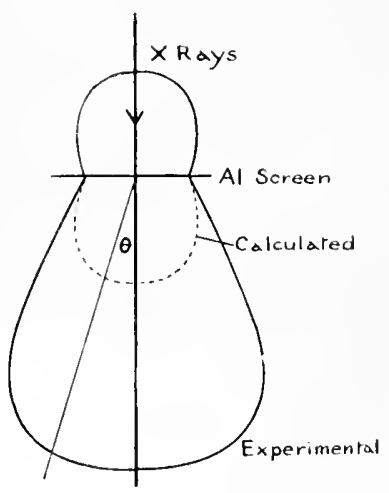

FIG. sf.-Distribution of scattered $\mathrm{X}$ rays from an aluninium screen. range, the approximate truth of the distribution formula derived from Sir .J. J. Thomson's theory of scattering :

$$
I_{\theta}=I_{\pi / 2}\left(1+\cos ^{2} \theta\right),
$$

where $I_{\theta}$ is the intensity of the seattered radiation along the direction angle $\theta$ to the primary beam. Thus the "fore and aft" intensity" is roughly twice that at right angles. Experiment shows, however, that the expression is inadequate for small values of $\theta$-the calculated values are too smalland that, moreover, the forward intensity always exceeds the backward. sometimes largely. Fig. 56 shows the distribution obtained by (rowther (P.R.S. 1912) in the case of an aluminium plate.

The seattering of $\mathrm{X}$ rays bears a strong resemblance to the seattering of light by fog (see p. 207).

\section{Polarisation of Scattered X Rays.}

In 1905. Barkla (P.T.) found that the seattered $\mathrm{X}$ rays from a plate bombarded by primary $\mathrm{X}$ rays do not distribute themselves quite uniformly in a plane at right angles to the line of flight of the primary rays, but tend to congregate in one particular plane passing through the line of flight of the primary rays. This plane of maximum intensity is at right angles to the path of the cathode rays in the generating X-ray tube. The intensity of the seattered rays falls off on cither side of this plane, and reaches a minimum in a 
perpendicular plane (sec Fig. 57). Thus, if $\mathrm{X}$ rays were visible, an observer, looking along the beam of primary $X$ rays at the plate, would notice that the seattered rays would be brighter in two opposite quadrants than in the intervening quadrants.

The distribution of the scattered rays thus reveals a peculiarity in the primary rays; evidently they also preclominate in one plane, and hence may be said to be polarised. If the seattered rays themselves are allowed to fall on a second radiator, the asymmetry or "polarisation " is more complete in the resulting twice-scattered rays.

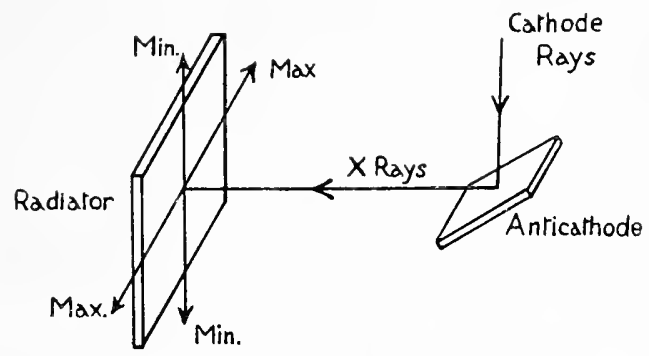

FIG. 57.-To explain polarisation of $\mathrm{X}$ rays.

Prof. Barkla measured his rays by an ionisation method. His results have been confirmed and extended by Haga (A.d.P. 1907), Bassler (A.d.P. 1909). Herweg (A.d.P. 1909), and Vegard (P.R.S. 1910), some of whom employed photographic methods.

In experimental work, it is convenient to use radiators which do not possess a marked characteristic radiation. The characteristic radiations from materials of very low or very high atomic weight are either very soft or absent altogether; and so carbon, paraffin wax, aluminium. lead, and metals of the platinum group are ordinarily to be preferred to metals of the chromium-zine group, which possess pronounced characteristic radiations. The characteristic radiations are not polarised, at least not to any appreciable extent, and their presence only serves to mask the results.

The polarisation in the case of carbon or wax amounts 
to about 10 per cent., i.e. the maximum intensity is about ?on times the minimum. By filtering out the soft rays from the primary beam by the use of a suitable screen, the polarisation can be doubled. Hardening the primary X-ray tube, howerer, apparently diminishes the effect.

Ham (P.R. 1910) has also proved that primary $\mathrm{X}$ rays are polarised, by direct measurement of the intensity in different directions from an X-ray bulb. He found that the intensity reaches a maximum in a plane through the anticathode at right angles to the cathode stream. The intensity decreases symmetrieally on either side of the maximum. Ham used a lead anticathode, and Miller (P.R. 1911) confirmed his results with a silver target. (Cf. p. 45.)

\section{Characteristic or "Monochromatid" $\mathrm{X}$ Rays.}

The rliscovery by Barkla and Sadler in 1908 (P.M.) of the various characteristic radiations ranks as of the first importanee. From an experimental point of view, the simplification brought about by the use of these radiations can hardly be overestimated. An ordinary X-ray tubc. generates a mixture of rays of many qualities, and the interpretation of the results obtained with such heterogeneous rays is correspondingly difficult. But by allowing $X$ rays to fall on different metals-copper', silver. iron, platinum. etc.-characteristic $X$ rays of uniform quality are given off which comprise a wide range of qualities. The quality of each of these radiations depends on the metal alone. and not at all on the exciting $X$ rays. The only proviso is that the exciting rays shall be harder than the characteristic radiation: if the primary rays are too soft. no characteristic radiation is generated.

When precantions are taken to eliminate the effects of the seattered and corpuscular rays. it is found that all the characteristic radiations are homogeneous and, unlike the scattered radiation, are uniformly distributed round the ladiator. The penetrating power of a characteristic radiation increases with the atomic weight of the element from 
which it is emitted, so that the characteristic radiation of any atom can exeite the corresponding radiation of a lighter atom, but not that of a heavier atom.

\section{$K$ and $L$ Series of Radiations.}

Experiment has shown that some elements give out at least two characteristic radiations under suitable conditions.

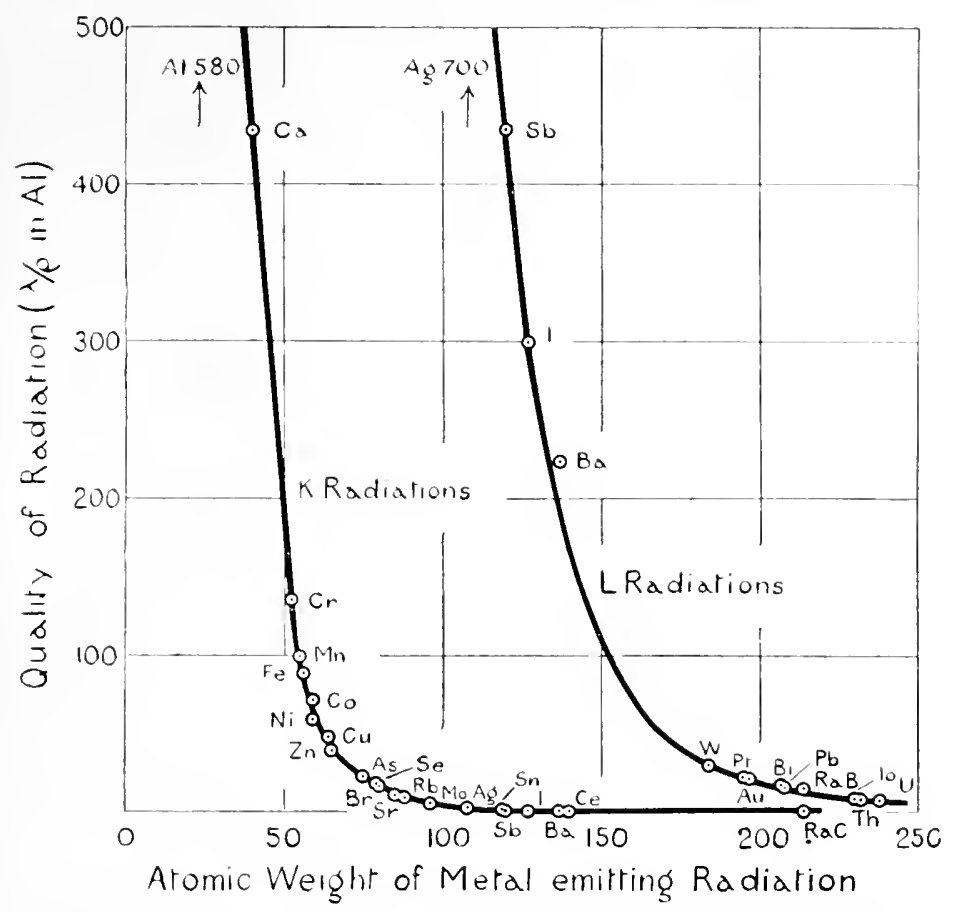

FIG. 58.- Relation between mass-absorption coeflicient (in Al) of a chacacteristic radiation and atomic weight of metal enitting radiation. The characteristic $\gamma$ rays are included (see 1.118 ).

Barkla has called these two types, series $K$ and series $L$ fluorescent radiations. For each metal, the $K$ radiation is something like 300 times more penetrating than the $L$ radiation. Both radiations beeome harder as the atomic weight of the radiator increases. With bodies of high atomic weight, the rays from an ordinary X-ray tube can only 
excite the soft eharacteristic radiation $L$. From other substances, radiation $K$ alone has been rletected; and from many light elements, neither radiation, up to the present. There is reason to believe, however, that all the elements give off both radiations, as well as other types not yet investigated.

At the moment, series $L$ Röntgen radiations have been got from the elements silver to uranium, comprising atomic weights from 108 to 239 . It may here be remarked that if it is safe to extrapolate the Chapman formula (p. 116), it follows that no element with an atomic weight less than 48 ean have an $L$ radiation. Series $K$ Röntgen radiations have been obtained over a range of clements from chromium to cerium (atomic weights 52 to 140).

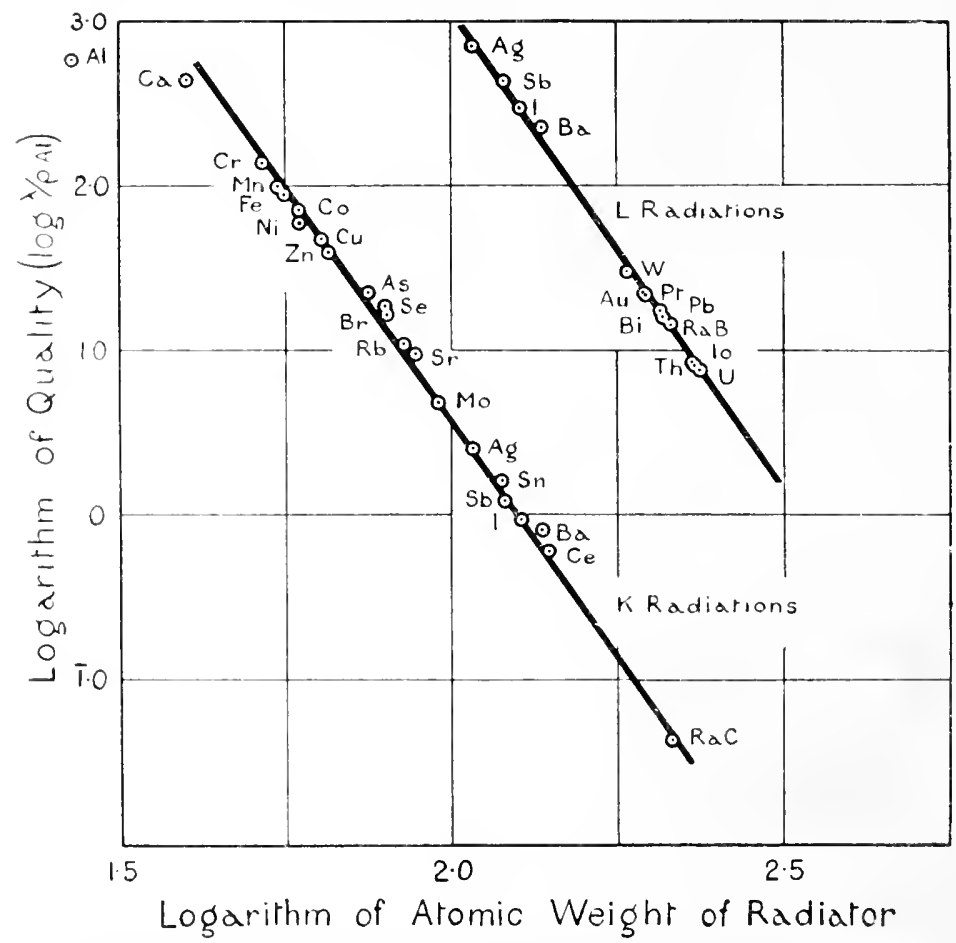

fia. 59.-Ciraph sisplaying Owen's ith power relation between the log of

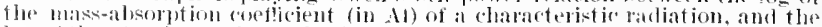

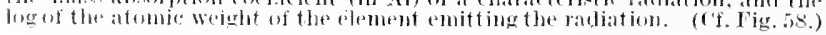


Owen's 5th-power Law connecting Quality of Characteristic Radiation with Atomic Weight of Emitting Metal.

In Table VIII, are given the qualities of the various eharacteristic radiations expressed as mass-absorption eoeffieients in aluminimm, together with the thickness of aluminium required to halve their intensity. Fig. 5s displays graphically the relation between the quality of the radiation and the atomic weight of the emitting metal.

Table Vill. Mass-Absorption Coefficients $(\lambda / \rho)$ in Aluminium of Characteristic Radiations.

$\lambda$ is defined by $I=I_{0} e^{-\lambda d}$ (see p. 100); $\rho$ is the density of aluminimu $(2 \cdot 7) ; d_{I / 2}$ is the thickness of aluminium required to reduce the radiation by one-half, and is calculated from the formula $d=\frac{0.2567}{\lambda / p}$, which is derived from the above. The corresponding thickness of animal tissue (or of water) is about ten times that of Al. The vahut: of $\lambda / p$ are due chiefly to Barkla, Sadler, Nicol, and Chapman.

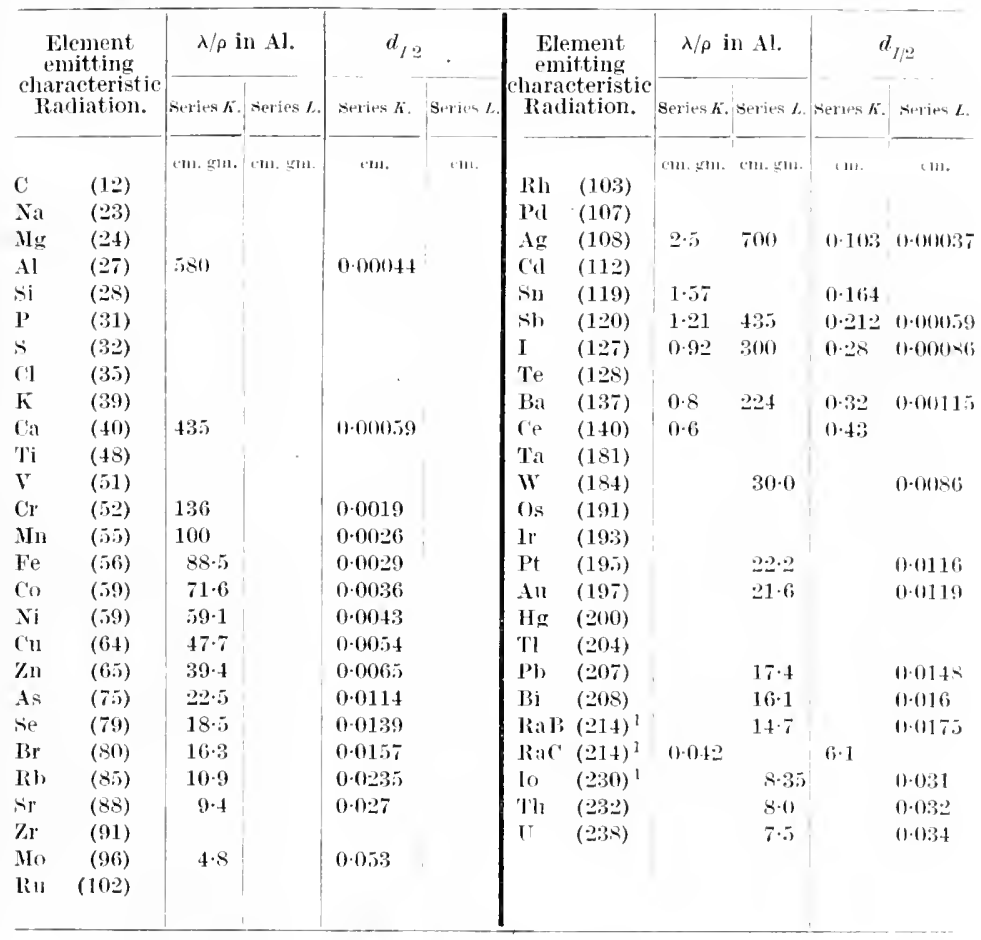

$1 \lambda$ rays (see p. 118). 
The general resemblance between the $K$ and $L$ curves will be remarked. If the logarithms of both coordinates of Fig. 58 are plotted, the result is two straight lines (Fig. 59), the slope of which indicates that the penetrability is roughly proportional to the 5th power of the atomic weight of the radiator. 'This result was first establisherl by E. A. Owen (P.R.S. 1912$)^{1}$ from his experiments on the absorption of characteristic rays in light gases (sce p. 136). If similar logarithmic curves were plotted for any other absorber than aluminium, the resulting straight lines would be parallel to the aluminium lines, except in the regions of selective absorption (see p. 129).

Whatever the physical significance of Owen's remarkable relation may prove to be, there is no doubt as to its utility in inferring the absorption coefficients of radiations as yet undiscovered.

\section{Relation between $K$ and $L$ Series.}

The characteristie radiations obviously correspond to the lines in an optical spectrum: and the well-known series relations between the wave-lengths of associated spectral lines suggested the probability of some such relation between the hard $(K)$ and soft $(L)$ series of $\mathrm{X}$ radiations. Whiddington $(N .1911)$ was able to derive a simple empirical relation connecting the penetrating powers of the two radiations with the atomic weight. If an element of atomic reight $A_{L}$ possesses a soft $(L)$ radiation of a certain hardness. then the atomic weight $\left(A_{K}\right)$ of the partieular element whose $K$ rarliation is of the same hardness, is given by

$$
A_{K}=\frac{1}{2}\left(A_{L}-50\right) \text {. }
$$

Chapman (P.R.S. 1912). having investigated the $L$ radiations from the metals of high atomic weight, derived the expresision

$$
A_{K}=! ?:\left(A_{L}-48\right) \text {, }
$$

which fits in mole elosely with the observed results.

As an example of the applieation of this formula. bismuth with an atomic weight of 208 is found to have a soft radiation

$$
\text { 'See also Kaufuamn (P. Z. 1913). }
$$


Which is of the same penctrating power as the hatd radiation from bromine (with an atomic weight of $\left.80\left\lfloor=\frac{1}{2}(208-48)\right\rfloor\right)$.

\section{Characteristic Radiations from the Heavy Elements.}

With clements of high atomic weight, the scattered radiation may be so excessive as to mask or eren swamp the characteristic rabliation. ('hapman (P.R.S. 1912), in an investigation of the characteristic rays of the heavy metals (from tungsten and platinum to uranium), attacked the difficulty by choosing an exceedingly penetrating beam of $\mathrm{X}$ rays, so that the seattered radiation was very much harker than the eharacteristic radiation. The heterogeneous mixture of characteristic radiation and the superposed seattered radiation was examined in the usual way by a series of aluminium absorption-sereens of increasing thickness, the

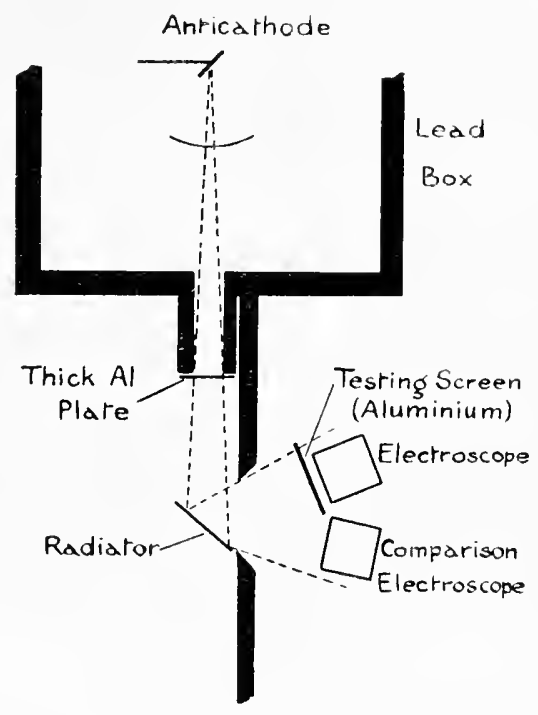

1it. 60.-Chapman's apparatus for investigatinf the characteristic radiations of the heary metals. result being gradually to remove the characteristic radiation. Ultimately, the residual rays consisted almost wholly of seattered radiation; its amount was thus revealed, and could be applied as a correction to the earlier observations witl the thinner sereens. In this way, the absorption curve of the characteristic radiation was ascertained; it revealed the homogeneity eommon to all such radiations.

Chapman (whose apparatus is shown in Fig. 60) worked with very thin radiators, and by so doing minimised the seattered radiation. For the homogeneous radiation, being soft, emerges only from a small depth: if this thickness is exceeded the result is merely to increase the proportion of 
scattered radiation which is able to emerge from deeper layers.

\section{Radiations other than $K$ and $L$.}

It has long been suspected that the $K$ and $L$ radiations are not, by any means, the only homogeneous radiations that an element can emit; and recently, evidence of the truth of this has been forthcoming. Bragg (P.R.S. 1913), in the course of his erystal-reflection experiments (see p. 189), has shown that, for instance, platinum gives out at least three homogeneous components, having $\lambda / \rho$ in aluminium equal to $35 \cdot 5,23 \cdot 7$, and (approx.) 11 respectively. Moseley and Darwin (P.M. 1913) similarly found for platinum, values $34,22,19$, and 16 , as well as a fifth weaker component. The second of these tallies with the $I$. radiation $(\lambda / \rho=2 \cdot 2 \cdot)$ from platinum.

In more recent work (pp. 198-201) Moseley and Bragg have obtained similar results for a variety of metals; and Laub (P.Z. Oct. 1913) has described experiments dealing with what he calls the " $I$ " radiations, of which $\lambda / \rho_{A 1}$ in the case of the iron radiation is $43 \cdot 9$, copper $23 \cdot 8$, and zine $18 \cdot 5$.

\section{Characteristic $\gamma$ Radiations from Radioactive Elements.}

Rutherford has recently brought forward evidence that the many and various groups of homogeneous $\gamma$ rays which radium emits can be regarded as so many characteristic $\mathrm{X}$ radiations produced by the expulsion of $\beta$ particles. Some of these groups correspond to the $K$ and $L$ radiations, others are much harder, and others, yet again, are softer. For example, the $\gamma$ rays from RaC are homogeneous and have a value of $\lambda / \rho$ in $\mathrm{Al}=0 \cdot 0424$, which finds a place among the $K$ series corresponding to the atomic weight, 214, of RaC. Again, Rutherford and Richardson (P.M. 1913) have shown that among the various groups of $\gamma$ pays from RaB are three which have values of $\lambda / \rho_{A 1}=85,14 \cdot 7$, and $0 \cdot 188$, the second of which appears to be the $L$ radiation for an atomic weight of 214 . Further, Chadwick and Russell (P.R.S. 191:) found that among the $\gamma$ rays from ionium (atomic weight 230) are homogeneous components having 
$\lambda / p_{A 1}=400,8.35$, and 0.15 respectively. The second of these corresponds to the $L$ series for a metal with an atomic weight of $2: 30$. A summary of the various characteristic $\gamma$ lays is given on p. 234 .

Ineidentally, we may record Gray's observation (P.R.S. 1912) that the $\gamma$ rays of RaE are capable of exciting the $K$ radiations of a number of metals including silver, lead, and barium.

\section{Very soft X Rays.}

Ordinary $X$ rays are usually produced by potentials of between say 10,000 to 100,000 volts or more, but it is possible to generate $\mathrm{X}$ rays with much lower voltages. Such $\mathrm{X}$ rays are soft and have only a short range in air, but they have much the same general properties as harder ray's.

Dember in 1911 gradually increased, by means of an electric field, the speed of the photo-electrons liberated by ultra-violet light, and found that they were capable of exciting $\mathrm{X}$ rays from a platinum antieathode when the speed reached that equivalent to $\mathbf{2 5 0}$ volts. From more recent work (D.P.G.V. July 1913) Dember lowers this voltage to $18 \cdot 7$, and ealeulates that the $\mathrm{X}$ rays produced have a wave-length of $7 \times 10^{-6} \mathrm{em}$, whieh is just beyond the ultra-violet.

Seitz (P.Z. 1912) got X rays from Pt with roltages ranging from 400 to 900 volts. Wehnelt and Trinkle (Sitz. Phys. Med. Soc. Erlangen, 37, 1905) generated soft $\mathrm{X}$ rays by the use of slow cathode rays from hot-lime cathodes (p. 8) exeited by voltages of from 400 to 1000 ; while Whiddington (P.C.P.S. 1912), using similar means and potentials from 130 to 220 volts, was able to detect the $\mathrm{X}$ rays from the residual gas in the discharge tube.

\section{Characteristic Light Rays.}

When a variety of qualities of $\mathrm{X}$ rays is allowed to penetrate a substance, it is found that the absorption beeomes abnormally large for the particular qualities of ray which are capable of exeiting the characteristic radiations of the substance (see p. 129). Such selectiveabsorption is accompanied by a large inerease in the eorpusenlar emission. This 
selective $\mathrm{X}$-ray effect is on all fours with the selective photoelectric effeet discovered by Pohl and Pringsheim (D.P.G.V. 1911 and 1912) in the case of ultra-violet light. They have ascertained that the emission of electrons produced by the impact of ultra-violet light on metals reaches a maximum for a particular wave-length of the light: the positions of these "absorption bands" for the alkali metals are approximately as follows:

\begin{tabular}{ll}
\multicolumn{2}{c}{ W'ave-length. } \\
$\mathrm{Li}$ & 2800 A.U. \\
$\mathrm{Na}$ & 3400 \\
$\mathrm{~K}$ & 4400 \\
$\mathrm{~Pb}$ & 4800
\end{tabular}

Thus these several ultra-violet radiations may be regarded as soft characteristic $X$ rays of the different metals.

It is worth while adding the remark here that Pohl and Pringsheim have sueceeded in earrying the photoelectric effect well into the infra-red $(10,000$ A.U.).

Characteristic X Rays are independent of Chemical Combination.

Chapman and Guest (P.C.P.S. 1911) showed that the intensity of the characteristic $\mathrm{X}$ radiation from a metal was the same, no matter whether the metal was combined or not. For example, a given weight of tin continued to give the same quantity of characteristic tin rays after it was eonverted into the nitrate. Thus, in common with all X-ray phenomena, the effect is a purely atomic one.

Chapman (P.M. 1911) found further that the vapours of methyl iodide and ethyl bromide gave out strong radiations oharacteristic of jodine and bromine respectively when struck by hard $\mathrm{X}$ rays.

Glasson (P.C.P.S. 1!10) noticed that the quality of the characteristic radiation from, say, iron was independent of whether the iron was free or combined; in the latter case, neither the valency nor the position of the ion was material, e.g. FeSO $)_{4} \mathrm{Fe}_{3} \mathrm{O}_{4}, \mathrm{Fe}_{2} \mathrm{O}_{3}, \mathrm{~K}_{4} \mathrm{Fe}(\mathrm{CN})_{6}$, all exeited iron rays of the same quality.

\footnotetext{
'One a.v. (Angström Unit) is $10^{-5} \mathrm{~cm}$.
} 


\section{The Direct Gereration of Characteristic Rays.}

By the ordinary "reflection" method, using a radiator at $45^{\circ}$ to the primary beam of $X$ rays, the amount of energy which is transformed into eharacteristic radiation does not at the most reach 50 per cent.; and of this, only a fraction, say $\frac{1}{10}$, manages to escape from the surface of the radiator. 'Thus the arrangement is very inefficient as a source of characteristic rays. The writer showed, however, in 1908 (P.T.) (see p. 36) that a large proportion of the radiation from the anticathole of an X-ray bulb may consist of the characteristic radiation of the metal of the anticathode, more especially if the bulb is soft. By the employment of screens of the same metal as the anticathode, the other radiations present are either absorbed or transformed into the characteristic radiation, theresult being an intense and almost pure beam of characteristic rays. 'The potential on the tube should not be too high, otherwise the proportion of heterogeneous primary rays in the enitted beam will inerease in amount.

Figs. 61 to 64, taken from the above paper, give the logabsorption eurves for three such different metals as AI, Cu, and Pt. The homogeneity of much of the radiation, when screen and anticathode are alike, will be apparent. With all three metals, there is a superposed softer homogeneous radiation, which is removed by quite thin screens. In the case of eopper, the $K$ radiation shows up prominently.

Figs. 6.3 and 64 show the way in which the radiation from a platinum anticathode is absorbed by aluminium and platinum screens respectively. In the former case, the (thick) absorption curve betrays no apparent homogeneity in the rays. It is, however, possible to analyse the curve into three homogeneous components, having $\lambda / \rho=5 \cdot 6,23 \cdot 7$, and 70 respectively. These are represented both in amonnt and hardness by the three thin lines. The hardest is probably independent radiation, the seeond proves to be the characteristic $L$ radiation of platimum. With the platimum sereen, the independent radiation has disappeared, and the absor])tion curve shows that the $\mathrm{X}$ rays transmitted by a screen $0.0005 \mathrm{~cm}$. thick are almost entirely homogeneous $L$ rays.

${ }^{1}$ See, for example, Fig. 60. 


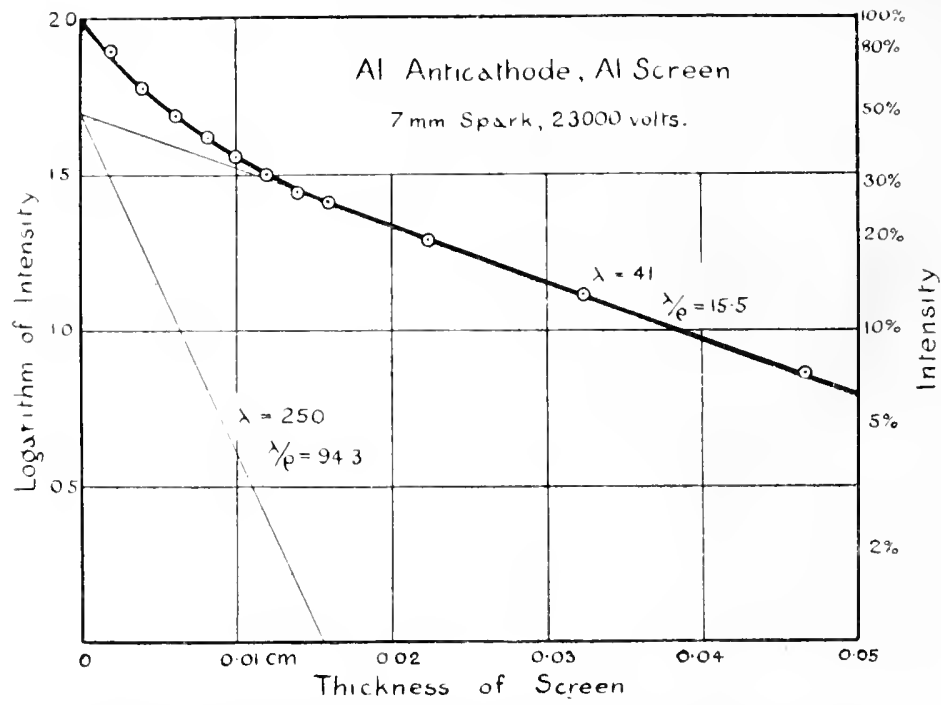

Fifi, 61.-The heary curve is the lng-absorption curve, for all $\mathrm{Al}$ sereen, of the $\mathrm{I}$ rays from an it anticathode. The curve can be resolved into two homogeneous components (indicated in anoment and absorbability by the lwo thin straight lines).

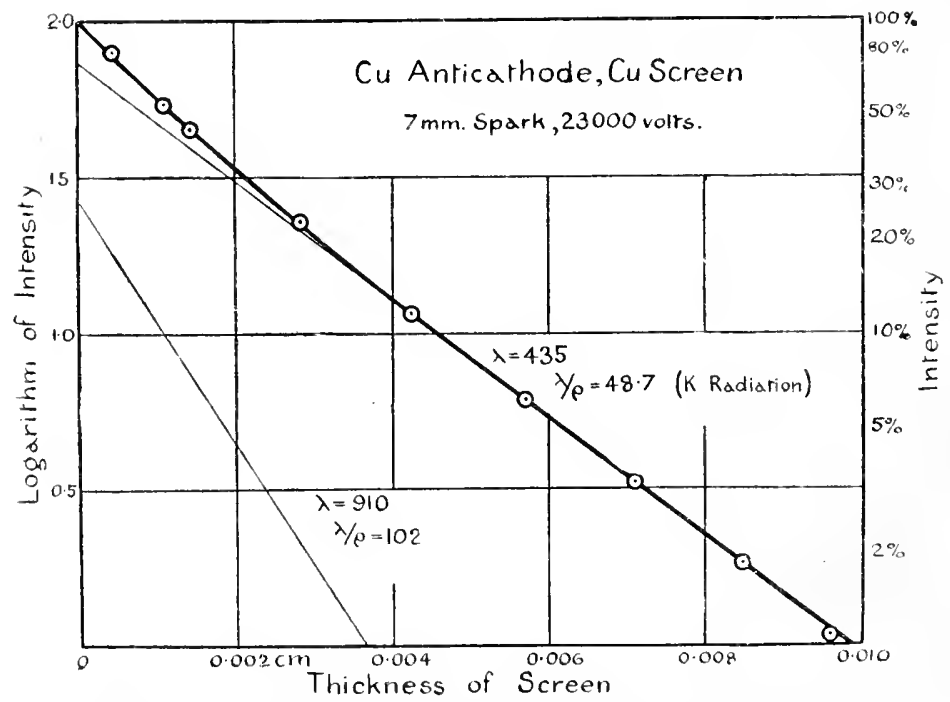

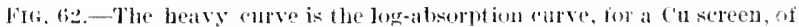
the $X$ rays trom a cuanticathode. The lomogeneity of molh of the ratiation is apparent. The "ulve can lop resolved into two homogeneous romponents (indicated in amonnt and absorbabitity by the two thin straght lines), one of which is the $K$ radiation of $\mathrm{Cu}$. 


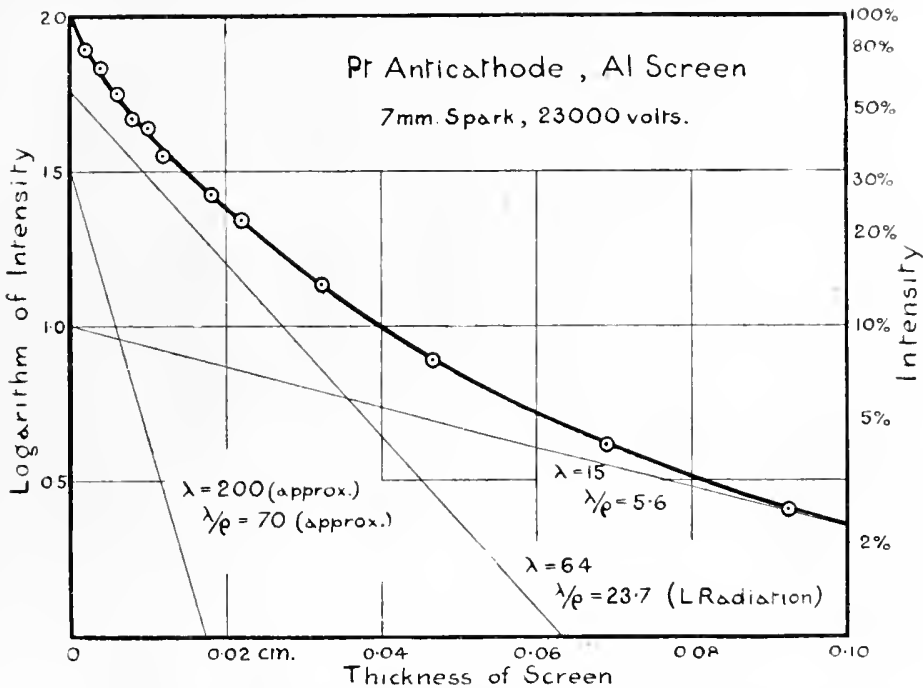

Fig. 63.- The heary curve is the log-absorption curve, for an 11 sereen, of the $\mathrm{I}$ rays from a Pt anticathorle. The curve an be resolved into three homogeneouscomponents (indicated in anount and absorbability by the three thin straight lines): one of which is the $L$ radiatjon of $\mathrm{Pt}$.

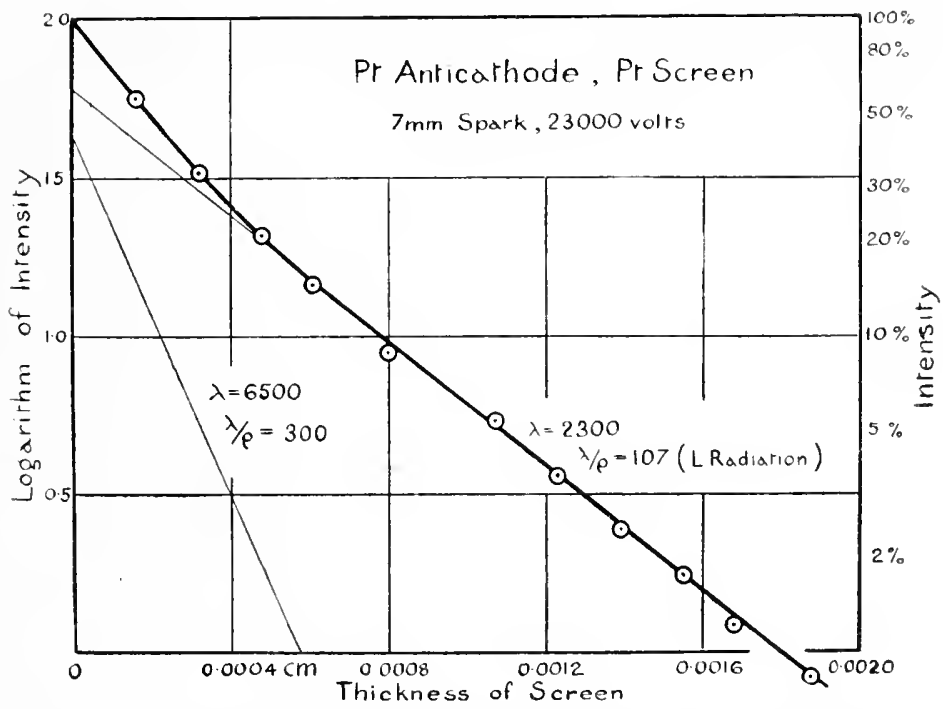

Fig. 64.-Combitions as in Fig. 63, except that the Pt. $\mathrm{X}$ rays are alsorbed by a $P L$ ireen instead of $A l$. The homogeneous $L$ radiation now predominates in the absorption curve, which is resolvable into the $L$ radiation and a second softer component. 
Quality of Characteristic Rays in terms of Parent Cathode Ray Velocity.

The writer in 1909 (sece./.Rt.s. 1913) attempted to associate. the hardness of the characteristic radiation emitted by an antieathode, with the speed of the cathode ray required to excite the radiation. The molerlying notion was that unless the cathode rays possessed a velocity greater than a certain

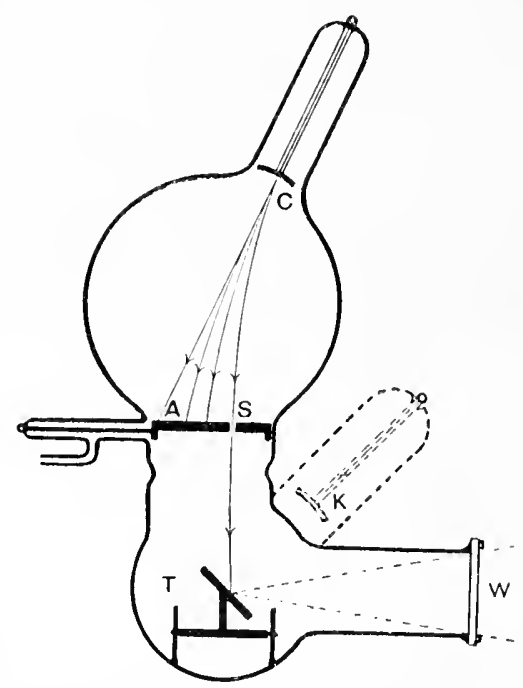

litx, fis. Apparatus for showing production of A ratys with catlende rats of virying speed. eritieal value, no characteristic rays would be generated. If this wore so, the I rays could, so to speak, be labelled in terms of the speerl of the exciting vathode rays.

Obviously a first sinplification was to work with eathocle rays of uniform speed. This can be done by the use of either (1) an influence machine or (2) a magnetic-spectrum method applied to a coil discharge. In the latter plan, the cathode ray cuergy is, at suitable pressures, largely concentrated in the fastest

cathode lays (see p. I6); and the method had other obvious advantages which led to its adoption.

The apparatus is indicated in Fig. 65. The cathode rays from $C$ were spread by a magnetic field into a maynetic spectrum, plainly visible along the plate anode, $A S$, which was coated with willemite. By varying the strength of the field, any part of the spectrum conld be brought over the slit, $s$. The pencil of eathode rays which passed through $S$ impinged on the anticathode, $T$ ', below, and a bundle of $\mathrm{X}$ rays passed out through the thin aluminium window, $W$, and was measured by an ionisation method. Some half-dozen anticathodes were mounted on a trolley as 
described on p. 36. The additional cathode $K$ was provided to bombard the anticathodes so as to liberate the occluded gas, which otherwise, by its continued emission, softens the tube during the actual measurements.

The experiments, which were arrested soon after their commencement, served, however, to show the cxtreme inefficiency of the slowest cathode rays as producers of $\mathrm{X}$ rays. As the different parts of the cathode spectrum were passed over the slit, and faster and faster cathode rays were brought into action, the rapid gain in the intensity of the $X$ rays was very noticeable. The increase in intensity eame in quite suddenly for some one speed of the cathode rays which did not appear to be the same for the different anticathorles employed.

\section{Whiddington's Experiments.}

In 1910 Whiddington carrjed ont a researeh on somewhat similar lines, and obtained quantitative measurements of

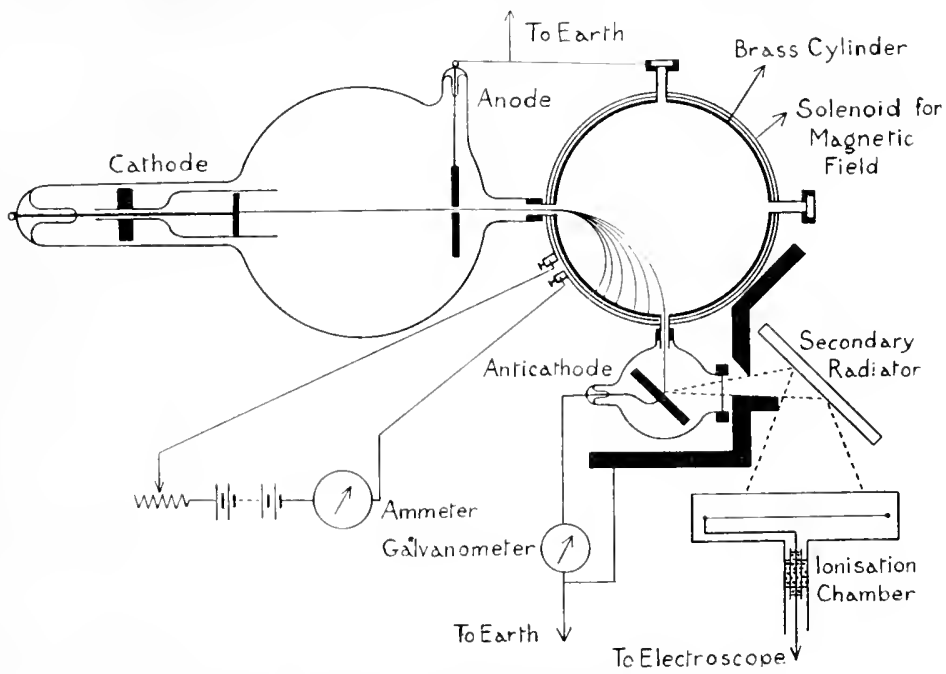

Fic. 6f.-- Whidhingtom's apparatus for comecting the speed of cathole rays with tlee quality of varioll characteristic radiations.

great importance (P.R.s. I911) for the $K$ radiations of a number of elements. His final apparatus is shown in Fig. 66. The cathode-ray spectrum was produced hy a solenoid 
which yielded a uniform and calculable magnetic field. The anticathode was of silver, and the generated $\mathrm{X}$ rays struck a secondary radiator. The speed of the cathode rays was increased (by the hardening device described on p. 70) until the secondary radiator emitted its characteristic radiation, which of course was duly indicated in the ionisation chamber. Below this critical value of the velocity, there was little effect in the chamber; above it, the ionisation current grew very rapidly. Thus the eathode ray in the $\mathrm{X}$-ray tube must possess a minimum velocity if it is to excite an $\mathrm{X}$ ray of given quality. Different radiators were tried, and the eritical velocity was found to be roughly proportional to the atomic weight of the radiator : in point of fact, the speed in ems. per sec. was 100 million $\left(10^{8}\right)$ times the atomic weight. Beatty (see next page) has sinee shown that the same result is true if the metal, instead of being used as a secondary radiator, is employed as an anticathode, as in Kaye's arrangement.

Thus, to recapitulate, if $V_{K}$ is the critical velocity of the cathode rays in ems. per sec., and $A$ is the atomic weight of the anticathode, then in the ease of the $K$ series of radiations, the empirical relation

$$
V_{K}=A \cdot 10^{8}
$$

is approximately satisfied for a range of elements from $\mathrm{Al}$ to Se.

By combining this expression with Chapman's formula (p. 116), it follows that for the $L$ series

$$
V_{L}=\frac{1}{2}(A-48) 10^{8} \text {. }
$$

In Table IX., Whiddington's experimental values for the $K$ radiations are given in heavy type in columns 3 and 5 . The values for the other $K$ radiations and the whole of the $L$ radiations are calculated by the formulae above. It must be understood that many of these radiations have not yet been discovered (see p. 115). 
Table IX. Minimun Speed of (athode Rays required to micite Characteristic Radiations.

\begin{tabular}{|c|c|c|c|c|c|c|}
\hline \multirow{2}{*}{\multicolumn{2}{|c|}{ Radiator. }} & \multirow{2}{*}{$\begin{array}{l}\text { A tomic Weight } \\
(0=16) .\end{array}$} & \multicolumn{2}{|c|}{$\begin{array}{l}\text { Critical Velocity of } \\
\text { Cathode Rays to excite }\end{array}$} & \multicolumn{2}{|c|}{$\begin{array}{l}\text { Requisite Potential to } \\
\text { impart Critical speed } \\
\text { to Cathole Rays.? }\end{array}$} \\
\hline & & & $K$ radiation. & $L$ radiation: & K rath. & $L$ radn. \\
\hline Hydro & & & $\mathrm{cm} \cdot \mathrm{sec}$. & $\mathrm{cm} . / \mathrm{sec}$. & volts. & volts. \\
\hline Carbon & & & $. \quad \times 10^{9}$ & 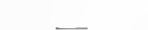 & & \\
\hline Alumini & & $12+2+3$ & $1.2 \times 110$ & - & II & - \\
\hline $1110 \mathrm{~m}$ & & 2 & $2.06 \quad$, & - & 1200 & $\longleftarrow$ \\
\hline hrom & - & $52 \cdot 0$ & $5.09 \quad$. & $2.0 \times 10^{8}$ & 7320 & 11 \\
\hline Iron - & - & 5 & $5.83 \quad$. & $3 \cdot 9$ & 9600 & $4: 3$ \\
\hline Nickel & - & 5 & $6 \cdot 18 \quad$. & $5 \cdot 4$ & 10,750 & 81 \\
\hline Copper & - & $63 \cdot 6$ & $6 \cdot 26 \quad$.. & $7 \cdot 8$ & 11.080 & 170 \\
\hline Zine - & - & $65 \cdot 4$ & $632 \quad$. & $8 \cdot 7$ & 11.280 & 210 \\
\hline nium & - & 7 & $y \cdot 38$ & $1.56 \times 10$ & 15,400 & 690 \\
\hline Rhodium & - & 10 & $1.03 \times 10^{10}$ & $2 \cdot 7$ & 29,900 & 2,100 \\
\hline Silver & - & $7 \cdot 9$ & $1 \cdot 08$ & $3 \cdot 1)$ & 33,0100 & 2.506 \\
\hline Tin & $\cdot$ & $119 \cdot 0$ & $1 \cdot 19$ & $3 \cdot 6$ & 40,000 & $3,60 \mathrm{c}$ \\
\hline Tumgste & - & 1 & $1.84 \quad$, & $6 \cdot 8$ & 95,0100 & 13,000 \\
\hline Platinum & - & $195 \cdot 0$ & $195 \quad$, & $7 \cdot 4$ & 108.000 & $15.00 \mathrm{i}$ \\
\hline Lead - & - & $207 \cdot 1$ & $207 \quad$. & $8 \cdot 0$ & 120,000 & 18,000 \\
\hline Tranium & - & $238 \cdot 5$ & $2 \cdot 38 \quad$ & $9 \cdot 5$ & 160,000 & 26,000 \\
\hline
\end{tabular}

\section{Energy of an X Ray.}

By slightly modifying the arrangement, and putting the ionisation chamber in place of the secondary radiator," Whiddington was able to eorrelate the energy of the X rays with the velocity of the parent eathorle rays, and so to establish the truth of a relation dedueed theoretically by Sir J. J. Thomson in 1907 , that the energy of an $\mathrm{X}$ ray is proportional to the fourth power of the velocity of the exeiting eathode ray. Beatty (P.R.S. 1913) has reeently proved that this relation is only true for "independent" $\mathrm{X}$ rays : if characteristie rays are generated, the expression no longer holds (see p. 107).

\section{Beatty's Experiments.}

Beatty (P.R.S. 1912) has shown that the bulk of the eharacteristic rays generated in Kaye's experiments (p. 1:21),

I See p. 96 for relation between cathode-ray speod and potential

2 See Fig. 66. 
is due to a direct transformation of the cathode radiation into characteristic radiation; and that only a small re-

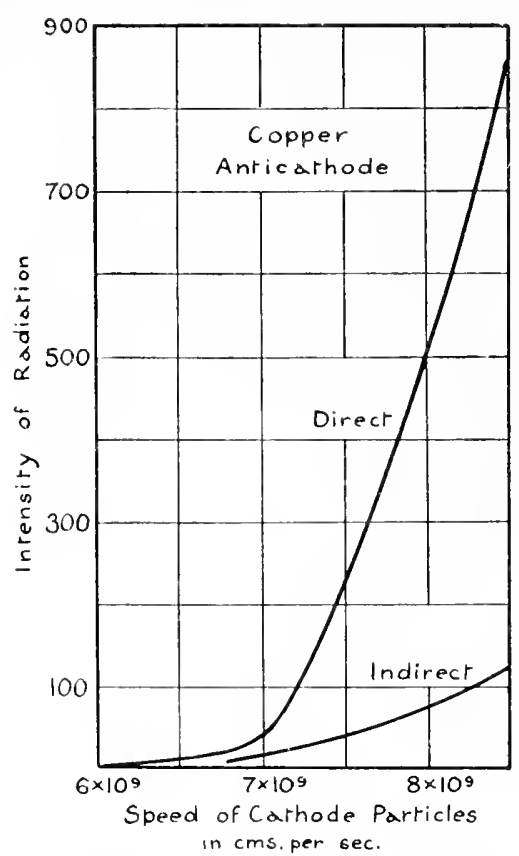

Frug. - Showing relative amounts of characteristiv $x$ rays generated directly and indirectly from a copper anticathode by athorle lays of it vallety of sureds. mainder owes its origin. as one would perhaps infer. to the indirect action of primary $\mathrm{X}$ rays in emerging from beneath the surface of the anticathode. Beatty obtained cathode rays of uniform speed by means of the magnetic-spectrum method. and was able to show that the direct and indirect effects occur simultaneously as soon as the speed of the cathode rays exceeds the critical value (see p. 126). Fig. 67 shows for the case of a copper anticathode, the relative amounts of characteristic copper radiation generated directly and indirectly by cathode rays of different velocities. Both effects disappear if the speed falls below $6 \cdot 25 \times 10^{9} \mathrm{~cm}$./ sec., a value which agrees very closely with Whiddington's critical speed for copper.

To overeome the difficulties of measuring the $\mathrm{X}$ rays due to the vagaries of a coil discharge, an ingenious null method was devised which consisted in balancing the current in the ionisation ehamber against part of that carried by the cathode-ray discliarge. Fig. 68 shows the connections. The interior of the antieathode tube $A$ was lined with aluminium and joined to the anticathode. The greater part of the cathode ray current passed to earth through the variable resistance $P$. A smaller fraction passed through the high resistance $Q$ to the ionisation chamber. The 
resistance $P$ was altered mutil the latter current just neutralised the leak in the ionisation chamber. (of the current leaving $A, P /(P+Q)$ goes to the chamber. Since

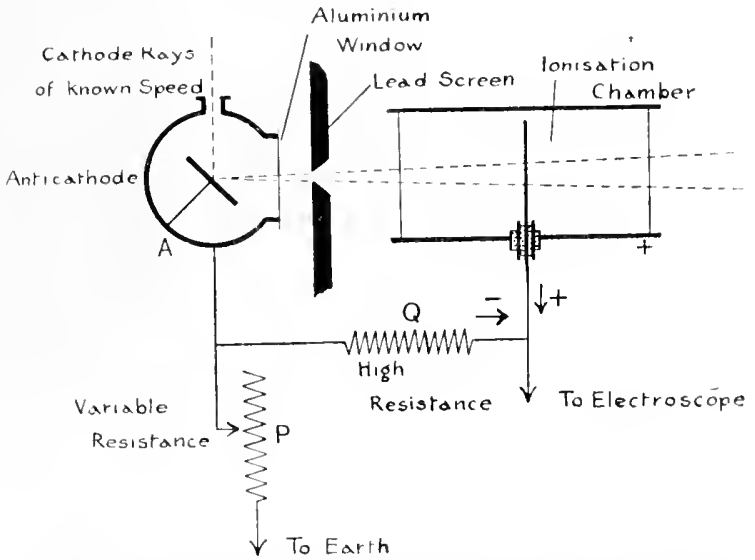

FIG. 68.-Beatty's apparatus for measuring the characteristic $\mathrm{X}$ rays generated directly and indirectly by cathode rays of various speeds (see Fig. 67).

(2) was very large- of the order of $10^{12}$ ohms-we may write this, $P / Q$. Thus the relative intensity of the $X$ rays is evaluated by determining $P$ in each ease.

\section{Absorption of Characteristic Radiations.}

Selective Absorption of Certain Qualities of Radiation by a Particular Element.

It is found that an element exhibits a maximum transparency for $\mathrm{X}$ rays of a quality identical with that of either of its own charaeteristie radiations; and, further, the absorption becomes abnormally large for $\mathrm{X}$ rays which have a penetrating power just greater than that of either of the characteristic radiations. For example, if the absorption in copper is measured for a variety of homogeneous $\mathrm{X}$ radiations from, say, calcium rays to cerium rays, then if we start with the soft Ca rays and pass up the series, the absorption in copper steadily diminishes in normal fashion as the rays are hardened. But as soon as the 
stage is reached when the I rays have become as penetrating as the Cu radiation, the absorption slows up, and reaches a minimum. With slightly harder rays the Cu $(K)$ radiation is exeited, and the absorption then rapidly inereases. As the incident rays are hardened still further, the absorption begins once more to diminish, and eventually reassumes the normal type, steadily lessening as the hardness increases, but now more rapidly than was the case before the "loo!n."

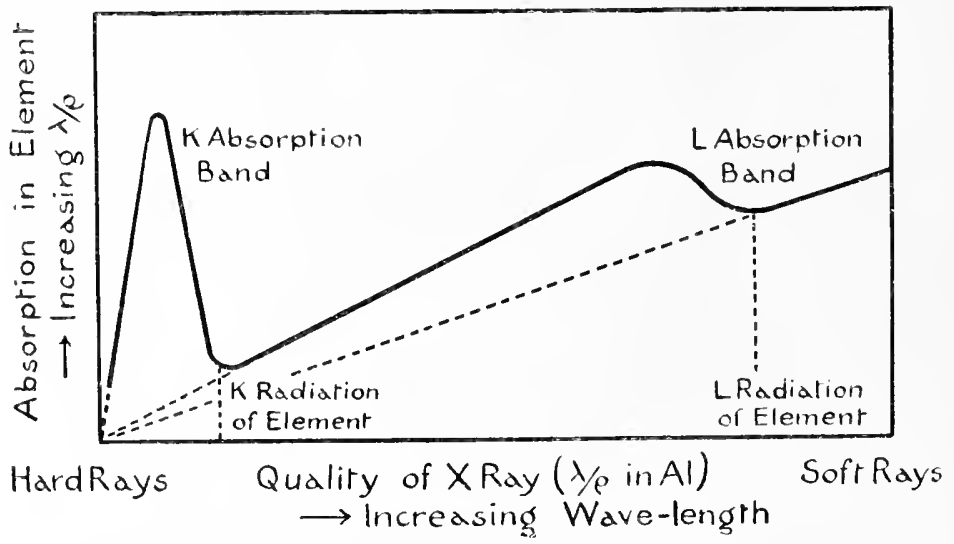

Wri, 69.- biagrammatic representation of the absorption by a particulate plenent of a range of analities of $\mathrm{X}$ rays. The absorption rearlies a minimum for rays iclentical in quality with either of the characteristi: rarliations: for rays a little harder than these, the absorption is abnormally high. Thus, in these regions there is selective absorption, but elsewhere the absorption is nolmai.

These various phenomena are displayed in Fig. 69, which shows, for a range of qualities of incident $X$ rays, the two loops in the absorption curve of an element whieh possesses both $K$ and $L$ radiations. It must be emphasised that Fig. 69 is purely diagrammatic and not at all to seale. As yet, the complete absorption curve for any single elenient has not been obtained. 'The corresponding eurve for an absorbing metal of lower atomie weight would have the loops shifted to the right; for one of higher atomie weight, to the left.

This selective transmission of the various eharacteristic 
radiations was well displayed in Kaye's experiments ${ }^{1}$ on the direct generation of characteristic rays from anticathodes of X-ray bulbs. Table X. shows the effect of interposing the same metal screen in turn in the path of the $X$ rays from various anticathodes. It will be noticed that, in most cases, the intensity of the transmitted rays is greatly augmented when the anticathode is of the same material as the screen. To provide a basis of comparison for the results for each metal screen, the intensity of the transmitted radiation from the $\mathrm{Al}$ anticathode is called 100 in the table.

'Table $\mathrm{X}$. Showing Seleutive Transmission of Various Raditions. (Al radiation $=100$.)

\begin{tabular}{|c|c|c|c|c|c|c|c|}
\hline \multirow{2}{*}{\multicolumn{3}{|c|}{ I rays from anticathode of }} & \multicolumn{5}{|c|}{ Screen of } \\
\hline & & & Al & $\mathrm{Fe}$ & $\mathrm{Ni}$ & $\mathrm{C}_{1} \mathrm{u}$ & 1 't \\
\hline Aluminium (27) & - & - & 100 & 100 & 100 & 100 & 100 \\
\hline Iron $\quad(56)$ & $\cdot$ & - & 160 & $600)$ & 340 & 380 & 160 \\
\hline Nickel & $\cdot$ & - & 180 & 200 & 740 & 570 & 220 \\
\hline C'opper & - & - & 210 & 210 & 810 & 740 & 2711 \\
\hline Platinum $\quad(195)$ & - & - & 530 & 450 & 480 & 480 & 670 \\
\hline
\end{tabular}

The selective absorption phenomena illustrated in Fig. 69 are further revealed from a scrutiny of Table XI., or, better still, from Table XII. In Table XI. are put out the mass-absorption coefficients of a number of characteristic radiations in various absorbers, while in Table XII. the values are, in every case, relative to the absorption in aluminium. Table XII. is, of course, immediately derivable from Table XI. Barkla and Collier (P.M. 1912) have pointed out that the shape of either of the absorption loops, indicated roughly in Fig. 69 for some particular absorber, is not only similar to, but identical with, the corresponding loop for any other absorber, provided proper choice is made of the scales of coordinates for each absorption curve. This may be secured by arranging that the particular ordinate corresponding to the characteristic radiation of the absorber, both occupies the same position and has the same length

$$
1 \text { See p. 121, and P.C.P.S. May } 1907 .
$$


马ु雪

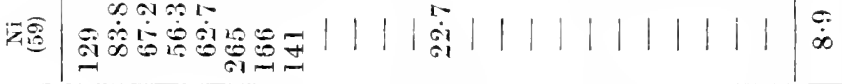

4.

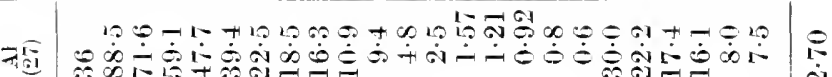

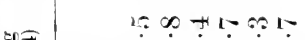

经过

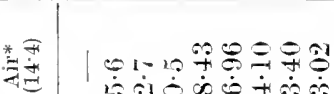

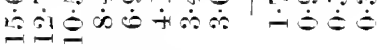

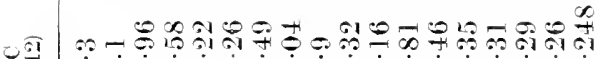

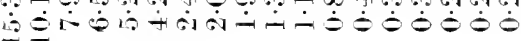

$\stackrel{+}{\grave{-}}$

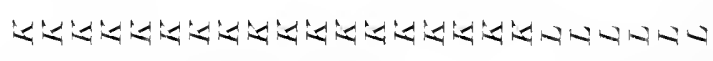

तิ

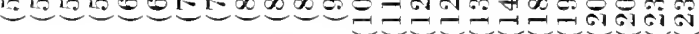

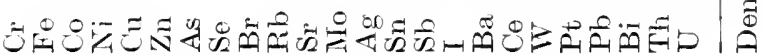




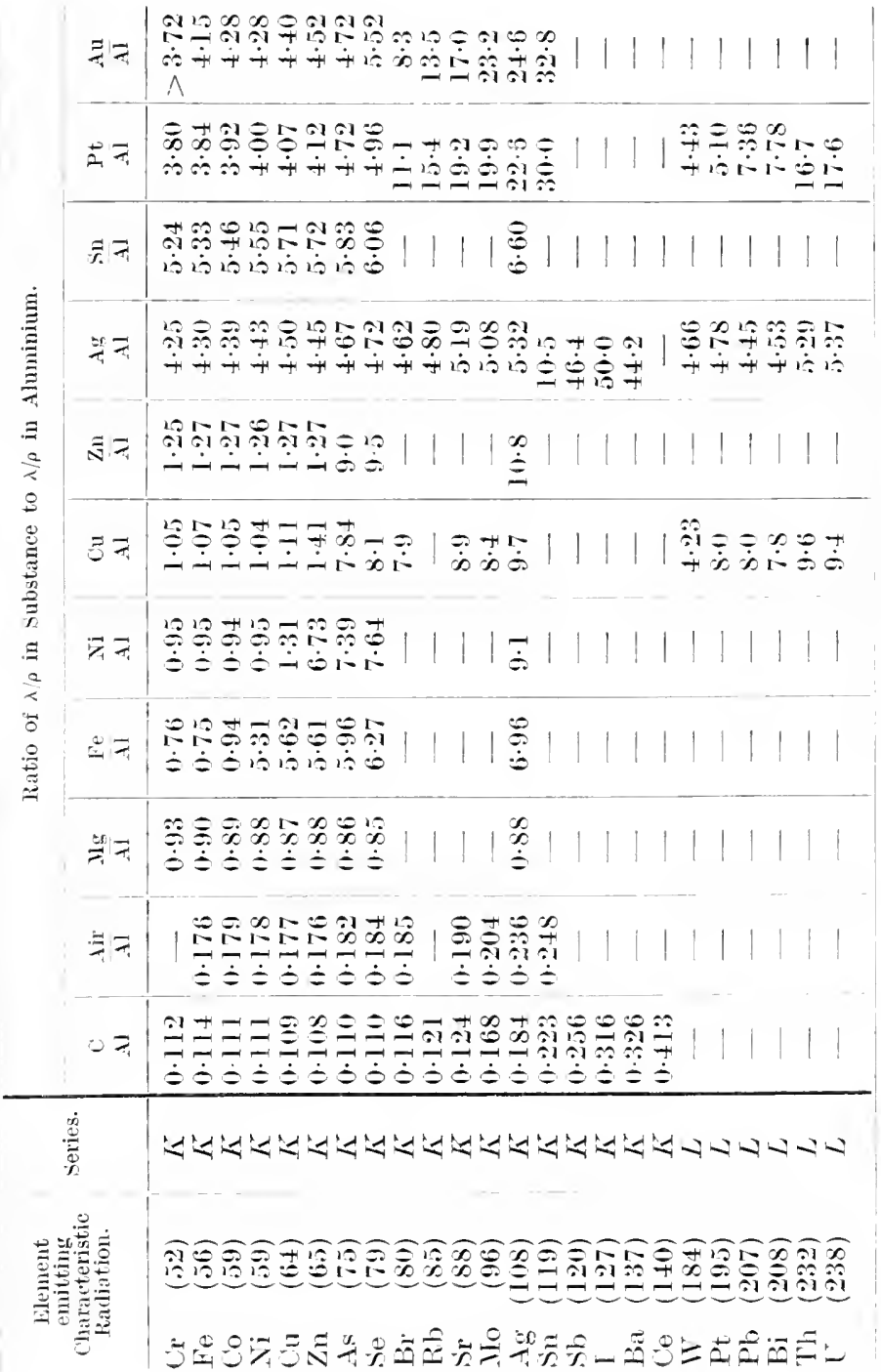


in all the different curves. In other words, by arranging the scales of absorption and wave-length so that the absorption of $\mathrm{Fe}(K)$ radiation in $\mathrm{Fe}$, of $\mathrm{Cu}(K)$ radiation in $\mathrm{Cu}$, etc., are all represented by the one point $(A)$ on the graph, the varions absorption eurves in the region of the $K$ loop will eoincide if superimposed. And similarly for the $L$ Iool).

\section{Barkla and Sadler's Relation for Normal Absorption.}

The eonstant absorption-ratio that exists, no matter what the hardness of the $\mathrm{X}$ ray, for each absorber outside the range of selective absorption, is well displayed in Table XII. Some of the departures from proportionality with the harder types of rays, in what should be regions of normal absorption, are due to the fact that the coefficients for many of the elements given in Table XI. have not been corrected for scattering. If we make the proper scattering correction (p. 109), it is found that the ratio of the absorptions of a radiation in any two particular elements is approximately constant, and does not depend on the quality of the radiation. provided only that such radiation does not excite the characteristic radiations of either element. This important relation was first pointed out by Barkla and Sadler.

To take an example, Barkla and Collier have shown that in the ease of earbon, the absorption values relative to aluminimm-which rise in Table XII. from 0.11 for soft rays to 0.41 for hard rays-become, when corrected for scattering, a steady value of 0.11 for all types of $\mathrm{X}$ ray.

\section{Selective Absorption of a Particular Radiation by Certain Elements.}

The selective absorption of $\mathrm{X}$ rays under certain conditions (to which we have referred above), is perhaps better brought out by Fig. 70 (taken from Barkla and Collier's paper, P.M. 1912), which exhibits the way in which the absorption of $\mathrm{Ni}(K)$ radiation in a number of elements varies with the atomic weight of the absorber.

It will be noticed that, if we start with the light elements. the absorption of the Ni rays increases steadily with the atomie weight of the absorbing substanee, so long as all 
the various eharacteristie radiations $(K, L, \ldots)$ of the absorber are excited. But as soon as the atomic weight of the absorber beeomes so high that its $K$ characteristic eeases to be excited (though the others remain), then the absorption suddenly drops. With higher atomie weights, the Ni radiation ean only excite the $L, M$, . . radiations, and so the absorption steadily increases until the stage when the Ni radiation no longer excites the $L$ radiation, and the

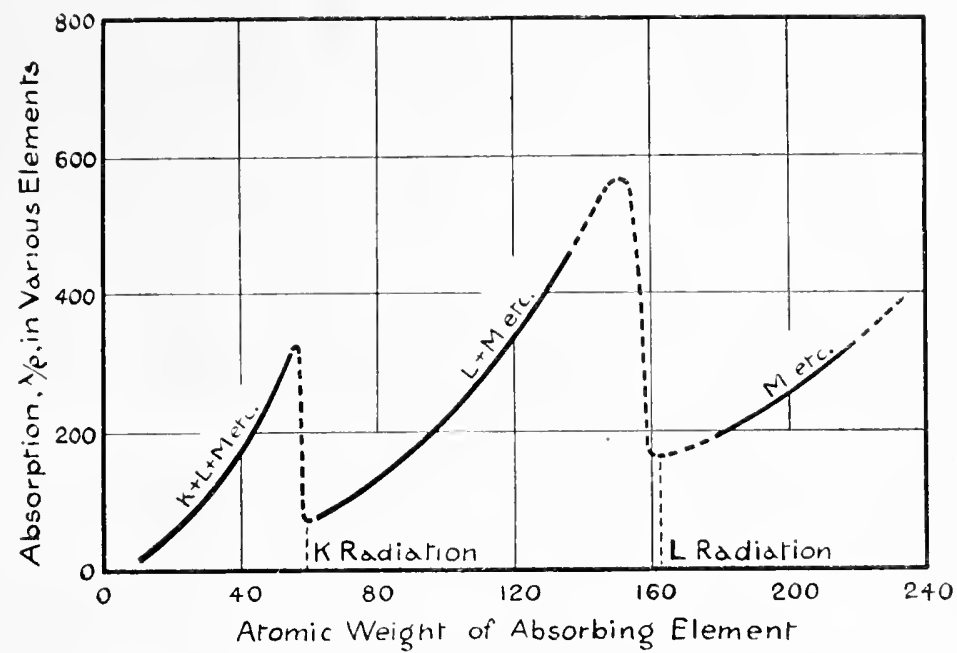

FIG. 70.- - Graph showing relat ion hetween the absorption of $\mathrm{Ni}(K)$ radiation hy various elements and the atomie weight of the absorbing element. The absorption passes through a minimm for a screen of Ni and also for one of atomic weight of about 1 tit (whose $L$ racliation is identical with the $\mathrm{Ni}(K)$ rays). Com?nare Fig. 54.

absorption falls once more. In other words, the transparency reaches a maximum with a nickcl sereen and also with one whose $L$ characteristic radiation is identical with the nickel $K$ radiation. Thus the regular eurve of increasing $\lambda / \rho$ with atomie weight of the absorber, is modified by the addition of sudden drops at as many regions as there are elements having one or other of their characteristic radiations identical with the $\mathrm{X}$ rays which are being absorbed.

Similar curves are obtained for any other characteristic radiation: if the radiation is harder, all the maxima and 
minima are displaced to the right, and, if softer, to the left.

It will be remarked that Fig. 70 is the analogue of Benoist's curve (p. 102) for heterogeneous $\mathrm{X}$ rays. Evidently, Benoist's rays were rich in components approximating to the characteristic radiation of silver, and this explains the absorption "loop" which is prominent in his curve for soft $\mathrm{X}$ rays and less pronounced in that for the harder rays.

\section{Absorption of Characteristic Radiations in Gases.}

E. A. Owen (P.R.S. 1912) measured the absorption of a number of eharacteristic radiations in light gases. To get

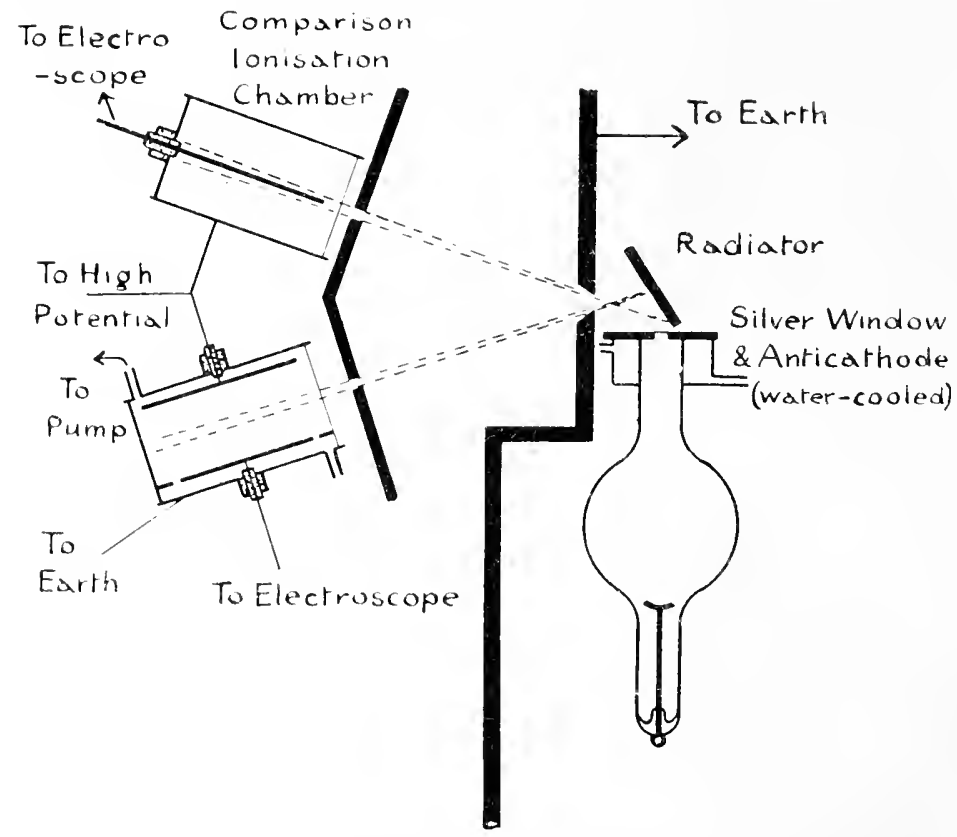

Fia. 71.--owen's apparatus for measuring the absorption coteficients of rharacteristic X lays in gases.

over the difficulty of working with the feeble radiations generated by the ordinary method of placing the radiator at an angle to the path of primary $X$ rays, (Owen employed the ingenions device of momting a thin silver anticathode 
as a window in the discharge tube. The various radiator's were placed near the outside of the window, and, by this means, intense charaeteristic radiations were obtained. Fig. 71 shows the apparatus. The antieathode was soldered to the glass, through the intermediary of an electrolytie deposit of copper; and to prevent the fusion of the anticathode by the eathode rays, it was watercooled.

A pencil of characteristic $(K)$ rays from a series of radiators ranging from iron to molybdenum entered an ionisation ehamber through a parehment window. The pencil was sufficiently narrow to prevent it striking the electrodes, which, together with the whole of the inner surface of the ehamber, were coated with paper. Both the nature and pressure of the gas in the chamber could be altered. A comparison chamber enabled the vagaries of the eoil diseharge to be overcome.

In some cases, e.g. $\mathrm{SO}_{2}$, the absorption at atmospherie pressure was very great for the softer rays, and measurements had to be made at lower pressures. Owen first showed that the absorption coefficients of any of the charaeteristic radiations in a gas varied directly with the pressure, as, of course. would be anticipated for a homogeneous beam.

Further, the absorption eoefficients of the different radiations in a particular gas proved to be proportional to the corresponding absorption coefficients in air, which goes to show that Barkla and Sadler's generalisation (p. 134) can be extended to gases. Owen was led to take the logarithms of the mass-absorption coefficients of the various radiations in a particular gas, and plot them against the logarithms of the atomic weights of the radiating metals. He found not only that the various observations all lay on a straight line, but that the different straight lines for the various gases were all parallel to each other. The slope of these lines showed that the absorption coefficient of a radiation is approximately inversely proportional to the fifth power of the a.tomic weight of the radiator. Owen's fifth-power law is exemplified for an aluminium absorber on p. 114.

Barkla and Collier (P.M. 1912) have also worked at ahsolp)tion in gases. Some of their results, as well as those of 


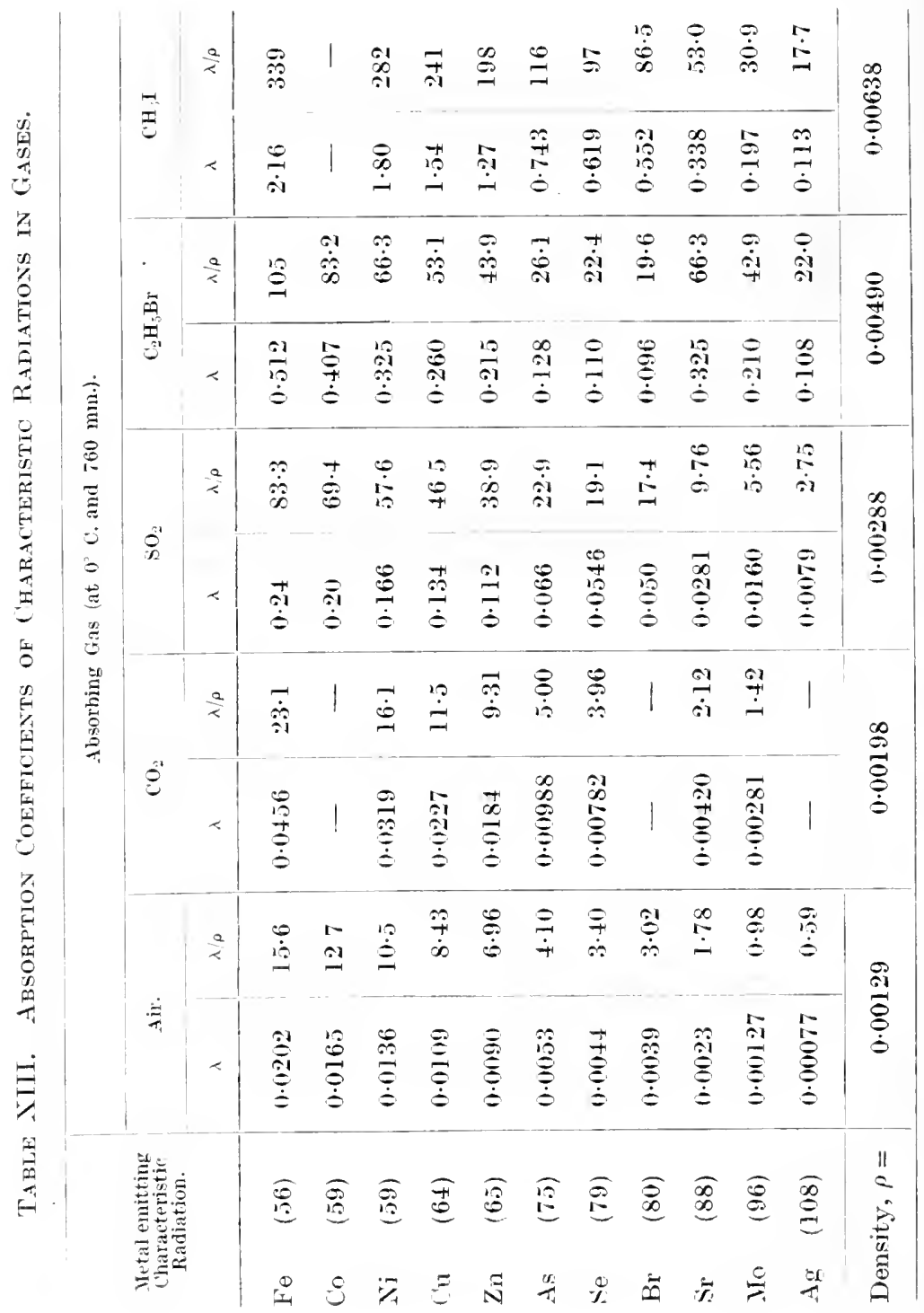


Owen, are incorporated in Table XIII., which gives the absorption coeffieients (in em.-gm. units) for air, earbon dioxide, and sulphur dioxide, ethyl bromide, and methyl iodide vapours.

\section{Corpitscitar Rays.}

Curie and Sagnae (C.R. 1900) first showed that when a plate was struck by $\mathrm{X}$ rays, part of the secondary radiation was negatively eharged.

The deteetion of these high-speed eorpuseles-as they have proved to be-is an casy matter, since the bombarded plate will eharge up positively if it is insulated in a vaenum. By measuring the rate of eharging, it would be possible to determine the number of corpuseles expelled per second; while, by applying an electric foree of suitable direction and magnitude, we could ascertain their speed. In actual praetice, this method of measuring velocities, while convenient for slow-speed eleetrons such as are liberated, for example, by ultra-violet light, is not very practicable in the ease of $X$ rays, owing to the magnitude of the potentials required.

The magnetie-defleetion method of determining high speeds is readily available if the stream of electrons is sufficiently intense; and this method was actually employed by Innes and others in the ease of the secondary X-ray eorpuseles (see below).

\section{Distribution of Corpuscular Rays.}

The intensity of the eorpuseular emission inereases with the atomie weight. The corpuseles preponderate in a direction at right angles to the beam of $X$ rays, which aecounts for the fact (shown by Laub. A.d.P. 1908) that there are more eorpuseles liberated by a glaneing beam of $\mathrm{X}$ rays than by a normal one.

Furthermore, when X rays are sent through a thin metal plate more corpuseles are given off on the far or " emergenee" side than on the near or "incidence" sicle. This is the more marked with hard X rays and with elements of low atomie weight. For example. Beatty (P.C.P.S. 1910) found with silver leaf, that while the excess amounted to no more than 
2 per cent. in the case of $\mathrm{Fe} X$ rays $^{1}$ (which are very soft), it attained 30 or 40 per cent. with the harder tin and aluminium rays. The speed is equally fast on both sides of the plate. On the other hand, Cooksey (P.M. July 1912) found that when the absorption of the exciting $\mathrm{X}$ rays in the layer of emitting metal is allowed for, the ratio of emergence to incidence corpuscular rays shows no certain variation either with the metal or the $X$ ray. The excess emergence rays were of the order of 20 per cent. for both gold and silver plates, and for a range of rays extending from $\mathrm{Cr} X$ rays to $\mathrm{Sn} X$ rays-providing an eighty-fold variation of penetrating power.

It may be added that Kleeman (P.R.S. 1910) and Stuhlmann (P.M. 1911) found much the same value for corresponding experiments with ultra-violet light.

\section{Velocity of the Corpuscular Rays.}

Dorn in 1900 first measured the velocity of these negative rays, and in 1907 Innes (P.R.S.) made a more complete examination. In his experiments, the $\mathrm{X}$ rays fell on a motal sheet in a vacuum, and the corpuscles emitted passed in succession through a couple of slits in lead sheets and were recorded on a photographic plate. The whole of the apparatus was exhausted for the reason that the corpuscles are seattered at ordinary pressures, and their paths are ton short to be followed. The velocity of the particles was ascertained from their deflection in a uniform magnetic field (produced by a pair of Helmboltz coils). Innes was able to establish the fact that the velocity of the corpuscle is independent of the distance of the $\mathrm{X}$-ray bulb from the emitting plate-a most important result. The distance was varied some eight or nime-fold without discernible effect on the speed obtained. Nor did alteration of the frequency or magnitude of the current through the X-ray bulb produec any change in the speed.

But an increase in the spark-gap, i.e. in the potential applied to the bulb, evidenced itself at once by a speeding up of the corpuscles. This is plainly shown in Table XIV.

\footnotetext{
'I.e. the characteristic $\mathrm{X}$ rays from iron.
} 
below. 'T'o derive absolute velocities from the measurements, it is necessary to assume a value for $e / m$ for the corpuscles; this was taken to be $1.7 \times 10^{7}$ E.M.U.

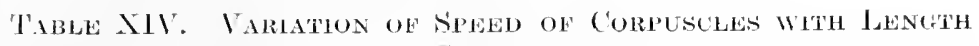
OF SPARK-GAP.

\begin{tabular}{|c|c|c|c|c|c|c|c|}
\hline \multicolumn{3}{|c|}{$\begin{array}{l}\text { Metal emitting } \\
\text { Corminseles. }\end{array}$} & \multirow{2}{*}{$\begin{array}{c}\text { Atomic } \\
\text { Wreight. } \\
\text { 6.j }\end{array}$} & \multirow{2}{*}{$\frac{\text { spark-gap. }}{39 \text { ctu. }}$} & \multicolumn{3}{|c|}{ Velveity of Corpuscles. } \\
\hline Zine & & - & & & 6.0 to 6.4 & & . sece. \\
\hline silver & - & - & 108 & $: 3 \cdot !$ & $3 \cdot 11$ to $7 \cdot 2$ & , & , \\
\hline ., & - & - & , & $19 \cdot 0$ & 6.1 to 8.1 & , & , \\
\hline Platinu & $m$ & - & 195 & $3 \cdot 2$ & $6 \cdot 1$ to $7 \cdot 4$ & , & , \\
\hline, & & - & , & $14 \cdot 0$ & $6 \cdot 5$ to $8 \cdot 0$ & , & , \\
\hline Gold & - & & 197 & $3 \cdot 4$ & $6 \cdot 1$ to $7 \cdot 5$ &,, &, \\
\hline , & - & - &, & 15.0 & $6 \cdot 2$ to $8 \cdot 1$ & , &, \\
\hline Lead & - & - & 207 & $5 \cdot 1$ & $6 \cdot 3$ to $7 \cdot 8$ & , &,, \\
\hline , & - & - & ," & $16 \cdot 0$ & $6 \cdot 4$ to $8 \cdot 3$ & ," & ," \\
\hline
\end{tabular}

It is apparent from the table that the nature of the naterial exerts little, if any, certain influence on the velocity of the corpuscles; but a more definite pronouncement is possible from the later experiments of Beatty (P.M. 1910) and of Sadler (P.M. 1910), both of whom used characteristic $\mathrm{X}$ rays.

\section{Absorption of Corpuscular Rays by Gases.}

Sadler has shown that the corpuscular radiation excited by characteristic rays is of uniform quality for any particular metal and follows an exponential law of absorption. This is true no matter what the metal or the characteristic rays. Thus, in each case, the corpuscular rays have a definite absorption coefficient, the value of which sadler found to be proportional to the atomic weight of the metal whose characteristic rays were being employed.

Both Sadler and Beatty cmployed a method in which two parallel plates were mounted opposite each other with a saturating electric field between them. The high-potential plate was bombarded with characteristic $\mathrm{X}$ rays, and the resulting stream of corpuscles proceeded towards the 
insulated plate, ionising the intervening gas. This ionisation was measured. Sadler cut down the corpuscular lays by moving one electrode and so lengthening their path in the gas; Beatty, on the other hand, raised the effective path by increasing the pressure of the gas, a method probably superior in accuracy.

The results of Beatty and Sadler are given in Table XV.

In spite of eonflicting data for some of the elements, the table shows plainly that the absorption coefficient (and thus the velocity) of the corpuscular rays is constant throughout for the same $\mathrm{X}$ ray and the same absorber, no matter what the nature of the atom from which the corpuseles are emitted.

The velocity, however, does depend very greatily on the quality of the characteristic $\mathrm{X}$ ray. Sadler concluded from his experiments that the corpuseular rays are an invariable accompaniment when charaeteristic rays, and possibly also scattered X rays, are produced. 'The corpuseular rays from a substance increase very markedly as soon as the substance begins to emit its characteristic $\mathrm{X}$ radiation, and possibly the former rays are conditioned by the presenec of the latter.

Whiddington (P.R.S. 1912) has shown that Beatty's results conform to the expression

$$
\lambda A^{4}=\text { const. }
$$

where $\lambda$ is the absorption cocfficient and $A$ the atomic weight of the metal supplying the characteristic $\mathrm{X}$ rays.

It follows, as a deduetion from the fourth power absorption formula for cathode rays (1). 10), that

$$
\lambda v_{0}^{4}=\text { const., }
$$

where $v_{0}$ is the velocity of a particle at the moment of projection from the plate.

Combining these expressions, we eonchude that

$$
v_{0} \propto A ;
$$

and, in fact, Beatty's measurements show that

$$
v_{0}=10^{8} . A \text {. }
$$

But this is the value of the eritical velocity which eathode rays must possess to generate a characteristic radiation (p. 126), and, therefore, it follows that the secondary corpus- 


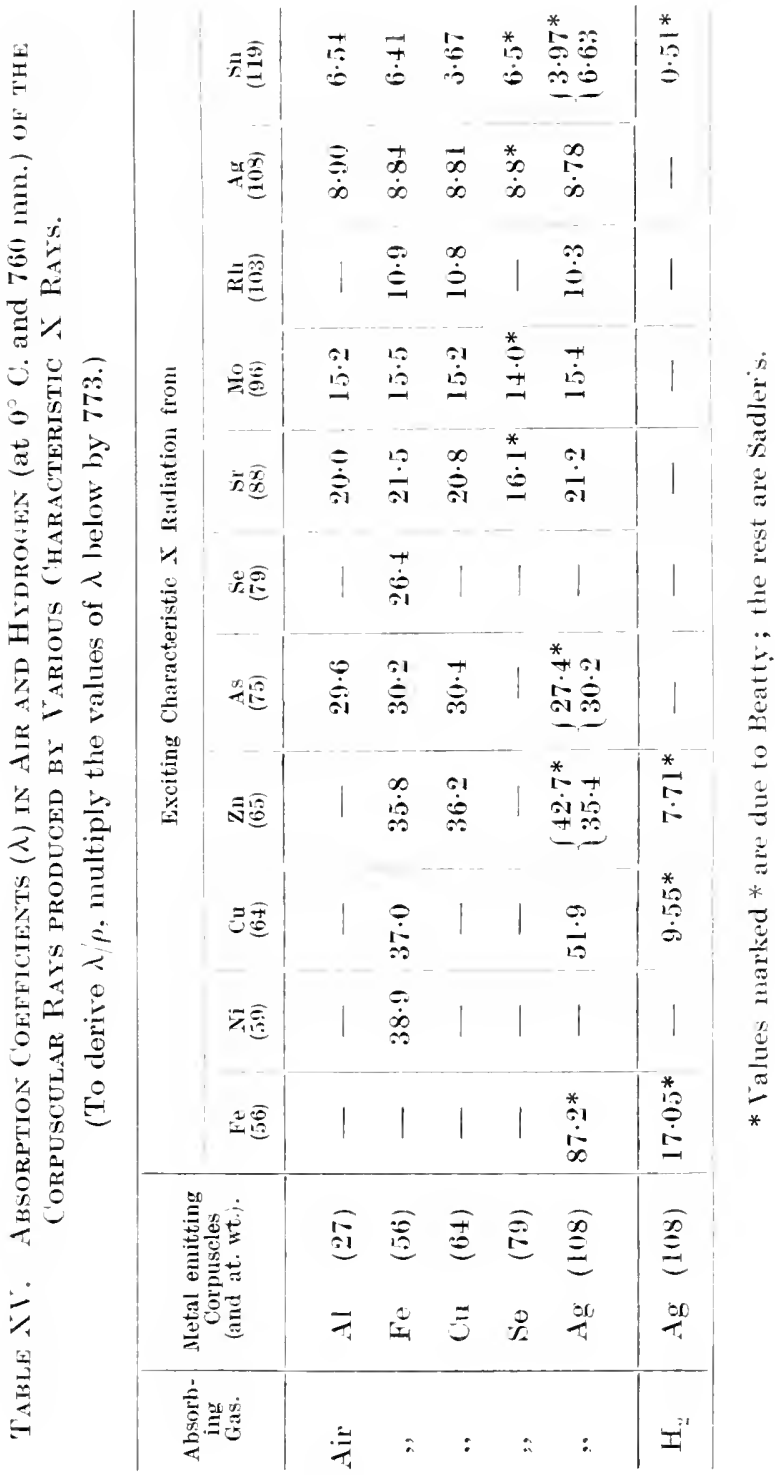


cular lays from $X$ rays have the same velocity as the original generating cathode ray's in the $X$-ray bulb-a result of great theoretical importance.

Fatigue Effect in Production of Secondary X Rays.

A number of experimenters, among them Nore (P.M. 1907), Gowdy (P.R. 1910), and Rieman (P.R. 1911), have obtained results which indicate that the output of secondary $X$ lays from a metal diminishes with time, and that the metal exhibits a fatigue effect under the action of the $X$ rays. It is now, however, pretty generally accepted that the effect is due largely, if not wholly, to chemical ehange of the surface by the action of the surrounding gas. A freshly prepared metal surface, obtained for instance by distillation in vacuo, shows little or no fatigue if the vacuum is continually maintained and any action due to gases thereby prevented. 


\section{CHAPTER $\mathrm{X}$.}

\section{FURTHER PROPERTIES OF X RAYS.}

\section{Ionisation BY X Rays.}

Whes $\mathrm{X}$ rays pass through a substance they here and there intrude into an atom, and are able to expel from it a corpuscle and so ionise the atom. But the proportion of atoms thus affected is extremely minute. Even in favourable cases, only one atom in a billion $\left(10^{12}\right)$ or more is ionised: the rest are passed over, presumably without receiving any energy or being influenced in any appreciable way.

\section{Ionisation and Pressure.}

The degree of ionisation depends greatly on the nature of the gas and on its pressure, as well as on the quality of the $\mathrm{X}$ rays. The ionisation produeed in a gas by the passage of $\mathrm{X}$ rays should, in the absence of any secondary radiation, be proportional to the mass of the gas, that is, to the pressure (at constant temperature). But usually, seeondary radiation is generated: if it is sufficiently penetrating to reach the electrodes, the ionisation it produces will be proportional to the square of the pressure. If the sccondary radiation were absorbed before reaching the electrodes, the ionisation would be simply proportional to the pressure.

But numerous observers agree that in the great majority of eases where the pressure is not very low, the ionisationpressure curve follows a straight line, ${ }^{1}$ and the inference

${ }^{1}$ For example, Crowther (P.R.S. 1908) using ordinary X rays; and Owen (P.R.S. 1912) with homogeneous $\mathrm{X}$ rays. The conditions must be such that no characteristic radiations are generated. 
would be that the ionisation is due either to the direct action of the $\mathrm{X}$ rays or to the easily absorbed corpuscular rays.

\section{$\mathrm{X}$ Rays ionise indirectly.}

It is now generally accepted that the ionisation produced by $\mathrm{X}$ rays is an indirect one and due solely to the eorpuscular rays; in other words, the secondary corpuscles carry all the ionising power but not all the energy. Prof. Bragg was the first to insist on the fact that $X$ rays spend little energy in their flight, and that they can therefore have little ionising action.

Beatty's results (P.R.S. 1911) on the ionisation of heavy gases- $\mathrm{SeH}_{2}, \mathrm{AsH}_{3}$, and $\mathrm{Ni}(\mathrm{CO})_{4}$ - gave great support to Prof. Bragg's theory. Beatty found that the quantity of the corpuseular rays was the same whether the substance was in the gaseous or solid condition. But indisputable proof of the correctness of Bragg's notion was given by C. T. R. Wilson from his condensation experiments (see p. 151$)$.

More recent work by Barkla and Philpot (P.BI. 1913) has established the additional fact that the relative ionisations produced by equal absorptions of $\mathrm{X}$ rays in gases are the same as those produced by the corpuscular rays.

\section{Relative Ionisation in Various Gases.}

Most of the carly experiments on gaseous ionisation were vitiated by the corpuscles released from the impact of the $X$ ravs against the electrodes or the stirface of the ionisation chamber. Crowther (P.R.S. 1908), in an investigation of the ionisation produced by heterogeneous $X$ rays in a large number of gases, took steps to avoid this difficulty. Some of Crowther's results are given in Table XVI.

With the exception of hydrogen, and possibly ethyl bromide, the degree of ionisation is evidently not affected much by the quality of the $\mathrm{X}$ rays. Owen (P.R.S. 1912) ${ }^{1}$ and Barkla and Philpot (P.M. 1913), working with a series of homogeneous $X$ rays of a great range of quality, have

${ }^{1}$ Owen's apparatus is shown on $\mu .136$. 


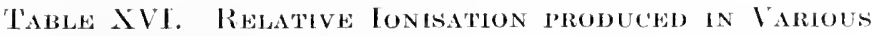
Gases bi Heterogeneous $X$ Rays.

\begin{tabular}{|c|c|c|c|c|c|}
\hline \multirow{2}{*}{ Gas or Vapour. } & & & \multirow{2}{*}{$\begin{array}{l}\text { Density } \\
\text { rekative to } \\
\text { Air }=1 .\end{array}$} & \multicolumn{2}{|c|}{ Ionisation relative to $\mathrm{Air}-1$. } \\
\hline & & & & soft $X$ Rays & Hard X Rays \\
\hline Hydrogen, $\mathrm{H}_{2}$ & - & - & 0.07 & 0.01 & $0 \cdot 18$ \\
\hline Carbon dioxide, $\mathrm{CO}_{2}$. & - & . & $1 \cdot 53$ & $1 \cdot 57$ & $1 \cdot 49$ \\
\hline Ethyl chloride, $\mathrm{C}_{2} \mathrm{H}_{5} \mathrm{Cl}$ & - & - & $2 \cdot 24$ & $18 \cdot 0$ & $17 \cdot 3$ \\
\hline Carbon tetrachloride, $\mathrm{CCl}_{4}$ & - & - & $5 \cdot 35$ & 67 & 71 \\
\hline Nickel carbonyl, $\mathrm{Ni}\left(\mathrm{C}^{\prime} \mathrm{O}\right)_{4}$ & - & - & $5 \cdot 90$ & 89 & 97 \\
\hline Ethyl bromide, $\mathrm{C}_{2} \mathrm{H}_{5} \mathrm{Br}$ & - & - & $3 \cdot 78$ & 72 & 118 \\
\hline Methyl iodide, $\mathrm{CH}_{3} \mathrm{I}$ - & - & - & $4 \cdot ! 6$ & 145 & 125 \\
\hline Mercury methyl, $\mathrm{Hg}\left(\mathrm{CH}_{3}\right)_{2}$ & - & - & $7 \cdot 93$ & 425 & - \\
\hline
\end{tabular}

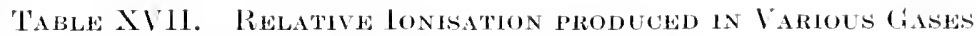
BY HomocieneOUS A RAYs.'

\begin{tabular}{|c|c|c|c|c|c|c|}
\hline \multirow{2}{*}{$\begin{array}{l}\text { Element emitting } \\
\text { Characteristic } \\
K \text { Katiliation. }\end{array}$} & \multicolumn{6}{|c|}{ Ionisation relative to $\mathrm{Air}=\mathbf{I}$. } \\
\hline & (Beatty). & (B. $\mathrm{NP}^{2}$. & $\begin{array}{c}\mathrm{CO}_{2} \\
(0 \text { wen }) .\end{array}$ & $\begin{array}{c}\mathrm{so}_{2} \\
\text { (Owein). }\end{array}$ & 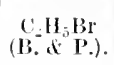 & 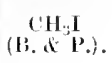 \\
\hline $\mathrm{Fe}$ & .00571 & $1 \cdot 37$ & $1 \cdot 58$ & $11 \cdot 3$ & $41 \cdot 2$ & \\
\hline $\mathrm{Ni}$ & & $1 \cdot 35$ & $1 \cdot 55$ & $11 \cdot 6$ & - & 162 \\
\hline ('n & .00573 & $1 \cdot 38$ & $1 \cdot 55$ & $11 \cdot 8$ & 42 & 152 \\
\hline Zin & .110570 & $1 \cdot 42$ & $1 \cdot 54$ & $11 \cdot 5$ & $+1 \cdot 6$ & \\
\hline As & .00573 & $1 \cdot 27$ & $1 \cdot 51$ & $11 \cdot 7$ & $42 \cdot 2$ & 158 \\
\hline Se & & $1 \cdot 31$ & $1 \cdot 53$ & $11 \cdot 8$ & $41 \cdot 7$ & \\
\hline $\mathrm{si}$ & & $1 \cdot 28$ & $1 \cdot 53$ & $11 \cdot 8$ & 153 & \\
\hline Mo & & $1 \cdot 28$ & $1 \cdot 54$ & $11 \cdot 5$ & $21: 3$ & IsS \\
\hline Apr & & $1 \cdot 32$ & & & 272 & $19 \mathrm{~s}$ \\
\hline Sil & .04 & $1 \cdot 29$ & & & $3: 35$ & 20.5 \\
\hline $\mathrm{sb}$ & & $1 \cdot 28$ & & & & - - \\
\hline 1 & & - & & & & 211 \\
\hline Bit & & 一 & & & & 2.51 \\
\hline
\end{tabular}

B. \& P., Barkla and Philpot.

${ }^{1}$ All the secondary radiations exeept scattered $\mathrm{X}$ rays were completely absorbed in the gas. With ethyl bromide and methyl iodide, however. this was not the ease with the $\mathrm{X}$ rays hard enough to exeite the charracteristic radiations of bromine and iodine respeetively. 
established the lact that the ionisation is independent of the hardness of the $X$ rays. The one proviso is that no characteristic radiations shall be excited in the gas. If a characteristic radiation is generated, both the ionisation and absorption are usually increased. These results are apparent fiom Table XVII.

\section{Total Ionisation in Various Gases.}

Owen derived also the important result that the total number of ions produced by the complete absorption of a beam of homogeneous $X$ rays in a gas is the same no mattel what the hardness of the rays or the nature of the gas, so long as the characteristic radiations are not excited. 'This result was extended and confirmed by Barkla and Philpot, who also showed the parallel effect for corpuscular rays, and that the total ionisation produced by a beam of homogeneous corpuscular rays is independent both of the velocity of the corpuscles and of the nature of the absorbing gas.

In regard to mixed gases the eonditions are complieated,

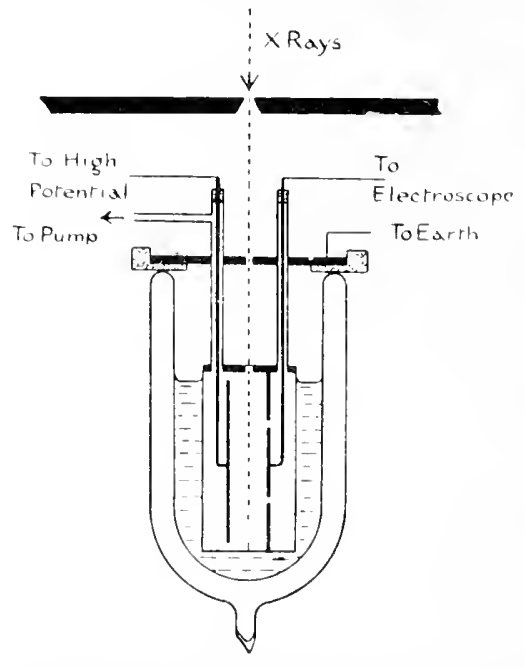

Ela. 72- Crowther's apparatus for showing that the degree of ionimation by $X$ rays in a gas is independent of the temperature. The guardring devios will be noticed. The apparatus is here showit as armaged for hiqud-air tempurature. and the results are difficult of interpretation. It appears probable that an additive law does not holel (Barkla and Philpot, P.M. 1913), and that when a mixture of two gases is traversed by $X$ rays the observed ionisation differs eonsiderably from the sum of the ionisations that would be observed if the pencil of $X$ rays went through the gases separately.

Ionisation and Temperature.

In 1909 Crow ther(P.R.S.) showed that the ionisation produced by $X$ lays was 
independent of the temperature, provided the density was kept constant. In these experiments, Crowther used a range of temperature from about $-180^{\circ}$ to $+184^{\circ} \mathrm{C}$., and took especial eare that the $X$ rays did not strike the testing electrodes. His apparatus as arranged for liquid air temperatures is shown in Fig. 72 .

\section{T. R. Wilson's Condensation Experiments.}

C.T.R. Wilson (P.R.S. 1912), in a series of remarkable experiments, has recently succeeded in rendering visible and photographing the tracks of the charged ions which are produced when a beam of $\mathrm{X}$ rays (or radium rays) passes through a gas. The method is based on the fact that supersaturated water vapour deposits on ions---just as it does on dust particles-and forms tiny drops. Thus the trail of a beam of $\mathrm{X}$ rays, itself invisible, becomes marked by a crowded line of cloud.

Wilson has been able to take instantaneous photographs of these condensation nuclei in the positions which they oceupied immediately after their liberation by the $\mathrm{X}$ rays.

Fig. 73 shows the apparatus. The air within the shallow condensation chamber was kept completely saturated with moisture by means of water in the bottom of the vessel. Supersaturation was produced by suddenly inereasing the volume of the chamber by exposing the under side of the movable bottom to a vacuum chamber. This was effected by a sharp pull (to the left) on the cord shown (in Fig. 73). which opened the valve below the eondensation apparatus. After the release of the valve, the cord pulled up with a jerk, the heavy weight attached to it was thus suddenly arrested, and the fine thread below it carrying a steel ball. snapped and the steel ball fell. In its descent, the ball passed in suceession through two spark-gaps. The first passage caused a Leyden jar flash through the X-ray bulh : the second similarly excited the illuminating spark.

The arrangements were such that a horizontal beam of X rays crosiced the centre of the chamber ; the illuminating spark flashed a peneil of light at right angles to the beam of X rays, and horizontally, or nearly so: and the camera 
was usually mounted horizontally on the opposite side of the chamber to the illuminating spark. An electric field was maintained between the upper and lower faces of the exjansion chamber.

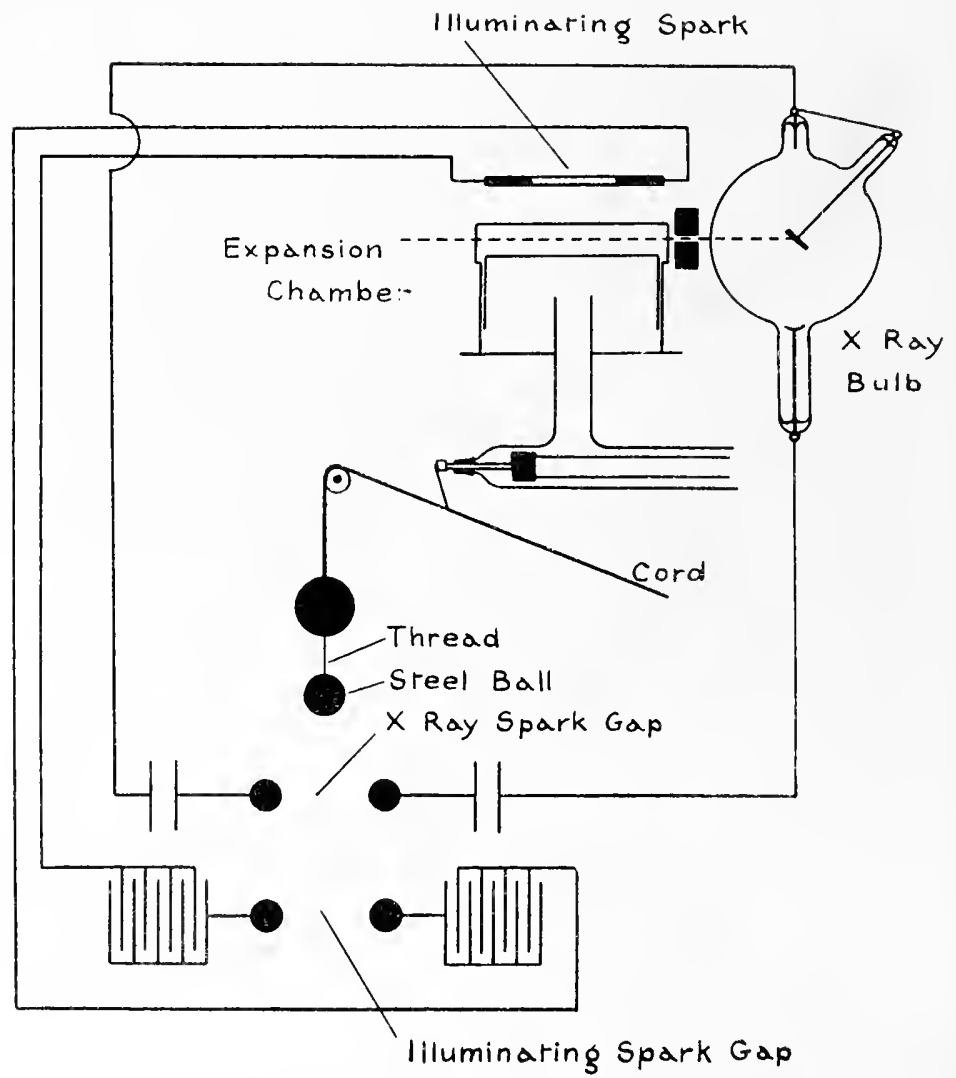

F19. 73.- Diagrammatic representation of C. T. R. Wilson's apparatus for photographing tlee track uf a beam of $\mathbf{X}$ rays in moist air.

The order of events in an experiment was, therefore, (1) expansion produeing supersaturation, (2) X-ray discharge producing ionisation in the elond chamber, (3) condensation of water on the ions, (4) passage of the spark for photographing the cloud tracks.

Wilson's instantaneous photographs (see Figs. I and 74) 
show the tracks of corpuscles starting within the beam of $\mathrm{X}$ rays and extending for some distance beyond it. There is no indication of any activity on the part of the $X$ rays other than the production of eorpuscles: and the track of the $\mathrm{X}$ ray is not distinguishable otherwise than as being the region in which corpuseles have their origin. The clond

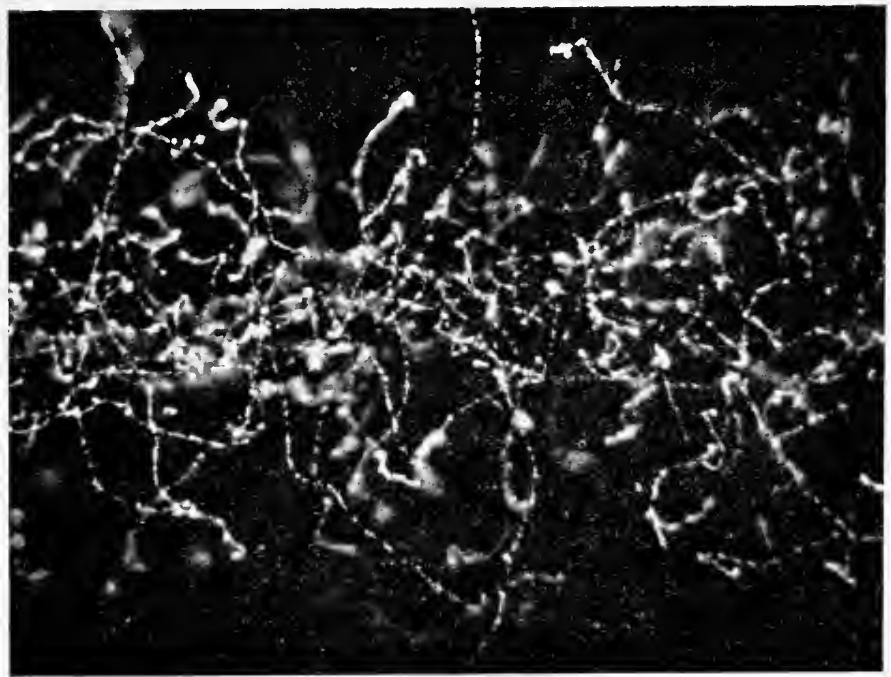

FIG. 74.-Photograph obtained hy C. T. R. Wilson of the path of a beam of $\mathrm{X}$ rays in air supersaturated with moisture (see p. 149). The beam of rays. about $2 \mathrm{~mm}$, in chameter, traversed the air (from ieft to right of the picture) immediately after the expansion which produced the supersaturation. The axis of the camera was horizontal, and the magnification of the photograph is 6 diameters.

trails show that the corpuscles start in all directions from within the path of the primary beam : they do not appear to exhibit preference for any particular direction.

The result is striking confirmation of the view whieh Prof. Bragg has advocated for some years-that the $\mathrm{X}$ ray is completely inoffensive and innoenous during its life, and that only on its disappearance does the effective agentthe corpusele-come to life. Ionisation by $\mathrm{X}$ rays appears, therefore, to be entirely a secondary process.

Fig. 2 shows a pencil of $\mathrm{X}$ rays passing obliquely through a eopper plate. The transmitted beam, though much less 
dense than the initial beam, can be plainly seen. From the copper issue corpuscular rays in all directions; these, which are responsible for the "halo" round the sheet, prove to be mostly of relatively long range. The characteristic copper radiation also excites corpuscular rays in the air, the majority of which have only a range of about $1 \mathrm{~mm}$. at atmospheric pressure, and are to be found scattered throughout the vessel. This may be compared with the $1 \mathrm{~cm}$. to $3 \mathrm{~cm}$. tracks of corpuscles from the primary X-ray beam. If silver is used instead of copper, the secondary corpuscles have a much longer path. The clear space shown on both sides of the copper sheet in Fig. 2 is due merely to the heat of absorption of the $\mathrm{X}$ rays and the consequent formation of a region of air which is not saturated.

Wilson attempted to display the crystal-reflection of $\mathrm{X}$ rays (see p. 186) by means of the above apparatus, but, for some reason, the reflected beam was ineffective in producing ions, and the plan did not succeed.

\section{Velocity of X Rays.}

In 1906, Marx in Germany published the results of an ingenious and elaborate investigation on the speed of the Röntgen rays. He excited an X-ray bulb by means of electric waves from an electrical-wire system; these waves also charged to a varying potential an insulated plate on which the $\mathrm{X}$ rays fell. The secondary corpuscles emitted from this plate were collected by a Faraday eylinder connected to an electrometer: the amount was obviously controlled by the phase-relation between the potenial of the plate and that of the cathorle of the Röntgen-ray bulb. If the various distances and the connecting wire lengths were adjusted so that the charge received by the Faraday cylinder was (say) a maximum, then it was found that if the distance of the $\mathrm{X}$-ray bulb from the insulated plate was increased by a certain amount, the wire along which the waves travelled to the plate harl to be lengthened by the same amount to restore the maximum. Thus. according to Marx, the Röntgen rays travel with the same velocity as 
electrie waves along wires, and, therefore, with the velocity of light, at any rate to within 5 per cent.

Marx's experimental arrangements were subjected to severe eriticism by Franck and Pohl, who, having repeated the experiments, doubted the validity of the method. In reply, $\operatorname{Iarx}$ (A.d.P. 1910 et seq.) has since carried out a new series of experiments which, he elaims, support his original result, but whieh nevertheless do not appear to have satisfied his crities (A.d.P. 1911).

All this work was carried out before the nature of the $\mathrm{X}$ rays was known; and there is now no reason for believing that $\mathrm{X}$ rays travel with a velocity other than that of light. 


\section{CHAPTER XI.}

PRACTICAL APPIICATIONS OF X RAYs.

\section{RaDiogRaphy.}

As extended treatment of this most important branch of the subject can be found in a number of existing works; it does not form part of the scope of this volume. A few points may, however, be noticed. A radiograph is, of comrse, nothing but a shadow picture, and natmrally care must be taken to place the subject symmetrically with regard to the bulb, so as to avoid unneessary distortion of the image. For perfectly sharp images, the $X$ rays should obviously proceed from a single point on the anticathode, but this, as has been remarked, is impracticable, and so it is usually beneficial to stop down the rays as much as is feasible. For this purpose, lead tube diaphragms are often employed, and can, in some medical cases, be made to serve a double purpose-for example, the kidneys, which are in continual periodic motion, can be arrested temporarily, for radiographic purposes, by pressing down such a tube tightly into the abdomen.

The greater the distance of the bulb from the fluorescent sereen or photographic plate, the more correct the picture; in practice the distance is nsually from 12 to 24 inches. The spark-gap should not exeeed 10 to 12 inches. With longer spark-gaps, rays too hard for radiographic purposes result. ${ }^{1}$

${ }^{1}$ In the same way, radiographs ohtained by radium $\gamma$ rays show mly slight contrast hetween substances of different density. 


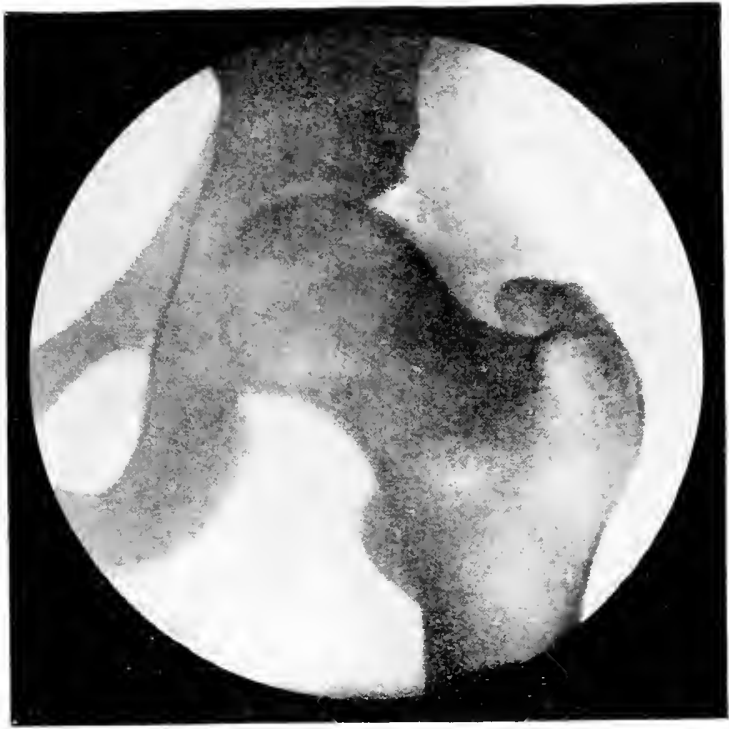

FIG. 75.-Radiograph of the hip-joint

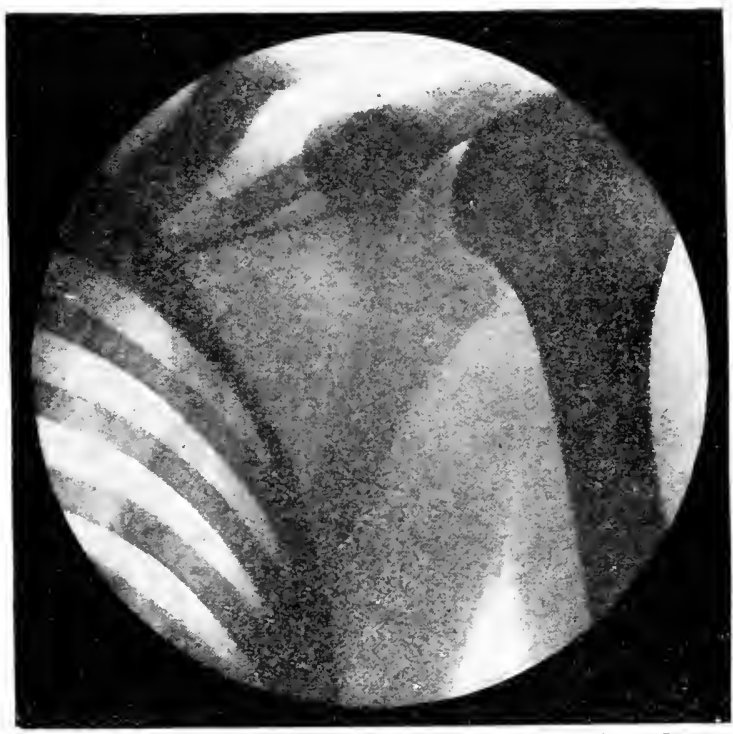

Fig. 76.--Rarliograph of the shoulder

Siemems Bros. 
Photographic exposures naturally vary enormously with the eoil, break, and tube used. With a hammer break, a 10-inch spark, and a tube in average condition, some 5 to

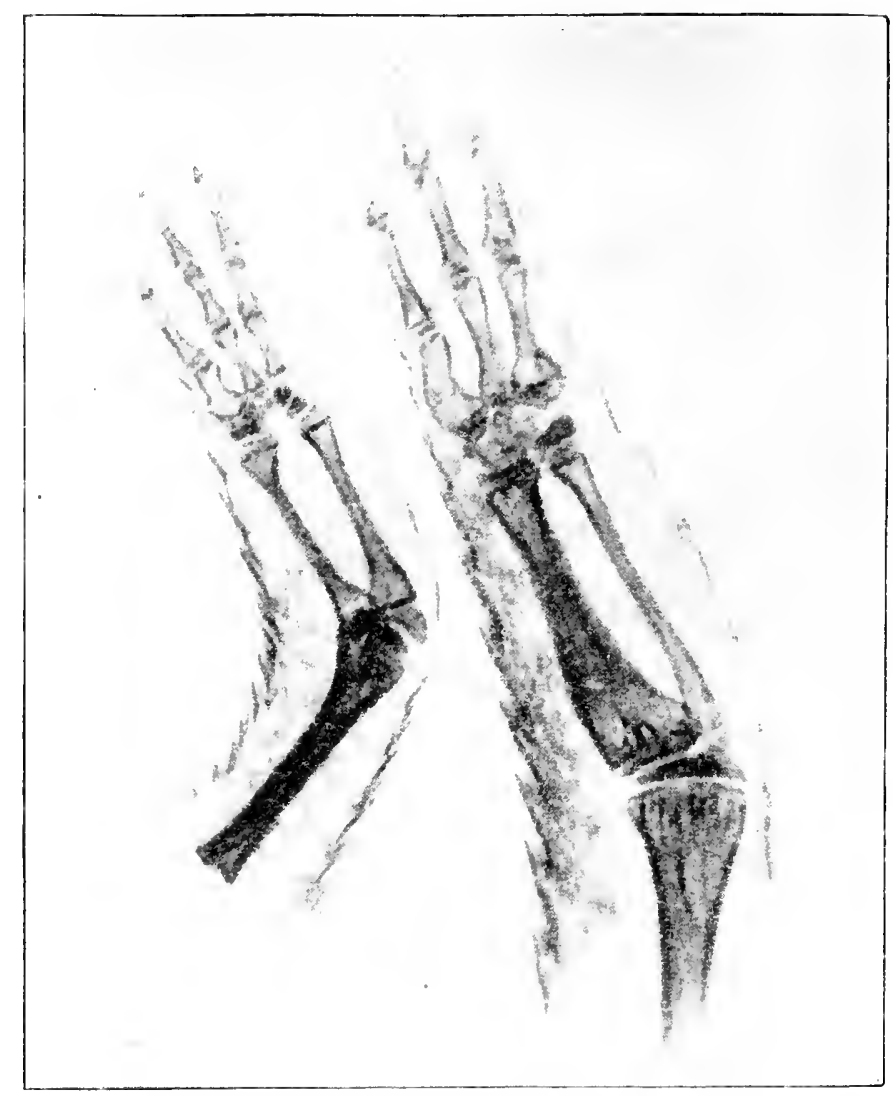

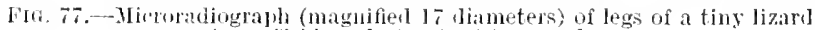
(seps Tridactylus). lis l'ierre cioby.

10 seconds is suitable for the hand: 20 to 30 seconds for the ankle: and a minute or more for the thicker parts of the borly. The latitude in X-ray photographic exposure is large, though it is important to avoid moler exposure.

The photographice plates anc placed with the film towards the bulb, amel most photographers agree that slow derelop- 
ment is useful for work such as this, where full detail is required. Two examples of modem radiography are shown in Figs. 75 and 76 .

As examples of uses other than medical for the $X$ ray's, one may notice their former employment in the Ceylon pearl-fishing industry to locate pearls in oysters withont opening the shells. The degree of transparency to $\mathrm{X}$ rays serves as a means of differentiation between paste and real diamonds: the heavy lead glass is much more opaque than the natural gem.

By the use of extremely soft $X$ rays, radiographs have recently been obtained of, for example, the soft tissues of the body (showing the veins and nerves), the wings of insects, the venation of leaves, and the structure of flowers. Radiomicrography of tiny objects forms one of the latest achievements of X-ray manipulation, an example of which by M. Goby (A.Rt.R. Dec. 1913) is shown in Fig. 77.

\section{Bismuth Radiography.}

The alimentary system may be radiographed by rendering the required part temporarily opaque through the administration of bismuth salts or emulsions with the food. This increases the contrast in the photograph. Fig. 78 show a good illustration of the method. Thorium oxide and barium sulphate are also used. A word of caution should be added, for the pronounced and very soft secondary rays that bismuth and other heavy metals emit, may actually be injurious. Chemical combination does not affect the rays from the constituent elements, so that bismuth salts give off secondary rays just like those from bismuth metal.

\section{Stereoscopic Radiography.}

In this work, two distinct pictures are taken in turn by moving the X-ray tube, between the exposures, 2 or 3 inches parallel to the surface of the plate, the distance between tube and subject being about 20 inches. The resulting photographs are examined in a stereoseope. The method affords a means of ascertaining the depth of a foreign substance in the body, and is often of great assistance in 


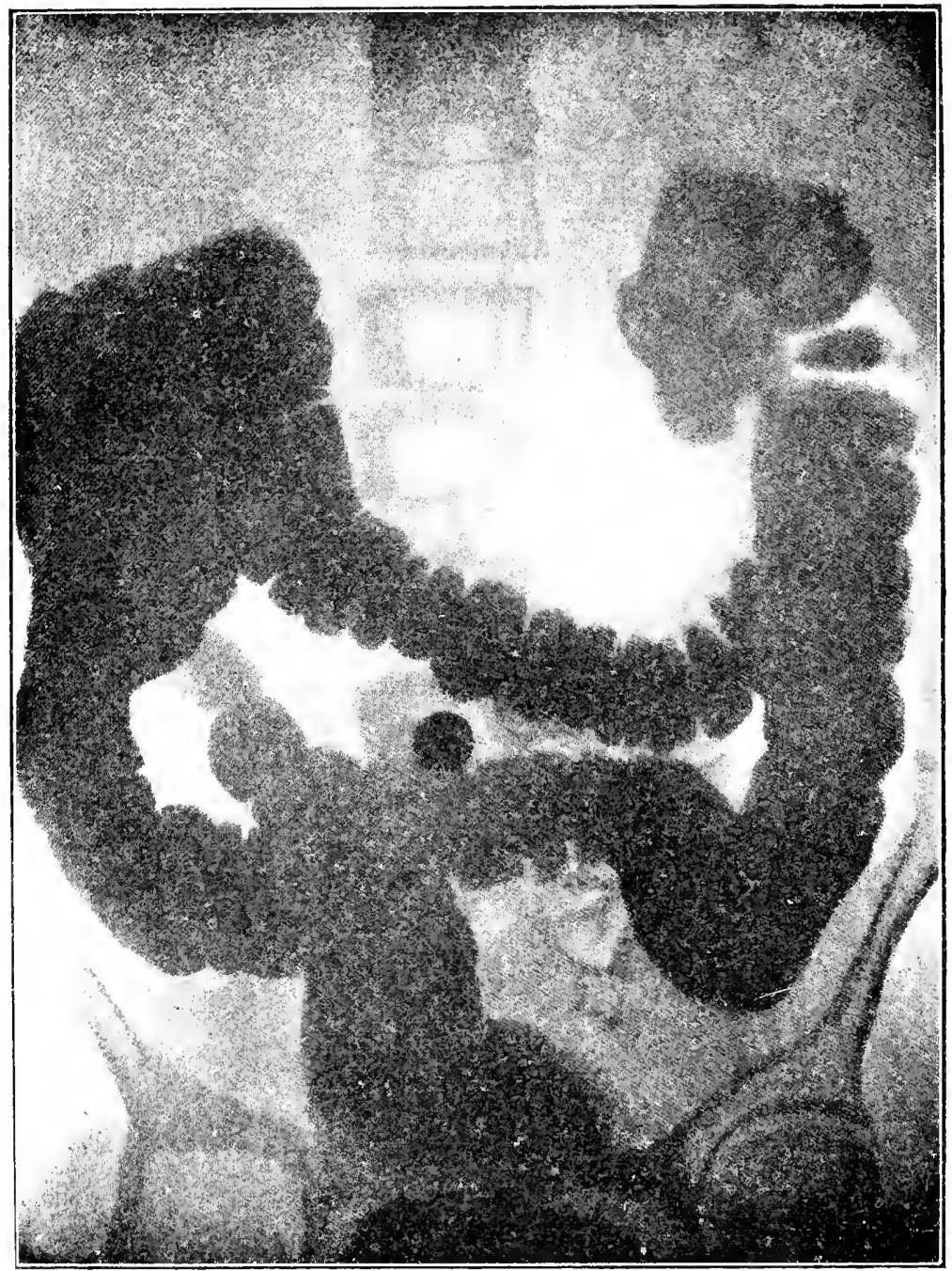

siruitures's.

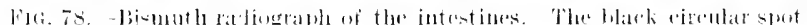

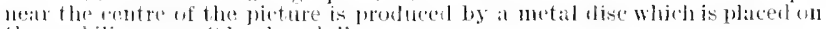
flu* Imblulions als al "landmatk."

diagnosis. There are other types of localisers, somene of which display much ingemuity of design; they aran be found fully described in the maker's catalogues. 


\section{Instantaneous Radiography.}

It is a far ery from the prolonged exposures in the early days of $\mathrm{X}$ rays to the instantaneous work that is possible with modern apparatus. Nowadays, snapshots can be taken through any part of the body, and almost any of the moving organs can be radiographed. The worker who requires exposures short and frequent enough for, say, einematograph films now experienees no diffieulties out of the ordinary.

If a single rapid photograph is all that is required, it is possible to secure it by comparatively simple means, and to send through an X-ray tube momentary currents of a magnitude undreamt of a few years ago. One method for obtaining practically instantaneous radiographs is to join the primary of a modern heavy current induction coil, or other high-tension transformer, straight to the direet-current town-lighting mains with the usual fuses in circuit. When the eurrent is switehed on, the fuses are immediately blown, and the consequent interruption of the current produces a powerful discharge through the seeondary winding and the Röntgen tube in eireuit with it. For such rapid exposures a simple X-ray tube without cooling and regulating devices suffices. Dessauer in 1909, by using a type of explosive fuse for the break, was able to take single flash radiographs with exposures of the order of $1 \frac{1}{10}$ sec. The momentary current through the tube was some 200 milliamperes or more, and the alternative discharge in air consisted of a broad band of flame 40 to $50 \mathrm{cms}$. long.

Sir James Mackenzie Davidson has recently succeeded in radiographing a bullet leaving the muzzle of a revolver. The bullet in its flight over the surface of a photographic plate broke the primary circuit of a coil somewhat after the fashion employed by Mr. Boys some twenty years ago in his flying-bullet photography. The resulting flash through a suitably disposed $\mathrm{X}$-ray tube in the secondary circuit gave a shadow photograph of the bullet.

Perhaps even more remarkable are Dr. Worrall's reeent experiments with a monster coil having a eore weighing some 3 hundredweights. With a primary eurrent of from 40 to 80 amperes at 240 volts, and the use of an explosion 
break, flash currentis of the order of 1.4 amperes lasting for an interval of from $\frac{1}{00}$ to $\frac{7}{1000}$ second were sent through al X-ray tube. The intensity of the discharge was such is to be capable of chiselling out a piece of metal from the anticathode and leaving a pit behind. Dr. Worrall has obtained very beautiful instantaneous radiographs by means of his apparatus.

The possibilities of the extension of such experiments its these are far from being exhausted. A transformer which weighs about half a ton was referred to by Mr. Duddell in his Presidential Address to the Institution of Electrical Engineers (1912). Given a eloser co-operation between the medical profession and the electrical engineer, mammoth apparatus and extrabdinary results may be looked for in the future.

\section{Intensifying Screens.}

But by the aid of intensifying screens (a device which dates back to 1897 ), instantaneous radiography is possible with a much less formidable equipment. The recent inprovements in such screens have removed the defects of grain, ete., which formerly militated against their extensive employment. The Sunic sereen, for example, is coated with a tungstate of calcium, which, fhoreseing as it does with a very actinic bluish light, is capable of reducing an exposure twentyfold. The screen is placed in close contact with the film of the plate and the $X$ rays are sent through the screen before reaching the plate. Owing to the after-huminescence, which persists for some minutes, the sereen should either be removed immediately after the exposure or not be disturbed for some little time.

\section{$\mathrm{X}$-ray Photographic Plates.}

'The large demand for photographic plates in radiography has brought about the introduction, by several firms, of plates specially coater for X-ray work. Dr. Kenneth Mees is responsible for a photographic plate ${ }^{\mathbf{1}}$ which presents some novel features. The plate is coated with an umusually thick

1 The Wratten and Wainwright $\mathrm{X}$-ray plate. 
emulsion containing a heavy metal along with the silver. The emulsion is thus rendered dense enough to arrest and record most of the incident rays, and the confusing secondary radiation from the glass backing is avoided. The result is a gain in definition and detail without any sacrifice in speed and contrast.

\section{Plastic Prints.}

On account of the pictorial beauty of the results, this method of printing deserves mention. From the original negative, a positive is printed on a lantern plate. The positive and negative, which should be equally dense, are mounted in accurate register, glass sides together. A print is then taken by means of light incident at an angle of about $45^{\circ}$, and a pieture thus obtained which shows psendorelief. Fig. 79 shows an example of plastic printing.

\section{Physiological applications of X Rays.}

\section{X-ray "Burns."}

The dangers of indiscriminate exposure to $\mathrm{X}$ rays are now common knowledge, but some of the pioneers in X-ray work bought their experience at the price of their lives. Undue exposure results in severe dermatitis or skin disease, followed in chronic cases by large and cancerous ulceration, scaling and shedding of the nails. Unfortunately, the extremely painful progress of the disease does not appear to be arrested by avoiding further exposure to the rays. Nor is there any known means of hastening recovery, though, according to Sir James Mackenzie Davidson, some relief and improvement has been obtained in superficial cases by the application of radium to the affected part in " doses" of some minutes at a time.

\section{Protective Devices.}

It is now known that X-ray "burns" are mainly due to the absorption by the skin of the very soft rays; such rays are easily arrested by sereening. The various protective devices (gloves, spectacles, aprons, etc.), now always 
employed for the safety of workers, rely on the absorptive properties of lead or leal salts in some form or other.

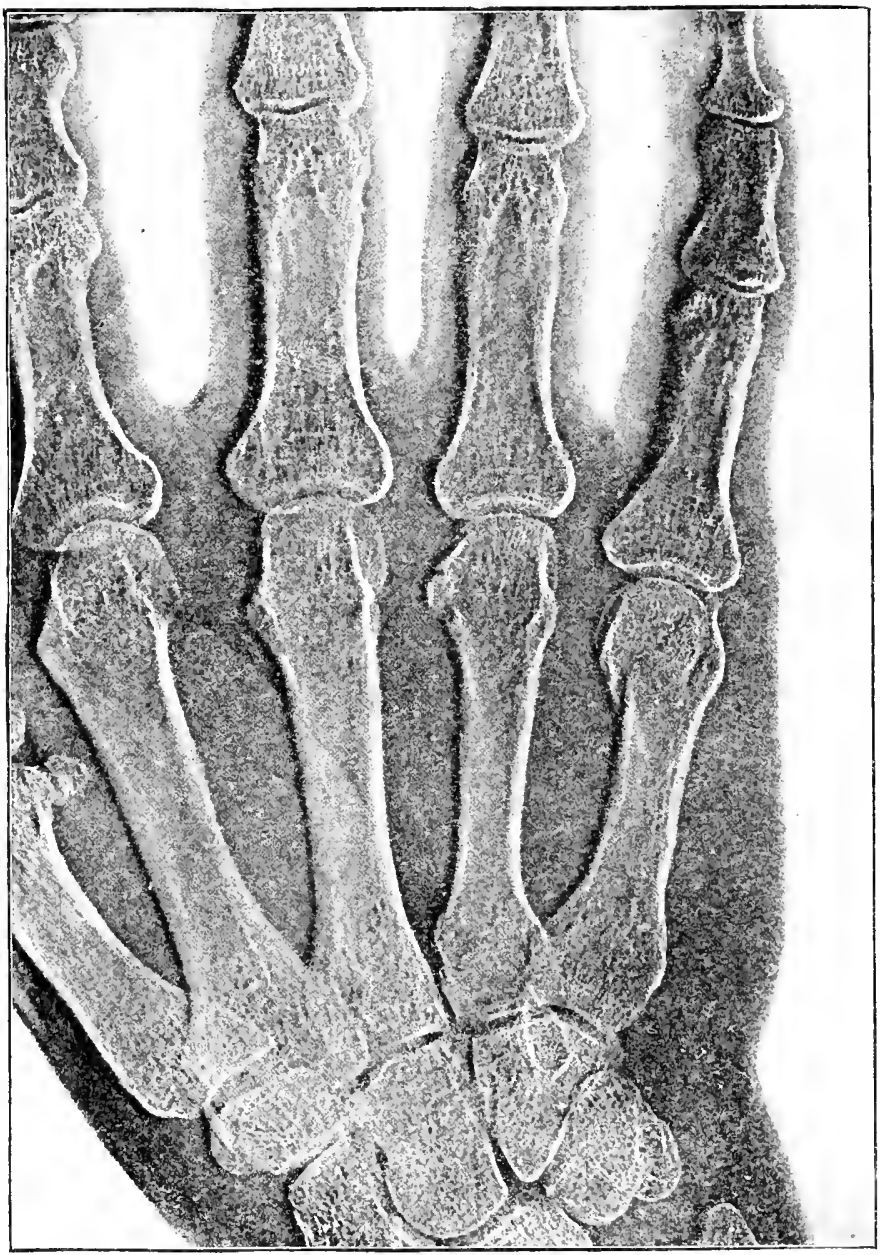

r. Thurstan Bullowt.

Fic, 79.- Plastic print of hand, showing fracture of heads of fourth and fifh metacalpal boues.

Impregnated rubber is often used, and Droit (C.R. 1912) has recently suceeceded in heavily loading silk tiscue with phospho-stamite of lad (up) to about $6 \mathrm{~s}$ per cent.), and 
so producing a material which, while extremely light and supple, affords adequate protection against the rays.

The Röntgen bulb is fitted with a lead glass sheath, or, in some instances, the bulb itself is made of lead glass provided with a window of soda or lithia glass to allow the rays to get out. Fluorescent screens used for examination work should be faced with lead glass (not less than 5 to $10 \mathrm{~mm}$. thick) on the side remote from the bulb.

For long continued exposures, the German Röntgen Society advocates as a protection for the body the following thickness of sereen :

$\begin{array}{llll}\text { Lead - } & - & - & 2 \mathrm{~mm} . \\ \text { Lead-impregnated rubber - } & 8 \mathrm{~mm} . \\ \text { Lead-glass - } & - & - & 10 \text { to } 20 \mathrm{~mm} \text {. }\end{array}$

\section{Physiological and Curative Action of X Rays. ${ }^{1}$}

It might be anticipated that an agency possessing such vital eharacteristies would, under control, find a wide field of application in the treatment of disease. This has proved to be the case, and, as their technique is being improved, the $\mathrm{X}$ rays are finding a sphere of activity quite dis inet from that of radiography. The method of "dosage" is usually that of the pastille (see p. 94) assisted by a tacheometer (or speed-counter) on the mercury break.

In many skin diseases, the action of the rays has been turned to account and has proved to be of notable service. The effects are not, however, confined to the skin; some of the internal organs, notably the spleen, are found to be even more susceptible. Happily the nervous system generally is not at all sensitive to the rays. One of the most. striking physiological effects of Röntgen rays is their action on the growing cells of the young; the growth of young animals is greatly stunted by the rays; the adult animal shows a greater capacity for resistance. Sweat glands and hair follicles are attacked and ultimately destroyed-a property which provides a signal cure for ringworm, and, with prolonged exposure, is eapable of producing total baldness.

\footnotetext{
${ }^{1}$ The writer is indebterl to a lecture by Sir James Mackenzie Davidson, at the Royal Institution in 1912 , for much of this section.
} 
The white corpuscles of the blood are affected by $\mathrm{X}$ rays, but the red corpuscles are very resistant. The treatment has been largely and successfully employed for rodent ulcers, but experience has shown that it does not provide a cure for malignant tumours and large cancerous growths, though it may arrest their rapidity of growth : this is equally true of radium treatment, though in this case the ontlook seems more hopeful. Apparent success has resulted from the employment of $\mathrm{X}$ rays in cases of tuberculosis of bones and joints. Curiously enough, Röntgen rays seem to have little or no action on bacteria, and, in this respect, stand out in marked contrast to ultra-violet light, which is most destructive to all forms of bacteria. $\mathrm{X}$ rays (and $\gamma$ rays) induce a sensation of luminosity in the retina, so that the shape of interposed obstacles can be made out by a blind-folded normal eye or even by a cataract-affected eye. A totally colour-blind eye may be abnormally sensitive to $X$ rays.

\section{Suitable Rays for Therapeutics.}

In the therapentic use of $\mathrm{X}$ rays, the one essential is tha: the rays shall be sufficiently hard to reach and be absorbed by the discased tissue. In treatment of the skin the very softest rays are the useful ones, but to do any good to more deep-seated parts harder rays are required. In this case the less penetrating rays should be removed to avoid their prejudicial action on the skin. An aluminium sereen $\frac{1}{2}$ mm. thick is generally sufficiently thick for the purpose. One difficulty in treating deep-seated tissue is that the harder rays are mainly seattered instead of being absorbed by the tissue. This small energy absorption means that the curative effects must be feeble. They could, of course, be enhanced artificially in some eases by bismuth treatment or the like.

It may be adcled that the therapentic effect of $\mathrm{X}$ rays often evidences itself prononneedly in the proximity of bones: this is probably due in part to the characteristic radiation emitted by the calcium of the bone. Similarly, zine and other metallic ointments might be employed to angment the effect in superficial treatment. 
The practice, which is often followed, of employing the same X-ray bulb for both curative and radiographic work is, of course, wasteful. Rays which are useful in therapeutics are obviously unsuitable for radiography, as in the latter case the essential thing is that the rays should not be absorbed, but should reach the photographic plate. ${ }^{1}$ As was remarked on p. 37, the iron, nickel, copper group of metals, when used as anticathodes, emit radiations very rich in soft rays, such as are suitable for curative work. There is no necessity for using a point souree of $\mathrm{X}$ rays in therapeutic work, and, in fact, the anticathode can advantageously be put out of focus, or, if necessary, a plane cathode used.

\section{Glasses specially Transparent to Soft X Rays.}

A bulb intended for skin treatment should be cither made of a glass specially transparent to $\mathrm{X}$ rays or provided with a window of such glass. Schott in 1899 was the first to make up a glass of this kind-a silico-borate of soda and alumina-as the result of experiments on the transparency of various oxides and carbonates to $X$ rays. His list reads in order of diminishing transparency-Li, B, Na, $\mathrm{Mg}, \mathrm{Al}, \mathrm{Si}, \mathrm{K}, \mathrm{Cu}, \mathrm{In}, \mathrm{As}, \mathrm{Ba}$, and $\mathrm{Pb}-\mathrm{a}$ sequence which is that of atomic weight. Schott's glass was never put on the market, as at that time the radiographic propertics of the $\mathrm{X}$ rays were the only ones considered, and in this respect the glass possesses no appreciable advantage over soda glass. C. E. S. Phillips' conducting glass (P.R.S.E. $1906)$, which is a mixture of silicate of soda and borax with a little lead glass, is also very transparent to $\mathrm{X}$ rays. Its coefficient of expansion is unusually high, but by the use of intermediate glasses, windows of it could probably be fused into X-ray tubes. Lindemann (1911) has recently constructed focus bulbs provided with windows of a glass of lithium borate, which, of all the glasses ever made, is probably the most transparent to soft $X$ rays. This glass

\footnotetext{
1 'The same thing oceurs in the use of radium. The highly penetrating $\gamma$ rays have no medical value; it is the softer $\gamma$ and the $a$ and $\beta$ rays which are arrested by the body.
} 
is not very permanent, however, but Messis. Cossor have recently brought out an improved lithium glass which can be worked and permits joints with platinum, so that X-ray bulbs can be constructed entirely of it (Fig. 45).

\section{Therapeutic Use of Characteristic Radiations.}

It has been suggested that the various characteristic radiations p. 112) would find application and lead to greater precision and efficiency in curative X-ray work. These ladiations are each of uniform quality, and it is, therefore, only a question of choosing a suitably hard radiation for the purpose in hand. But characteristic $\mathrm{X}$ rays, as ordinarily generated, are so feeble that hours of exposure are required in place of the minutes necessary with primary $X$ rays from a bulb. The writer showed, however, in 1908 (p. 121), that, with a soft bulb, a considerable proportion of the rays from an anticathode may consist of its characteristic radiation. By this means, an intense beam could be obtained from a tube provided with a suitable metal for anticathode and a window of thin glass or aluminium. It is further advantageous to use a thin filtering screen of the same metal as the anticathode. Better still, perhaps, in some respects, would be to make the window itself of the metal whose radiation is desired and to use the window also as anticathode. Such a tube with a window soldered to the glass was, in fact, used by Owen (see p. 136).

\section{Therapeutic Use of Cathode Rays.}

If, as Prof. Bragg has long maintained, and, as is now generally believed, the $\mathrm{X}$ ray is in itself ineffective and owes all its activity-physical and chemical-to the electrons which it produces when arrested, then the only purpose the $X$ ray serves in therapeutics is to plant the action deeper in the body. To produce therapeutic action at any particular point, there must first of all be transformation of the $X$ rays into corpuseular rays, and then absorption of these corpuscular rays. If cathode rays themselves were simply discharged at the skin by means, say of a Lenard tube (p. 5), they could not penetrate more than about 
if $\mathrm{mm}$. i.e. about the thickness of a cigarette paper. ${ }^{1}$ Possibly such a treatment might be valuable for some surface ailments, more especially as the radiation would certainly be accompanied by an abundance of very soft $\mathrm{X}$ rays from the aluminium window.

1 The $\beta$ rays of radium with their higher veloeities penetrate, of course, much farther. 


\section{('HAP'TER XII.}

\section{INTERFERENCE AND REFLECTION OF $\mathrm{X}$ RAYS.}

\section{Early Attempts to diffract X Rays.}

From time to time, a good deal of ingenuity has been exereised by various experimenters in testing whether there are, on the boundaries of the shadows east by sullall obstacles, variations in the intensity of the $\mathrm{X}$ rays corresponding to optical diffraction fringes. Röntgen (1898) could not satisfy himself on the point. Haga and Wind (Wied. Ann. 18991901) experimented with a V-shaped slit, a few thousandths of a millimetre broad at its widest point, and obtained, in their photographs of the slit, broadenings of the narrow part of the image: if the effect were due to diffraction, the same amount of broadening with light would be associated with a wave-length of about $1.3 \times 10^{-8} \mathrm{~cm}$.

It must be confessed that the result is in accorlanee with those recently obtained by erystal-reflection methods (p. 201), but Walter and Pohl (A.d.P. 1908), who repeated Haga and Wind's experiments, found that the width of the image of the slit was largely affected by secondary effects in the photographic plate depending on the amount of energy sent through the slit, with the result that different times of exposure gave rise to images of different widths. They conchuded that the diffraction effect was not proven, and that their own experiments went to show that the wave-length of an $\mathrm{X}$ ray does not exeeed $10^{-9} \mathrm{~cm}$.

\section{Attempts to refract $\mathrm{X}$ Rays.}

Many attempts have also been made to refract $X$ rays. Röntgen, for example, tried prisms of a variety of material 
such as ebonite, aluminium, and water. He also attempted to eoneentrate the rays by lenses of glass and ebonite. Chapman (P.C.P.S. 1912) experimented with a prism of ethyl bromide vapour-a substance which is strongly ionised by $\mathrm{X}$ rays. Two distinct experiments were condueted, in which the conditions might have been expected to favour a positive result. In one, the $\mathrm{X}$ rays were such as to stimulate markedly the radiation eharacteristie of bromine ( $p$. $132)$; in the other, the rays were of a type that was selectively absorbed by the vapour. In neither case, however, eould any trace of refraction be diseovered.

\section{Reflection Experiments.}

Many fruitless efforts have also been made to reflect $\mathrm{X}$ rays. We now know that the obstacle in the way of stecess to such experiments was the extreme shortmess of the wave-length of the $\mathrm{X}$ rays. The speeular reflection of ordinary light waves is rendered possible by the faet that the irregularities remaining in a polished surface are small compared with the wave-length of light. But irregularities negligible for light waves become all important with $\mathrm{X}$ rays, and a refleeting surface, such as mereury or plate glass, deals with $\mathbf{X}$ rays in mueh the same way as a surface covered with immumerable facets scatters light rays in all directions with no trace of regular reflection as a whole.

It was Prof. M. Laue of Munich who, believing that $\mathrm{X}$ rays were short light rays with wave-lengths of an atomic order of magnitude, ${ }^{1}$ coneeived in 1912 the notion that the regular grouping of the atoms in a crystal, which modern crystallography affirms, should be capable of producing interferenee effeets with the $X$ rays, in a way analogous to that in which diffraction gratings deal with light waves. Laue's theory was at once put to the test and triumphantly justified by Friedrieh and Knipping (A.d.P. 1913). Later, W. L. Bragg, at Cambridge, showed that $\mathrm{X}$ rays were regularly

1 Planck's theory of radiation lad led Wien in 1907 and Stark in 1908 to values of $0.7 \times 10^{-8}$ and $0.6 \times 10^{-8} \mathrm{~cm}$. respectively for the wave-length of an $\mathrm{X}$ ray. 
reflected by cleavage planes of erystals, and could apparently be focussed by bent shects of mica. These experiments and their later developments we may now consider in some detail.

\section{Laue's Theory.}

Crystallographers have gradually developed the theory introduced by Bravais in 1850, which eontemplates the atoms of a crystal as residing at the angular points of a "space-lattice." In a crystal, like atoms are regarded as forming a perfectly regular system of points in space, each and every kind of atom present in the crystal conforming to its own independent system. These different point-systems,

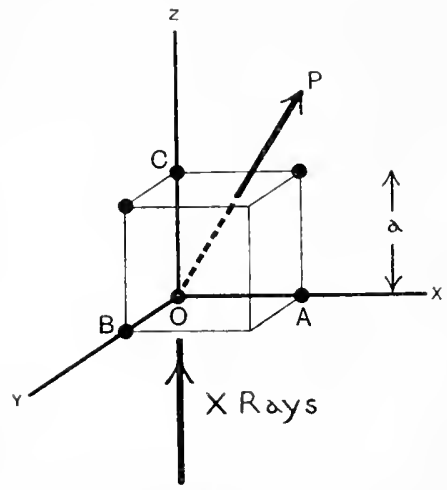

Fig. s0.- Representation of the diffraction of $\mathrm{X}$ rays by the atoms at the corners ui an elementary cube of a cubic crystal. of course, interpenetrate, the result being a parallel net-like arrangement of points, to which the term "space-lattice" is applied. Thus the crystal naturally divides itself up into a large number of precisely identieal elements, in all of which the same relative positions of the atoms are maintained. This elementary volume is, in a sense, the brick from which the erystal pattem is built up everywhere after the same plan.

The several atoms thus repeat themselves at definite intervals, and Laue's notion was that the resulting regular avenues of atoms should be capable of acting as a threedimensional diffraction grating for rays of suitably short wave-lengths.

Lane first considered the case of a simple cubic crystal, and assumed that the atoms were arranged at the corners of little elementary cubes-this being the simplest eubic point-nystem possible. As the ineident $\mathrm{X}$ rays pass through the crystal, they influence the atoms en route, and a secondary wavelet spreads from each atom as a wave passes over it. Let us take for convenience axes of reference parallel to 
the sides of a cube and an origin at the centre of one of the atoms, $O$. (Fig. 80 shows the atoms in the $x z$ and $y z$ planes of the lattice.) For simplicity, eonsider a beam of $\mathrm{X}$ rays to enter the cube in the direction of the $z$ axis. Let us ascertain the conditions which will ensure that the wavelets from all the various atoms in the lattice shall co-operate or "be in phase" in some partieular direction $O P$, whose direction cosines are $a, \beta$, and $\gamma \cdot{ }^{1}$

It is sufficient for the purpose to take the cases of the nearest atoms to $O$ on the axis, viz. $A, B$, and $C$, and express the conditions that the wavelets from these atoms shall be in phase with that from $O$. These conditions are

$$
\left.\begin{array}{rl}
a \alpha & =h_{1} \cdot l, \\
a \beta & =h_{2} \cdot l, \\
a(1-\gamma) & =h_{3} \cdot l,
\end{array}\right\}
$$

where $a$ is the distance between neighbouring atoms (i.e. one side of the eube), $l$ is the wave-length of the $\mathrm{X}$ rays, and $h_{1}, h_{3}$, and $h_{3}$ are integers representing the number of complete wave-lengths that the waves from $A, B$, and $C$ respectively are ahead of the wave from $O$.

From (1) we obtain

$$
\frac{a}{h_{1}}=\frac{\beta}{h_{2}}=\frac{(1-\gamma)}{h_{3}}=\frac{l}{a},
$$

and therefore $u, \beta$, and $(1-\gamma)$ ought to be in a simple numerical ratio.

From a consideration of the other eubes grouped round the $z$ axis, it is apparent that there is a number of other points of maximum intensity situated precisely like $P$ with reference to the $z$ axis, so that if a photographic plate is placed to receive the transmitted $\mathrm{X}$ rays, there should appear, where the waves eo-operate, a group of spots of fourfold symmetry.

\section{The Experiments of Friedrich and Knipping.}

Lane's theory was put to the test of experiment at Laue's request by Friedrich and Knipping (A.d.P. 1913). All that

\footnotetext{
1 That is, $\alpha, \beta$, and $\gamma$ are the cosines of the angles which $O P$ makes with the axes of $a, y$, and $z$ respectively.
} 
was required was to arrange that a parallel beam of $\mathrm{X}$ rays should, after traversing a crystal, be received on a photographic plate, so that any directions showing "interference maxima" would be registered as spots. The apparatus used is shown in Fig. 81.

The $\mathrm{X}$ rays emitted from the bulb were cut down by lead stops, so that a narrow pencil of rays fell on the crystal, behind which a photographic plate was placed a few cms. distant. The first crystal that was tried gave the result anticipated from the theory. The photographic plate showed an intense undeflected spot round which was grouped a

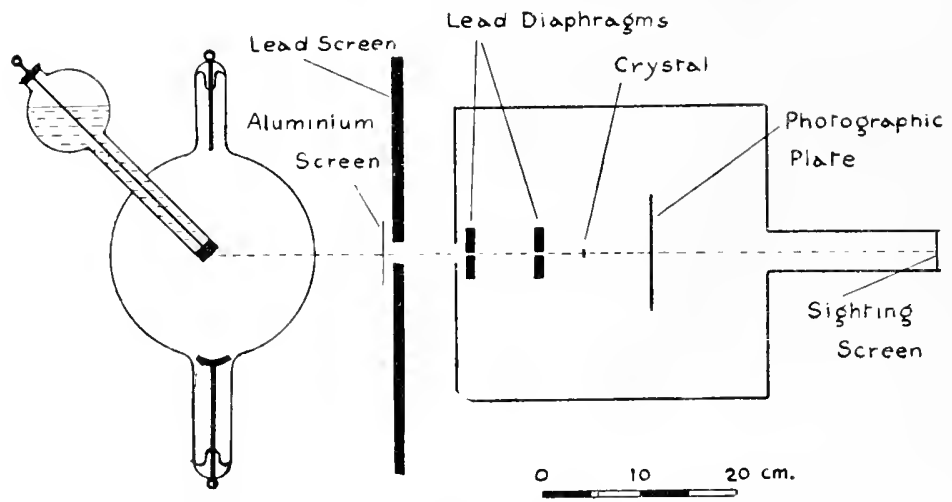

IfG. S1.-Friedrich aud Knipling's aplaratus for showing dilfraction of $\mathrm{I}$ rays by transmitting them through a clystal.

number of diffracted spots, some of which were deviated by as much as $40^{\circ}$ from the original direction of the rays (see Figs. 82 and 84). If the crystal were moved parallel to itsclf, the grouping of the spots was unaffected. By altering the distance of the photographic plate from the crystal, the spots, while showing but little alteration in size, increased or diminished their displacement from the centre. Further, if the erystal was rotated so as to make a clifferent angle with the primary beam, the pattern on the plate was affected: by careful adjustment, it was possible to obtain positions in which the spots grouped themselves quite symmetrically round the centre spot.

The results were generalised for a number of different 


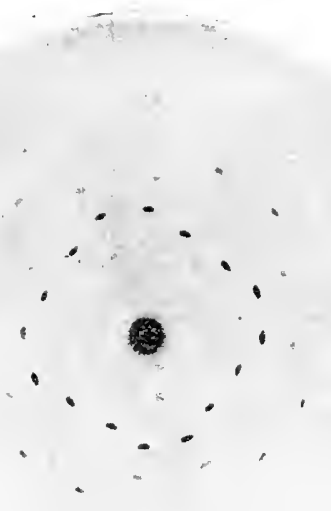

FIG. 82.-Pattern of Laue spots obtained by friedrich ant Kuipping when $\mathrm{X}$ rays are diflracted by a zinc-honde arystal. The incident rays are prarallel to a culbic axis of the rivstal.

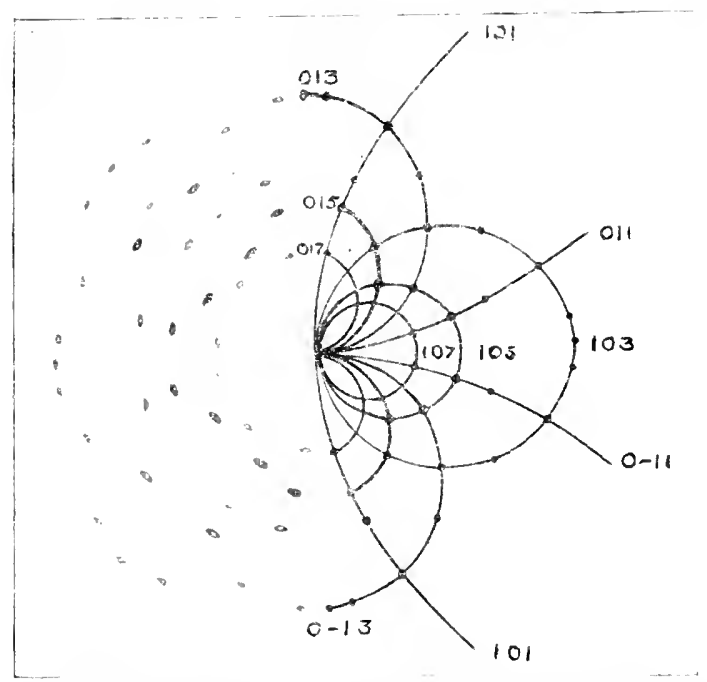

FIG. 83.-W. L. Bragg's construction to explain the position of the Taue

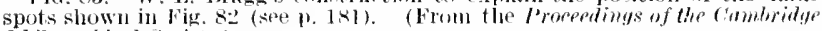
Philosophical simeipt!l.) 
erystals. It was found that exposures of some hours were necessary to obtain good results, since by. far the greater proportion of the rays was unaffeeted and undeviated by the erystal. Shorter exposures, however, sufficed to reveal the more intense spots.

\section{Laue's Results for Zinc-blende.}

Figs. 82 and 84 are reproductions of the results obtained in the case of zine-blende when the rays travel along two different axes of symmetry in the erystal. Knowing the coordinates of any spot on the photographie plate relative to reetangular axes having their origin at the point where the primary beam strikes the erystal, we ean get at once the direetion cosines, $a, \beta$, and $(1-\gamma)$ of the ray which gives rise to that particular spot, and hence we can deduee the values of the parameters $h_{1}, h_{2}$, and $h_{3}$. Now, as remarked above, since $h_{1}, h_{2}$, and $h_{3}$ are whole numbers, these values of $u, \beta$, and $(1-\gamma)$ should be in a simple numerical ratio. This was actually found to be the ease in all the photographs. In no instance was it necessary to assume a number for $h_{1}, h_{2}$, or $h_{3}$ greater than 10 to give the values of $\alpha, \beta$, and $(1-\gamma)$ a whole number ratio. This in itself is strong eonfirmation of the theory that the spots are due to interference.

Each spot has its own values of $h_{1}, h_{2}$, and $h_{3}$. These have to conform to equations (1). The associated values of $a, \beta$, and $\gamma$ have further to obey the relation

$$
\alpha^{2}+\beta^{2}+\gamma^{2}=1,
$$

and so it follows that there is only one value which $l / a$ ean have to satisfy all the equations for each spot. Thus every spot gives a different wave-length, sinee the values of $h_{1}$, $h_{2}$, and $h_{3}$ are different for the different spots. It is here that an important distinction arises between a crystal grating and a line-grating. In a line-grating an interference maximum is ahays possible, no matter what the wave-length; that in to say, the grating yields a continuous speetrum with incident white light. But in the case of a threedimensional grating, certain wave-lengths only are eligible 


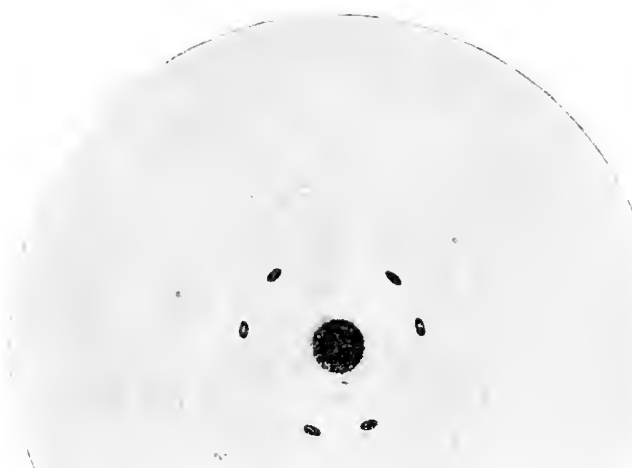

Fif. 84.- Pattern of Lane spots oltaned by Friedrich and Knipping, when $\mathrm{X}$ rass are diffracted by a zine-hlemde "rystal. The indident rays are patralled

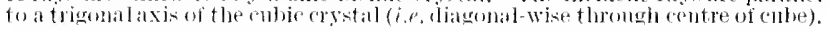

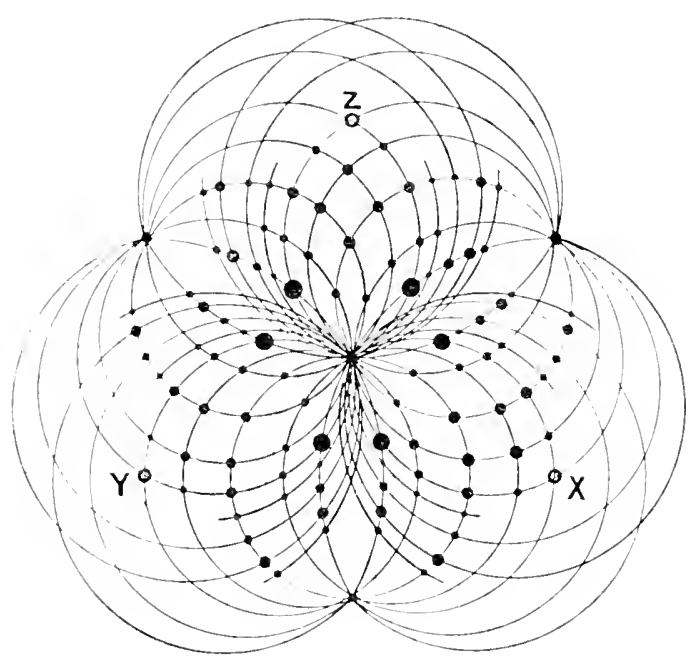

FIa. 5.5.-W. L. Bragg's method of stereographic projection, applied to the case in Fig. 84 (see 1.182 ). 
to form interference maxima, so that a continuous spectrum is impossible. A similar effect may be imitated by mounting half-silvered parallel plates in front of an ordinary linegrating. If white light is now thrown on the grating, the former continuous spectrum will be replaced by a line spectrum representing a series of definite wave-lengths.

The Laue photographs seem to show that while, in general, the larger the values of the integers $h_{1}, h_{2}$, and $h_{3}$, the fainter are the spots to which they correspond, yet, at the same time, the smallest integers do not represent the most intense spots as one would be led to infer by analogy with a diffraction grating, for which the low-order spectra are generally the brightest. Not only that, but certain spots associated with simple values of $h_{1}, h_{2}$, and $h_{3}$ are absent altogether. But if the pattern were the most general possible, then all values of the integers, at any rate up to a cortain limit, should be represented on the plate.

A satisfactory theory must account for these anomalies, and Laue sought to explain them by assuming that the primary beam was made up of a limited number of independent homogeneous constituents, the absence on the plate of a spot with simple parameters being ascribed to the absence of the particular wave-length, which alone is capable of forming the spot in question. It was pointed out above that any fixed values of $h_{1}, h_{2}$, and $h_{3}$ gave a definite value for $l / a$, but it is evident that if we took the same multiples of all these values, say, $n h_{1}, n h_{2}$, and $n h_{3}$, the equations (1) on p. 171 would still be satisfied, but now by a wave-length $l / n$ instead of $l$. By adjusting the values of $h_{1}, h_{2}$, and $h_{3}$ in this way, Lane was able to account for all the spots in the photographs by assuming the existence of only five different wave-lengths in the incident beam.

The explanation is not, however, entirely satisfactory, because these five wave-lengths should give many other spots which do not appear in the photographs.

\section{The Lane Spots for a Zinc-blende Crystal.}

A zinc-blende crystal belongs to the eubic system, and crystallography distinguishes between three elementary 
point systems of eubie symmetry, namely those eomtaining:

(1) points at each corner of the elementary cube,

(2) points at each corner and one at the centre of the eube, and

(3) points at the corners and at the centres of the eube faces.

Laue assumed that zinc-blende belongs to the first system, but in point of fact it almost certainly belongs to the third, as Pope and Barlow have shown from other considerations. IV. L. Bragg (P.C.P.S. 1912) was led to examine the Laue spots of zine-blende from this point of view.

Adopting this view of the structure, Bragg supposed, as before, that axes are taken with origin at an atom $O$ (Fig. $s 6$ shows the atoms in the $x z$ and $y=$ planes), and that when the various atomis are stimulated by the $\mathrm{X}$ rays (incident along the $z$ axis), $O$ emits a warelet which in the direction $O P$ is $h_{1}$

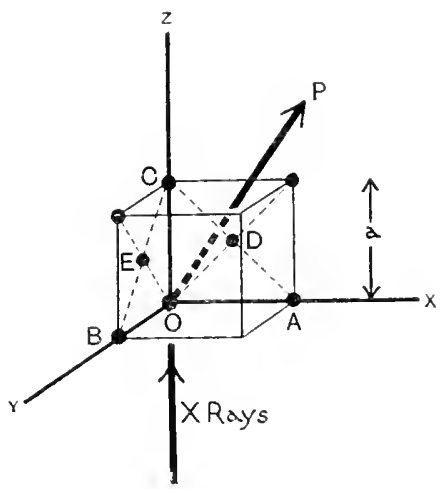

FIf. 86.- Representation of the diffraetion of $\mathrm{X}$ rays by the atoms at the corners and face-entres of an elementary pube of a culdit* arytil. wave-lengths behind that from atom $A$ on the $x$ axis, and so on. The equations (1) on p. 171 ensure that all the corner atoms (including that at the origin) shall emit wavelets which are in phase along $O P$. It is necessary to obtain the eorresponding eonditions for the centre-face atoms (such as $D$ and $E$ ), so that their wavelets also shall be in phase with those from the corner atoms.

The difference in phase between the wavelets from $D$ and $O$ will be $\left(\frac{h_{1}}{2}-\frac{h_{3}}{2}\right)$ ware-lengths, since $D$ is situated in the midlle of the face of the eube. This must be a whole number of wave-lengths to give an interference maximum along OP ; and it follows that $h_{1}$ and $h_{3}$ must either be both 
odd or both even. The same must also hold for $h_{2}$ and $h_{3}$. This at once explains why the complete series of values of $h_{1}, h_{2}$, and $h_{3}$ for the Laue spots is not represented on the photograph.

Consider first of all the set of spots in the appropriate Laue photograph of zinc-blende (Fig. 82), which have $h_{3}=$ unity. The corresponding wave-lengths prove to have every possible value greater than a limiting wave-length of $l=0 \cdot 034 a$, where $a$ is the length of the side of an elementary cube. The sets of values corresponding to wave-lengths approaching $l=0 \cdot 06 a$ are responsible for the two very intense spots in the inner square of the pattern; all other wave-lengths smaller or greater than $0.06 a$ give fainter spots until, for the limiting wave-length $0.034 a$, they are barely visible. Bragg accordingly concluded that the $X$ rays utilised in this particular Lane pattern formed a continuous spectrum, with a maximum intensity in the region of $l=0 \cdot 06 a$.

Exactly similar results are obtained for the sets of numbers having $h_{3}=2$. There are two very intense spots which form the outer square, and, in addition, a few others considerably fainter. Similarly for $h_{3}=3$, in which series there are still fewer spots.

In Table XVIII. ${ }^{1}$ is displayed a typical set of values of l/a for the different spots corresponding to $h_{3}=1$.

The table is very interesting becamse of its completeness; within a certain range of wave-lengths, every spot antieipated from theory is registered on the photographic plate.

Thus Bragg's results afford strong support to the atomic grouping which Pope and Barlow claim for the zinc-blende space-lattice. In later work, Bragg has shown that the zinc-blende diffraction pattern is due almost entirely to the heavier zine atoms. The sulphur atoms are situated on a similar parallel lattice. which may be reached by stepping along one quarter of the diagonal of the elementary aube of the rine-lattice.

${ }^{1}$ Sre W. I. Bragg's paper in Science Progress, January 1913, to which the writer is mueh indebted. 


\section{TABLE XVIII.}

Zinc-blende crystal ; incidout $X$ rays parallel to a cubje axis. Values of wave-length for $h_{3}=1$.

\begin{tabular}{|c|c|c|c|c|c|}
\hline \multirow{2}{*}{$\begin{array}{l}\text { Value } \\
\text { of } h_{2 .} \text {. }\end{array}$} & \multicolumn{5}{|c|}{ Values of $l a$, for $h_{3}=1$. } \\
\hline & $h_{1}=1$ & $h_{1}=3$ & $h_{1}=5$ & $h_{1}=7$ & $h_{1}=9$ \\
\hline 1 & $\begin{array}{l}\text { (off the } \\
\text { photograph) }\end{array}$ & $0.178(\mathrm{~m})$ & $0.073(v)$ & $0.039(v)$ & $\begin{array}{l}0.02+ \\
\text { (invisible) }\end{array}$ \\
\hline 3 & $0.178(\mathrm{~m})$ & $0 \cdot 104(v)$ & $0.057(v)$ & $0 \cdot 034(f)$ & $\begin{array}{l}0.022 \\
\text { (invisible) }\end{array}$ \\
\hline 5 & $0 \cdot 07: 3(v)$ & $0 \cdot 0.57(v)$ & $0 \cdot 039(m)$ & $\begin{array}{l}0.027 \\
\text { (invisille) }\end{array}$ & - \\
\hline 7 & $0 \cdot 0.39(f)$ & $0 \cdot 034(f)$ & $\begin{array}{l}0.027 \\
\text { (invisible) }\end{array}$ & 一 & - \\
\hline 9 & $\begin{array}{l}0.024 \\
\text { (invisible) }\end{array}$ & $\begin{array}{l}0.022 \\
\text { (invisible) }\end{array}$ & - & 一 & - \\
\hline
\end{tabular}

[The letters $v, m$, and $f$ indicate the intensity of the spots- " $v$ " signifying very intense, " $m$ " moderately intense, and " $f$ " faint.]

\section{W. L. Bragg's Theory of the Laue Spots.}

Bragg was led to bring forward an altemative explanation of the Laue interference phenomena from the point of view of the parallel and equidistant planes of atoms which can be pictured in a erystal. Many systems of planes can, of eourse, be chosen, but we can confine the choice to the relatively few systems in which the planes are rich in atoms.

Contrary to the view of Laue, Bragg (as mentioned above) supposed that the incident beam of $\mathrm{X}$ rays contained (like white light) every possible wave-length over a wide range, and thus formed a continuous speetrum of ravs. Imagine then that such a beam falls on a crystal, and let us assume that when it strikes a system of parallel planes of atoms a small amount of energy is reflected by each plane. The wave front of the reflected beam from a particular plane is formed by the wavelets sent out by the individual atoms in the plane. If the distance between successive planes is $d$, and the glancing angle of the rays is $\theta$, the train of waves reflected from the different planes in the system 
will follow each other at intervals of $2 d \sin \theta$; and if the wave-length is such that this distance is equal to a whole number of wave-lengths, the waves will reinforce each other, and we shall get an interforence maximum in that direction. Hence in this case, when the incident beam contains every possible ware-length, a particular system of planes in the crystal picks.out, so to speak, the right wave-lengths, and the result of the simultaneous working of all the various systems of planes is to resolve the beam into its constituents. If the angle of incidence is altered, then different wavelengths will in general be selected to form the interference maxima.

On this view, the different intensities which the various spots exhibit might be due either to an unequal distribution of the energy in the spectrum of the incident $\mathrm{X}$ rays or to a difference in the closeness of packing of the atoms in the rarious reflecting planes.

Bragg's methot of regarding the interference is, of course, analytically equivalent to that of Lave. The reflectionmethod has the great advantage of being more readily pictured, especially in considering what happens when a crystal is rotated, in which event the pattern of spots is distorted exactly as it would be if the spots were reflections in plane mirrors. By changing the angle of incidenee, we alter the phase difference $(2 d \sin \theta)$ between waves from successive planes; and so a spot produced initially by a certain wave-length continues to represent without break a sequence of the wave-lengths present in the incident beam. If, as Lane imagined, certain wave-lengths only were present in the incident $\mathrm{X}$ rays, then as the erystal was slowly tilted spots would suddenly appear and disappear on the plate; but, on the contrary, when the experiment is tried, the same spots ean be traced continuously across the plate. It is also interesting to notice that some spots are very much changed in intensity as the crystal is tilted. One spot, for instanec. which is barely visible in the symmetrieal pattern. becomes, in another position of the crystal. the most intense of all, beeanse its new wave-length now eoineides with the maximum in the spectrum of the $\mathrm{X}$ rays. 
The elliptical shape of the Lane spots is a direct consequence of the fact that the incident pencil of $\mathrm{X}$ rays is not strictly parallel but slightly conieal, and so the reflected pencil, which is obliquely received on the photographic plate, shows an elliptical section.

\section{Elliptical Loci of Laue Spots.}

With prolonged exposures, many more spots appear on the photographie plate than ean be detected in Fig. 82. As Fig. 83 shows, the various spots group themselves naturally on ellipses of various sizes, all of which pass through the

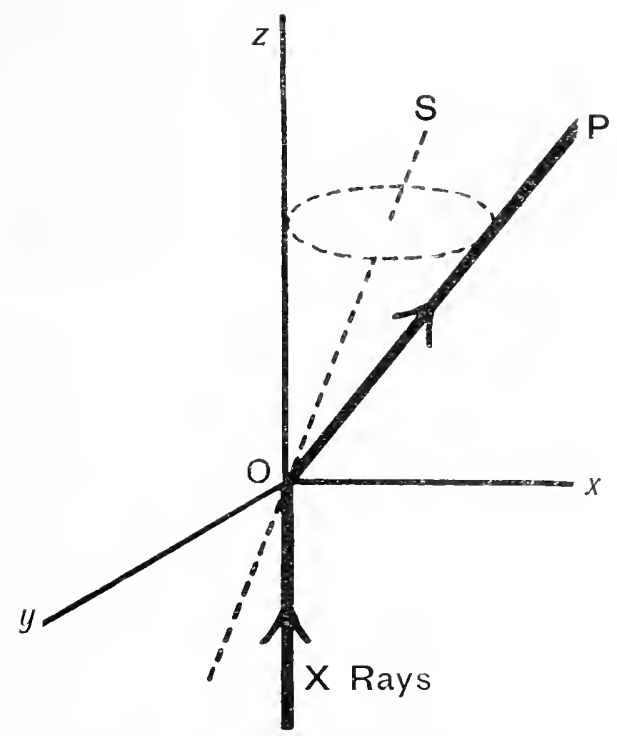

FIG. 87.-Construction demonstrating elliptical loci of Lane spots.

central spot. These ellipses, which are nearly cireular, are sections of circular cones having the incident beam as a generator. The elliptical locus is a consequence of the fact that the various systems of parallel planes which can be selected in a crystal may have all manner of orientations: the atoms are grouped on parallel straight lines as well as on parallel planes, and each of these rows has a set or planes parallel to it. For example, suppose as before that a beam 
of $X$ rays travels along the $z$ axis, and consider a elosely packed plane of atoms passing through the line OS (Fig. $87), S$ being a point in the $x z$ plane. If this plane of atoms contains the $y$ axis, then the reflected beam will pass along $O P$. But there is a family or "zone" of planes of atoms which can also be selected as passing through $O S$, and as we pass in rotation from one of these planes to another, the reflected beam $O P$ will sweep out a circular cone with $O S$ as "zone-axis." The trace on the photographic plate (which is at right angles to the $z$ axis) will accordingly be an ellipse which passes through $O z$ and touches the $y z$ plane.

Similarly, if the plane is rotated about a zone-axis which is in the $y z$ plane and passes through the origin, the ellipse passes through the $z$ axis and touches the $x z$ plane. Now suppose that there is a plane of atoms in the erystal which contains both these zone-axes, then the reflected beam from this plane will give a spot at the intersection of the two ellipses obtained as above.

We can in this way, by drawing ellipses corresponding to rotations about various axes through the origin, locate almost all the Laue spots. This is done in Fig. 83, which graphically displays a key to the spots for zinc-blende when the incident rays traverse a cubic axis of the crystal.

The ellipses are marked in cach ease with the co-ordinates of the atom nearest the origin through which the axis of rotation passes. The seales of co-ordinates are measured in terms of a unit equal to half the distance between consecutive points along the axes. This unit is chosen because the ouly system competent to account for all the Laue spots in the case of zinc-blende, is that in which there are points both at the comers and face centres of the elementary cube (see p. 177).

\section{Stereographic Projection of Laue Spots.}

In representing a Laue pattem diagrammatically, it is tedions and inconvenient to draw the various elliptical loci. A much easier method is, however, possible without unduly distorting the pattern. 
Suppose the X-ray beam $A O$ (Fig. 88) traverses the crystal at $O$, the undeviated beam striking the photographic plate $Z D$ at $Z$. Let $O S$ be a "zone-axis "; the rays reflected in the family of planes which pass through this zone-axis lie on a eireular cone, of which $O S$ is the axis and $O Z$ and $O P$ are two generators. This cone cuts the sphere of which $O Z$ is a radius, in a eirele of which $Z B$ is a diameter. The projection of this eircle on the plane $Z D$ from the "pole" $A$ is also a eirele, of which $Z P^{\prime}$ is a diameter and $S$ is the contre.

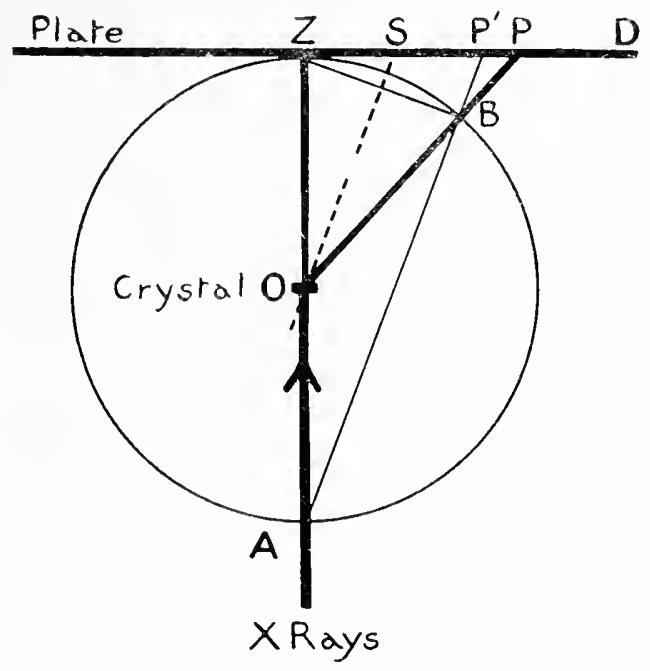

Fit. 88.-Geometrical construction to explain stereographic projection of Laue spots.

Thus, if we consider the Lane pattern which is formed on the surface of the sphere $Z B A$, and then projeet this pattern on the plane $Z D$ from the pole $A$, we shall have a new projection in which the ellipse with $Z P$ as major axis is replaced by the cirele on $Z P^{\prime}$. The distortion of the pattern of spots by the transformation is very small except in the regions remote from the centre; and we now have the convenience of drawing circles instead of ellipses. It is easy to calculate the positions of the centres of the circles, such as $S$, from the dimensions of the pattern when the crystal is symmetrieally placed. 
An application of this method of projection to the case of zinc-blende is shown in lig. S5. It will be observed how closely the diagram follows the eorresponding photograph obtained by Friedrich and Kinipping (Fig. 84).

\section{Display of Laue Spots by Fluorescent Screen.}

Terada (Proc. Math.-Phys. Soc. Tokyo, Ap. 1913) found that by the use of a sufficiently transparent crystal and a not too narrow bean of $\mathrm{X}$ rays, ${ }^{1}$ he could detect the Lane spots visually by means of a fluorescent sereen.

On rotating the crystal, the elliptical loci of spots referred to above are strikingly displayed.

The fluorescent method is likely to be especially useful for a rapid initial examination of a crystal. It is also of value for watching the progressive behaviour of a crystal which is being subjected to physical or chemical treatment. For instance, it was found that on heating a crystal of borax, the spots remained visible until the erystal was almost entircly melted.

\section{Interference by Metallic Crystals.}

Little work has been done so far on metallie crystals. Leene (P.M. Oct. 1913) found that if a beam of $\mathrm{X}$ rays was passed through freshly rolled metal sheets, a symmetrical pattern was formed on a photographic plate placed behind the sheet. The axis of symmetry of the pattern was paralled to the direction in which the sheet had been rolled. A rotation of the sheet in its own plane produeed a corresponding rotation of the spots in the pattern. If the sheet were heated and allowed to eool, the pattern Wais replaced by a number of radial streaks arranged in a circular band around the undeflected spot. A very old specimen of metal gave the same result. These radial streaks are undoubtedly due to reflection from small erystals formed in the one case by age and in the other by annealing.

The subject was also investigated by Owen and Blake ( $N$. Feb. 19, 1914), who adopted a reflection method. A piece of eopper was cut in two and one of the pieces was

${ }^{1} 5$ to $10 \mathrm{~mm}$. diameter. 
amnealed, while the other was untreated. A beam of $\mathrm{X}$ rays was allowed to fall in turn on each of the samples, with the result that a large number of spots were obtained on a photographic plate in the case of the ammealed specimen, while no effeet was produced with the other speeimen. 'The difference is, in the one case, to be accounted for by the presence of imnumerable small crystals variously oriented, each of which reflects its quotum of the original beam, while in the unamnealed specimen there is an absence of crystalline strueture and regular atomic grouping. The experiments answered equally well if the surfaces were highly polished or badly tarnished.

Owen and Blake further obtained the Laue spots for a metallie erystal. Owing, however, to the difficulty of securing a single erystal, the resulting patterns were not symmetrieal. Crystals of antimony, zinc, and an aluminium alloy (50 per cent. Al, 50 per cent. C'u) were tried.

\section{Interference Phenomena with $\gamma$ Rays.}

We have every reason to believe that the great penetrating power of most $\gamma$ rays is clue to the shortness of their wave-length as compared with that of $\mathrm{X}$ rays. It follows that for pronouneed reflection of $\gamma$ rays the parallel planes of atoms in a crystal should be very elose together. It might be anticipated that crystals which show marked X-ray reflection would not be so successful with the hardest $\gamma$ rays, and this, together with the fact that a beam of $\gamma$ rays is always very weak, explains the very long exposures which have been found to be neeessary to give even faint photographic impressions of the reflected beam. Probably better results eould be obtained with dense metal crystals, in which the atomic planes are nearer together than in most erystalline salts, or by using crystals of great thiekness.

Shaw (P.M. July 1913) found that by exposing, for several weeks, a plate of mica to $\gamma$ rays, at almost grazing ineidenee, he obtained, on a photographic plate, a series of lines which were, however, too faint to allow accurate measurement. 
Rutherford and Andrade ( $N$. Oct. 30, 1913) have recently carried out a similar investigation, using as the source of their $\gamma$ rays a thin-walled a ray tube which contained 100 millicuries ${ }^{1}$ of radium emanation. The $\gamma$ rays are given off by the products of the emanation, viz. RaB and RaC. A pencil of rays was allowed to fall on a crystal of rock-salt, and the reflected beam was examined photographically. Now, as was remarked on p. 118, among the groups of homogeneous $\gamma$ rays from RaB is a strong charaeteristic $L$ radiation, whose $\lambda / \rho$ in $\mathrm{Al}$ is 14.7 .

From the known data of the erystal it was caleulated that this $L$ radiation should be reflected at a grazing angle of $9^{\circ}$, and on examination the photographic plate was found to show a group of fine lines between $8^{\circ}$ and $10^{\circ}$. A similar group of lines was obtained with a grazing angle of $2^{\circ}$ : it is possible that these are first-order lines, of which the second or third order are in the $9^{\circ}$ position. Similar results were obtained for a crystal of potassium ferrocyanide.

\section{The "Reflection" of X Rays.}

It will have been remarked how completely and satisfactorily the various Laue phenomena are interpreted on IV. L. Bragg's view of reflection from planes of atoms. Bragg was led, at the suggestion of C. T. R. Wilson, to ascertain whether $\mathrm{X}$ rays were regularly reflected from cleavage planes in crystals: such planes are known to be very rich in atoms. Mica at once suggested itself, and the experiment, when tried, proved immediately successful, only a few minutes' exposure being required to give a visible impression on a photographic plate.

A fuller investigation of the reflection phenomena was carried out by Prof. W. H. Bragg and his son, IV. L. Bragg. Their work, which is of great importance, is described in a series of papers in the Proceedings of the Royal Society for 191:3 and 1914. Experiments on similar lines were conducted at the same time by Moseley and Darwin (P.M.

I A millicurie is the amount of emanation in equitibrium with 1 milligramme of radium. 
191:3) at Manchester. In both investigations, an X-ray spectrometer was used in which an ionisation chamber wats substituted for the customary telescope, while a lead tube with slits acted as the collimator and ensured a fine pencil of rays. ${ }^{1}$ Bragg's apparatus is illustrated in Fig. 8!.

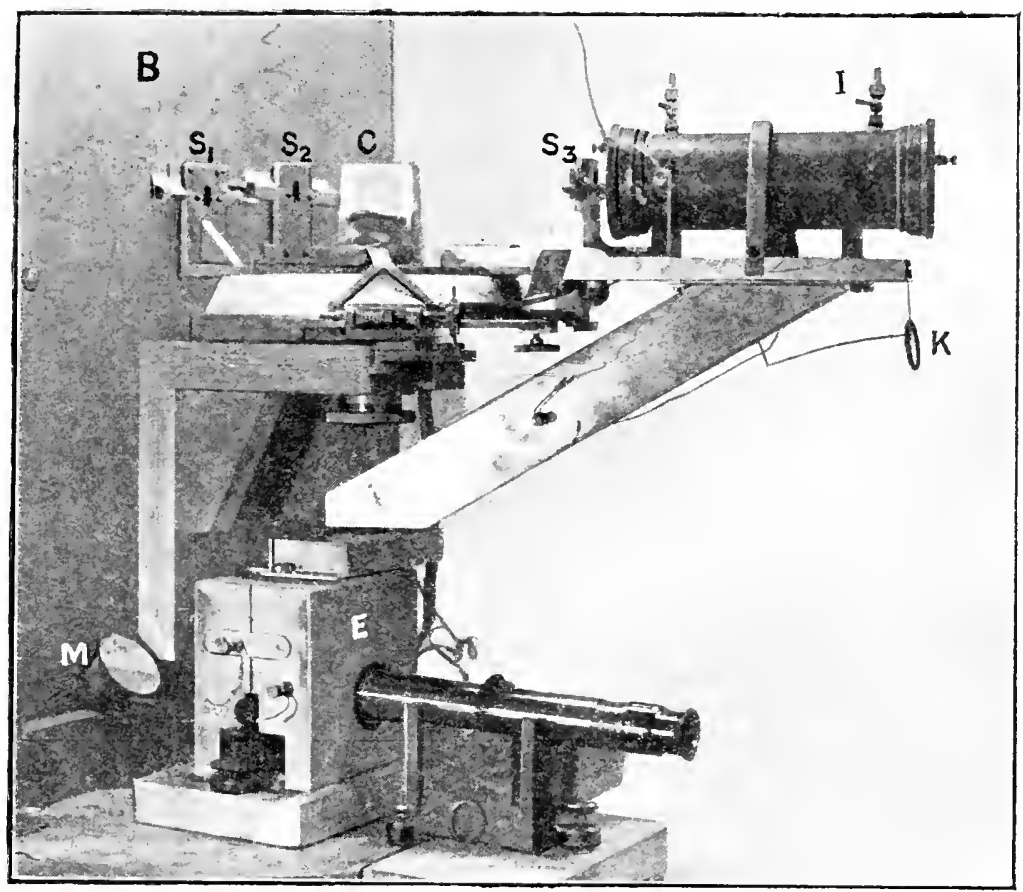

FIf. 89.-Photograph of Bragg's $\mathrm{X}$-ray spectrometer. $D$ is a box confaining

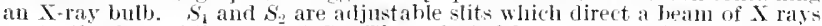
on to the face of the erystal $C$. The reflected heam passes through the sit $S_{3}$ into the ionisation chamber $I$, where it is recorded by the tilted slectroscope in the metal box $E . \quad K$ is an earthing key ; 1, , a mirror for illuminating the electroscope. $C$ and $I$ can each be rotat ab abot the axis of the spectroneter.

Of the pencil of $\mathrm{X}$ rays which falls on the face of the crystal, only a small fraction is reflected. In order to increase the effect in the ionisation chamber, the Braggs filled it with a heavy gas or vapour, usually sulphur dioxide.

${ }^{1}$ In more recent work Moseley ('..11. Dec. 1913) has empioyed a photugraphic method (see p. 199). 
Moseley and Darwin used helimm and angmented the effect by an ingenious method depending on ionisation by collision, such as is described on p. 89. The crystal was mounted as a reflector on the central revolving table. There is no need to polish the surface of the crystal, as the underlying planes of atoms are the effective agents: in many cases, Prof. Bragg merely rubs the surface on sand-paper. The ordinary method of fracturing a erystal so as to provide a cleavage surface is apt to produce incipient if invisible fissures in other cleavage planes in the erystal; these, together with the natural faults which occur in many er'ystals, are probably the cause of the multiple images or ghosts which have worried many experimenters. The X-ray bulb should be very "soft "-in many of Bragg's experiments the cathode stream (see p. 34) was visible over its whole length.

While the reflected beam has all the properties of $\mathrm{X}$ rays, and is, in general, similar to the incident beam, it differ's in one important particular, that of penetrating power. This is due to the fact that the different constituents of the incident beam are not reflected equally by the erystal, with the result that the two differ in their average hardness. The reflected beam may indeed be considerably harder than the incident beam.

All the experiments, however, go to show that both incident and reflected radiations consist essentially of the

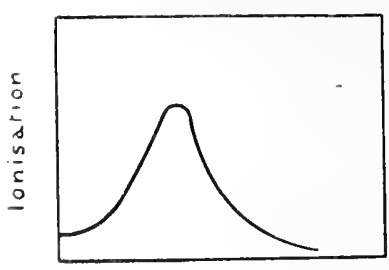

Angle of Reflecrion FIt. 90. same constituents, but that these constituents are present in different proportions in the two beams.

Fig. 90 shows graphically the way in which the ionisation varies as the chamber is moved across the region of the reflected beam. No matter what the angle of incidence, the position of maximum ionisation corresponds with great precision to the angle of optical reflection, although the magnitude of the maximum ionisation varies greatly with the crystal and its position. 
If for any particular erystal-face a series of measurements is made at varying angles of incidence, and the strength of the reflected beam is plotted against the glaneing angle, then, while there is a general reflection of the rays at all angles, the reflection increases very greatly as grazing incidence is approached.

Superposed on this curve, there is, at certain very sharply defined angles, a sudden and large increase in the intensity,

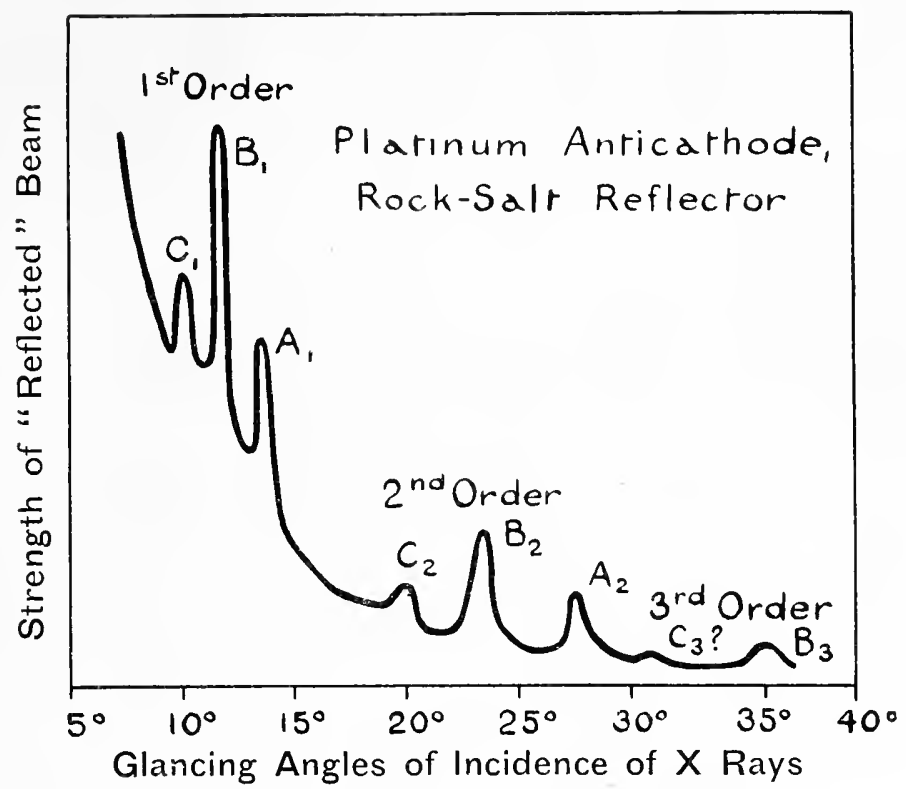

FIG. 91.-- Showing intensity-distribution of spectrmm of $\mathrm{X}$ rays from platinum. There are three main spectrim lines, and a large proportion of " white " or general $\mathrm{X}$ rays.

which shows itself as marked peaks on the curve. Fig. 91 is the eurve obtained by the Braggs for the rays from a platinum anticathode. The reflector in this instance was a rock-salt erystal, though the general form and relative proportions were found to be the same for all the crystals examined.1 The curve shows three prominent peaks (marked

1 Zine-blende, potassium ferrocyanide, potassium bichromate, quartz, calcite, and sudium ammoninm tartrate. 
$A, B$, and $C$ in the figure) thrice repeated. The rays corresponding to each of these peaks are found to be homogeneous when tested by the usual absorption method. Corresponding peaks in the different series prove to be closely related : not only are the absorption coefficients of the rays producing, for instance, $B_{1}, B_{2}$, and $B_{3}$ identical, but the sines of their reflection angles are in simple ratio. For example, the several angles of reflection of the $B$ peaks are

$$
11^{\circ} \cdot 55,23^{\circ} \cdot 65 \text {, and } 36^{\circ} \cdot 65 \text {. }
$$

The sines of these angles are

$$
0.200,0.401 \text {, and } 0.597 \text {, }
$$

which are very nearly in the ratio of 1,2 , and 3 .

There can be little doubt as to the interpretation of these results. The peaks $A, B$, and $C$ represent three different sets of homogeneous rays which appear as first, seeond, and third order spectra. Rays of a definite quality are reflected from a crystal when, and only when, the crystal is set at the correct angle. The three groups of rays are not manufactured in the erystal, for their properties prove to be the same, no matter what erystal is used. The incident $\mathrm{X}$ rays consist, in fact, of "independent" rays of all wave-lengths with an admixture of homogeneous radiations characteristic of the platinum anticathode (compare Kave and Beatty's results on pp. 36 and 127).

Moseley and Darwin (loc. cit.), using rather more refined apparatus, similarly detected five homogeneous constituents in the platinum radiation : peaks $B$ and $C$ are, in fact, close doublets (see p. 201). The proportions of these constituents appeared to depend on the state of the X-ray bulb.

Barkla and Martyn (P.P.S. 1913), using a divergent pencil of $\mathrm{X}$ rays, demonstrated somewhat similar results photographically ; and Owen and Blake (N. April 10, 1913), by using narrow pencils of rays, obtained photographic spectra of lines so well defined as to permit great accuray of measmrement. To increase the separation between the lines, the plate was mounted very obliquely to the reflected beam. The angles of reflection agreed very elosely with those obtained by Moseley and Darwin. 


\section{The Two Methods of Analysis.}

To recapitulate, there are then two distinct methods of crystal-analysis depending on $\mathrm{X}$ rays.

(1) The Laue transmission method, which uses the independent, heterogeneous (or "white") X rays that commonly constitute the greater part of the output from an ordinary bulb. The crystal plays a part somewhat like that of a "crossed" transmission grating, and the structure of the crystal controls the pattern of the diffracted spots.

(2) The Bragg spectrometer method, which employs the homogeneous $X$ radiations and uses the crystal as a reflection grating. The structure of the erystal evinces itself in the distribution and intensity of the spectrum lines among the various orders. The Bragg method gives the data by which the dimensions of the lattices of crystals can be compared, and the X-ray spectrometer has already proved itself a powerful instrument for examining crystalstructure. The Laue method, on the other hand, can only supply information concerning the nature of the lattices, and that in a limited degree.

\section{Crystal-Structure.}

We must now refer, if only briefly, to the recent important work which has been done by $\mathrm{WV}$. L. Bragg (P.R.S. 1913) on the structure of crystals.

In order to arrive at the strueture of a crystal and the dimensions of its space-lattice, we require to determine

(1) to what point system it belongs;

(2) what are the several distances separating the atomie planes parallel to the different crystal faces.

On these lines, Bragg attacked, first of all, the problem of the strueture of the halogen salts of the alkaline metals, all of which form cubie crystals.

\section{(1) Nature of the Space-Lattice.}

The salts dealt with were the chlorides of sodium and potassium, and the bromide and iorlide of potassinm. The 
Latue patterns were obtained for each of these when the $X$ rays fell normally on a plate eut parallel to a cube-face. On a priori grounds, we might anticipate that these ehemically similar bodies would all belong to the same point system and give identical Laue patterns. On the eontrary, when the tests were made it was found that

(1) potassium ehloride gave rise to a simple pattern such as would be produced by a simple cubic lattice of the first kind (p. 177) ;

(2) potassium bromide and iodide each produced the pattern charaeteristic of the face-centred lattice of the third kind (p. 177);

(3) sodium ehloride gave a third pattern more complex than either of the others, and apparently intermediate between them.

The most obvious and plausible explanation of this dissimilarity is that the relative masses of the two eonstituents affect the diffracting ability of the molecule. It is reasonable to infer that a heavy atom would form a better diffracting eentre than a light one, and, if we assume this to be the ease, the apparently strange results beeome rational. In the case of potassium ehloride, the atomie weights of potassium and chlorine $\left(39^{\cdot} 1\right.$ and $35 \cdot 5$ respeetively) are suffieiently close for the atoms to be equally efficient as diffraeting centres. The disparity in the atomie weights of sodium and ehlorine (23) and $35 \cdot 5)$ complieates the rock-salt pattern. while with potassium iodide (39.1 and 127) and bromide $(39 \cdot 1$ and $79 \cdot 9)$ one atom is so mueh heavier than the other that the system consists in effect of only one kind of atom on a simple space-lattice.

We have now to eoneeive a grouping of metal and halogen which, though common to all four salts, will bring out the points of difference. Following Bragg's notation, let us distinguish between the two kinds of diffraeting eentres in a salt by calling one blaek and the other white. Then the points must be arranged in such a way that

(1) there are equal numbers of black and white; 
(2) the arrangement of points, black and white, taken all together is that of the first enbic space-lattiee, viz. points at the eorners only of each elementary cube (p. 177) ;

(3) the arrangement of blacks alone or of whites alone is that of the third eubic space-lattice, riz. points at the corners and face-centres (p. 177).

An arrangement which gives this result is shown in Fig. 92. The space-lattice formed by the whites is the same as that formed by the blacks, each of the two being the third

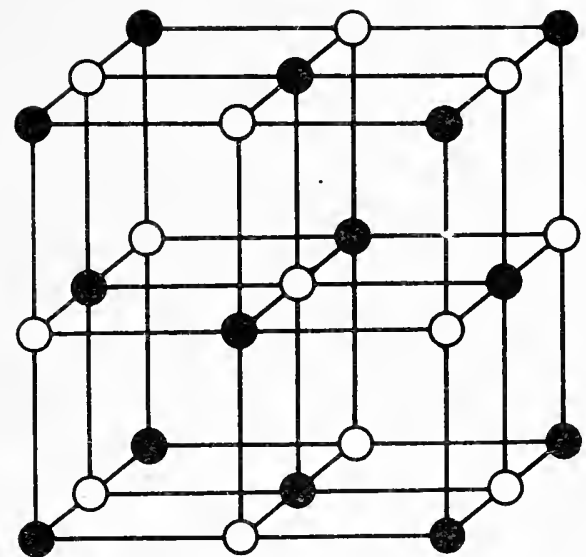

FIG. 92.-Representation of two types of diffracting centres in a cubic crystal.

system. If black and white centres become identical, as in $\mathrm{KCl}$, the lattice becomes the simple enbic one of the first type.

The evidence for this arrangement of the atoms in these halogen salts seems very weighty, but we are still unable to say with certainty whether the diffracting unit at each point of the system eontains only one atom or more. Bragg has, however, brought strong support in favour of the view that single atoms are associated with each centre. Laue photographs were obtained for three such different substances as zine-blende $(\mathrm{ZnS})$, fluorspar $\left(\mathrm{CaF}_{2}\right)$, and ealeite $\left(\mathrm{CaCo}_{3}\right)$; in each case the $\mathrm{X}$ rays traversed the erystals 
along the trigonal axes. ${ }^{1}$ The patterns proved to be identical, whieh points to the fact that the diffracting centres are arranged on precisely similar space-lattices in all three eases.

But, sinee a space-lattice is an arrangement in which eaeh point is situated relatively to its neighbours in exactly the same way as every other point, it would be impossible to arrange complex moleeules in a space-lattiee unless only one point in each moleeule were affective. We are led to infer that, at any rate in the above cases, each molecule acts as a single point, by reason of the fact that it contains one atom much heavier than the rest; and that it is the lattice of the heaviest atom in the molecule which is responsible for the diffraction pattern observed. ${ }^{2}$

Thus far, well and good, but to eomplete the argument in support of the view that each diffracting centre contains only one atom, we need to know the eomparative dimensions of the lattice of the several erystals. This we ean get by the X-ray spectrometer, as we will now proceed to indicate.

\section{(2) Separation-Distances of Atomic Planes.}

A knowledge of the angles at which the various $\mathrm{X}$-ray "peaks" are refleeted in the speetrum of an element, enables us to find the distanee between the planes of the reflecting system in terms of the wave-length of the $X$ rays coneerned. By measuring the first-order value of the glaneing angle $\theta$ in

$$
l=2 d \sin \theta
$$

for the reflection curres from the three primary planes of the erystal, we can derive the several values of $\frac{d_{1}}{l}, \frac{d_{2}}{l}, \frac{d_{3}}{l}$ for the three prineipal directions. We ean thus dednee both the form of the elementary parallelopiped and the value of $\frac{d_{1} l_{2} d_{3}}{l^{3}}$ or $\frac{V}{l^{3}}$. where $V$ is the volume of the parallelopiped. Now, if $\rho$ is the density of the erystal, the mass

I I.e. diagonal-wise through the eentre of the eube.

"Bragg's later work leads him to the eonclusion that the seattering power of an atom is proportional to its atomic weight. 
associated with each parallelopiped, and so presumably with each diffracting eentre, is $V \rho$. If $M$ is the molecular weight of the substance, the number of molecules associated with each centre is $\frac{V \rho}{M}$, which we may write $l^{3}\left(\frac{V}{l^{3}} \cdot \frac{\rho}{M}\right)$. If, in a series of comparative experiments, $l$ is kept eonstant, then the expression within the brackets is proportional to the number of molecules per centre, and ean, moreover, be evaluated by experiment. Bragg proeecded to do this for a number of different erystals, each of which eontained one heary atom, viz. zine-blende $(\mathrm{ZnS})$, fluorspar $\left(\mathrm{CaF}_{2}\right)$, ealeite

TABLE XTX. ${ }^{1}$

\begin{tabular}{|c|c|c|c|c|c|c|c|c|}
\hline Crystal. & Lattice. & $\begin{array}{c}\text { Density } \\
\rho\end{array}$ & ${ }_{\text {MI }}^{\text {Mol. Wt. }}$ & Face. & $\theta$ & $\frac{d}{l}$ & $\frac{V}{l^{3}}$ & $\frac{V \rho}{l^{3} M}$ \\
\hline Sylvine, KCl & Simple eubie & $1 \cdot 97$ & $74 \cdot 5$ & $\begin{array}{l}(100) \\
(111)\end{array}$ & $\begin{array}{l}10 \cdot 2 \\
18 \cdot 0\end{array}$ & $\begin{array}{l}2 \cdot 86 \\
1 \cdot 62\end{array}$ & $\begin{array}{l}23 \cdot 4 \\
22 \cdot 2\end{array}$ & 0.605 \\
\hline $\begin{array}{c}\text { Rock-salt, } \\
\mathrm{NaCl}\end{array}$ & $\begin{array}{l}\text { Face-centrod } \\
\text { cubie }\end{array}$ & $2 \cdot 1.5$ & $58 \cdot 5$ & 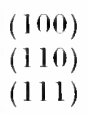 & $\begin{array}{r}11.4 \\
16.0 \\
9.8\end{array}$ & $\begin{array}{l}2.53 \\
1 \cdot 82 \\
2.95\end{array}$ & $\begin{array}{l}32 \cdot 5 \\
33.9 \\
33 \cdot 5\end{array}$ & $1 \cdot 22$ \\
\hline $\begin{array}{l}\text { Zinc-blende, } \\
\text { ZnSS }\end{array}$ & $\begin{array}{l}\text { Face-centred } \\
\text { cubic }\end{array}$ & $4 \cdot 06$ & $97 \cdot 0$ & $(110)$ & $16 \cdot 5$ & 1.76 & $30 \cdot 8$ & 1.28 \\
\hline $\begin{array}{l}\text { Eluorspar, } \\
\text { CaFs: }\end{array}$ & $\begin{array}{l}\text { Face-centred } \\
\text { cubic }\end{array}$ & $3 \cdot 18$ & $78 \cdot 0$ & $\begin{array}{l}(100) \\
(111)\end{array}$ & $\begin{array}{l}11.7 \\
10 \cdot 3\end{array}$ & $\begin{array}{l}2 \cdot 46 \\
2 \cdot 79\end{array}$ & $\begin{array}{l}29 \cdot 8 \\
28 \cdot 3\end{array}$ & $1 \cdot 18$ \\
\hline $\begin{array}{l}\text { Calcite, } \\
\text { CaCO }\end{array}$ & $\begin{array}{c}\text { Rhombo- } \\
\text { hedral }\end{array}$ & $2 \cdot 71$ & $100 \cdot 0$ & $\begin{array}{l}(100) \\
(111)\end{array}$ & $\begin{array}{l}10 \cdot 5 \\
11 \cdot 2\end{array}$ & $\begin{array}{l}2 \cdot 74 \\
2 \cdot 60\end{array}$ & 44.8 & $1 \cdot 22$ \\
\hline $\begin{array}{l}\text { ron pyrites, } \\
\text { FeS }_{2}\end{array}$ & $\begin{array}{l}\text { Face-centred } \\
\text { cubic }\end{array}$ & $5 \cdot 03$ & $120 \cdot 0$ & $(100)$ & $12 \cdot 1$ & $2 \cdot 39$ & $27 \cdot 3$ & $1 \cdot 15$ \\
\hline
\end{tabular}

${ }^{1}$ In this table-

$\theta=$ glancing angle of Pt $B$ peak, first order.

$l=$ wave-length of $\mathrm{Pt} B$ peak.

$d=$ distance between planes parallel to the face investigated.

$\mathrm{l}^{r}=$ volume of elementary parallelopiped, calculated from this value of $l$ and a knowledge of the nature of the lattice. 
$\left(\mathrm{CaCO}_{3}\right)$, iron pyrites $\left(\mathrm{FeS}_{2}\right)$, and rock-salt (NaCl). Using in every ease the homogeneous rays of the $B$ peak of Pt, he found that the value of the quantity was, within a few per cent., the same for all substances. His results are put out in Table XIX.

Thus the number of molceules associated with each diffracting eentre is the same, and if we take into consideration the very different constitution of these erystals, this fact seems to point to the assoeiation of one molecule, and one alone, with each diffracting eentre. By combining this result with the deductions on p. 194, it would seem that, sinee there is only one heavy atom in each molecule, the pattern obtained with the various erystals is due to a spacelattice formed by the association of only one heavy atom with each eentre.

It will be noticed that potassium ehloride gives a value for $V \rho / l^{3} M$ equal to half that for the other crystals, the explanation being that the two atoms. being of nearly the same weight, are equally effeetive as diffracting eentres, and that a parallelopiped with haif the side is now the erystal unit.

The above argument is obviously not a complete proof of this important point, but the probability of the truth of the assumption that each centre represents a single atom has been strengthened by each and every one of the many varieties of erystals subsequently examined.

In later work, Bragg has been able to alloeate the positions of both the light and heavy atoms in many types of erystals.

Dimengions of Space-lattice and Wave-lexgth of $\mathrm{X}$ RAYs.

If the arrangement assigned to the alkaline salts is correct, we are now in a position to ealculate the wave-length of the $B$ peak. Pt radiation, for

$$
7^{\prime}\left(\frac{I^{r}}{l^{3}} \cdot \frac{\rho}{M}\right)=1
$$


Take the case of rock-salt (Na(1),

Molecular weight, $M=58.5 \times 1.64 \times 10^{-21}$ grammes.

Density, - - $\rho=2.15 \mathrm{~g}$ ill./c.e.

$V / l^{3}=33 \cdot 3$ (experinentally determined).

whence

$\therefore l^{3}(33.3 \times 2 \cdot 15)=58.5 \times 1.64 \times 10^{-21}$

and

$l^{3}=1 \cdot 34 \times 10^{-24}$

which gives us the wave-length of the homogeneous radiation of the $B$ peak of platinum.

By means of the values of $d / l$ given in Table XIX., we can calculate the lattice-constants for any of the erystals inrestigated.

\section{Platinum $L$ Radiation.}

The mass-absorption coefficient in $\mathrm{Al}$ of the rays constituting the $B$ peak of platinum was meastued by Bragg and found to be 23.7. From Fig. 59 this value corresponds either to a $K$ eharacteristic radiation from an element of atomic weight 72.5 or an $L$ eharacteristic radiation from one of atomic weight 198 . The atomic weight of platinum is 195: the agreement is too elose to be fortuitous, and there can be little doubt that the $B$ peak is due to the $L$ radiation.

We have the means of deriving further relations. From Whiddington's rule for $K$ radiations (p. 126) we can calculate that the cathode-ray energy necessary to excite the $K$ radiation from an atom of weight 72.5 is about $2 \times 10^{-8}$ ergs. This energy should be equal to the energy of the X ray cxcited, which, if Planck's radiation formula holds in this connection, is given by $h v^{1}$ or $h V / l . h$ is Planck's constant $\left(6.55 \times 10^{-27} \mathrm{erg}\right.$ sec. $), \nu$ is the frequency of the radiation, and $V$ is the velocity of light. Now we have just shown that $P t h$ racliation has a wave-length of $1 \cdot 10 \times 10^{-8} \mathrm{cmll}$, and therefore

$$
\begin{aligned}
\frac{h V}{l} & =\frac{6.55 \times 10^{-27} \times 3 \times 10^{10}}{1.10 \times 10^{-8}} \\
& =1.78 \times 10^{-8} \mathrm{ergss}
\end{aligned}
$$

-which is in fair agreenent with the calculated vahue.

$1 \mathrm{hv}$ is the energy of a quantum, according to Planck's theory. 


\section{X-ray Spectra.}

In later work (P.R.s. 1913 and 1914) the Braggs have condueted further experiments using a variety of antieathodes. The three allied metals, osmium, iridium and platimm, yield X-ray spectra with certain common charaeteristics. Each eontains three main groups of homogeneous rays, together with a good proportion of general

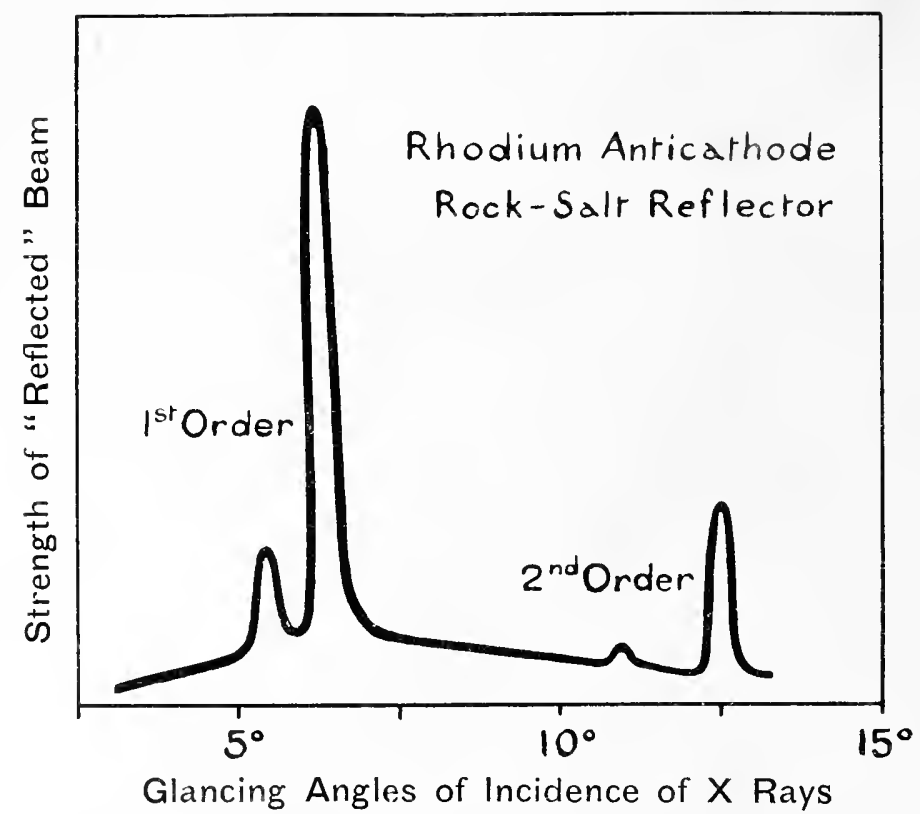

Fit. 9:3.-Sivectrum slowing distribution of energy in $\mathrm{X}$ rays from rhorlium. There is a large proportion of monochromatic radiation, ind very little "white", or general rafliation.

iatliation. The spectra of pallatium and rhodium are very similar to each other; each is very nearly homogeneous, at any rate with a soft bulb (sce p. 121), and contains little general racliation. On this account, both radiations have been employed a great doal by the Braggs in their later crystal experiments. Fig. 93 shows the rhodium speetrum.

It needs to be pointed out that Figs. 91 and 93 are examples of X-ray spectra of which the general form depends on the circumstances. While it is true that the spectral lines 
themselves are invariable in position, their relative intensity and that of the general radiation are modified by such faetors as the hardness of the X-ray bulb, the presence of any filtering sereens, the type of diseharge, and, of eourse, on the resolving power of the spectrometer. The ehemical nature of the erystal also exerts a marked effect on the distribution of the energy. Bragg has shown that this is due to the seleetive alssorption by the atoms of the erystals of the various components of the $\mathrm{X}$ rays.

\section{Moseley's Experiments.}

Moseley (P.M. Dee. 1913) has reently examined photo-

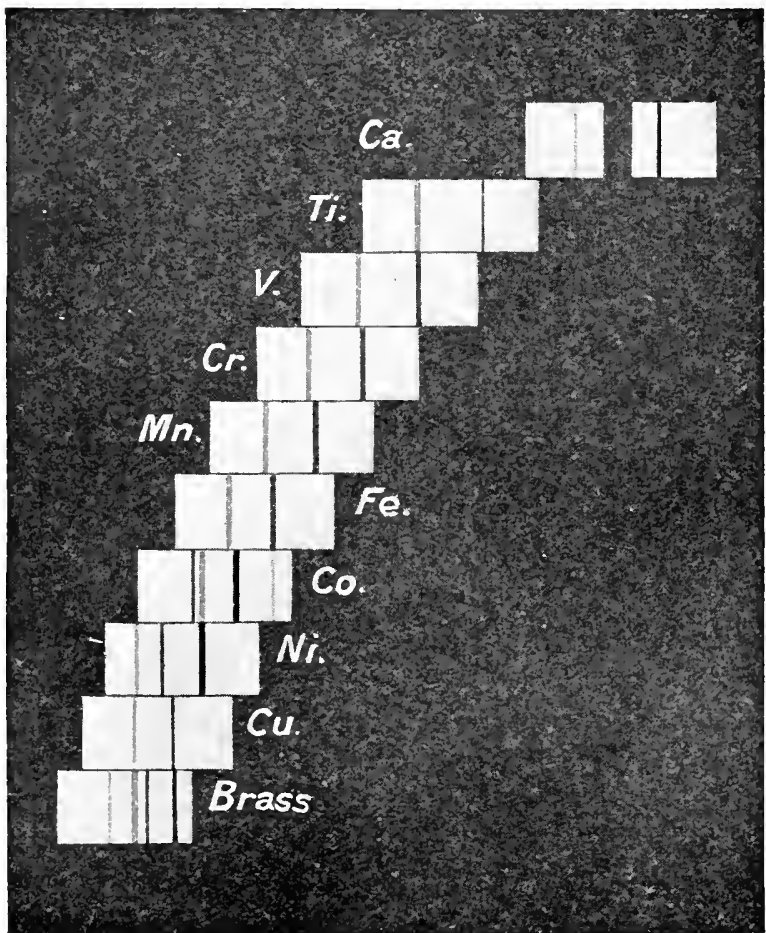

\section{$\longrightarrow$ Increasing Wave Length}

Fic. 94.--Noseley"s photographs of the $\mathrm{X}$-ray or high-frequency spectra from a number of metallic anticathodes. The spectra, which are in the thit urder, are placed anproximately in register in the figure. The wave-lengths are given on p. 2ul. For each metal, the more intense line, with the longer wave-length, is the $K$ characteristic radiation. The brass show the $\mathrm{kn}$ and Cu lines; the cobalt contained both nickel and iron as impurities. 
graphically the spectrum of $\mathrm{X}$ rays produced by a crystal of potassium ferrocyanide used as a reflection grating. The method has the advantage of doing away with the neeessity of keeping the source of radiation constant. Moseley employed Kaye's apparatus for generating characteristic $\mathrm{X}$ rays (p. 121), and found that for a range of elements extending from calcium to zinc, the spectrum consisted in each case of two sharply defined lines, of which the longer wave-length was the more intense; this latter is doubtless the $K$ radiation. The varions spectra are placed in approximate register in Fig. 94. It will be noticed that the wavelength increases as the atomic weight diminishes. The presence of any impurities is clearly shown in the spectra; the simplicity of the spectra suggests a powerful method of chemical analysis. The characteristic radiations are apparently very homogeneous, to judge by the photographs. Moseley has made important deductions from his results, bearing on Rutherford and Bohr's theories of the structure of the atom (see p. 18).

A series of wave-lengths of the rarious "lines" in the X-ray spectra is given in Table XX.

\section{Relation of Wave-length to Atomic Weight.}

From Whiddington's results (p. 125) the energy of a characteristic $\mathrm{X}$ ray is roughly proportional to the square of the atomic weight; and, at the same time, aceording to Planck's quantum theory of radiation, the energy of an $\mathrm{X}$ ray is inversely proportional to its wave-length. We have an opportunity of testing this in Table XX., where the wave-lengths of the $K$ radiations of twelve metals are given. Taking one of the intermediate metals (cobalt) as a standard of reference, the relative values come out as follows:

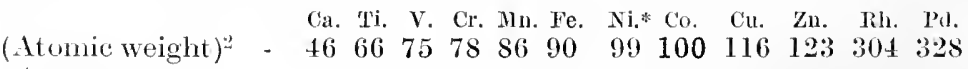
1/(Wave-length) - $53 \quad 6572 \quad 78 \quad 8592108100116 \quad 124298314$

Thus the wave-lengths are approximately proportional to the reciproeals of the squares of the atomie weights, over a considerable range of atomic weights.

* From an $\mathrm{X}$-raty point of view, $\mathrm{Ni}$ behaves like an elenent with an atomic weight of alout $61 \cdot 5$. 
Table XX. WAVE-Lengths on Monochromatil ol Homogeneous X RaYs.

The values below are due to Moseley, Moseley and Darwin, and Bragg. They are given to the nearest 0.005 A.U. All the measurements depend on W. L. Bragg's estimate of the atomic distances in the case of rock-salt (1. 197). Seo p. 235 for later values.

\begin{tabular}{|c|c|c|c|c|c|c|}
\hline \multicolumn{2}{|l|}{ Element. } & $\begin{array}{l}\text { Atomic } \\
\text { Weight. }\end{array}$ & \multicolumn{2}{|c|}{ Wave-length. } & \multicolumn{2}{|c|}{ Remarks. } \\
\hline Calcium & - & $40 \cdot 1$ & $\begin{array}{l}3 \cdot 36 \times \\
3 \cdot 09\end{array}$ & ${ }_{,}^{-8} \mathrm{~cm}$. & $\begin{array}{l}\text { Strong } K \\
\text { Weak }\end{array}$ & $\begin{array}{l}\text { iation. } \\
\text {, }\end{array}$ \\
\hline Titanium & - & $48 \cdot 1$ & $\begin{array}{l}2 \cdot 76 \\
2 \cdot 525\end{array}$ & , & $\begin{array}{l}\text { Strong } K \\
\text { Weak }\end{array}$ & ," \\
\hline Vanadium & - & $51 \cdot 1$ & $\begin{array}{l}2 \cdot 52 \\
2 \cdot 30\end{array}$ & , & $\begin{array}{l}\text { Strong } K \\
\text { Weak }\end{array}$ & ., \\
\hline Chromium & - & $52 \cdot 0$ & $\begin{array}{l}2 \cdot 30 \\
2 \cdot 09\end{array}$ & , & $\begin{array}{l}\text { Strong } K \\
\text { Weak }\end{array}$ & , \\
\hline Mangantso & - & $54 \cdot 9$ & $\begin{array}{l}2 \cdot 11 \\
1 \cdot 92\end{array}$ & , & $\begin{array}{l}\text { Strong } / 5 \\
\text { Weak }\end{array}$ & ," \\
\hline Iron - & - & $5.5 \cdot 9$ & $\begin{array}{l}1 \cdot 945 \\
1 \cdot 765\end{array}$ & , & $\begin{array}{l}\text { Strong } k \\
\text { Weak }\end{array}$ & , \\
\hline Cobalt - & - & $59 \cdot 11$ & $\begin{array}{l}180 \\
1 \cdot 63\end{array}$ & , & $\begin{array}{l}\text { Strong } 15 \\
\text { Weak }\end{array}$ & ," \\
\hline Nickel - & - & $58 \cdot 7$ & $\begin{array}{l}1 \cdot 66 \\
1 \cdot 505\end{array}$ & , & $\begin{array}{l}\text { Strong } K \\
\text { Weak }\end{array}$ & ", \\
\hline Copper - & - & $63 \cdot 6$ & $\begin{array}{l}1 \cdot 55 \\
1 \cdot 40\end{array}$ & , & $\begin{array}{l}\text { Strong } K \\
\text { IVeak }\end{array}$ & ," \\
\hline Zine - & - & $65 \cdot 4$ & $\begin{array}{l}1 \cdot 445 \\
1 \cdot 305\end{array}$ & , & $\begin{array}{l}\text { S'trong } K \\
\text { Weak }\end{array}$ & ", \\
\hline Rhodium & - & $102 \cdot 9$ & $\begin{array}{l}0 \cdot 605 \\
0.53\end{array}$ & , & $\begin{array}{l}\text { Strong } K \\
\text { Weak }\end{array}$ & , \\
\hline Pallarlium & - & $105 \cdot 7$ & $\begin{array}{l}0.575 \\
0.51\end{array}$ & , & $\begin{array}{l}\text { Strong } K \\
\text { Weak }\end{array}$ & , \\
\hline 'Tantalum & - & $181 \cdot 0$ & $\begin{array}{l}1 \cdot 525 \\
1 \cdot 3: 3 \\
1 \cdot 29\end{array}$ & $\begin{array}{l}\text {, } \\
., \\
.,\end{array}$ & $\begin{array}{l}\text { Strong } L \\
\text { Weak } \\
\text { Weak }\end{array}$ & $\begin{array}{l},, \\
,, \\
,\end{array}$ \\
\hline $\begin{array}{l}\text { 'L'mngsten } \\
\text { Platinum }\end{array}$ & - & $\begin{array}{l}184 \cdot 11 \\
195 \cdot 2\end{array}$ & $\begin{array}{l}1 \cdot 25 \\
1 \cdot 305 \\
1 \cdot 11 \\
1 \cdot 09 \\
0 \cdot 95 \\
0 \cdot 92\end{array}$ & $\begin{array}{l},, \\
, \\
, 1 \\
, y \\
,\end{array}$ & $l$ & , \\
\hline
\end{tabular}


It nlay be added that C. G. Darwin (P.M. Feb. 1914) remarks, from a scrutiny of Moseley's wave-lengths and Barkla's absorption coefficients (p. 115) for a considerable range of qualities of homogencous $X$ rays, that if $\lambda$ is the absorption coefficient and $l$ is the wave-length, then

$$
l^{\frac{1}{2}} \propto \lambda^{\frac{1}{5}} \text { almost exactly. }
$$

But from the above,

$$
l^{\frac{1}{2}} \propto \frac{1}{(\text { atomie weight })^{\prime}}
$$

and therefore

$$
\lambda \propto \frac{1}{(\text { atomic weight })^{5}}
$$

-which is Owen's fifth power law, refered to on 1). 116.

\section{Wide Range of Electromagnetic Waves.}

With the addition of $\mathrm{X}$ rays to the list of electromagnetic waves already known, the table of wave-lengths is extended greatly in one direction. At the other end of the scale are the waves which were originally discovered by Hertz and are now used in wireless telegraphy. The longest wavelength generated up to the present is about 15,000 metres, or a little over nine miles: the shortest is a few millimetres. The wares ordinarily used in "wireless" are a few thousand metres long, e.g. the wave-length of the wireless time signals from the Eiffel Tower is 2000 metres; of the Navy signals, from 600 to 1800 metres; of trans14]antic signals, 7000 metres or more.

Next to Hertzian waves, in order of maguitude, come the infra-red or heat rays, the greatest wave-length yet observed being $i^{\frac{1}{0}} \mathrm{~mm}$. We pass from these right through the visible spectrum to the ultra-violet rays, which have been explored as far as wave-length $10^{-5} \mathrm{~cm}$.; these are examined photographically. An extreme form of ultraviolet rays is probably represented by the "Entladungstrahlen" which are emitted from electric sparks, or the negative glow in a discharge tube (see Laird, P.R. 1911). 
Next come $\mathrm{X}$ rays with wave-lengths of the order of $10^{-8}$ em., and beyond them the most penetrating of all--the $\gamma$ rays-of whose waye-lengths little is yet known.

The various wave-lengths are summarised in Table XXI.; they cover, as will be seen, the amazing range of about one thousand million million fold.

Table XXI. Wave-lengths of Electronagnetic Raditions.

\begin{tabular}{|c|c|c|}
\hline Find of Wave. & & Wave-length in cms. \\
\hline Hertzian waves & - & to 0.4 \\
\hline Infria-red rays & - & to $7.7 \times 10^{-5}$ \\
\hline Visible light rays - & - & $7 \cdot 7 \times 10^{-5}$ to $3 \cdot 6 \times 10^{-5}$ \\
\hline Ultra-violet rays - & - & $3 \cdot 6 \times 10^{-5}$ to $10^{-5}$ \\
\hline Entladungst rahlen & - & about $10^{-6}(?)$ \\
\hline I rays - & - & about $10^{-s}$ \\
\hline$\gamma$ rays - & - & about $10^{-!}(?)$ \\
\hline
\end{tabular}




\section{CHAP'TER XIII.}

'THE NATURE OF' THE I RAYS.

The diseovery of the $\mathrm{X}$ rays by Röntgen, and their immediate applieation in surgery, excited the popular interest to an astonishing degree. Geissler tubes, no matter what their suitability, were in immediate demand by a strangely interested public. The seientific joumals of 1896 bear witness to the many workers, who turned, if only for a time, from their usual pursuits, eager to test the extraordinary properties of the new rays. Naturally enough, among sueh an army of enthusiasts, speculation as to the nature of the rays was not marked by any great restraint; a few of the responsible suggestions may be briefly recalled.

Röntgen, Boltzmann, and others regarded the rays as longitudinal ether-vibrations of short period and great wavelength: Janmann added to this a transverse eomponent: Goldhammer, Sagnae, and many others believed that the new rays were extremely short transverse ether-waves akin to ultra-violet light; on the other hand, Re took the view that the wave-length, far from being short, was infinitely long: Sutherland considered $\mathrm{X}$ rays to be due to internal vibrations of the electrons within the atom : other workers held that the rays were a manifestation of the breaking up of molecules into atoms at the target: Michelion suggested that Röntgen rays were ether vortices: Stokes put forward a theory of irregular pulses in the ether; and finally, many physieists, inchuding at one time, Röntgen himself, and more recently Prof. Bragg, inclined to the view that the rays were flights of material particles which resembled 
strongly, and were possibly an extreme though electricallynentral form of, the parent cathode rays.

It is only within the last year or so that controversy has been stilled by the discovery that $\mathrm{X}$ rays can be reflected and diffracted by crystals. There can scarcely be any doubt now that $\mathrm{X}$ rays are identical with ultra-violet light of extremely short wave-lengths; wave-lengths, in fact, of the order of the diameter of the atom.

Yet it is not quite all plain sailing, for while it secms certain from the extreme precision observed in the reflection experiments that $X$ rays are regular light waves and occur in trains of great length, yet the difficulty is that in many of their properties the rays behave strangely like streams of discrete entities, the effects of which are localised in space in much the same way as are the effects of rifle bullets. The difficulty is not, however, unique; it is now known to be common to all forms of radiation. The Newtonian laws implying perfect continuity and infinite divisibility of time and space have, until recently, found complete credence; but in the very nature of things they do not seem to be reconcilable with modern experiment, which suggests that energy radiation is essentially discontinuous and must take place by finite "jumps." As to the mechanism by which this is accomplished, it is at present obscure and still a matter for speculation. ${ }^{1}$

To meet the difficulty, J. J. Thomson, in his nucleated pulse theory, has suggested that all the various light radiations consist of concentrated and localised electromagnetic impulses which travel with the speed of light in some one direction through the ether (see p. 213). Planck's quantum theory, as developed by Einstein and Stark (P.Z. 1909 and 1910 ) similarly argues that $\mathrm{X}$ radiation (in common with all radiation) is made up of definite and indivisible increments which ean travel without loss or alteration of form, the energy of these "bundles" being proportional to the frequency of the radiation. The same difficulty was felt by Prof. Bragg when he put forward his corpuscular or neutral-

1 For an excellent treatment of this subject see N. R. Campbell, Hodem Electrical Theory, 2nd ed. 1913. Also Rep. Brit. Assoc. Sect, A, 1913. 
pair theory of the $\mathrm{X}$ ray. This theory, which regarded an $\mathrm{X}$ ray as a neutral corpuscle, was conspicuously successful in predicting and interpreting the energy transfers met with in the inter-relations of the cathode rays and $\mathrm{X}$ rays.

On the other hand, almost all the well established results of the undulatory theory of light seem to be irreconcilable with entity views such as these. Nucleated light does not appear to conform to the marvellous explanation of interference and diffraction, which Young and Fresnel founded on a theory of spreading waves, nor does it obviously lead to the general laws of reflection and refraction which are apparently obeyed by all waves, from the shortest $\mathrm{X}$ rays to the longest Hertzian.

\section{Points of Resemblance between Light Rays and X Rays.}

The essential identity of $\mathrm{X}$ rays and light rays cannot be denied, in view of the work on crystal-reflection, but, notwithstanding, it will be useful and not without interest to summarise the remaining points of resemblance which experiment has revealed between $X$ rays, $\gamma$ rays, and light rays : in many cases it would be anticipated that the effects would differ only in degree. For example, the ionising effect of ultra-violet light on gases (first established by Lenard in 1900 , and more recently and completely by Hughes, P.C.P.S. 1911) is relatively feeble when eontrasted with the more vigorons activity of $\mathrm{X}$ rays.

Again, all three agencies cause the ejection of corpuscles from metals, and experiment has shown that:

(1) The intensity of the incident rays does not affect the speed, but merely the number of the ejected corpuscles (p. 140).

(2) The speed is controlled by the quality of the incident rays, ${ }^{1}$ but not at all by the metal (p. 141). [With

' In the case of ult ra-violet light, Hughes (P.T. 1912) finds experimentaliy that the energy rather than the speed of the fastest electrons is proportional to the frequency of the light. This confirms a deduction from Planck's quantum theory (p. 205), which regards the photoclectric effect as due to a quantum handing over its encrgy to an electron. Hughes found the velocity of emission to vary from metal to metal. 
ultra-violet light the range of speeds is from about $10^{7}$ to $10^{8}$ ems. per see. ; with X rays $10^{9}$ to $10^{10}$; with $\gamma$ rays, $10^{10}$ to $2 \cdot 99 \times 10^{10}$.]

(3) The secondary corpuscles tend to continue in the line of flight of the original rays (p. 139).

(4) There is a selective emission of corpuseles for certain wave-lengths of the rays (pp. 119 and 142).

These results are common to all three rays.

There are further points of resemblance. As was noticed on p. 108, if an element is exposed to $\mathrm{X}$ rays, then, in general, two different classes of $\mathrm{X}$ rays are given out by the substance. Of these, one is identical in nature with the incident rays, and is nothing more than so much scattered radiation; the other is a radiation charaeteristic of the element, and does not depend at all on the nature of the exciting rays, provided only that they are harder than the characteristic radiation. 'This latter feature at once recalls Stokes' law of fluorescence. Apart from some exceptions, Stokes lawthat the frequeney of the exciting light is always greater than that of the fluorescent light-holds generally for light rays. The analogy with $\mathrm{X}$ rays is complete.

An even more striking similarity is presented if the distribution of the two seeondary $\mathbf{X}$ radiations is compared with the distribution of light in kindred circumstanees. When light is allowed to fall on minute particles in suspension, as in a fog, it is found that the scattered light is not uniformly distributed, but varies in amount in different directions. The scattered light emitted parallel to the original beam is double that at right angles; the intermediate intensities are proportional to $\left(1+\cos ^{2} \theta\right)$, where $\theta$ is the angle measured from the original beam. But if the particles emit fluorescent light as well as seattered, the fluorescent light is equaily intense in all directions.

In just the same way, it is found (p. 110) that the intensity of the scattered $\mathrm{X}$ rays obeys, at any rate approximately, a $\left(1+\cos ^{2} \theta\right)$ law over a considerable angular range: and that the "fore and aft" intensity is very roughly twiee that at 
right angles. And, to complete the parallel, the characteristic $X$ radiations show a uniform distribution just as fluorescent light does.

Other points of resemblance between $X$ rays and light rays have been notieed from time to time in the preceding pages. One point of difference is provided by the phenomena of absorption. In the case of light, it is known that many of the dark lines in the absorption spectrum of a body are in the same position as the bright lines in its emission spectrum: in other words, a body, under suitable conditions, is eapable of absorbing strongly its characteristic light radiations. But, with $\mathrm{X}$ rays, on the contrary, we find that an element is especially transparent to its characteristic $\mathrm{X}$ radiations (see p. 129), and it is only for rather harder rays than these that the absorption becomes abnormally large.

We may now consicler the ease for the restricted entity hypothesis. It will be convenient first of all to recall the main features of Stokes' famous theory of the $\mathrm{X}$ rays.

\section{The Ether-Pulse Theory of Stokes.}

Sir George Stokes promulgated the pulse theory of the $\mathrm{X}$ rays in the Wilde Lecture before the Manchester Literary and Philosophiçal Society, on July 2, 1897. He considered that " when the charged molecules 1 from the cathode strike the target, it is exeeedingly probable that by virtue of their charge they produce some sort of disturbance in the ether. This non-periodic disturbanee or 'pulse' would spread in all clirections, so that, on this view, the Röntgen emanation consists of a vast and irregular suceession of isolated and independent pulses starting from the points and at the times at which the individual charged molecules impinge on the target. We know of no reason beforehand forbidding us to attribute an exeessive thimness to the pulses" ; and to the narrowness of these pulses Stokes attributed some of the differences between ordinary light and $\mathrm{X}$ rays, which,

\footnotetext{
1 This was in the days when the eathole rays were thought to be moleenles.
} 
apart from this, resemble each other closely ${ }^{1}$ : both consist of electric and magnetic forces at right angles to each other and to the direction of propagation, but in the $X$ rays there is not that regular periodic character occurring in trains of waves of uniform wave-length.

Thus a Röntgen pulse on Stokes' theory is somewhat analogous to the crack of a whip when it is suddenly stopped, or the flash of flame when a projectile strikes a target. Briefly, the theory claims that the energy of an $\mathrm{X}$ ray is contained within a thin spherieal shell which travels outwards with the speed of light in all directions, from the place where the speed of a cathode ray is suddenly changed. The faster the eathode ray and the more abrupt the change in its speed, the thinner and more energetic the pulse. By the laws of electrodynamics, such pulses of intense electric and

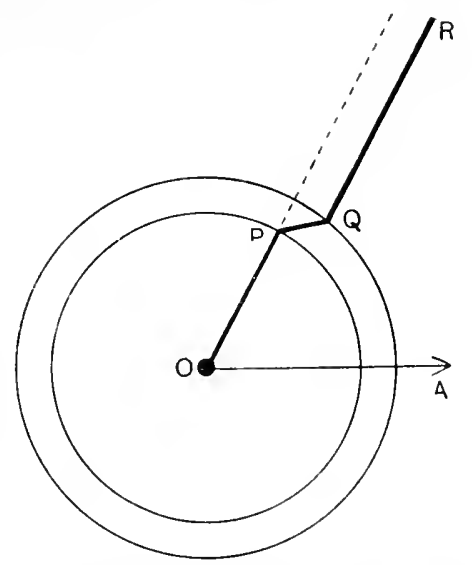

Fig. 95.-Representation of spreading pulse, showing kink in line of force $O P Q \bar{R}$ attached to the charged particle $O$, the velocity of which has been suddenly altered. magnetic forces are inevitable when rapidly moving electrified particles are suddenly stopped or started.

\section{The Polarisation of $\mathrm{X}$ Rays.}

The polarisation of $\mathrm{X}$ rays (p. 110) follows as an immediate deduction from the pulse theory. The theory contemplates secondary radiation as owing its origin to the disturbances produced in the corpuseles when the primary $X$ rays pass over them. While the $\mathrm{X}$ rays are thus accelerating the corpuscles, each gives out a pulse of electric and magnetie

1 It should here be mentioned that, as a result of the work of Rayleigh, Schuster, and others, our notions of the nature of white light have been modified in recent years, and it is now gencrally aceepted that white light (like "independent" $\mathrm{X}$ rays) consists of irregular pulses which are capable of being transformed into trains of sine-waves by the various diffraeting or refracting instruments. 
force-the secondary Röntgen pulse. A single primary pulse may produce a great number of secondary pulses with properties which depend on the grouping, etc., of the corpuscles. Thus, on this point of view, there is, to use Sir J. J. Thomson's apt comparison, much the same difference between the primary and secondary rays as there is between the sharp crack of lightning and the reverberations of thunder.

The argument in the polarisation experiments is that since in an X-ray tube the cathode rays are all travelling in the same direction, then in the resulting pulses the electric forces (which are at right angles to the direction of motion of the cathode rays) will lie in planes passing through that direction, and not at right angles to it (see Fig. 57). In other words, the particular pencil of $\mathrm{X}$ rays which is employed will be concentrated in the plane which contains both $\mathrm{X}$ rays and cathode rays.

Hence the motion of the excited corpuscles in the radiator will also be mainly in this plane, and so the intensity of the secondary radiation will be a minimum in this plane, and a maximum at right angles to it, a result which agrees with that actually found. The fact that the $\mathrm{X}$ rays are only partially polarised, may be ascribed to the fact that the cathode rays in the $\mathrm{X}$-ray tube are not stopped in a single collision, but describe many directions before finally coming to rest.

\section{Modification of Spreading-pulse Theory necessary.}

But cxperiment has clearly establisherl that the theory of the spreading pulse needs extensive modification. It will be profitable to review the trend of the results (to some of which we have already referred), that have led to the theory in its modified form. Categorically these are:

(1) When $X$ rays encounter a gas, only an exceerlingly small fraction-less than one in a billion--of its molecules become ionised ${ }^{1}$ (p. 145).

\footnotetext{
1 The same difficulty oenurs in understanding why, when ultra-violet light falls on metals which show photoelectric properties. such a very small proportion of the particles are liberated.
} 
(2) The extent of this ionisation is unaffected by temperature (p. 148).

(3) When $\mathrm{X}$ rays encounter a metal, the corpuscles ejected have a velocity which

(a) does not depend on the intensity of the $\mathrm{X}$ rays, and so is independent of the distance of the metal from the X-ray bulb (p. 140),

(b) increases continuously with the hardness of the $\mathrm{X}$ rays (p. 140),

(c) does not depend on the nature of the metal (p. 141),

(d) is equal to the velocity of the cathode rays in the X-ray bulb (p. 142).

(4) These ejected corpuscles are not evenly distributed, but tend to pursue in the main the original direction of the $\mathrm{X}$ rays. The effeet is most pronounced with metals of small atomic weight and hard $X$ rays (p. 139).

In considering the first result, we may recall that according to the ether-pulse theory in its original form, all the molecules of a gas are equally exposed to the $X$ rays, and we are led to infer that those few which become ionised must have been in a state very far removed from the average. Their abnormal condition cannot be attributed to an exceptionally high kinetic energy, for the kinetic theory of gases would then require that the ionisation should vary rapidly with the temperature-and we are immediately confronted with result (2).

We may, however, claim that the ionisation is controlled by the internal conditions of the different atoms, rather than by their kinetic energy. The phenomena of radioactivity lead us to believe that atoms possess large stores of internal energy which are not readily unlocked by outside agencies; and if it should be the case that the possession of an exceptional amount of internal energy means weakened stability, then it might easily happen that only abnormal atoms would be ionised by $X$ rays. Or, again, it might be that an atom is capable of collecting energy from many $X$ rays until it has enough for one electron. On either view, the 
ejection of corpuscles from a metal subjected to $\mathrm{X}$ rays is interpreted as the outward sign of a sort of radioactive explosion of some of the atoms rendered temporarily unstable. The $\mathrm{X}$ ray thus acts merely as a trigger to start the explosion; the corpuscles come from the atom, and owe their energy to it alone. That their velocity should be independent of the intensity of the $\mathrm{X}$ rays follows at once, and is in accord with result $(3 a)$.

But we have now to explain why the speed of the corpuscles is not independent of the quality of the $\mathrm{X}$ rays (result (4)). Why should the velocity be greater when the $\mathrm{X}$ rays are hardened, if their only effect is that of a trigger action? and further, why should the path of a corpuscle be influenced by the direction of the $\mathrm{X}$ ray, if the latter merely preeipitates the disintegration of the atom? On the explosion theory, neither result could be anticipated; nor should we be unreasonable in expecting that the disintegration of different metals would lead to very different velocities of the ejecter corpuscles. The reverse is the case. We are, in fact, left with no alternative but to suppose that the energy of the corpusele is derived from that of the $\mathrm{X}$ ray.

Now, result ( $3 a$ ) remarks that the energy of the corpuscle is independent of the distance of the X-ray tube. But, for reasons similar to the above, the $\mathrm{X}$ ray must derive its cnergy directly from the parent cathode ray, and, according to the pulse theory, it distributes this energy over an everenlarging surface. The argument is fatal to the spreadingpulse theory. The energy of the $\mathrm{X}$ ray must, it is evident, be confined within very narrow bounds which do not widen as the $X$ ray travels. ${ }^{1}$ Combining this result with (3d) above, we are led to conclude that the $\mathrm{X}$ ray is a minute cntity whose energy is not frittered away along its track, but is handed over completely to one corpuscle and no more on suitable encounter with an atom.

This is a statement of the case for the entity hypothesis, and the difficulty remains of reconciling it with the ordinary clectromagnetic theory of Maxwell. Of the attempts which

1 Sommerfeld (1911) maintains that the pulse theory is eompetent to explain part, at any rate, of this lecalisation of energy. 
hibe been made, we may here refer briefly to the broad outlines of Sir J. J. Thomson's nucleated pulse theory.

\section{The Nucleated or Localised Pulse Theoris of J. J. THomson.}

Sir J. J. Thomson's theory of the X ray assumes a fibrous structure in the ether, and pictures a eorpuscle as the seat of a tube of force which stretehes out into space. When a cathode ray has its velocity altered, the radiated energy runs along this tube, as a kink runs along a stretehed wire. The energy is confined to the region of the kink, and it is not given up until it strikes a corpuscle, to which it can then transfer its energy without waste. The nucleated pulse is equivalent to Stokes' pulse, with the exception that instead of spreading out uniformly in all directions, it is confined to one direetion only.

Professor Thomson further believes that the energy of light is distributed in analogous fashion; that individual light waves are not continuous, but correspond to a collection of wires along which the various disturbances travel; and that if a wave-front could be made visible we should get, not continuous illumination, but a series of bright speeks on a dark ground. The energy is not, therefore, uniformly distributed throughout the whole volume of the waves, but is concentrated in "bundles."

The rays diminish in intensity with increasing distance owing to the greater separation of the "batehes," and not to the enfeeblement of individual units. The distribution of energy thus resembles that contemplated by the Newtonian emission theory of light, aceording to which the energy was located on moving partieles sparsely disseminated throughout spaee.

In the case of $\mathrm{X}$ rays the phenomena are sharply defined, but with light rays they are much more involved. The diseontinuous wave-front theory, in fact, regards $X$ and $\gamma$ rays as light in its ultimate simplicity. This agrees with experiment : the general laws eovering the behaviour of $\mathrm{X}$ rays are obeyed with fewer exceptions than is the case with light. 


\section{"Fluctuation" Experiments with $\gamma$ Rays.}

Experimenters have naturally sought to establish by direet means the presumed discrete nature of light rays and $\mathrm{X}$ rays.

As is well known, the spinthariseope of Sir $\mathrm{Wm}$. Crookes exhibits for the a rays of radium fluctuations both in time and space. Similarly, the effects predieable for $\beta$ rays have been observed ; and since 1910 a number of workers, among them ron Schweidler (1910), E. Meyer (1910), Laby and Burbidge (1912), and Burbidge (1913), have endeavoured to detect corresponding fluctuations in the ionisation produced by $\gamma$ rays in a gas. For this kind of work, a steady souree of rays is absolutely essential, and so $\gamma$ rays have been worked at rather than $\mathrm{X}$ rays.

Laby and Burbidge (P.R.S. 1912) used two ionisation chambers, identical in all respects, and disposed them symmetrically about and equidistant from the radium emitting the $\gamma$ lays. If the $\gamma$ radiation has a spherical wave surface, then the ionisations in the two chambers will have a constant ratio. If, on the other hand, the $\gamma$ rays are circumscribed entities, emitted in random directions, as a rays are, then the number entering each chamber in a given time will fluctuate. There is one outstanding difficulty: if Prof. Bragg's view as to the indirect process of ionisation by $\gamma$ rays is correct (p. 146), the fluctuations might be produced by a variation in the number of $\beta$ rays generated by each $\gamma$ ray. The fluctuations which Laby and Burbidge actually observed in their experiments cannot, therefore, be interpreted with certainty.

More recently E. Meyer (A.d.P. March 1912), using somewhat similar apparatus, finally conchuded that a single $\gamma$ ray an produce ionisation in more than one direction and on more than one occasion : the numbers of $\gamma$ rays emitted by the same source in two different directions do not appear to be independent. Meyer's experimental arrangements have been criticised by Burbidge (P.R.S. 1913). Meyer's results are, however, in accord with those of Rutherford (P.M. Oct. 1912), who has recently found reasons for supposing that a swift $\beta$ ray may give rise to several $\gamma$ rays in escaping from 
an atom, and still retain part of its original energy. One may here refer to the work of Chadwick (P.M. 1912), who has obtained evidence that a rays, like $\beta$ rays, are able to excite $\gamma$ rays when they fall on ordinary matter. This would suggest that it is kinetic energy lather than velocity which is the determining factor.

\section{"Fluctuation" Experiments with Light Rays.}

N. R. Campbell (P.C.P.S. 1909, 1910) attacked the problem of light emission by the "fluctuation" method, with the object of discriminating between the ordinary and entity light hypotheses. Unfortunately the difficulty of finding a source of light which is very intense and also extremely constant proved insurmountable.

Taylor (P.C.P.S. 1909) approached the problem from a different standpoint. All ordinary optical phenomena are average effects, and are therefore incapable of differentiating between the usual electromagnetic theory of light and a restricted entity type. If, however, the intensity of light in a diffraction pattern were so greatly reduced that only a few of the indivisible bundles of energy could occur at once on a zone, the ordinary phenomena of diffraction would be modified. The method of attack was to photograph the shadow of a needle under various illuminations, and with exposures chosen such that the total energy supplied was constant. Exposures ranging from a few seconds to three months were employed, but no variation in the sharpness of the diffraction pattern could be detected in the different photographs.

Thus the more direct attempts to confirm the "discontinuous" nature of light and of $\mathrm{X}$ rays have not met with success.

\section{The Outstanding Problem of Radiation.}

It will be apparent that the problem of the nature of the I ray cannot yet be dismissed. We have succeeded in establishing the essential identity of $\mathrm{X}$ rays and light rays, and the interest has, accordingly, shifted its ground. The difficulties, conspicuous with Röntgen rays, have merged into 
those which all classes of electromagnetic. waves are found to present in greater or less degree. The full secret of the nature of $\mathrm{X}$ rays will doubtless be revealed when we find the key to the overshadowing problem of the mechanism of radiation in general. We are left confronted with the riddle of modern physics. 


\section{APPENDIX 1.}

IN connection with Röntgen's discovery, Sir James Hackenzie Davidson has been kind enough to write down for me his recollections of an interview with Prof. Röntgen not very long after the discovery of the $\mathrm{X}$ rays.

"While travelling on the Continent in 1896 I made a pilgrimage to Würzburg, and called at Professor Röntgen's house in the evening, and was kindly granted an appointment for the following morning. I presented myself about 11 a.m., and was shown into a laboratory which contained a eoil and a small eylindrical-shaped X-ray tube. Professor Röntgen, a tall man with dark bushy hair, a long beard, and very kindly and expressive eyes, reeeived me eordially. He could not speak mueh English; I was still worse at German. However, by means of English and some Latin we made ourselves intelligible to one another. He exeited the tube and showed me various shadows on a fluorescent sereen. On eaeh of the terminals of his coil he had a small aluminium ball, $1 \mathrm{~cm}$. in diameter, which he told me he used as an alternative spark-gap to test the hardness of the tube. He ineidentally remarked that he found a tube had its maximum photographie effect when it was working just at 2.5 cms. alternative spark-a faet whieh I have always found to be correet. I asked some blunt questions as follows:

Q. "What were you doing with the Hittorf tube when you made the discovery of the $\mathrm{X}$ rays? '

$A$. "I was looking for invisible rays.'

Q. "What made you use a barium platino-eyanide sereen?' 
A. " In Germany we use it to reveal the invisible rays of the spectrum, and I thought it a suitable substance to use to detect any invisible rays a tube might give off.'

"He then detailed how he made the discovery. He said he had covered up the Hittorf tube with black paper so as to exclude all light, and had the screen (which was simply a piece of cardboard with some crystals of barium platinocyanide deposited on it) lying on a table 3 or 4 metres from where the covered tube was situated, ready to be used. He excited the tube to ascertain if all light was excluded. This was so, but to his intense surprise he found the distant sereen shining brightly!

"I asked him, "What did you think?' He said very simply, 'I did not think, I investigated.'

. Incidentally, he told me how he had taken a photograph through a pine door which separated two of his laboratories. On developing the negative, he found a white band across it, which, he ascertained, corresponded to the beading on one of the door panels. He stripped the beading off, and fomd the band of shadow was due not to the increased thickness of wood but to the 'plumbum' (white lead really) the doormaker had employed in attaching the strip of wood.

"He seemed amused at my remonstrating with him about keeping the 'screen' lying about in his laboratory. I told him it was a 'historical screen,' and should be preserved in a glass case! I hope he has carried out this suggestion. For the sudden shining of that 'sereen' undoubtedly led to one of the greatest discoveries in modern times."

J. M. D. 


\section{APPENDIX 11.}

\section{The Cooldoge X-ray Tube.}

Dr. W. Coolide ${ }^{1}$ (P.R. Dec. 1913) has derigned a new X-ray bulb which marks an important step in the progress of radiography and radiotherapy. The eathode and anticathode are mounted parallel to and facing each other, some 2 ems. apart, in the centre of the bulb. The chief novelty lies in the eathode. This consists of a small Hat spiral of tungsten wire, surrounding which is a molybdenum

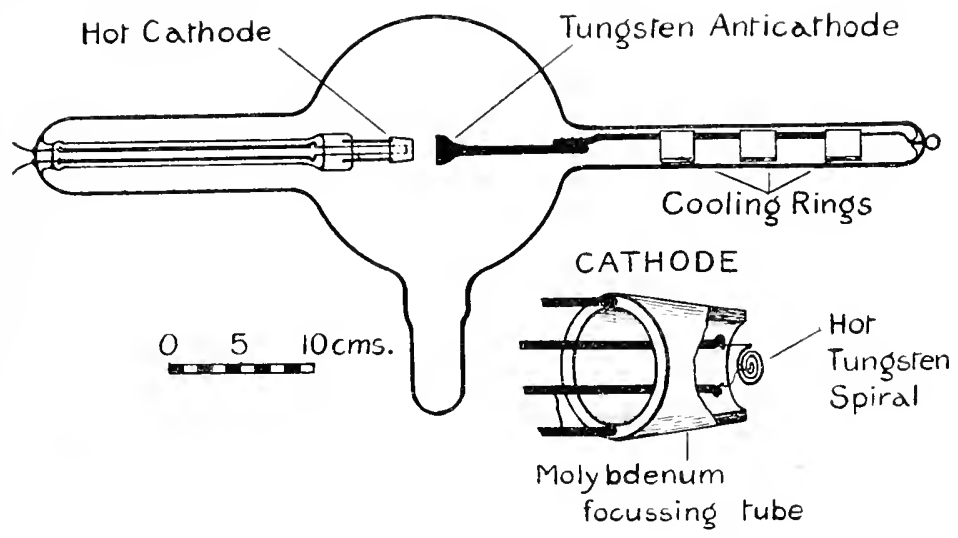

Fig. $96 .-$ Coolidge $X$-ray tube.

tube, the two being electrically connected. The tungsten spiral is heated by a subsidiary electric current (as with a

1 Of the General Electric Co.'s Research Laboratory, Schenectady, New York. 
Wehnelt cathode, p. s), and so becomes a source of electrons (or cathode rays) to an extent which increases rapidly with the temperature. The molybdenum tube serves to focus the stream of electrons (see p. 71) on the anticathode, which is of tungsten and unusually heavy. There is no additional anode.

The vacuum within the tube is extremely high-about 1000 times that of an ordinary X-ray tube-with the result that unless the cathode is heated, it is impossible to send a discharge through the tube. Furthermore, the greatest care is taken in freeing the electrodes and the glass walls from gas, before sealing off, after exhaustion.

The intensity of the $\mathrm{X}$ rays is precisely and readily controlled by adjusting the temperature of the cathode. At high temperatures $\left(2300^{\circ} \mathrm{C}\right.$. or so) an enormous output of $\mathrm{X}$ rays is possible. For example, such a tube has been run, on a $7 \mathrm{~cm}$. alternative spark-gap, for hours at a time, with a steady current of 25 milliamperes passing through the tube continuously.

The penetrating power of the rays depends, as in the ordinary tube, on the potential difference between the clectrodes. Either direct or alternating potential can be used to excite the tube, for the hot cathode allows the current to pass only in one direction, except indeed when the anticathode also becomes very hot. As a result, with a coil discharge, the "inverse" current is entirely abolished.

Owing to the low pressure, positive rays do not play an essential rôle, and there is in consequence no evidence of cathodic sputtering. There are slight traces of blackening due to vaporisation of the tungsten.

By reason of the care taken in exhaustirg the tube, there is no appreciable change in the vacuum, and, therefore, in the output of $\mathrm{X}$ rays, even after a rum of many hours. The focal spot does not wander but remains perfectly steady.

The starting and rumning voltages are the same, and the tube is remarkable in showing no fluorescence of the glass as in the ordinary $\mathrm{X}$-ray tube, so that its appearance affords little notion of the output or indeed of any activity at all. 
The apparatus appears to indicate a very great step forward, and once the technique is mastered, we are justified in expecting revolutionary changes in $\mathrm{X}$-ray dosage and radiography.

\section{The Lilienfeld X-ray Tube.}

In the Lilienfeld tube, the disposition and design of both anticathode and eathode are as in the usual X-ray tube. Two additional "priming" electrodes are provided; one of these, which is in close proximity to the anticathode, is raised to incandescence. The other, which is an aluminium cylinder, forms the anode of this priming circuit. As in the Coolidge tube, the vacuum is extremely low, but it suffices to apply about 500 volts to the priming eircuit, in order to enable the main discharge to pass.

The tube permits ready and accurate adjustment of the output, and exhibits no hardening effects. One of them has been in steady use for a considerable time at Leipzig For further particulars see a paper by Dr. Roscnthal in the Fortschritte auf dem Gebiete der Röntgenstrahlen for June 191:;, an abstract of which is given in A.Rt.R. for Feb. 1914. 


\section{APPENDIX TII.}

\section{THE PRODUCTION OF HIGH VACUA.}

A BRIEF notice may be taken of the present methods of exhansting vaenum tubes. The very highest vaeua can be got by making use of the extraordinary absorptive powers for gases of charcoal (e.g. cocoanut char-

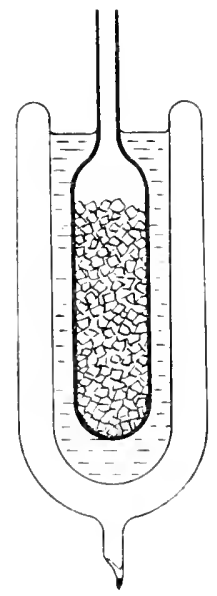

Fut, 97-Tube containing rharcoal immersed in

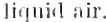
coal) when immersed in liquid air-a remarkably quick and effective method we owe to Prof. Dewar. Oxygen, nitrogen, water vapour, ete., are absorbed to large extents, hydrogen rather less so, helium and neon least of all. It is essential that the charcoal should be previously heated in situ ${ }^{1}$ and the emitted gas pumped off before applying the liquid air. Angerer (A.d.P. 19J1) records a pressure of $8 \times 10^{-7} \mathrm{~mm}$. Hg by the use of chareoal and liquid air.

With one exception, all the varions mechanical pumps for the production of vacua employ the plan of repeatedly abstracting and isolating, by means of a solid or liquid "piston," a certain fraction of gas from the ressel to be exhausted, and delivering it elsewhere. The exception is a strikingly ingenious "molectiar pump" reeently introduced by Gaede."

1 As a practical precaution, a plug of glass-wool slould be inserted above the chareral, to stop the small carbon particles, whieh are expelled when the rharenal is heated, from passing over into the apparatus.

a see Engineering, Sept. 20, 1933. 
It depends for its success on the viscous dragging of gas by the surface of a cylinder rotating within a second cylinder at a speed comparable with the velocities of the molecules of the gas, which are accordingly impoverished in one direction and accumulated in the other. The pump is extremely rapid in action, but requires the initial pressure to be reduced to a few mms. of mercury by an auxiliary pump. There is no piston, but always free communication, through the molecular pump, between the vessel to be exhausted and the auxiliary pump. With a speed of rotation of 12,000 revs. per min., and an initial vacuum of $\frac{1}{20} \mathrm{~mm}$., Gaede records the remarkably low pressure of $2 \times 10^{-7} \mathrm{~mm}$. It is very interesting to note the susceptibility of the pump to the molecular velocity of the gas present. For the same velocity of the cylinder, a lower pressure is attainable with air (molecular velocity 500 metres/sec.) than with hydrogen (molecular velocity 1800 metres/sec.), as may be shown by scavenging the vacuum with one or the other gas. The pump shares with the cooled-charcoal method the advantage of not requiring any drying agent-vapours are sucked away as readily as gases. For such a rapid type of pump the connecting tube must not be restricted in bore; the remark, indeed, applies to all pumps.

Still more recently (1914), Gaede has put on the market a new hand-driven piston pump. which ean produce very high vacua with great rapidity, and is capable of dealing with water-vapour.

Next come the various types of mercury pumps-the Töpler and Sprengel in a variety of modifications, some of them designed to be automatic in action. The rotary mercury pumps, such as the Gaede, have come into extensive use, and possess the great advantage that they can be motordriven-a feature commending itself to all who have worked with the hand-manipulated Töpler. In regard to mercury (and oil) pumps it is well to remember that they will not pump vapours, ${ }^{1}$ and that the vapour pressure of mercury

\footnotetext{
1 To obtain high vacua it is, therefore, necessary to remove water vapow by means of a drying agent such as phosphorus pentoxide. Other vapours can be frozen out by means of liquid air.
} 
at ordinary temperatures is about $\frac{1}{1000} \mathrm{~mm}$. mercurya fact which does not always tally with the elaims sometimes advaneed on behalf of this or that pump. ${ }^{1}$ Mercury pumps ought not to be set the task of exhausting from a high initial pressure-they work best as finishing-off pumps.

For the earlier stages of exhausting there is available a varicty of oil-pumps which can be motor-driven, and some of which ean deal with large quantities of gas. Ordinary heavy engine-oil works well in these pumps and has a low vapour pressure. A drying chamber should be used in conjunction with an oil-pump, or the oil may emulsify and the efficiency of the pump will suffer.

\section{Gas held by Walls of Tube.}

A great deal of gas-mostly hydrogen and moisture-is held by the electrodes and the walls of a vacuum tube. To liberate the gas, the diseharge should be run for some time to suit the conditions under which the tube is intended to be used. ${ }^{2}$ This, of eourse, ought to be done by the maker before the tube is sealed off from the pump. The walls of the tube hold this surface gas tenaciously-it appears to be largely moisture whieh is held bound as a condensed surface layer. To get rid of it, the tube has to be heated to between $300^{\circ}$ and $400^{\circ} \mathrm{C}$., at which stage there is a great evolution of gas. If this is pumped off while the tube is hot, the vacuum will be found to improve greatly when the tube is cooled, and will not deteriorate with time so much as it otherwise. would.

\section{"Finishing-off" Processes.}

There are one or two "finishing-off" processes to follow a pump, which are well known to research workers. Cocoanut chareoal, when used as anode, or the liquid alloy of potassium and sodium, when used as cathode, absorb

1 [ $t$ is, however, possible for a pump to exhaust somewhat lower than the vapour prossure of the liquid used. A really good water injector (filter) pmop will exhaust to about $7 \mathrm{mms}$. of merenty, whereas the vapour pressure uf water at atmospherie temperatures is some 12 to $15 \mathrm{mms}$.

2 At higher pressimes, more enrent ean be passed throngh the tube. and the edectroles can be made hoter than at very low presines. 
ordinary gases, if the discharge is not too heavy. Yellow phosphorus is converted to red by bombardment with cathode rays ; the change is accompanied by a diminution in pressure, due partly to the lower vapour pressure of the red allotrope, and partly to the fact that under the discharge the red phosphorus combines with any oxygen, nitrogen or hydrogen present, forming compounds with very small vapour pressures. This latter method is used in exhausting the Lodge vacuum valve (p. 67): the presence of the phosphorus compounds is further useful in regulating the vacuum during the subsequent use of the valve.

Table XXII. gives a notion of the capabilities of various pumps.

\section{TABLE XXII.}

\begin{tabular}{|c|c|c|}
\hline \multicolumn{2}{|l|}{ Pump. } & Attainable Vacuum. \\
\hline & & $\mathrm{mm} . \mathrm{Hg}$. \\
\hline Gaede molecular - & - & $0 \cdot 000,000,2$ \\
\hline Gaede rotary (mere & y) & $0 \cdot 000,01$ \\
\hline Improved Töpler & Areury) & $0 \cdot 000,01$ \\
\hline Gaede piston & - & $0 \cdot 000,05$ \\
\hline Geryk (oil) - & - & $0 \cdot 000,2$ \\
\hline Sprengel (mercury) & - & $0 \cdot 001$ \\
\hline Injector (water) - & - & 7 \\
\hline
\end{tabular}




\section{APPENDIX IV.}

\section{ELEOTRICAL INSULATORS.}

OF the available insulators, ebonite, sulphur, amber, sealing wax and fused silica are at present the only ones at all suitable for electroscopic work. With all of these, care should be taken to avoid fingering-grease is fatal to insulation. In testing insulation, it should be remembered that a delicate electroscope may indicate signs of surface electrification for some hours after new insulation has been put in. Such electrification may be dissipated by means of a spirit lamp, or, better, by placing some uranium oxide near the insulator. To reduce the absorption of the electric charge which occurs to a greater or less extent with all insulators, ${ }^{1}$ the size of insulating supports should be kept as small as possible in electrometer work.

Ebonite that is really good is difficult to obtain nowadays; it seems to be regarded by most rubber manufacturers as a convenient means of using up rubber refuse unfit for anything else. Some of its defects are occasionally due to the materials used in polishing. Modern ebonite ages with some rapidity in sunlight, and on damp days may, owing to the film of sulphuric acid which forms on its surface, almost play the rôle of a conductor. In a room which gets much sunshine most modern ebonite usually turns a dirty yellow colour in a few weeks, though some of the ebonite made ten or twenty years ago will cxhibit no signs of deterioration. Notwithstanding its defects, ebonite whieh has had its

1 Paraftin wax, which is an excellent insulator, shows this soaking effect to a marked and objectionable degree. 
surface recently renewed is an exeellent insulator. Ebonite offers the great advantage of being easily workable.

Sulphur is eonvenient, in that it can be east to shape. In this operation the vessels (glass or poreelain) and sulphur used should be clean, and the temperature should be raised but slightly above the liquefying point of the sulphur. In this limpid condition it can, for example, be poured or sucked into elean warmed glass ${ }^{1}$ tubing, if sulphur plugs are required. The tubing ean be readily slipped off later by slightly warming the outside. For some hours after solidification, sulphur can be turned to size or pared to shape with great ease. The insulating properties improve for some time after setting. There is no better insulator than sulphur, but, after a few months, especially in a room which gets much sunshine, its insulating qualities generally fall off to a considerable extent.

Amber is an excellent insulator, and is almost always reliable. It ean, of course, be obtained in the form of pipe stems, which can be mounted in position with sealing wax. The Amberite and Ambroid eompanies supply amber pressed to convenient shapes and sizes. Amber has the disadvantages of being somewhat brittle and rather expensive.

Sealing Wax is particularly useful in that it combines the qualities of an insulator and an air-tight cement with a very low vapour pressure. The insulating properties depend very much on the quality of the wax. One of the most reliable is " Bank of England." The usual eare must be taken to avoid indiscriminate fingering. The insulating ability of the wax will be impaired, if in its manipulation it is allowed to cateh fire and carbonise, or if a luminous flame is used. -As shellac is hygroseopie, sealing wax as an insulator is somewhat susceptible to damp weather.

Fused Silica yields place to none in its insulating qualities. Its specific resistance has been determined at the National Physical Laboratory to be greater than $2 \times 10^{14} \mathrm{ohm} \mathrm{cms}$. at $16^{\circ} \mathrm{C}$. Fused siliea is praetically independent of atmospherie humidity, and in the form of rod or tubing is particularly convenient as an insulating material. It is the only

${ }^{1}$ Not metal, unless lined, say, with paper. 
high-class insulator which is unimpaired by moderate heat; it is, however, spoilt if subjected to very high temperatures. Fused silica is now very cheap, but unfortunately the modern furnace methods of production camnot be relied upon to yield a product which possesses the insulating properties of the more expensive silica made by the oxyhydrogen flame. This remark applies alike to the clear transparent variety and the air-streaked satin-like kind. The furnace silica scems to be contaminated in some way, possibly by carbon from the electric furnace. Silica intencled for insulation purposes should, of course, be alkali-free. 


\section{APPENDIX $V$.}

'Table XXIII. 'T'he Elements in 'The Order of' ATomile WEIGHTS.

Intemational atomic weights for 1914; $\mathrm{O}=16$. The intemational atomic weights are fixed yearly by an international committee of chemists, consisting at present of Profs. F. W. Clarke (U.S.A.), W. Ostwald (Germany), T. E. Thorpe (Gt. Britain), and G. Urbain (France). The list below comprises 83 elements.

\begin{tabular}{|c|c|c|c|c|c|}
\hline $\begin{array}{c}\text { Atomic } \\
\text { Weight. } \\
0=16 .\end{array}$ & Element. & & $\begin{array}{c}\text { Sym- } \\
\text { bol. }\end{array}$ & First isolated by & Date. \\
\hline $1 \cdot 008$ & Hydrogen & - & $\mathrm{H}$ & Cavendislı & 1766 \\
\hline $3 \cdot 99$ & Helium - & - & $\mathrm{He}$ & Ramsay and Cleve * & 1895 \\
\hline $6 \cdot 94$ & Lithium - & - & $\mathrm{Li}$ & Arfvedson & 1817 \\
\hline $9 \cdot 1$ & Beryllium & & & & \\
\hline & (Glucinum) & - & $\mathrm{Be}$ & Wöhler and Bussy & 1828 \\
\hline $11 \cdot 0$ & Boron - & - & B & Gay-Lussac \& Thénard & 1808 \\
\hline $12 \cdot 00$ & Carbon - & - & $\mathrm{C}$ & - & Prehistoric \\
\hline $14 \cdot 01$ & Nitrogen- & - & $\mathrm{N}$ & Rutherford & 1772 \\
\hline $16 \cdot 00$ & Oxygen - & - & $\mathrm{O}$ & Priestley and Scheele & 1774 \\
\hline $19 \cdot 0$ & Fluorine & - & $\mathbf{F}$ & Moissan & 1886 \\
\hline $20 \cdot 2$ & Neon & - & $\mathrm{Ne}$ & Ramsay and Travers & 1898 \\
\hline $23 \cdot 00$ & Sodium - & - & $\mathrm{Na}$ & Davy & 1807 \\
\hline $24 \cdot 32$ & Magnesium & - & $\mathrm{Mg}$ & Liebig and Bussy & 1830 \\
\hline $27 \cdot 1$ & Aluminium & - & $\mathrm{Al}$ & Wöhler & 1827 \\
\hline $28 \cdot 3$ & Silicon - & - & $\mathrm{Si}$ & Berzelius & 1823 \\
\hline $31 \cdot 04$ & Phosphorus & - & $\mathrm{P}$ & Brand & 1674 \\
\hline $32 \cdot 07$ & Sulphur - & - & $\mathrm{S}$ & - & Prelistoric \\
\hline $35 \cdot 46$ & Chlorine & - & Cl & Scheele & 1774 \\
\hline $39 \cdot 10$ & Potassium & - & Ii & Davy & 1807 \\
\hline $39 \cdot 88$ & Argon - & - & $\mathrm{A}$ & Rayleigh \& Ramsay & 1894 \\
\hline $40 \cdot 07$ & Calcium . & - & $\mathrm{Ca}$ & Davy & 1808 \\
\hline $44 \cdot 1$ & Seandium & - & $\mathrm{Sc}$ & Nilson and Cleve & 1879 \\
\hline $48 \cdot 1$ & Titanium & - & $\mathrm{Ti}$ & Gregor & 1789 \\
\hline $51 \cdot 0$ & Vanadium & - & $\mathrm{V}$ & Berzelius & $18: 31$ \\
\hline $52 \cdot 0$ & Chromium & - & $\mathrm{Cr}$ & Tanquelin & 1797 \\
\hline $54 \cdot 93$ & Manganese & - & $\operatorname{Mn}$ & Galm & 1774 \\
\hline $55 \cdot 84$ & Iron - & - & $\mathrm{Fe}$ & - & Prehistoric \\
\hline $58 \cdot 68$ & Nickel - & - & $\mathrm{Ni}$ & Cronstedt & 1751 \\
\hline $58 \cdot 97$ & Cobalt - & - & Co & Brand & 1735 \\
\hline $63 \cdot 57$ & Copper - & - & $\mathrm{Cu}$ & - & Prehistoric \\
\hline $65 \cdot 37$ & Zine - & - & $Z_{n}$ & Mentd. by B. Valentine & 15 centy. \\
\hline $69 \cdot 9$ & Gallium - & - & Ga & L. de Boisbaudran & $1875^{\circ}$ \\
\hline $72 \cdot 5$ & Germanium & - & $\mathrm{Ge}$ & Winkler & 1886 \\
\hline $74 \cdot 96$ & Arsenic - & - & As & Albertus Magnus & 13 centy. \\
\hline $79 \cdot 2$ & Selenium & - & Se & Berzelius & 1817 \\
\hline $79 \cdot 92$ & Bromine & - & $\mathrm{Br}$ & Balard & 1826 \\
\hline $82 \cdot 92$ & Krypton & - & $\mathrm{Kr}$ & Ramsay and Travers & 1898 \\
\hline $85 \cdot 45$ & Rubidium & - & $\mathrm{Rb}$ & Bumsen and Kirchhoff & 1861 \\
\hline
\end{tabular}

* Janssen and Lockyer (in sum), 1868. 


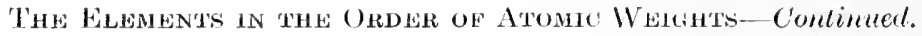

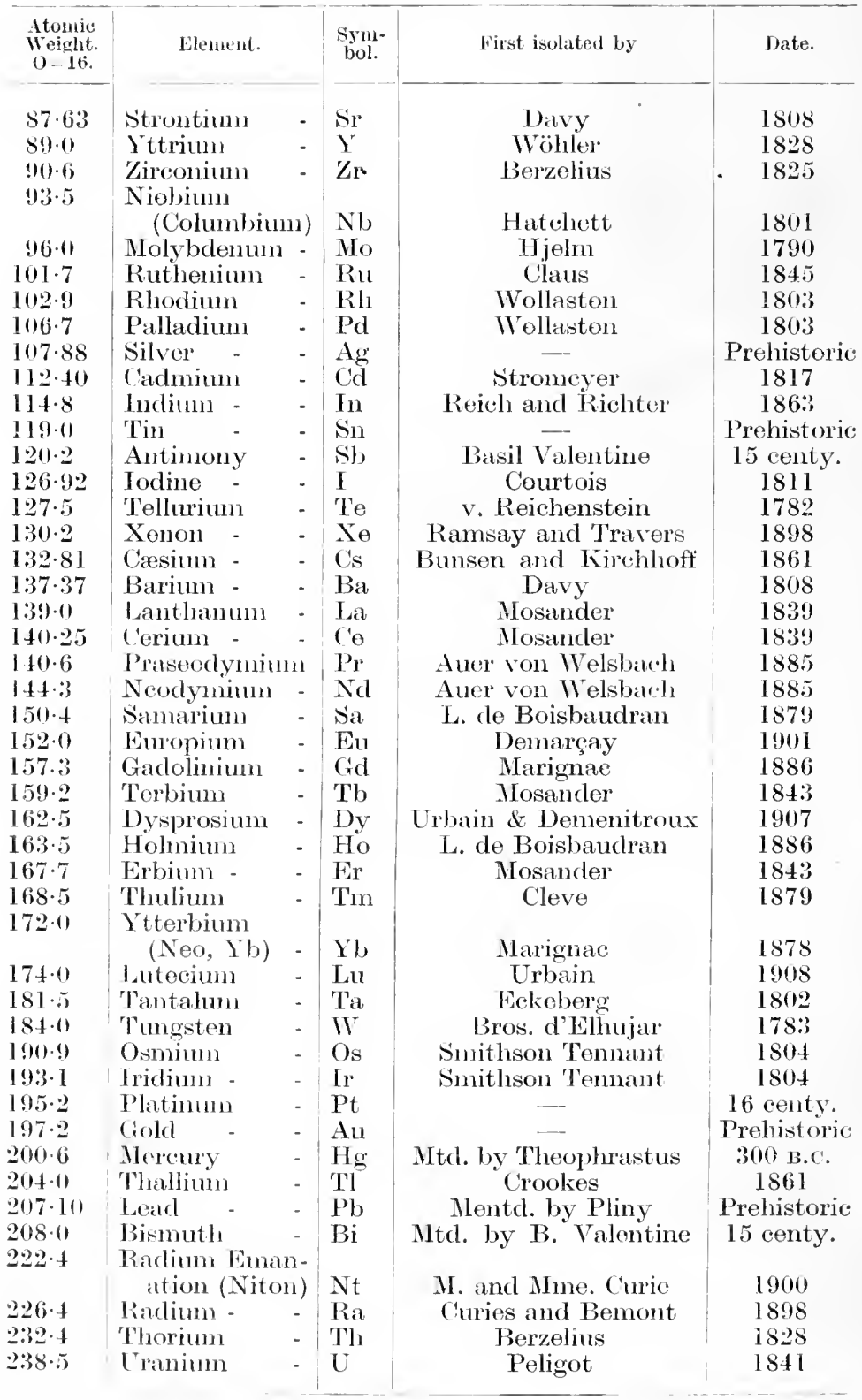


Atome Weichts of the Radoactive filenents.

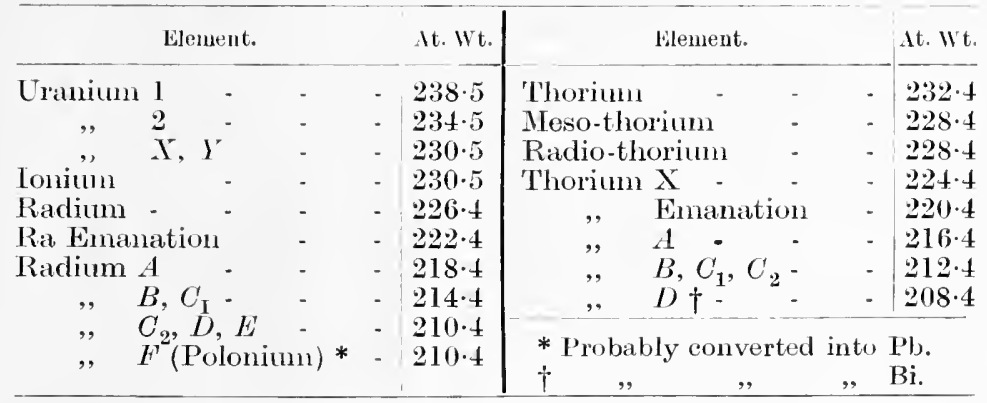

The atomic weight of actinium is probably about 230 .

'Table XXIV. Atomic Weights and Densities of the Elements.

\begin{tabular}{|c|c|c|c|c|c|c|c|c|}
\hline glement. & $\begin{array}{l}\text { Atomic } \\
\text { Weight. }\end{array}$ & Density. & Element. & $\begin{array}{l}\text { Atoinie } \\
\text { Weight. }\end{array}$ & Density. & Element. & $\begin{array}{l}\text { Atomie } \\
\text { Weight. }\end{array}$ & Density. \\
\hline & 27 & $2 \cdot 70$ & $\mathrm{He}$ & 4 & $0.178 \div$ & $\mathrm{Rb}$ & 85 & 1.532 \\
\hline & 120 & $6 \cdot 62$ & $\mathrm{H}$ & 1 & $0.08987+$ & Ru & 102 & $12 \cdot 3$ \\
\hline & 40 & $1 \cdot 78 t$ & $\mathrm{In}$ & 115 & $7 \cdot 12$ & $\mathrm{Sa}$ & 150 & $7 \cdot 8$ \\
\hline & 75 & $5 \cdot 73$ & $I$ & 127 & 4.95 & $\mathrm{Se}$ & 44 & - \\
\hline & 137 & $3 \cdot 75$ & Ir & 193 & $22 \cdot 41$ & Se & $7 !)$ & $4 \cdot 5$ \\
\hline & 9 & $1 \cdot 93$ & $\mathrm{Fe}$ & 56 & $7 \cdot 86$ & $\mathrm{Si}$ & 28 & $2 \cdot 3$ \\
\hline & 208 & $9 \cdot 80$ & $\mathrm{Kr}$ & 83 & $3 \cdot 708 \ddagger$ & $A g$ & 108 & $10 \cdot 5$ \\
\hline & 11 & $2 \cdot 5 ?$ & La & 139 & $6 \cdot 12$ & $\mathrm{Na}$ & 23 & 0.971 \\
\hline & 80 & $3 \cdot 10$ & $\mathrm{~Pb}$ & 207 & $11 \cdot 37$ & $\mathrm{Sr}$ & 88 & $2 \cdot 54$ \\
\hline & 112 & $8 \cdot 64$ & Li & 7 & 0.534 & $\mathrm{~S}$ & 32 & $2 \cdot 07$ \\
\hline & 133 & $1 \cdot 87$ & Lu & 174 & - & $\mathrm{Ta}$ & 181 & $16 \cdot 6$ \\
\hline & 40 & $1 \cdot 55$ & IIg & 24 & $1 \cdot 74$ & Te & 127 & 6.25 \\
\hline & & & Mn & 55 & $7 \cdot 39$ & $\mathrm{~Tb}$ & 159 & - \\
\hline mond & 12 & $3 \cdot 52$ & $\mathrm{Hg}$ & 200 & $13 \cdot 56$ & $\mathrm{Tl}$ & 204 & $11 \cdot 9$ \\
\hline aphite & 12 & $2 \cdot 3$ & 110 & 96 & $10 \cdot 0$ & Th & 232 & $11 \cdot 3$ \\
\hline s carbon & & $1 \cdot 9$ & $\mathrm{Nd}$ & 144 & $6 \cdot 96$ & Tin & 168 & - \\
\hline & 140 & $6 \cdot 92$ & $\mathrm{Ne}$ & 20 & $0.9002 \div$ & Sn & 119 & $7 \cdot 29$ \\
\hline & 35 & $3 \cdot 23 t$ & $\mathrm{Ni}$ & 59 & $8 \cdot 9$ & $\mathrm{Ti}$ & 48 & $4 \cdot 50$ \\
\hline & 52 & $6 \cdot 50$ & $\mathrm{Nb}$ & 93 & $12 \cdot 75$ & WV & 184 & $18 \cdot 8$ \\
\hline & 59 & $8 \cdot 6$ & $\mathrm{~N}$ & 14 & $1 \cdot 2507 \div$ & $\mathrm{U}$ & 238 & $18 \cdot 7$ \\
\hline & 64 & $8 \cdot 93$ & Os & 191 & $22 \cdot 5$ & $\mathrm{~T}$ & 51 & $5 \cdot 5$ \\
\hline & 162 & $\cdots$ & $\mathrm{O}$ & 16 & $1 \cdot 429 \dagger$ & Xe & 130 & $5.851 \div$ \\
\hline & 167 & $4 \cdot 77 ?$ & $\mathrm{Pd}$ & 107 & $11 \cdot 4$ & $\mathrm{Yb}$ & 172 & - \\
\hline & 152 & - & $\mathrm{P}$ & 31 & $2 \cdot 2$ & $\mathrm{I}$ & 89 & $3 \cdot 8 ?$ \\
\hline & 19 & $1 \cdot 69 \div$ & $\mathrm{Pt}$ & 195 & $21 \cdot 5$ & $\mathrm{Zn}$ & 65 & $7 \cdot 1$ \\
\hline & 157 & - & K & 39 & $0 \cdot 862$ & $\mathrm{Zr}$ & 91 & $4 \cdot 15$ \\
\hline & 70 & 5.95 & $\mathrm{Pr}$ & 141 & $6 \cdot 48$ & & & \\
\hline & 72 & $5 \cdot 47$ & Ria & 226 & $?$ & Paper & 一 & $1 \cdot 0$ \\
\hline & 197 & $19 \cdot 32$ & Rh & 103 & $12 \cdot 44$ & & & \\
\hline
\end{tabular}

† Grms. per litre at $0^{\circ} \mathrm{C}$. and $760 \mathrm{~mm}$. 
Table IXV, I $I_{10} e^{-\lambda}$. Table connecting $I_{i} I_{11}$ and $\lambda d$. E.g. if $\lambda d=\cdot 993, I I_{0}=\cdot 5 . \quad e=2 \cdot 71828$. (See p. 100.) (From Kitye d Laby's Physical Constants.)

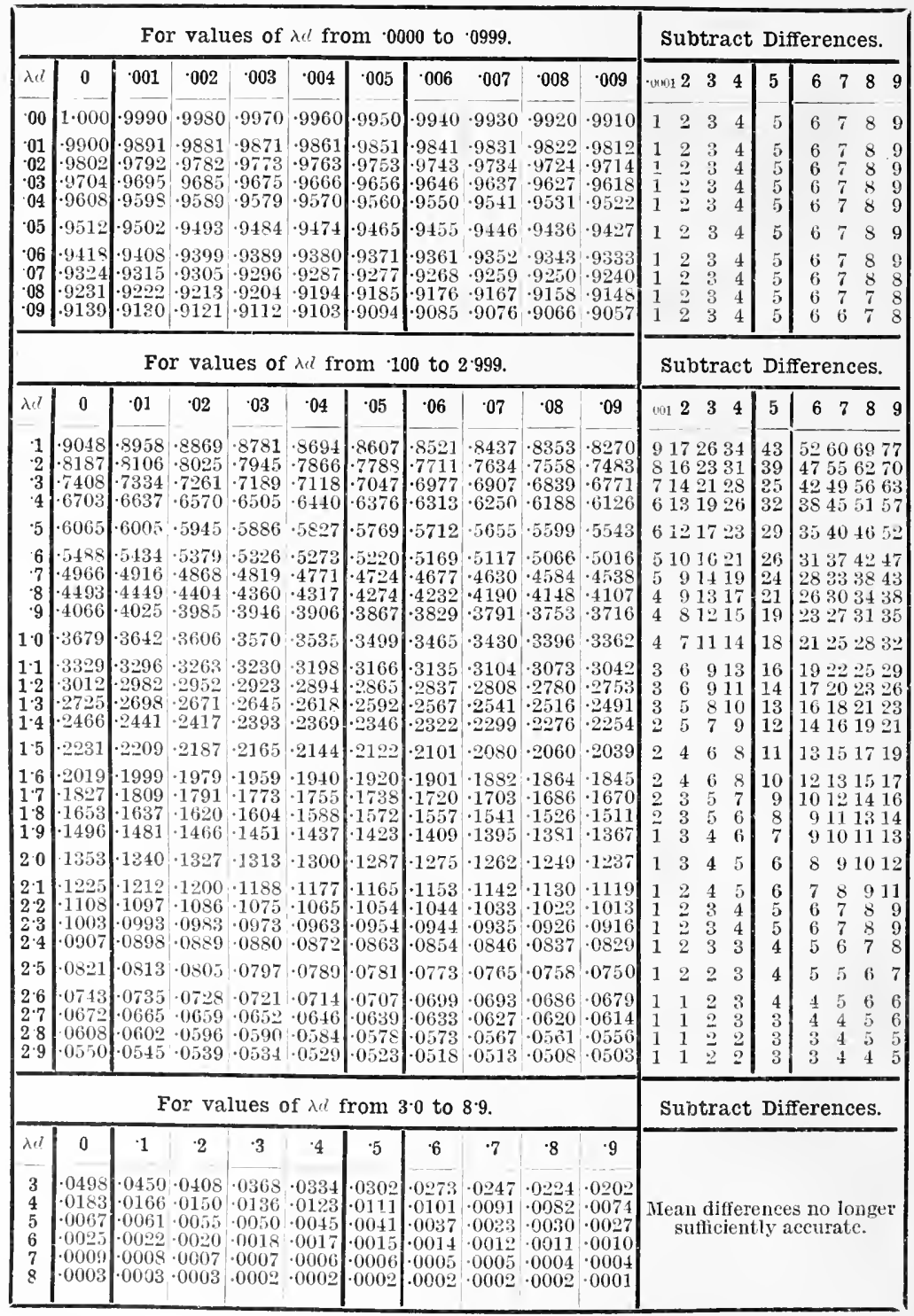




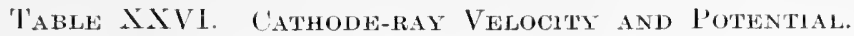

Cathode-ray velocities in cms./sec., corresponding to various voltages.

The values are calculated by the formula, $V=5.95 \sqrt{E} \cdot 10^{7}$, where $V$ is the velocity and $E$ the voltage (see p. 96).

\begin{tabular}{|c|c|c|c|c|c|c|c|c|c|c|}
\hline \multicolumn{11}{|c|}{ For voltages from 0 to 990.} \\
\hline & 0 & 10 & 20 & 30 & 40 & 50 & 60 & 70 & 80 & 90 \\
\hline 0 & $0^{\times 10^{9}}$ & $\begin{array}{r}\times 10^{9} \\
0.188\end{array}$ & $\begin{array}{r}\times 10^{9} \\
0.266\end{array}$ & $\begin{array}{r}\times 10^{9} \\
0 \cdot 326\end{array}$ & $\begin{array}{r}\times 10^{3} \\
0 \cdot 376\end{array}$ & $\begin{array}{r}\times 10^{4} \\
0 \cdot 421\end{array}$ & $\begin{array}{c}\times 10^{9} \\
0 \cdot 461\end{array}$ & $\begin{array}{c}\times 10^{9} \\
0.498\end{array}$ & $\begin{array}{c}\times 10^{9} \\
0 \cdot 533\end{array}$ & $\begin{array}{r}\times 10^{9} \\
0.565\end{array}$ \\
\hline 100 & 0.595 & $0 \cdot 6 \geq 4$ & 0.652 & 0.678 & $0 \cdot 704$ & $0 \cdot 7: 39$ & 0.753 & 0.776 & 0.798 & $0 \cdot 8 \div 0$ \\
\hline 200 & $0.8+2$ & 0.862 & 0.883 & 0.902 & 0.922 & 0.941 & 0.960 & 0.978 & 0.996 & $1 \cdot 014$ \\
\hline 300 & 1.031 & 1.048 & 1.065 & 1.081 & 1.097 & 1.113 & 1.129 & $1 \cdot 145$ & $1 \cdot 160$ & 1.176 \\
\hline 400 & $1 \cdot 191$ & $1 \cdot 205$ & $1 \cdot 2=20$ & $1 \cdot 234$ & $1 \cdot 248$ & $1 \cdot 263$ & 1.277 & $1 \cdot 290$ & $1 \cdot 304$ & $1 \cdot 318$ \\
\hline 500 & $1 \cdot 331$ & $1 \cdot 34 \div$ & $1-357$ & 1.370 & $1 \cdot 383$ & ].396 & $1 \cdot 409$ & $1 \cdot 4 \cdot 21$ & $1 \cdot 434$ & 1.446 \\
\hline 600 & 1.458 & 1.170 & $1 \cdot 482$ & 1.494 & 1.506 & 1.517 & $1 \cdot 529$ & 1.541 & 1.552 & 1.564 \\
\hline 700 & 1.575 & 1.586 & 1.597 & 1.608 & 1.619 & $1 \cdot 630$ & 1.641 & 1.651 & $1 \cdot 66^{\circ}$ & 1.673 \\
\hline 800 & $1 \cdot 683$ & $1 \cdot 694$ & 1.705 & 1.715 & $1 \cdot 725$ & 1.735 & 1.745 & 1.755 & $1 \cdot 766$ & 1.776 \\
\hline 900 & 1.786 & $1 \cdot 796$ & $1 \cdot 806$ & $1 \cdot 815$ & 1.825 & 1834 & $1 \cdot 844$ & 1.954 & 1.864 & 1.873 \\
\hline \multicolumn{11}{|c|}{ For voltages from 1000 to 9900 . } \\
\hline & 0 & 100 & 200 & 300 & 400 & 500 & 600 & 700 & 800 & 900 \\
\hline & $\times 10^{9}$ & $\times 10^{9}$ & $\times 10^{9}$ & $\times 10^{9}$ & $\times 109$ & $\times 10^{9}$ & $\times 10^{9}$ & $\times 10^{9}$ & $\times 10^{6}$ & $\times 10^{5}$ \\
\hline 1000 & $1 \cdot 88$ & 1.97 & $2 \cdot 06$ & $2 \cdot 15$ & $2 \cdot 23$ & $2 \cdot 31$ & $2 \cdot 38$ & $2 \cdot 45$ & $2 \cdot 52$ & $\stackrel{2}{2} 59$ \\
\hline 2000 & $2 \cdot 66$ & $2 \cdot 73$ & $2 \cdot 79$ & $2 \cdot 85$ & -9.92 & 2.98 & $3 \cdot 04$ & 3.09 & $3 \cdot 15$ & $3 \cdot 21$ \\
\hline 3000 & $3 \cdot 26$ & $3 \cdot 31$ & $\overline{3} \cdot 37$ & $3 \cdot 42$ & $3 \cdot 47$ & 3.52 & 3.57 & $3 \cdot 62$ & 3.67 & $3 \cdot 7 \cdot 2$ \\
\hline 4000 & $3 \cdot 76$ & $3 \cdot 81$ & $3 \cdot 86$ & 3.90 & $3 \cdot 95$ & $3 \cdot 99$ & $4 \cdot 04$ & $4 \cdot 08$ & $4 \cdot 12$ & $4 \cdot 17$ \\
\hline 5000 & $4 \cdot 21$ & $4 \cdot 25$ & $4 \cdot 29$ & $4 \cdot 33$ & $4 \cdot 37$ & $4 \cdot 41$ & $4 \cdot 45$ & $4 \cdot 49$ & 4.53 & 4.57 \\
\hline 6000 & $4 \cdot 61$ & $4 \cdot 65$ & 4.69 & $4 \cdot 72$ & $4 \cdot 76$ & $4 \cdot 80$ & $4 \cdot 84$ & $4 \cdot 87$ & $4 \cdot 91$ & $4 \cdot 94$ \\
\hline 7000 & $4 \cdot 98$ & $5 \cdot 01$ & 5.05 & 5.08 & $5 \cdot 12$ & $5 \cdot 15$ & $5 \cdot 19$ & $5 \cdot 22$ & $5 \cdot 26$ & 5.29 \\
\hline 8000 & $5 \cdot 33$ & $5 \cdot 36$ & $5 \cdot 39$ & 5.42 & $5 \cdot 45$ & $5 \cdot 49$ & 5.52 & 5.55 & $5 \cdot 59$ & $5 \cdot 62$ \\
\hline & $5 \cdot 65$ & $5 \cdot 68$ & $5 \cdot 71$ & $5 \cdot 7 \overrightarrow{1}$ & $5 \cdot 77$ & $5 \cdot 80$ & $5 \cdot 83$ & $5 \cdot 86$ & $5 \cdot 89$ & $5 \cdot 92$ \\
\hline \multicolumn{11}{|c|}{ For voltages from 10,000 to 199,000 . } \\
\hline & 0 & 1000 & 2000 & 3000 & 4000 & 5000 & 6000 & 7000 & 8000 & 9000 \\
\hline & $\times 10^{4}$ & $\times 10^{9}$ & $\times 10^{9}$ & $\times 10^{9}$ & $\times 10^{9 !}$ & $\times 10^{9}$ & $\times 10^{! 4}$ & $\times 10^{9}$ & $\times 10^{9}$ & $\times 10^{\prime}$ \\
\hline 10,000 & 5.95 & $6 \cdot 3 \cdot 4$ & 6.52 & 6.78 & $7 \cdot 04$ & $7 \cdot 29$ & 7.53 & $7 \cdot 76$ & $7 \cdot 98$ & 8.20 \\
\hline 20,000 & 8.42 & 8.62 & 8.83 & $9 \cdot 02$ & $9 \cdot 22$ & $9 \cdot 41$ & $9 \cdot 60$ & $9 \cdot 78$ & $9 \cdot 96$ & $10 \cdot 14$ \\
\hline 30,000 & $10 \cdot 31$ & $10 \cdot 48$ & $10 \cdot 65$ & $10 \cdot 81$ & $10 \cdot 97$ & $11 \cdot 13$ & $11 \cdot \% 9$ & $11 \cdot 45$ & $11 \cdot 60$ & 11.76 \\
\hline 40,000 & 11.91 & $12 \cdot 05$ & $12 \cdot 20$ & $12 \cdot 34$ & $12 \cdot 48$ & $1 \cdot 2 \cdot 63$ & 12.77 & $12 \cdot 90$ & $13 \cdot 04$ & $13 \cdot 18$ \\
\hline 50,000 & $13 \cdot 31$ & $13 \cdot 44$ & $13 \cdot 57$ & $13 \cdot 70$ & $13 \cdot 83$ & $13 \cdot 96$ & $14 \cdot 09$ & $14 \cdot 21$ & $14 \cdot 34$ & $14 \cdot 46$ \\
\hline 60,000 & 14.58 & $14 \cdot 70$ & $14 \cdot 82$ & $14 \cdot 94$ & $15 \cdot 06$ & $15 \cdot 17$ & $15 \cdot 29$ & $15 \cdot 41$ & $15 \cdot 52$ & $15 \cdot 64$ \\
\hline 70,000 & 15.75 & $15 \cdot 86$ & $15 \cdot 97$ & $16 \cdot 08$ & $16 \cdot 19$ & $16 \cdot 30$ & $16 \cdot 41$ & $16 \cdot 51$ & $16 \cdot 62$ & $16 \cdot 73$ \\
\hline 80,000 & $16 \cdot 83$ & $16 \cdot 94$ & $17 \cdot 0.5$ & $17 \cdot 15$ & $17 \cdot 25$ & $17 \cdot 35$ & $17 \cdot 45$ & $17 \cdot 55$ & $17 \cdot 66$ & 17.76 \\
\hline 90,000 & 17.86 & $17 \cdot 96$ & 18.06 & 18.15 & 18.25 & $18 \cdot 34$ & 18.44 & $18 \cdot 54$ & $18 \cdot 64$ & 18.73 \\
\hline 100,000 & $18 \cdot 8$ & $18 \cdot 9$ & $19 \cdot 0$ & $19 \cdot 1$ & $19 \cdot 2$ & $19 \cdot 3$ & $19 \cdot 4$ & $19 \cdot 5$ & $19 \cdot 6$ & $19 \cdot 7$ \\
\hline 110,000 & $19 \cdot 7$ & $19 \cdot 8$ & $19 \cdot 9$ & $20 \cdot 0$ & $20 \cdot 1$ & 20.2 & $20 \cdot 3$ & $20 \cdot 4$ & $20 \cdot 4$ & $20 \cdot 5$ \\
\hline 120,000 & $20 \cdot 6$ & $20 \cdot 7$ & $20 \cdot 8$ & $20 \cdot 9$ & $20 \cdot 9$ & $21 \cdot 0$ & $\because 1 \cdot 1$ & $\therefore 1 \cdot 2$ & $21 \cdot 3$ & $21 \cdot 1$ \\
\hline 130,000 & $21 \cdot 5$ & $21 \cdot 6$ & $21 \cdot 7$ & $21 \cdot 7$ & $21 \cdot 8$ & $21 \cdot 9$ & $22 \cdot 0$ & $2 \cdot 2 \cdot 1$ & $22 \cdot 1$ & $22 \cdot 2$ \\
\hline 140,000 & $2 \cdot 2 \cdot 3$ & $22 \cdot 4$ & $22 \cdot 5$ & $22 \cdot 5$ & $22 \cdot 6$ & $22 \cdot 7$ & $22 \cdot 8$ & $22 \cdot 8$ & 22.9 & $23 \cdot 0$ \\
\hline 150,000 & $23 \cdot 1$ & $23 \cdot 1$ & 23.2 & $23 \cdot 3$ & $23 \cdot 4$ & $23 \cdot 4$ & $23 \cdot 5$ & $23 \cdot 6$ & $23 \cdot 7$ & 23.8 \\
\hline 160,000 & $2: 3 \cdot 8$ & 23.9 & $24 \cdot 0$ & $94 \cdot 1$ & $24 \cdot 1$ & $24 \cdot 2$ & $24 \cdot 3$ & $24 \cdot 3$ & $24 \cdot 4$ & $24 \cdot 5$ \\
\hline 170,000 & $24 \cdot 5$ & $24 \cdot 6$ & $24 \cdot 6$ & $24 \cdot 7$ & $24 \cdot 8$ & $24 \cdot 9$ & $24 \cdot 9$ & $\overline{25} \cdot 0$ & $25 \cdot 1$ & $25 \cdot 1$ \\
\hline 180,000 & $25 \cdot 2$ & $25 \cdot 3$ & $25 \cdot 4$ & $25 \cdot 4$ & $25 \cdot 5$ & $25 \cdot 6$ & $25 \cdot 6$ & $25 \cdot 7$ & $25 \cdot 8$ & $25 \cdot 9$ \\
\hline 190,000 & $25 \cdot 9$ & $26 \cdot 0$ & $26 \cdot 1$ & $26 \cdot 1$ & $26 \cdot 2$ & $26 \cdot 3$ & $26 \cdot 3$ & $26 \cdot 4$ & $26 \cdot 5$ & $26 \cdot 5$ \\
\hline
\end{tabular}


'TABLe XXVII. ('HARACTERISTIC $\gamma$ RaYs.

Rutherford and Richardison, I’.M. 1913 and 1914 (soo p. 118). The absorption coefficionts in aluminium may be contrasted with those for $\mathrm{X}$ rays on $\mathrm{p}$. 115.

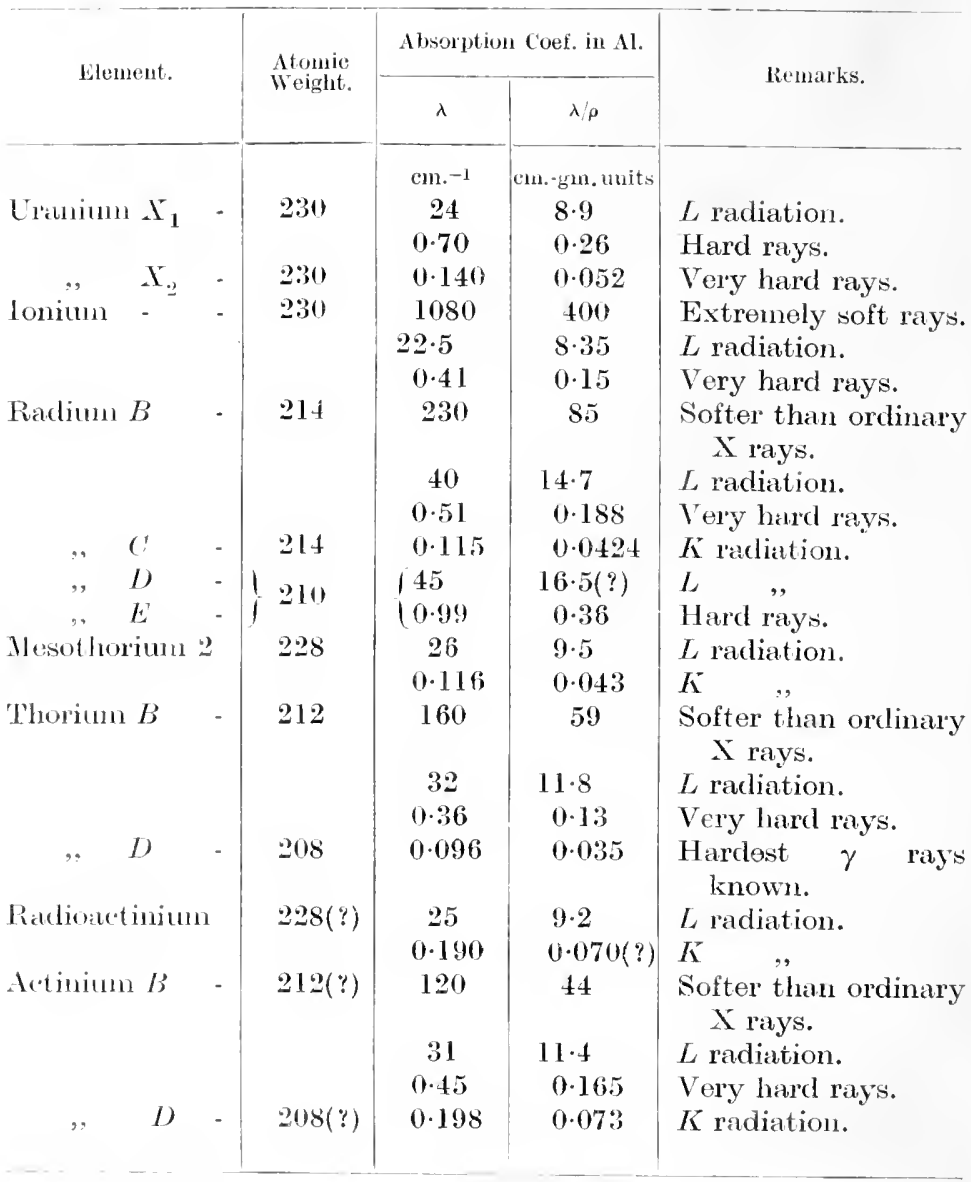




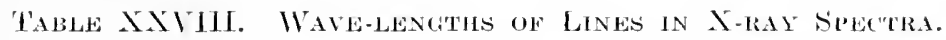

The values below are due to Noseley (I'.M. April 1914). 'They include some of those given on p. 201 . The most intense line is ealled $\alpha$, the next $\beta$. Thero are other lines present in both the $K$ and $L$ series, Reference should be mado to Moseley's papers (see p. 199).

\begin{tabular}{|c|c|c|c|c|c|}
\hline & \multicolumn{2}{|c|}{$\boldsymbol{K}$ Series. } & & \multicolumn{2}{|c|}{$L$ Series. } \\
\hline & $\alpha$ & $\beta$ & & $\alpha$ & $\beta$ \\
\hline $\mathrm{Al}$ & $\begin{array}{c}\times 10^{-8} \mathrm{~cm} . \\
8.364\end{array}$ & $\begin{array}{c}\times 10^{-8} \mathrm{~cm} \\
7.912\end{array}$ & $\mathrm{Zl}$ & $\begin{array}{c}\times 10^{-8} \mathrm{~cm} \\
6.091\end{array}$ & $\times 10^{-8} \mathrm{~cm}$. \\
\hline $\mathrm{Si}$ & $7 \cdot 142$ & $6 \cdot 729$ & $\mathrm{Nb}$ & $5 \cdot 749$ & $5 \cdot 507$ \\
\hline Cl & $4 \cdot 750$ & - & No & $5 \cdot 423$ & $5 \cdot 187$ \\
\hline$\pi$ & $3 \cdot 759$ & $3 \cdot 463$ & Ru & $4 \cdot 861$ & $4 \cdot 660$ \\
\hline $\mathrm{Ca}$ & $3 \cdot 368$ & $3 \cdot 094$ & Rh & 4.622 & - \\
\hline $\mathrm{Ti}$ & $2 \cdot 758$ & 2.524 & $\mathrm{Pdl}$ & $4 \cdot 385$ & $4 \cdot 168$ \\
\hline$V$ & $2 \cdot 519$ & $2 \cdot 297$ & $\mathrm{Ag}$ & $4 \cdot 170$ & - \\
\hline $\mathrm{Cl}^{\prime}$ & $2 \cdot 301$ & $2 \cdot 093$ & Sin & $3 \cdot 619$ & - \\
\hline Мn & $2 \cdot 111$ & $1 \cdot 818$ & sib & $3 \cdot 458$ & 3.245 \\
\hline Fe & $1 \cdot 946$ & 1.765 & Lat & $2 \cdot 676$ & $2 \cdot 471$ \\
\hline $\mathrm{Co}^{\prime}$ & $1 \cdot 798$ & $1 \cdot 629$ & $\mathrm{C}^{\prime} \mathrm{e}$ & $2 \cdot 567$ & $2 \cdot 360$ \\
\hline $\mathrm{Ni}$ & $I \cdot 662$ & $1 \cdot 506$ & $\operatorname{Pr}$ & $2 \cdot 471$ & $2 \cdot 265$ \\
\hline $\mathrm{Cu}$ & $1 \cdot 549$ & $1 \cdot 402$ & Nd & $2 \cdot 382$ & $2 \cdot 175$ \\
\hline $\mathrm{Zn}$ & $1 \cdot 445$ & $1 \cdot 306$ & $\mathrm{Sa}$ & $2 \cdot 208$ & 2.008 \\
\hline $\mathrm{Y}$ & 0.838 & - & Eu & $2 \cdot 130$ & 1.925 \\
\hline $\mathrm{Zr}$ & $0 \cdot 794$ & - & Gd & $2 \cdot 057$ & $1 \cdot 85: 3$ \\
\hline $\mathrm{Nb}$ & 0.750 & - & $\mathrm{Ho}$ & $1 \cdot 914$ & $1 \cdot 711$ \\
\hline Mo & 0.721 & - & $\mathrm{Er}$ & $1 \cdot 790$ & $1 \cdot 591$ \\
\hline Ru & $0 \cdot 638$ & - & $\mathrm{Ta}$ & $1 \cdot 525$ & $1 \cdot 330$ \\
\hline $\mathrm{Pd}$ & 0.584 & - & W & $1 \cdot 486$ & - \\
\hline $\mathrm{Ag}$ & 0.560 & - & Os & $1 \cdot 397$ & $1 \cdot 201$ \\
\hline- & - & - & $\mathrm{Ir}$ & $1 \cdot 354$ & $1 \cdot 155$ \\
\hline - & - & - & $\mathrm{Pt}$ & $1 \cdot 316$ & $1 \cdot 121$ \\
\hline- & - & - & Au & $1 \cdot 287$ & 1.092 \\
\hline
\end{tabular}




\section{INDEX.}

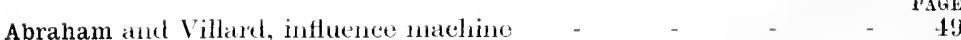

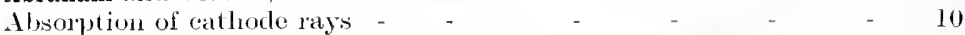

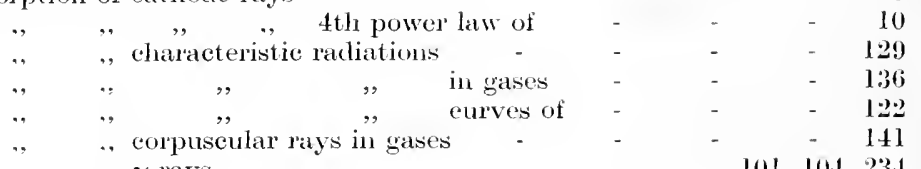

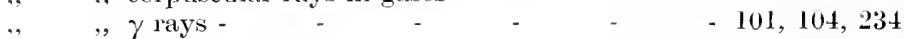

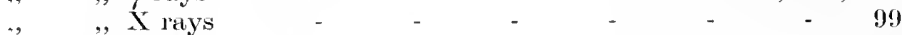

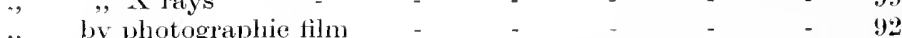

" selective - $\quad$ - $\quad$ - $\quad$ - $\quad-102,129,134$

Absorption-coefficients of characteristic ladiations in Al - $\quad 115$

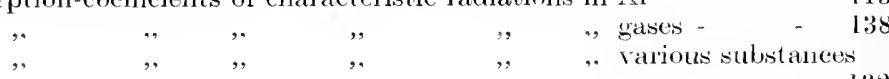

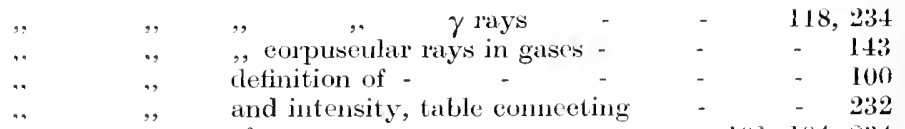

,, $\quad$ of $\gamma$ rays - $\quad-\quad$ - $\quad-101,104,234$

, , , X rays - $\quad-\quad$ - $\quad$ 10], 103

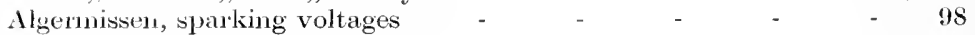

Alkali-halogen salts, space-lattiees of $\quad-\quad-\quad-\quad-\quad-192$

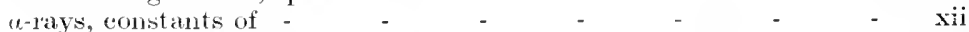

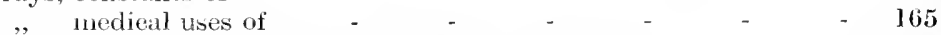

Amber, Anbroid, Amberite, insulating properties of $\quad-\quad$ - 227

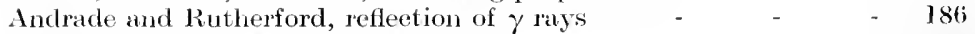

Angerer, chareoal and liquid-air vaeua - $\quad-\quad \ldots \quad-222$

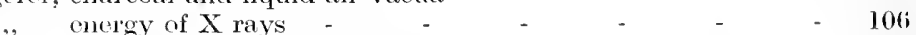

". heat generated by absorption of X rays - $\quad-\quad 57$

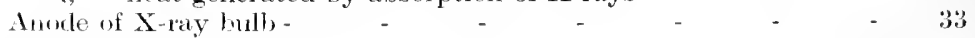

, glow -

Anticathode, atomic weight and efficieney of $\quad-\quad 35$

.. charaeteristie rachation from - $\quad-\quad 36,1: 2$

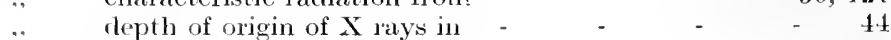

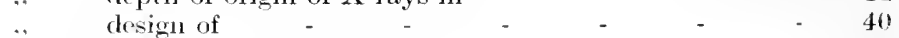

." list ribution of $\mathrm{X}$ rays from - $\quad-\quad-45$

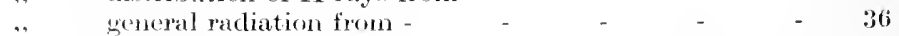

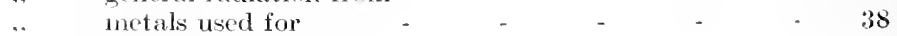

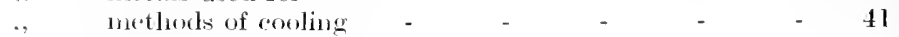

" abliquity of - $\quad$ - $\quad$ - $\quad 44$ 


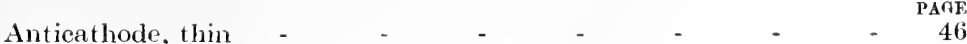

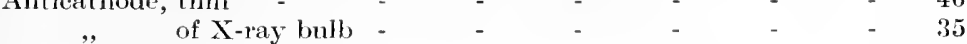

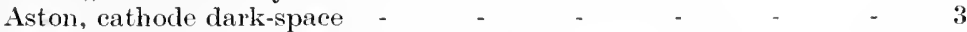

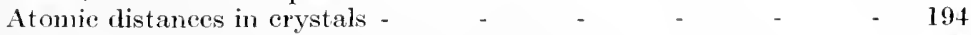

,. weight and efficiency of anticathode $\quad-\quad \ldots \quad-35$

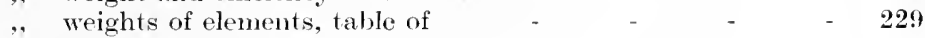

Aurora -

Austin and Holborn, eathodic sputtering - _ _ _ _ $\quad$ - 81

Automatic methods of softening $\mathrm{X}$-ray bulb _ - _ $\quad$ - it

Ayres and Barkla, scattering of X rays - _ _ _ _

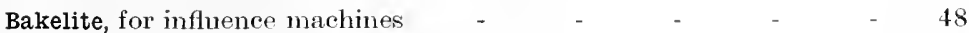

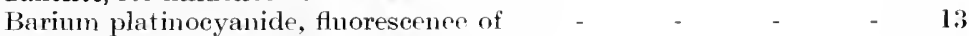

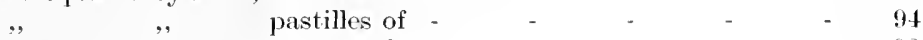

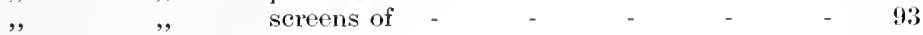

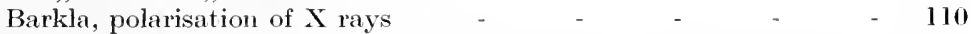

Barkla and Ayres, scattering of X rays - $\quad$ - $\quad$ - $\quad$ - $\quad$ - 110

,, , Collier, absorption of characteristic racliations in gases - 137

," ," , shape of absorption curves for characteristie

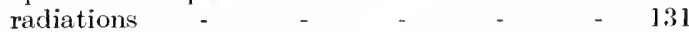

, , Martyn, reflection of X rays _ _ _ _ _ $\quad$ - 190

, , , , , selective action of X rays on photographic plates $\quad 91$

,. , Philpot, ionisation independent of quality of X rays - 146

, , , X-ray and corpnscular ionisation in gases - 146

", ", Sadler, absorption-relation for characteristic radiations 134

", ", , discovery of characteristic X rays - 112

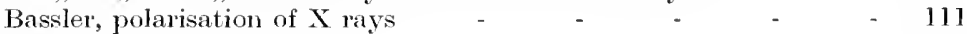

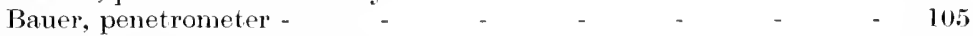

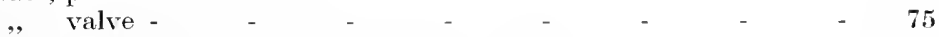

Beatty, absorption of corpuscular rays in gases $\quad-\quad$ - $\quad-141$

.. characteristic X rays and cathode rays - $\quad$ - $\quad 127$

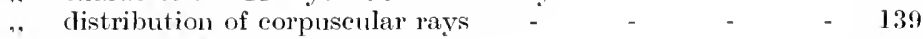

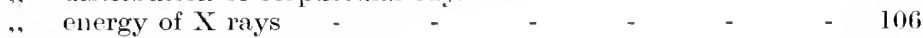

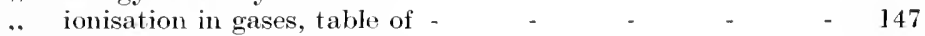

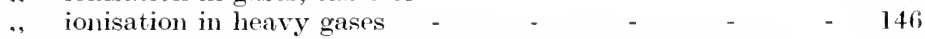

,. veloeity of cathorle rays anrl potential applied to tule - 16

13ecquerel, discovery of radioactivity $y^{+} \quad-\quad \ldots \quad-\quad-\quad 30$

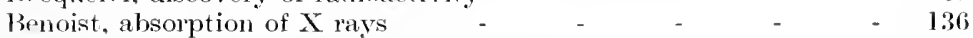

., liscovery of ionisation by $\mathrm{X}$ rays - $\quad-\quad 25$

., penetrometer $\quad-\quad$ - $\quad$ -

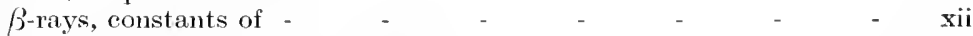

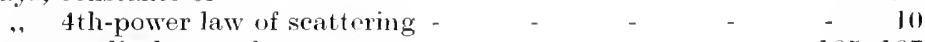

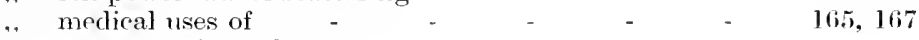

"See also "Cathode rays."

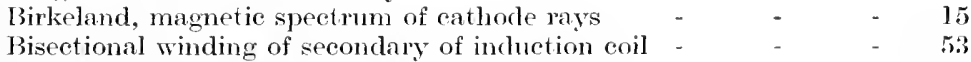

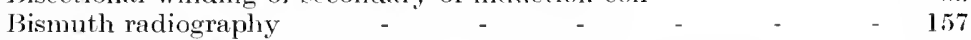

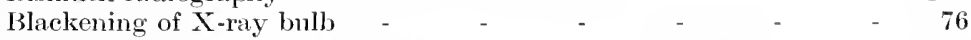

13lake and Owen, diffraction of $X$ rays by metallic erystals - _ $\quad 184$

, ,, spectra of X rays - - $\quad-\quad$ - 190

Blythswood and Scoble, current through X-ray buIl, - _ 86

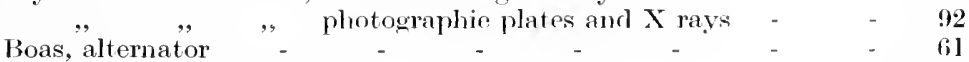

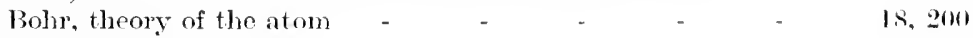




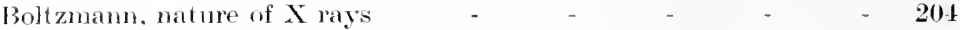

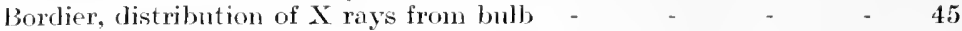

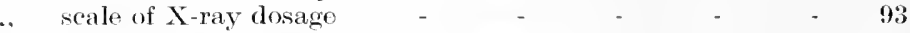

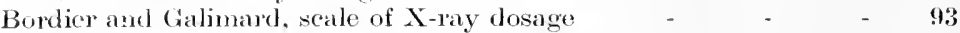

Bragg. W. H. (1'rof.), characteristic X rays from platinum - $\quad 118,189$

.. cospuscular theory of X rays - _ $\quad$ - 205

, indircet action of X-ray ionisation _ _ $\quad$ - 146

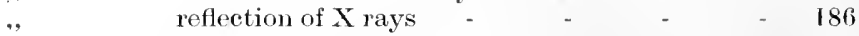

.. wave-length of X rays - _ _ _ _ _ $\quad 201$

X-ray spectrometer

187

lirage, W. L., atomic distances
characteristic $\mathrm{X}$ $\begin{array}{rrr}\text { characteristic X rays from platinum - } & - & 194-197 \\ - & - & -\end{array}$

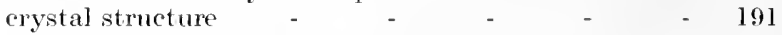
experiments on diffraction by zine-blende crystals - $\quad 176$

179

179

Braun tube -

Bravais, theory of erystal-structure - $\quad$ - $\quad$ - $\quad$ - 170

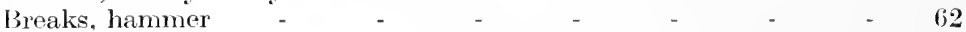

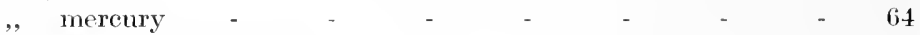

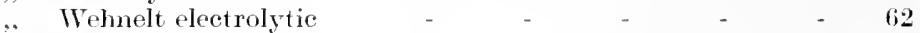

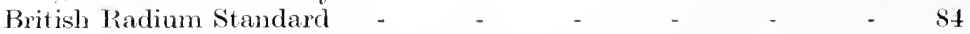

Bumstead, heat generated by absorption of $\mathrm{X}$ rays - $\quad$ - $\quad 87$

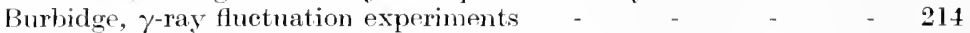

Burbidge and Laby, $\gamma$-ray fluetuation experiments - $\quad$ - $\quad 214$

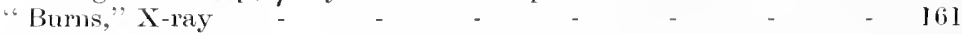

Butcher, Deane, standardisation of X rays - $\quad$ - $\quad$ - 84

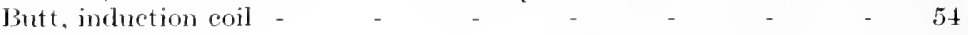

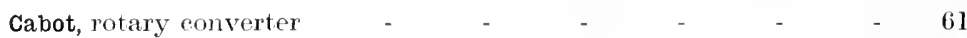

Caldwell-Swinton, electrolytic break - $\quad$ - $\quad$ - $\quad$ - $\quad 64$

Campbell, N. R., discontinuity of radiation - _ - _ _ $\quad-\quad 205$

$$
\text { ,. fluctuation experiments with light - } 215
$$

Campbell-Swinton, see Swinton.

Canal rays

Carpentier, induetion coil - _ -

19

50

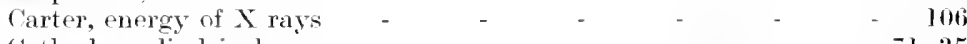

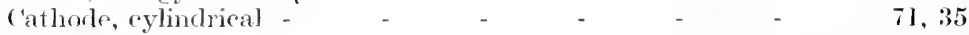

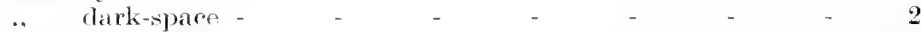

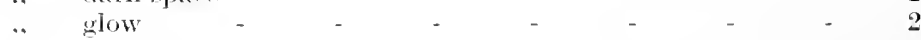

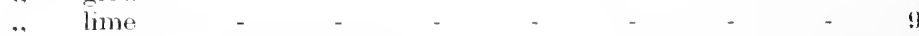

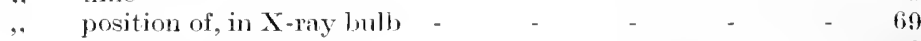

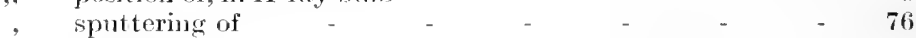

, llehnelt

". of X-ray bulb _

('ithoule-rays, alsorption and transmission of $\quad-\quad$ - $\quad 10$

., $\quad$. and characteristic rays, table comnecting $\quad-\quad 127$

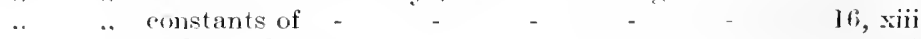

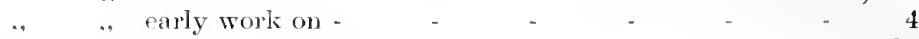

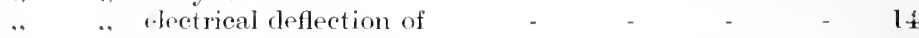

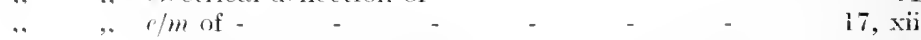

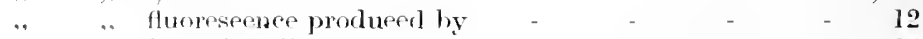

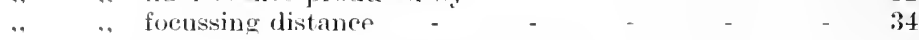

,. $\quad$.. fourth-pmirre law of absomption of $\quad$ - $\quad$ - 10 
Cathode-rays, furnace

\begin{tabular}{|c|c|c|c|}
\hline , &. & heating effects of & - \\
\hline ,", & ," & ionisation produced by & - \\
\hline ," & ,. & magnetic deflection of & - \\
\hline , & ," & magnetic spectrum of - & - \\
\hline ", & ," & mnemonic for deflection of & - \\
\hline ", & $\because$ & nature of & - \\
\hline & & therapeutic use of & - \\
\hline & .. & thickness of metal requires & o refleet \\
\hline & , & velocity of & - \\
\hline
\end{tabular}

PAGE

Cathodic disintegration or sputtering

17. xii

233

Charlwick, absorption of $\gamma$ rays in air

, $\quad \gamma$ rays from $\alpha$ rays

76

103

215

" and Russell, characteristic $\gamma$ rays

Chapman, characteristic radiations from heavy elements

118

117

$\begin{array}{lll}, " & \text { mass-absorption coefficients } & \text { vapours } \\ ,, & \text { refraction of X rays } & -\end{array}$

120

115

169

120

Chapman and Guest, characteristic rays from salts -

Characteristic $\gamma$ rays -

$\gamma$ rays -
light rays
$\mathrm{X}$ rays

, absorption of -

, ,", , in gases -

," and cathode-ray velocity

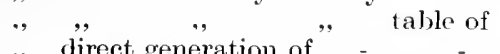

", direct generation of "

, from heavy elements .

,. independent of chemical combination -

, selective absorption of -

,, tables of absorption in aluminium

.

," , , , , "gases -

" ," ," ,", elements, varions

Christen, penetrometer

," therapentic uses of

118, 234

119

112

129

136

124

127

121

117

120

129. 134

$-115$

- 138

$-132$

$-166$

197,235

105

149

100

109

$$
\text { of absorption, definition of }
$$

Cocfficient of absorption, definition of

Coil, induetion, condenser of - 
Condensation experiments of C. T. R. Wilson

Mosciclsi

Conductivity, thermal, of elements -

Cooksey, distribution of corpuscular rays

Coolidge, X-ray bulb -

Cooling of anticathodes

rore of induction roil

Corpuscles

('orpusenlay rays (secondary), alsorption of. in gases

\begin{tabular}{|c|c|c|c|c|}
\hline ,. & ", & Curie and Sagnae - & - & - \\
\hline , & ., & distribution of & - & - \\
\hline$\because 4$ &, & ionisation in gases & - & - \\
\hline ". & , & at right angles to $X$ rays & - & - \\
\hline . & , & table of absorption-coeffic & cients in & gases \\
\hline ,. & , & ,, ,, velocities of & - & - \\
\hline , & , & therapeutic uses of & - & - \\
\hline & , & velocity of & - & - \\
\hline
\end{tabular}

Corpuscular theory of $\mathrm{X}$ rays

Cossor, lithium glass -

$$
\text { , X-ray bulbs - }
$$

Cox, break

, induction coil

C'rookrs, cathode rays

, cathodic sputtering of metali

, dark-space

, focus-tube -

. fluorescence in glass, fatigue of

.. method of softening discharge tube

. nature of cathode rays

.. radiometor -

aube

Crowther, ionisation (X-ray) and pressure

, scattering of $X$ rays

, $\mathrm{X}$-ray ionisation in gases -

., , , $\quad$ and temperatirrc

C'rystals, Bragg's theory of diffraction by

, Lauc"s

, space-lattice of (definition) -

, theory of structure of

Curative action of eharacteristic ravs

$$
\text { ," . "X } \mathrm{X} \text { rays }
$$

C'mie, Mne., International Radium Standard

. P.. piézo-électrique

. aud Sagnae, cospuscular rays -

current through tulse and $\mathrm{X}$-say intensity

., wave-form of, in primary and secondary of induction roil -

71, :35, 21!

('vlindrical cathode

$$
\text { (1) }
$$

Dark-space, Crookes, or eatliodr

$$
\text { Faraclay }
$$

Darwin, wave-Jengths of monoclmonatio X pays -

Darwin and Moseley, characteristic rays from platimum

$$
\text { reflection of } X \text { rays }
$$


Davidson, J. Mackenzie, curative properties of $\mathrm{x}$ rays

" $\quad$ instantaneous radiograph of bullet $\quad-159$

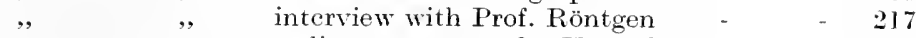

,, , radium-treatment for X-ray burns _ 161

Day and Eve, absorption of $X$ rays in air - $\quad-\quad \ldots \quad-103$

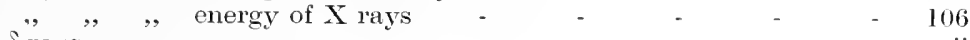

$\delta$ rays

Dember, very soft $\mathrm{X}$ rays

Densities of elements

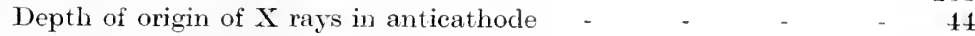

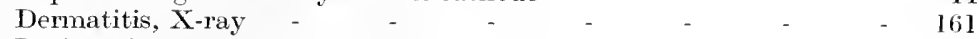

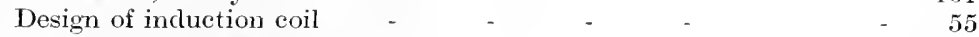

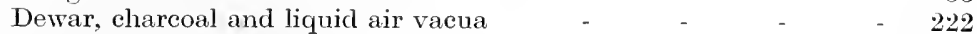

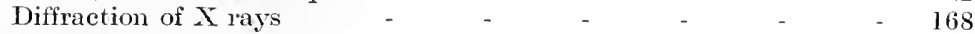

, $\quad$, , by metallic crystals - $\quad$ - $\quad$ - $\quad$ - 184

, " , , zinc-blende $\quad$ - $\quad$ - $\quad$ - $\quad$ - 17t

Direct generation of characteristic X rays - _ _ - $\quad 121$

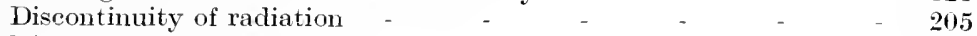

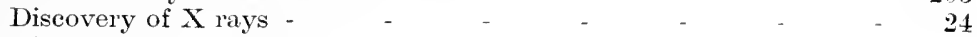

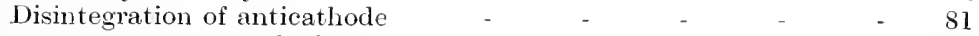

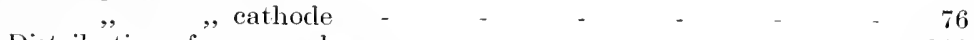

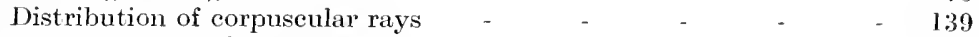

139
140

110

45,112

46

87

140

94

162

160

66

58

" wave-form of secondary currents

Dufour, discovery of ionisation by $\mathrm{X}$ rays - $\quad-\quad-\quad-\quad 25$

Ebonite, for influence machines

, insulating properties of

Eiffel Tower, wireless waves from

Einstein, quantum theory of $\mathrm{X}$ rays

Einthoven galvanometer

Electrical insulat ors

Electrification on surface of X-ray bulb

Electrodes of X-ray bulb

Electrolytic interrupter

Electromagnetic waves, table of

Electrometers

Electron

., number in atom

,, positive, not known

", theory of magnetism

, , , matter -

Electroscopes " matter -

Elements, table of atomic weights of 
Elements, table of densities of

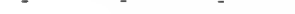

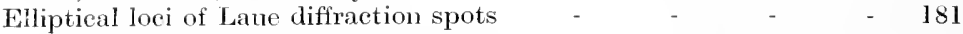

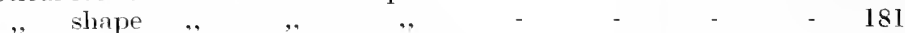

EIster and Geitel, coloration of X-ray bulb - $\quad-\quad 43$

$e / m$ of cathode rays -

, positive rays

Energetics of an X-ray bulb -

Energy of a cathode ray

$$
, \text { an X ray - }
$$

Entladungstrahlen

Ether-pulse theory of Stokes

Eve and Day, absorption of $\mathrm{X}$ rays in air

$$
,, \quad, \quad, \quad \text { energy of } \mathrm{X} \text { rays }
$$

Ewen and Kaye, volatilisation of metals

\section{Faraday cylinder}

, dark-space -

, in production of secondary rays

Fizean, condenser of induction coil

Fluctuation experiments with $\gamma$ rays

Flnorescence by cathode rays

$$
\text { light rays }
$$

$$
\text { in glass, fatigue of }
$$

, $\quad$ of glass at moderately high pressures

$$
\text { low , - } \quad \text { - } 12
$$

.. $\quad$ of lithium chloricle by cathode rays and positive rays - 19

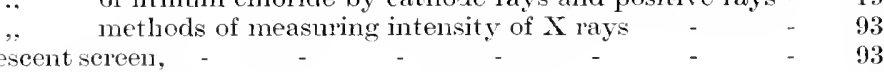

Flnorescent screen,

, .. display of Laue diffraction spots $\quad-\quad{ }^{2} \quad 184$

Focus tube, Crookes"

Gaede, inercury pump

$$
\begin{aligned}
& ., \quad \text { molecular ., } \\
& ,, \quad \text { piston , } \\
& ,, \quad \text { rotary , }
\end{aligned}
$$

Galimarr and Bordier, scale of X-ray dosage

. fluctuation experiments

.. from u rays

.. interference of

.. reflection

Gardiner, distribution of $\mathrm{X}$ rays from bulb - 
Gardiner, magnetic displacement of anticathode focus-spot -

PAGE , photomicrograph of anticathode

40,43

Gases, absorption of characteristic rays in

141

,, corpuscular

104

, $\quad, \quad, \quad, \quad, \quad$ X rays in

103

224

xvii

77

83

165

47

47

165

, insulating properties of

, lithium

, transparency of, for $\mathrm{X}$ rays

163,165

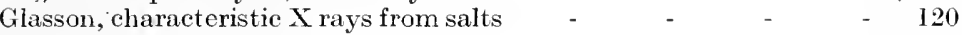

, ionisation by cathode rays -

Goby, radiomicrography

12

157

204

73

Goldsmith, penetration of mica by positive rays

Goldstein, cathode rays

, electrification of glass round cathode

Gouy, gas bubbles in glass walls of X-ray tube

Gowdy, fatigue of production of secondary rays

Granquist, cathodic sputtering

Gray, characteristic $\gamma$ rays

Guest and Chapman, characteristic $\mathrm{X}$ rays from salts

4

70

72

144

81

38,119

120

Haga, polarisation of $\mathrm{X}$ rays -

111

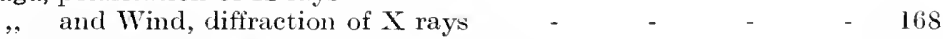

Half-value thicknesses for absorption, table of - $\quad-\quad-115$

Ham, depth of origin of X rays in anticathode - $\quad$ - $\quad$ - 44

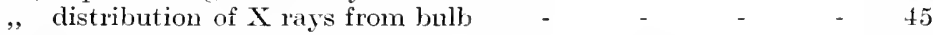

,, polarisation of X rays - _ - $\quad$ - $\quad-\quad 112$

,, thickness required for complete reflection of cathode rays - 45

Hammer break

Hardness of an X-ray bulb

Hehl, cathode-glow

, cathode rays

Hertz, nature of cathode rays

Hertzian waves, wave-length of

Herweg, polarisation of $\mathrm{X}$ rays

High-frequency oscillations in primary circuit

, , , spectra of metals - -

High-tension transformers

Hill, hardening of discharge tube

- Hittorf, cathode rays

, tube

Hodgson, gas absorption by anode

Holborn and Austin, cathodic sputtering

Holzknecht, scale of X-ray dosage 
Homogeneous $\mathrm{X}$ rays

PAGE

Hughes, energy of photoelectrons

,, ionisation by ultra-violet light

206

206

Hulst, influence machines

Humuzesen, discovery of ionisation by $\mathrm{X}$ rays

"I" radiation -

Induction coil, condenser of -

$$
\begin{aligned}
& \text {, , core of } \\
& \text {, , ", detailed account of - } \\
& \text {, , , design of - . } \\
& \text {, , , elementary account of } \\
& , \quad, \quad \text {, primary tube of } \\
& \text {,, , primary winding of - } \\
& " \quad, \quad \text { secondary winding of }
\end{aligned}
$$

Innes, velocity of corpuscular rays -

Instantaneous radiography -

Insulators, electrical -

226

Intensifying screens -

Intensity of $\mathrm{X}$ rays, fluorescence methods of measuring

160

91

87

" $\quad, \quad, \quad, \quad$ ionisation $\quad, \quad$ methods of measuring "used in medicine

" , ", ", photographic methods of measuring

Interference of " $\gamma$ rays thermal

International Radium Standard

Interrupter, sparking at

Wehnelt electrolytic, design of -

Inverse currents,

, , , as affected by coil design -

,. -square law for X-ray intensity -

Ionisation chambers -

,, by collision

, in heavy gases

,, independent of quality of $\mathrm{X}$ rays -

28

55

85

90

89

146

146

., methorls of measuring X-ray intensity

Jackson's focus bulb - 
Kanalstrahlen

PAGE

Kathodenstrahlen

19

Kaufmann, fifth-power law of eharacteristic radiation $\quad-\quad-116$ various anticathodes

$\begin{array}{lllll}\text { Keene, diffraction of X rays by metallic crystals } & - & - & & - \\ \text { Kienböck, scale of X-ray dosage - } & - & - & - & -\end{array}$

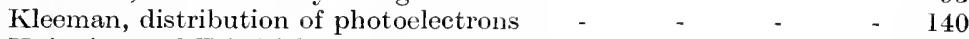

Knipping and Friedrich, crystals and X rays _ - $\quad$ - $\quad 169,171$

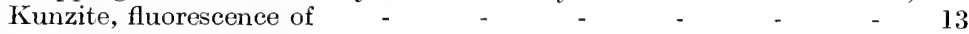

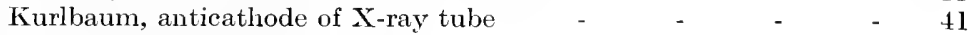

$\mathrm{I}$ characteristic radiations

Laby and Burbidge, $\gamma$-ray fiuctuation experiments - _ _ $\quad 214$

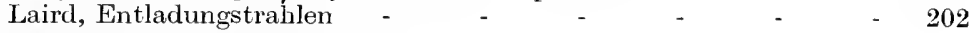

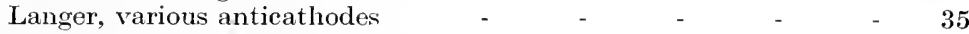

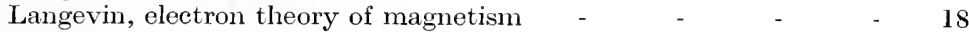

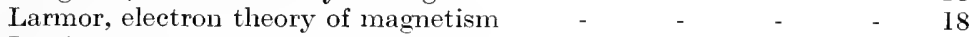

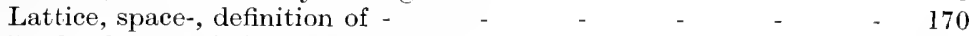

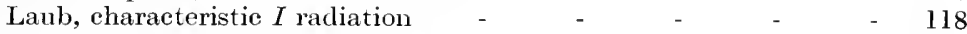

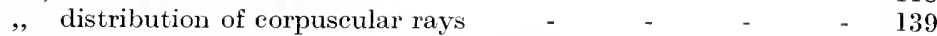

Laue, diffraction spots, displayed by fluorescent screen _ $\quad$ - 184

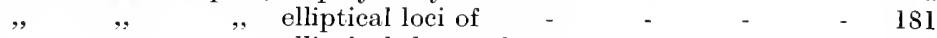

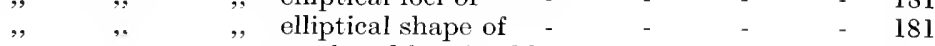

,, ", ", produced by zinc-blende - $\quad$ - $\quad$ - 174

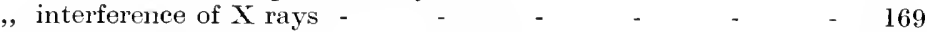

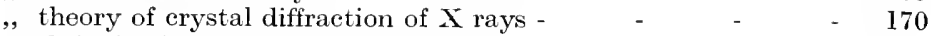

Lenard, ionisation by ultra-violet light - _ _ - $\quad$ - 206

, law of absorption of cathode rays - $\quad-\quad+\quad-10$

, rays

Light rays and $\mathrm{X}$ rays, resemblance between $\quad$ - _ _ $\quad 206$

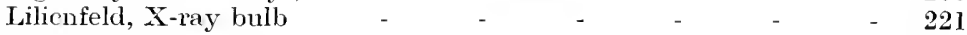

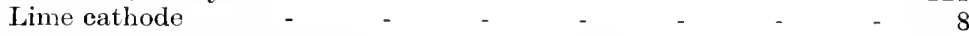

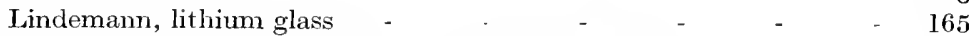

Lithium chloride, fluorescence of, by cathode and positive rays $\quad-\quad 19$

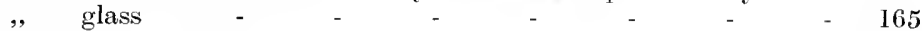

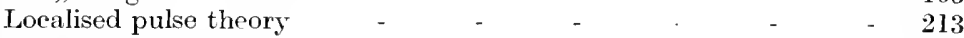

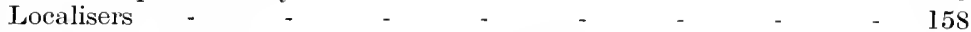

Lodge, Sir Oliver, current through X-ray bulb _ $\quad$ - $\quad . \quad 86$

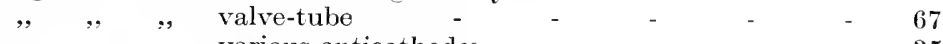

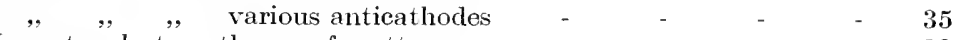

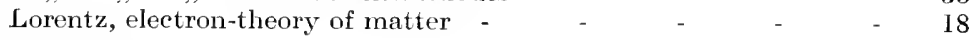

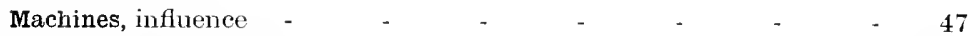

,. Wimshurst - $\quad$ - $\quad$ - $\quad$ - $\quad$ - $\quad$ - $\quad$ - 48

Mackenzie and Soddy, absorption of gas by sputtered metal _ $\quad 74$

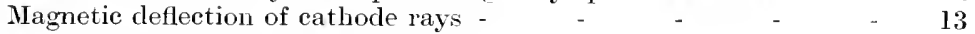

," spectrum ,, $\quad, \quad$.

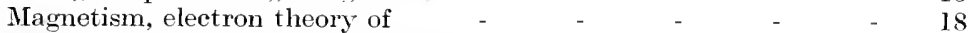

Maltézos, electrification of glass round cathode $\quad-\quad-\quad-\quad-\quad 70$

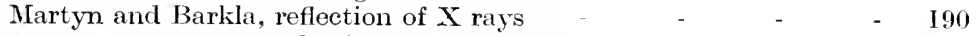

Marx, velocity of X selective action of $X$ rays on photographic plate 91

Mass-absorption coefficients, see Absorption coefficients.

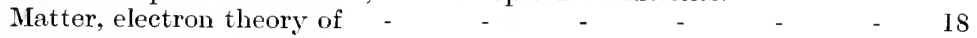


Mees, Kenneth, photographie plates for X ray work

Melting points of elements

Mercmy-breaks

Metallic erystals, diffraction of $\mathrm{X}$ rays by

Metals used as anticathodes -

Meyer, $\gamma$-ray fluctuation experiments

Michelson, vortex theory of $\mathrm{X}$ rays -

Micro-radiography

Miller, polarisation of $\mathrm{X}$ rays

.. Leslie, valve -

Mixed gases, ionisation in

Monochromatic $\mathrm{X}$ rays

More, fatigue in produetion of secondary $\mathrm{X}$ rays

39

64

184

38

214

204

157

112

67

148

112

144

Moscicki condenser

Moseley, X-ray spectra

Hoseley and Darwin, characteristic rays from platinum

\section{6}

199,235

118. 201

186 , . , , reflection of $\mathrm{X}$ rays

Muller, X-ray bulbs -

Multisectional winding of secondary of incluetion coil -

National Physical Laboratory, Radimm Standard

Negative glow

, ion

Nentral-pair theory of the $\mathrm{X}$ ray

Newton, eorpuscular theory of light -

Nickel, platinised, use as anticathode

Nieol, mass-absorption eoefficients

Noiré and Sabouraud, scale of X-ray dosage

Northem lights

Nucleated pulse theory of $\mathrm{X}$ rays

\section{4}

1

xii

205

8,213

40

115

93

17

213

Obliquity of anticathode

Occlusion methods of softening X-ray bulb -

Oil-pumps

Opacity, rlefinition of

Opacity-logarithm

Oscillograph records of primary and secondary currents

Osmosis methods of softening X-ray bulb

Owen, absorption of eharacteristic radiations in gases

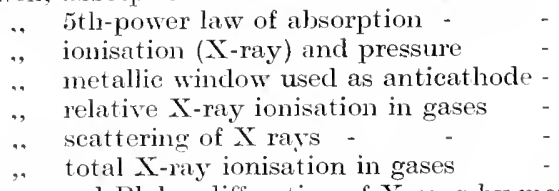

Owen and Blake, diffraction of $\mathrm{X}$ rays by metallic crystals -

$$
\text { . . . . } \quad \text { spectra of } \mathrm{X} \text { rays - }
$$

Palladium, use as anticathode

Pascluen, attempt to deflect $\gamma$ rays magnetically $\quad$ - $\quad+\quad$ - $\quad 25$

$$
\text { galvanometer }
$$

Pastille method of dosage

Penetrometers 
Perrin, negative charge on cathode ray

Phillips, C. E. S., conducting glass

PAGE

" $\quad$ " function of anode -

165

33

84

Philpot and Barkla, ionisation independent of quality of X rays - $\quad 146$

, " , X-ray and corpuscular ionisation in gases - 146

Photoelectric effect, selective

146
120

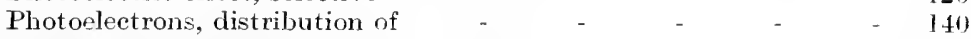

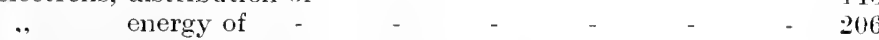

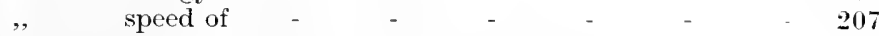

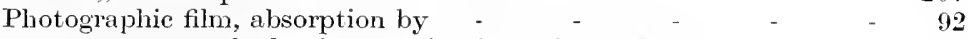

.. methods of measuring intensity of $\mathrm{X}$ rays $\quad 91$

.. plate, selective action of $\mathrm{X}$ rays on - $\quad-\quad 51$

,. plates for radiography - - $\quad$ - $\quad-160$

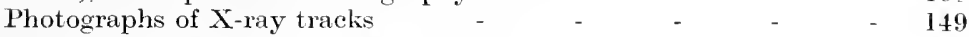

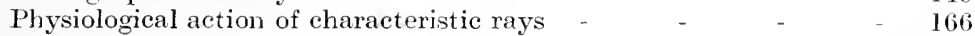

163

\begin{tabular}{cccccc} 
Planck, quantum theory of X rays & - & - & - & - & 205,206 \\
, theory of radiation - & - & - & - & - & - \\
\hline
\end{tabular}

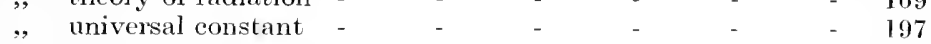

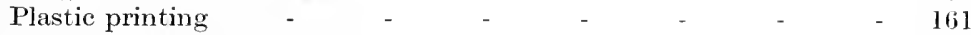

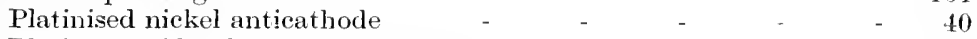

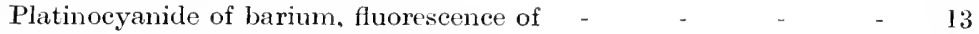

94

93

Platinum radiation $\quad$ -

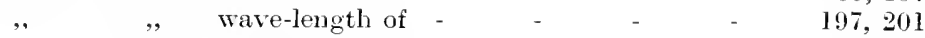

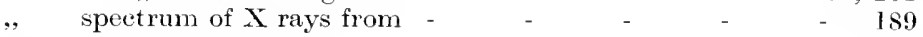

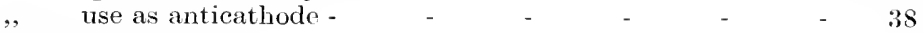

Plücker, cathode rays -

., cathodic sputtering -

, Jarclening of discharge tube

, tube

PohI and Franck, veloeity of $\mathrm{X}$ rays

, , Pringsheim, characteristic light rays

, , Walter, diffraction of $\mathrm{X}$ rays

Point and plane spark-gap -

Polarisation of X-rays

Positive column

, electron, absence of -

, ion

.. rays

,,$e / m$ of -

, striae

Potassium-sodium alloy, absorption of gases by

Pressure and ionisation (X-ray) in gases

Primary tube of induction coil , winding

Pringsheim and Pohl, characteristic light rays

Production of high vacua

Progressive hardening of $\mathrm{X}$-ray bulb

Protective devices against $\mathrm{X}$-ray burns

Pulse-theory of $\mathrm{X}$ rays, Stokes

4

77

71

xvii

153

120

168

66

110

209

1

20

xii

19

21

2

224

145

52 
Pulse-theory of $\mathrm{X}$ rays, modification necessary

Pucleated - , -

Quality of X rays, methods of measuring $, \quad, \quad, \quad$ and potential on tube

Quantum theory of $\mathrm{X}$ rays

Quartz (fused), insulating properties of

Radiation, discontinuity of

Radiochromometer

Planek's theory of

Radiography

$\begin{array}{ll}, & \text { bismuth } \\ , & \text { instantaneous } \\ , & \text { micro- - } \\ \text {, } & \text { stereoscopic }\end{array}$

Radiometer, Crookes'

Radio-mierography -

Radium $\gamma$ rays

, Standard, Intemational and British

, treatment of $\mathrm{X}$-ray burns

Ramsay and Collie, gas in glass of X-ray bulb

Rayleigh, condenser of induction coil

Re, nature of $X$ rays -

Recoil atoms

Rectifiers

Rectifying properties of X-ray bulb -

References to Jommals

"Reflection" of cathode rays

Refraction of $X$ rays -

$$
, \quad \quad, \quad \times \text { rays }
$$

"Relief " photographs of $\mathrm{X}$ rays

"Reverse" eurrents (see also inverse currents)

"Revolution of the corpusele

Rhodium, use as anticathode

Richardson and Rutherford, characteristic $\gamma$ rays

Rieman, fatigue in production of secondary $\mathrm{X}$ rays -

Poberts, volatilisation of metals

Roberts and Jones, function of condenser of induction coil

Roberts-Austen, interdiffusion of metals

Rock-salt, atomic distances in

$$
\text { " crystal structure of }
$$

Roiti, various anticathodes -
Röntgen, diffraetion of $\mathrm{X}$ rays 
Rutherford and Anclrade, reflection of $\gamma$ rays

PAGE

Rutherford and Richardson, characteristic $\gamma$ rays

186

Sabouraud and Noiré, scale of X-ray dosage -

115,234

Sadler, absorption of corpuscular rays in gases

93

," and Barkla, aJssorption relation for characteristic radiations

141

Sagnac and Curie, corpuseular rays

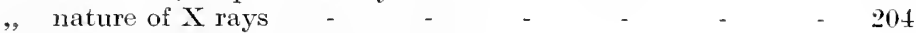

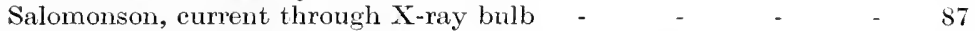

, inflnence of dielectric in mercury breaks _ - $\quad-65$

," penetrometer - $\quad-\quad$ - $\quad-\quad$ - $\quad-104$

, wave-form of current in primary of induction coil $\quad 5$

Sanax break

65

88

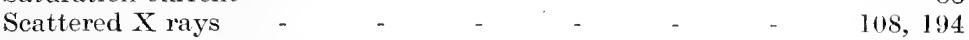

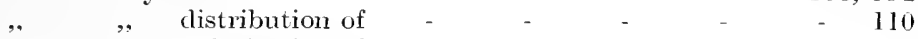

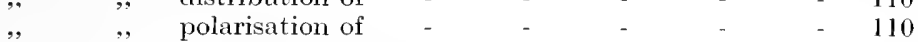

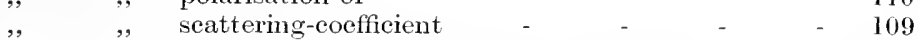

, , , X rays and light, resemblance between _ _ - 207

Schott, glass specially transparent to X rays $\quad-\quad{ }^{2} \quad-165$

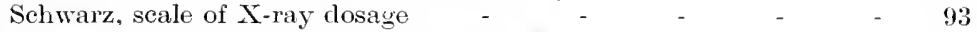

Schweidler, $\gamma$-ray fluctuation experiments - $\quad-\quad{ }^{2} \quad-\quad 214$

Scoble and Blythswood, current through X-ray bulb $\quad$ - $\quad$ - 86

Se , , . $\quad$ photographic plates and X rays - 92

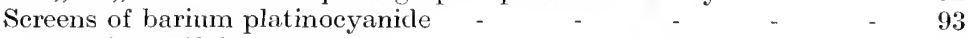

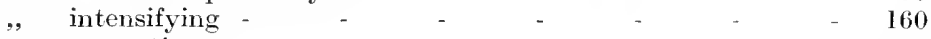

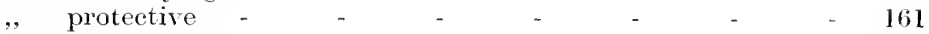

Sealing-wax, insulating properties of $\quad-\quad \ldots \quad-\quad 2 \quad 227$

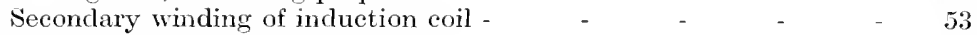

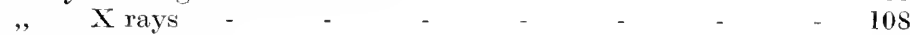

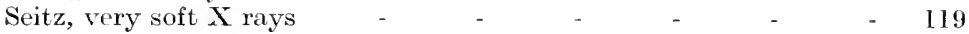

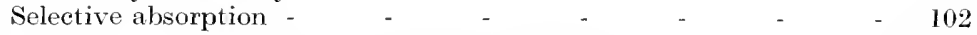

, $\quad$ " of characteristic radiations $\quad-\quad \quad-\quad 129,134$

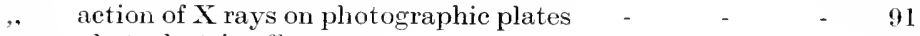

,. photoelectric effect - $\quad-\quad$ - $\quad-\quad$ - $\quad-\quad$ - 120

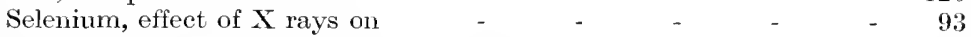

Separation distances of atomic planes in crystals $\quad-\quad-\quad-\quad 194$

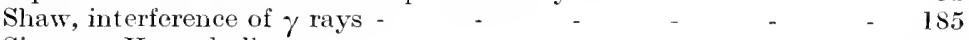

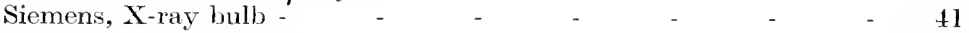

Silica, fused, insulating properties of $\quad-\quad \ldots \quad-\quad-\quad 227$

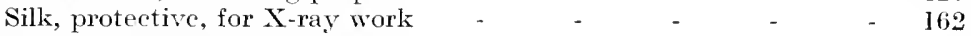

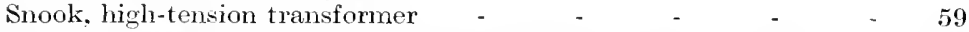

Soddy and Mackenzie, absorption of gases by sputtered metal $\quad$ - 74

Sodium-potassium alloy, absorption of gases by $\quad-\quad \ldots \quad-\quad 224$

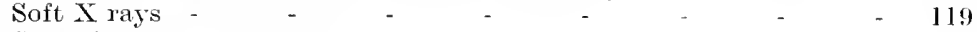

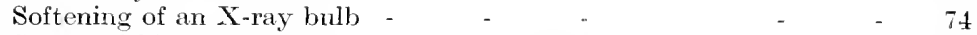

Sommerfeld, spreading-pulse theory of X rays $\quad-\quad-\quad-\quad 212$

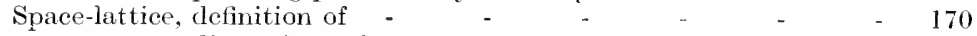

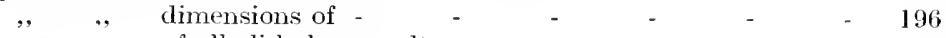

Spark-gap, point and plane -

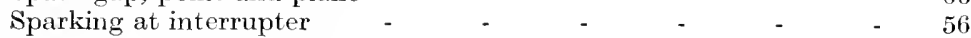

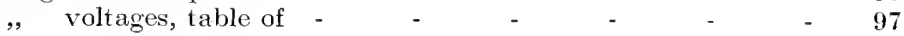


Spectrometer for $\mathrm{X}$ rays

Spectrum of cathode rays

". , X rays -

Speed of $\mathrm{X}$ rays

Sprengel pump

Sputtering of cathode

thermal

Standard of radioactivity

Standardisation of $\mathbf{X}$ rays

Stark, distribution of $\mathrm{X}$ rays from thin anticathodes

. wave-lengths of $\mathrm{X}$ rays

, quantum theory of $\mathrm{X}$ rays

Steinmetz, sparking voltages

Stereographic projection of Laue diffraction spots

Stereoscopic radiography

Stokes, ether-pulse theory of $\mathrm{X}$ rays

, law of fluorescence

Stoney, Johnstone, use of term "electron " -

Straubel, osmosis ralve

Striae in discharge tube

Strutt, active nitrogen

Stuhlmann, distribution of photo-electrons -

Sublimation of metals

Sulphur, insulating properties of

Sunic screen -

Sutherland, nature of $\mathrm{X}$ rays

Swinton, Campbell-, adjustable cathode

\begin{tabular}{|c|c|c|}
\hline & $\cdots$ & fluorescence in glass, fatigue of \\
\hline & , & hardening of discharge tube \\
\hline & 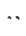 & historical X-ray bulb \\
\hline & $"$ & shape of beam of cathode rays \\
\hline & $\cdots$ & various anticathodes \\
\hline
\end{tabular}

Tantalum, use as anticathode -

Taylor, fluctuation experiments with light - $\quad-\quad-\quad 215$

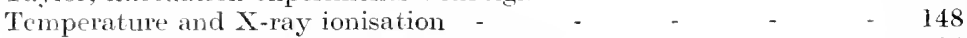

Terada, fluoresecnt sereen observations of Laue spots $\quad-\quad-184$

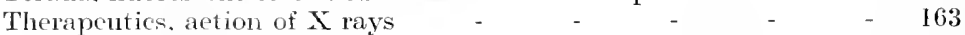

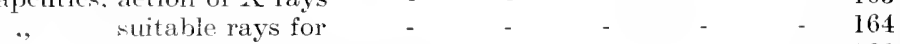

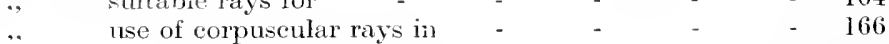

$\because \quad, \quad$ characteristic rays in - $\quad$ - $\quad \ldots \quad-166$

Themal conductivities of elements - $\quad-\quad \ldots \quad \ldots \quad-39$

" methods of measuring intensities of X rays - $\quad-\quad 87$

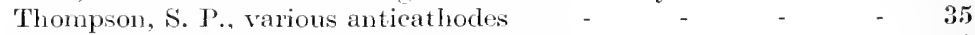

Thomson, J. J., current through X-ray bulb - $\quad$ - $\quad$ - $\quad$ - 86

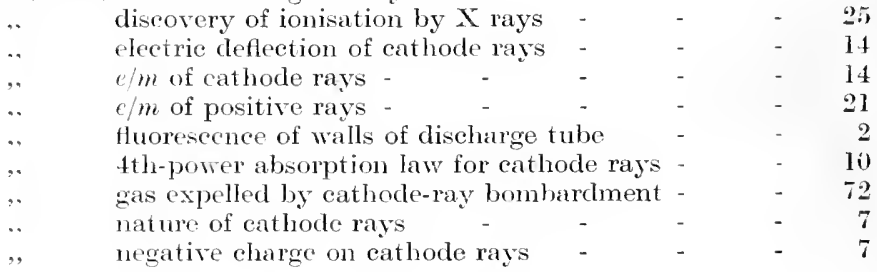




\section{INDEX}

Thomson, J. J., nucleated or localised pulse theory of $\mathrm{X}$ rays

PAGE

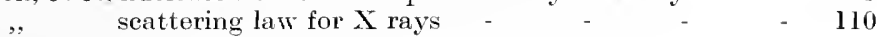
, theory of the atom -

Tiede, eathode-ray furnace

Töpler, pump

, sparking roltages

Total ionisation in gases

89,148

Transformers, high tension

Transmission of cathode rays -

Transparency, definition of

10

93

," of substances to $\mathrm{X}$ rays

101

Trinkle and Wehnelt, very soft $\mathrm{X}$ rays

119

Trowbridge, long-spark voltages

$9 \mathrm{~s}$

Tungsten, use as anticathode

38,219

,. cathode

219

Ultra-violet light, ionisation by

206

Vacua, production of -

Valve, Bauer -

222

, osmosis

, tubes -

Varley

Vegard, polarisation of $\mathrm{X}$ rays

Velocity of cathode rays

, , , , , $\quad$ and potential, table of $\quad-\quad-\quad-\quad 233$

, .. corpuscular rays -

", "Wehnelt cathode rays

, "X rays

Villard, gas bubbles in wall of $\mathrm{X}$-ray tube

, osmosis valve

, valve tube

Villard and Abraham, influence machines

Violet coloration of X-ray bulb

Violle, interrupter

Volatilisation of metals

75

74

66

6

111

16

9

152

72

74

66

49

83

62

82

Walter, attempt to deflect $\mathrm{X}$ rays magnetically $\quad-\quad-\quad-\quad \mathbf{2 5}$

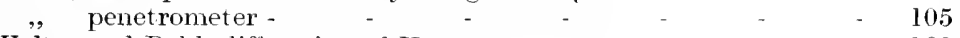

Walter and Pohl, diffraction of X rays - - - - + 168

Warburg, thickness required for complete reflection of cathode rays $\quad 45$

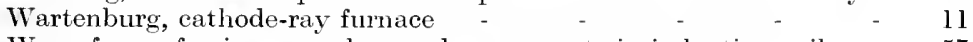

Wave-form of primary and secondary currents in induction coil - $\quad 57$

Wave-length of various electromagnetic waves - $\quad-\quad-202$

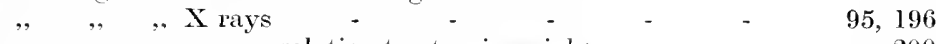

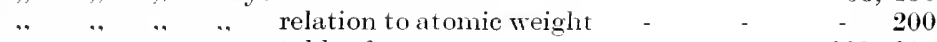

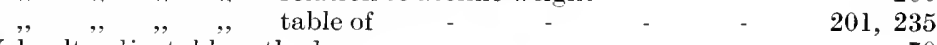

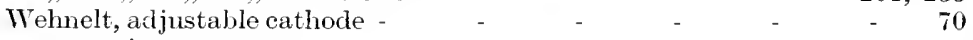

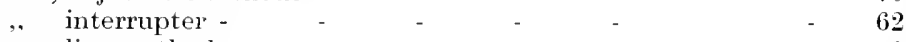

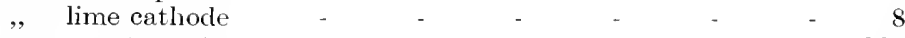

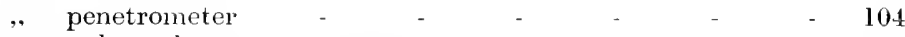

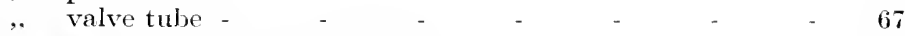

Wehnelt and Trinkle, very soft X rays $\quad-\quad-\quad-\quad-\quad 119$

Whiddington, adjustable cathode : - _ - $\quad$ - 70 
Whiddington, characteristic $\mathrm{X}$ rays and cathode-ray velocity - formula connceting $K$ and $L$ radiations _ _ $\quad 116$

, fourth-power law of absorption of cathode rays $\quad-10$

, $\quad$ soft X rays from Wchnelt eathode - _ - $\quad 119$

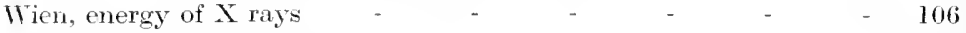

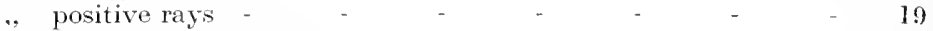

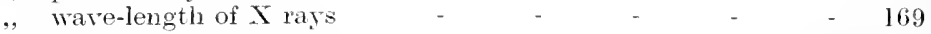

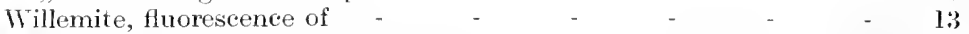

Willows, hardening of discharge tube $\quad-\quad \ldots \quad-\quad \ldots \quad-\quad 72$

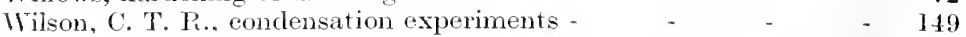

.. $\quad$ " reflection of $\mathrm{X}$ rays $\quad-\quad$ - $\quad$ - $\quad$ - 186

Wilson, W. H., function of endenser of induetion coil $\quad-\quad 52$

.. ", high-frequency oscillations in primary circuit of

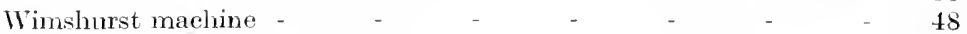

Wind and Haga, difiraction of $\mathrm{X}$ rays $\quad-\quad \ldots \quad-\quad 168$

Winding of primary of induction coil $\quad-\quad \ldots \quad-\quad 51$

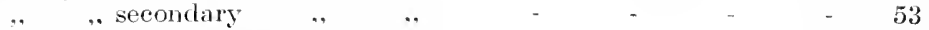

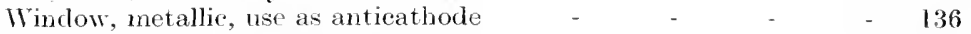

Winkelmann, harchess of X-ray tube - - - - 68

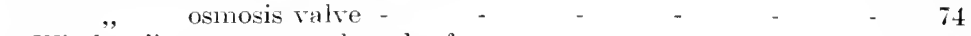

"Wireless" waves, wave-length of - $\quad$ - $\quad$ - $\quad 202$

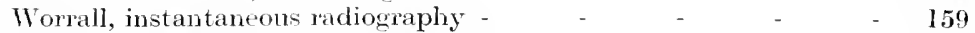

Wratten and Wainwright, X-ray plate - $\quad-\quad-\quad-160$

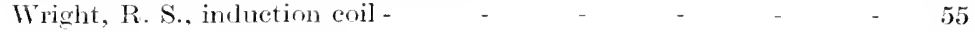

Zinc-blende, crystalline structure of - $\quad-\quad+\quad-\quad-174$

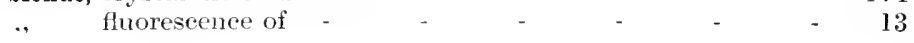





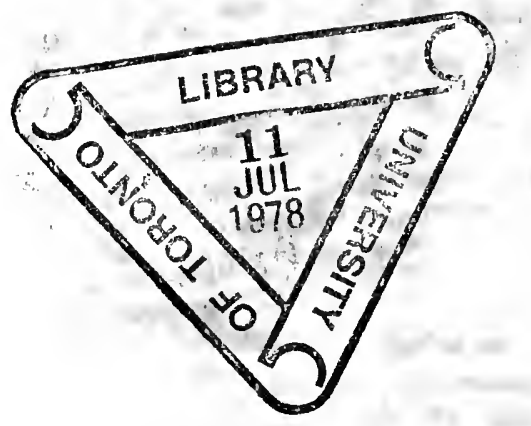




\section{PLEASE DO NOT REMOVE}

CARDS OR SLIPS FROM THIS POCKET

\section{UNIVERSITY OF TORONTO LIBRARY}

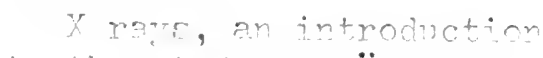

to the studur of portmen

rave 
